\title{
ASSESSMENT OF A VOLUNTARY NONLEAD AMMUNITION OUTREACH PROGRAM ON MIDWESTERN NATIONAL WILDLIFE REFUGES
}

A Dissertation
presented to the Faculty of the Graduate School
at the University of Missouri-Columbia
In Partial Fulfillment
of the Requirements for the Degree
Doctor of Philosophy
By
John H. Schulz
Dr. Sonja Wilhelm Stanis, Dissertation Supervisor
(December 2020)


The undersigned, appointed by the dean of the Graduate School, have examine the dissertation entitled

\section{ASSESSMENT OF A VOLUNTARY NONLEAD AMMUNITION OUTREACH PROGRAM ON MIDWESTERN NATIONAL WILDLIFE REFUGES}

presented by John H. Schulz, a candidate for the degree of Doctor of Philosophy and hereby certify that, in their, opinion, it is worthy of acceptance.

Associate Professor Sonja A. Wilhelm Stanis

Assistant Professor Damon M. Hall

Assistant Professor Christine Jie Li

Associate Professor Mark Morgan

Associate Professor Elisabeth B. Webb 


\title{
Dedication
}

This dissertation is dedicated to three individuals from the U.S. Fish and Wildlife Service (USFWS). Without their continual support and encouragement this project would not have occurred. Tom Cooper (USFWS Region 3, Migratory Bird Program Chief) and Jeanne Holler (USFWS Region 3, Conservation Planning Chief - Refuges) played instrumental roles in acquiring the necessary funding and provided critical guidance throughout the project. Ed Britton (Wildlife Refuge Manager, Savanna District, USFWS Upper Mississippi River National Wildlife and Fish Refuge) was my primary contact with the implementation team throughout the project. His experience, enthusiasm, and guidance were always helpful and appreciated.

I must also recognize the significant contributions of my advisor, Dr. Sonja Wilhelm Stanis. Her willingness to work with a nontraditional graduate student must have caused her to pause several times, but she was always patient and helpful. I cannot imagine having worked through the myriad of obstacles without her guidance and kindness.

\section{Additional thoughts}

\author{
"Truth," said a traveler, \\ "Is a rock, a mighty fortress; \\ "Often have I been to it, \\ "Even to its highest tower, \\ "From whence the world looks black." \\ "Truth," said [another] traveler, \\ "Is a breath, a wind, \\ "A shadow, a phantom; \\ "Long have I pursued it, \\ "But never have I touched \\ "The hem of its garment." \\ And I believed the second traveler; \\ For truth was to me \\ A breath, a wind, \\ A shadow, a phantom, \\ And never had I touched \\ The hem of its garment
}




\section{Acknowledgments}

I am grateful for the willingness and support from U.S. Fish and Wildlife Service staff who participated with surveys and interviews. Transcription assistance was provided D. Derryberry, and E. Heienickle; assistance with coding interviews provided by L. Groshong. Financial support for this work was provided by the University of Missouri-School of Natural Resources, the J. Raymond White Fellowship, Audubon Missouri, U.S. Fish and Wildlife Service-Region 3, and the U.S. Geological SurveyMissouri Cooperative Fish and Wildlife Research Unit. The Missouri Cooperative Fish and Wildlife Research Unit is jointly sponsored by the Missouri Department of Conservation, the University of Missouri, the U.S. Fish and Wildlife Service, the U.S. Geological Survey and the Wildlife Management Institute. Any use of trade, firm, or product names are for descriptive purposes only and does not imply endorsement by the U.S. Government. 


\section{Table of Contents}

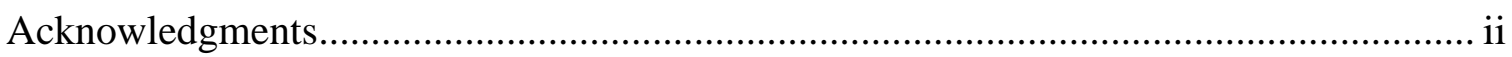

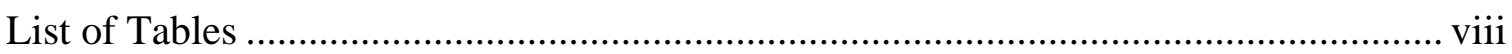

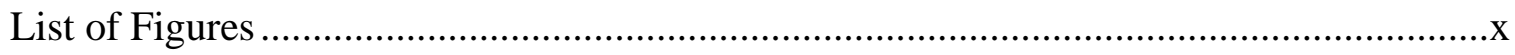

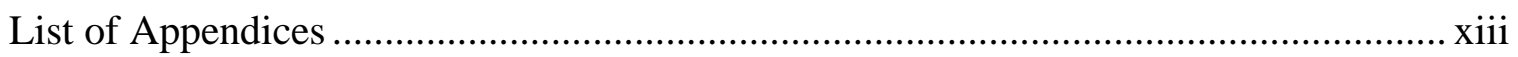

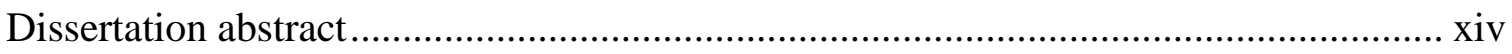

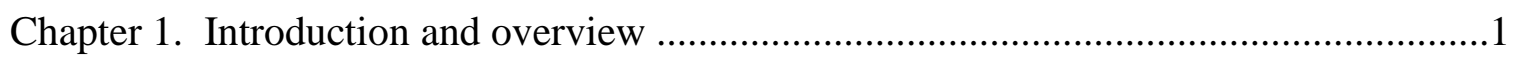

1.1. Introduction and background .......................................................................... 1

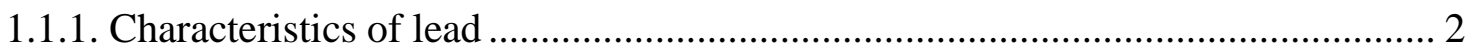

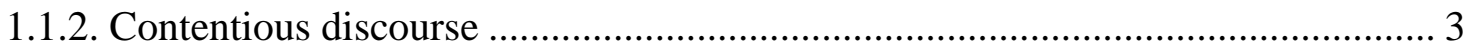

1.1.3. Impacts and policy of lead poisoning in wildlife and humans .............................. 5

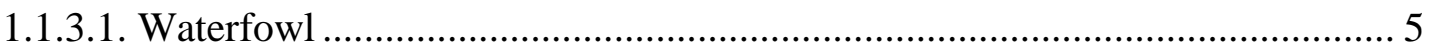

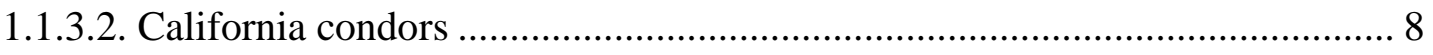

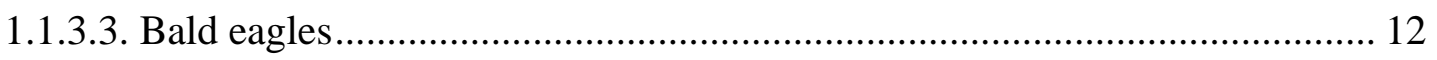

1.1.3.4. Mourning Doves ........................................................................................ 13

1.1.3.5. Human health and lead exposure from spent ammunition ........................... 14

1.1.4. Hunters' perceptions and behaviors of lead poisoning ...................................... 15

1.1.4.1. Benefits and uses of theoretical behavioral models...................................... 17

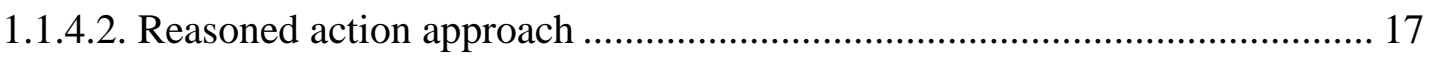

1.1.4.3. Diffusion of innovation theoretical framework ............................................ 21

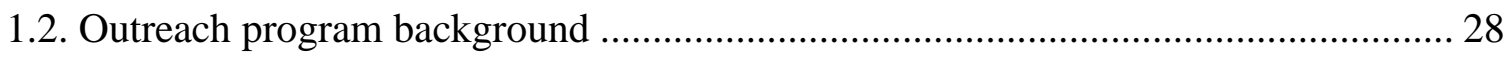

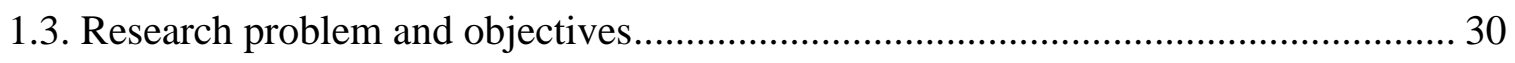

Chapter 2. Communication Strategies for Reducing Lead Poisoning in Wildlife and

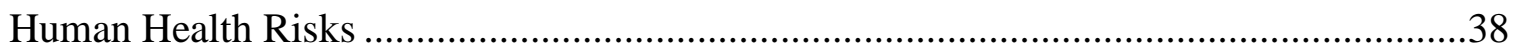


Abstract

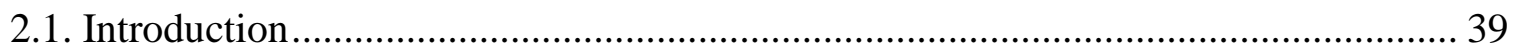

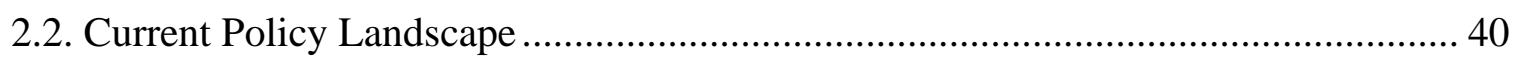

2.3. Past and Present Issues......................................................................................... 42

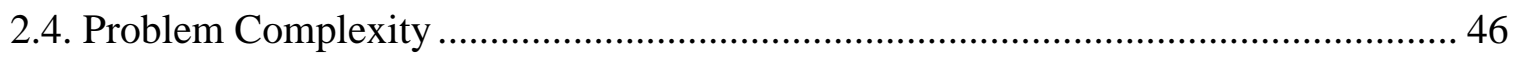

2.5. Need for a More Strategic Approach ..................................................................... 49

2.5.1. Hunters' Perception and Behaviors of Lead Poisoning ...................................... 49

2.5.2. Benefits and Uses of Theoretical Behavioral Models in Evaluation Research... 50

2.5.3. Diffusion of Innovation Theoretical Framework ………………………............ 51

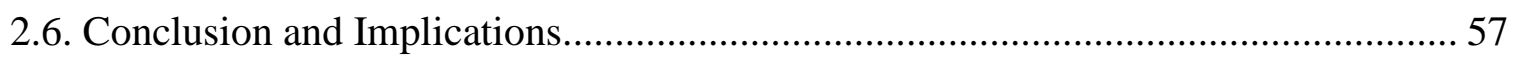

Chapter 3. Until It's a Regulation It's Not My Fight: Complexities of a Voluntary

Nonlead Hunting Ammunition Program......................................................................61

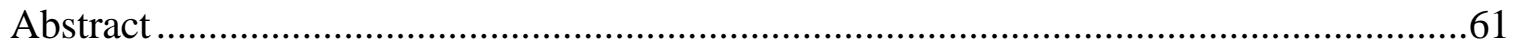

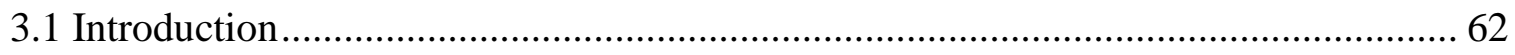

3.1.1 Wildlife and human lead exposure from spent hunting ammunition ................... 62

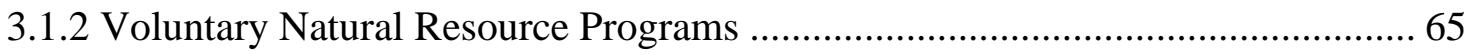

3.1.3 Voluntary nonlead ammunition outreach programs ............................................ 66

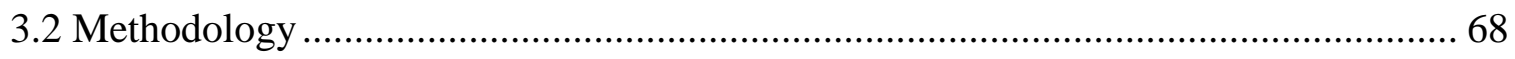

3.2.1 Nonlead Outreach Program and data collection.................................................. 68

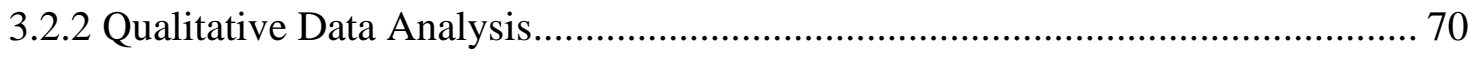

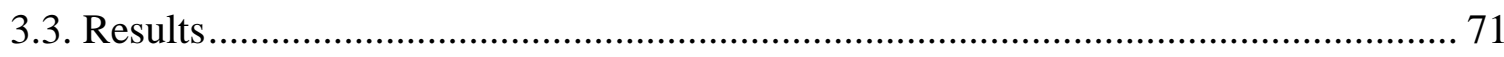

3.3.1. Challenges of dealing with complex issues.................................................... 71

3.3.1.1. Administrative restraint and uncertainty ..................................................... 71 


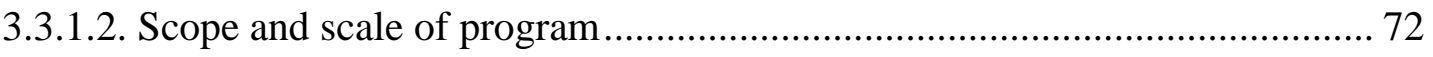

3.3.1.3. Human health not our responsibility ......................................................... 73

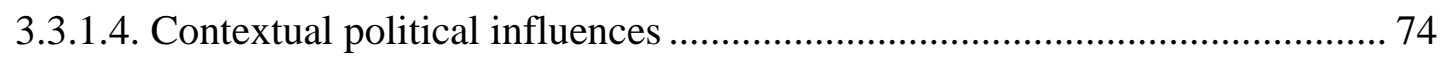

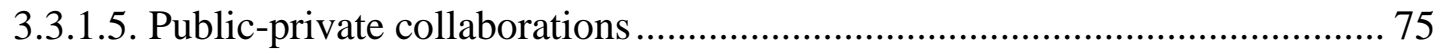

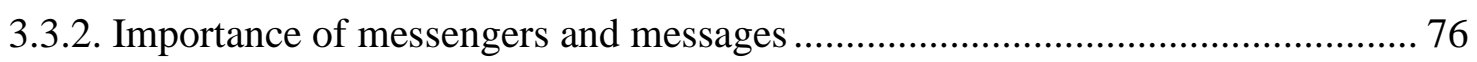

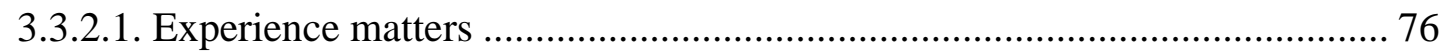

3.3.2.2. Salience of human health risk ......................................................................... 77

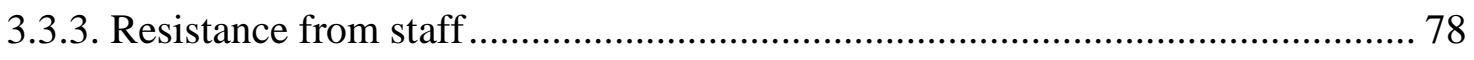

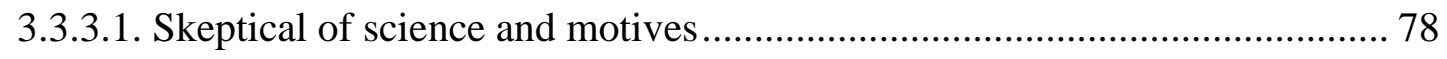

3.3.3.2. Competing priorities and limited resources ................................................ 79

3.3.3.3. Regulatory and voluntary perceptions - a mixed bag ................................... 80

3.3.3.4. Nonlead cost and availability perceptions .................................................... 81

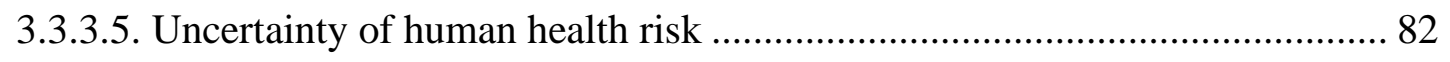

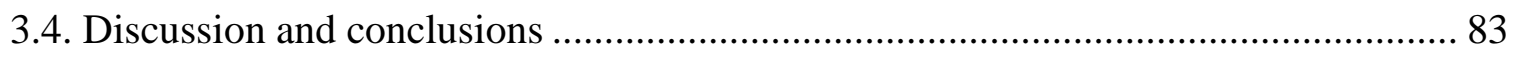

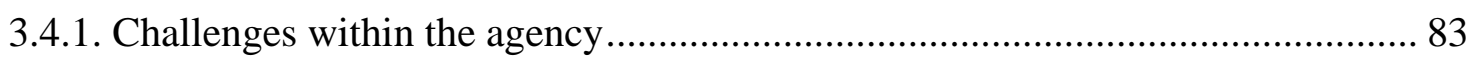

3.4.2. Effects of contextual factors on program implementation ................................. 86

3.4.3. Elements of successful voluntary programs .................................................... 91

Chapter 4. Perspectives from natural resource professionals: Attitudes on lead ammunition risks and use of nonlead ammunition ......................................................94

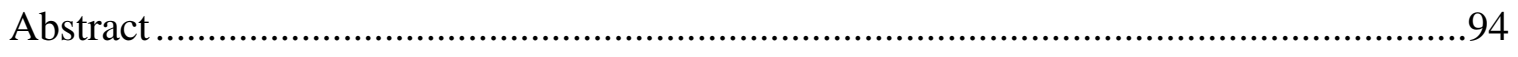

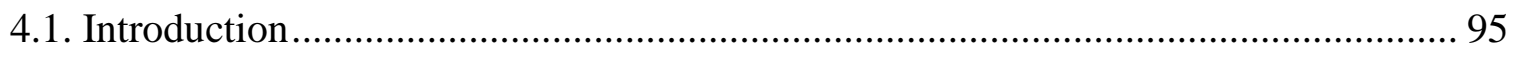

4.1.1. Lead exposure from hunting and fishing ...................................................... 95

4.1.2. Nonlead alternatives and behavioral change ……............................................ 97 
4.1.3. Need for study

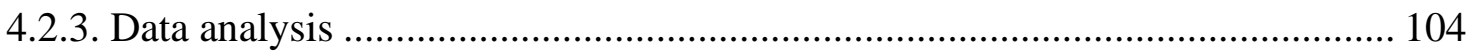

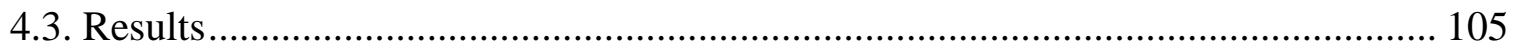

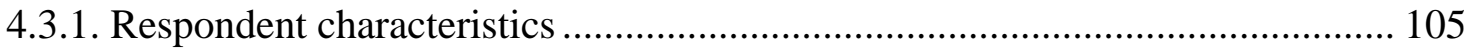

4.3.2. Mortality threats to bald eagles .............................................................. 105

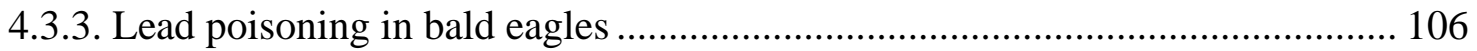

4.3.4. Lead exposure risk in people.............................................................. 107

4.3.5. Shooting characteristics of nonlead........................................................ 108

4.3.6. Socio-economic nonlead ammunition factors ........................................... 109

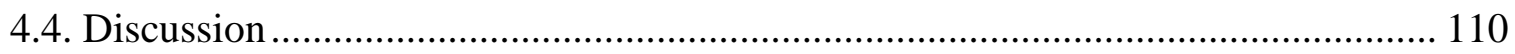

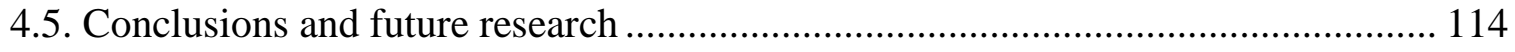

Chapter 5. Factors Affecting Staff Support of a Voluntary Nonlead Ammunition

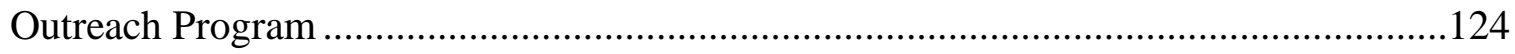

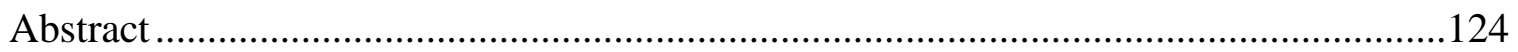

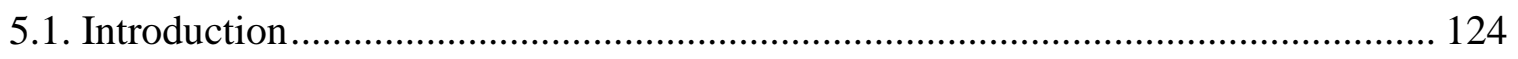

5.1.2. Characteristics of voluntary conservation programs .................................. 125

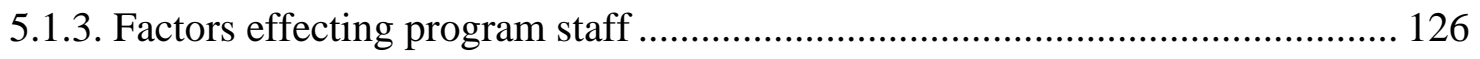

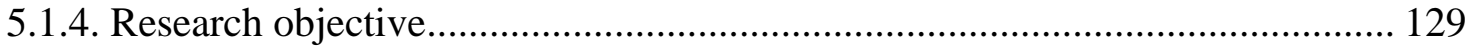

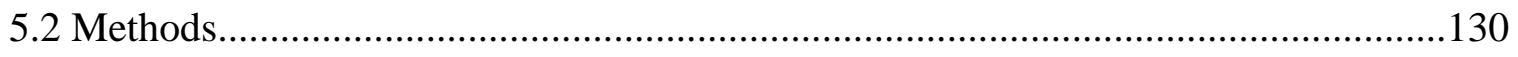

5.2.1. Study area and nonlead program ........................................................ 130

5.2.2. Survey design and implementation ................................................... 131

5.2.3. Regression model variables............................................................... 132

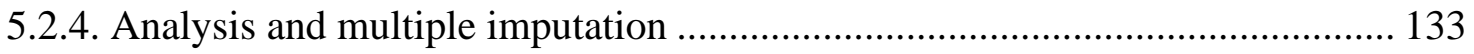


5.3. Results

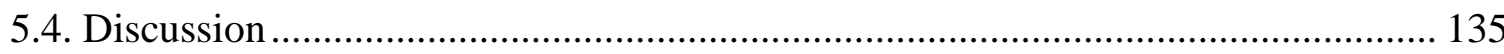

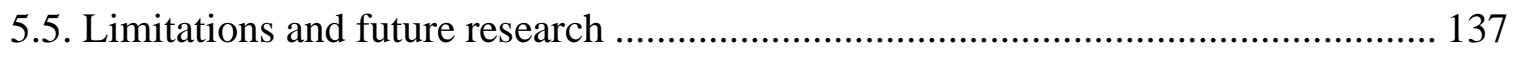

Chapter 6. Structured Observations at Hunt Orientation Sessions ...............................146

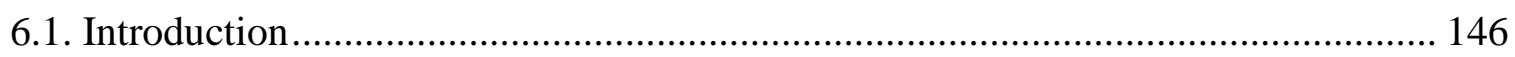

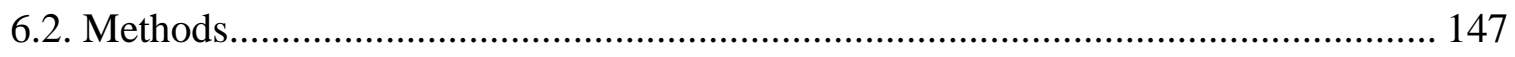

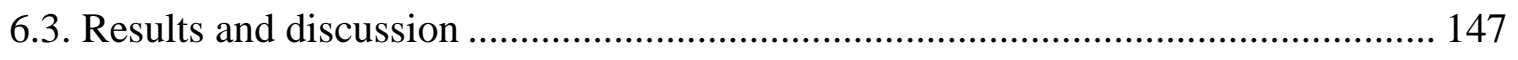

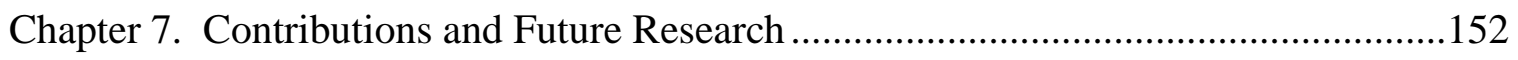

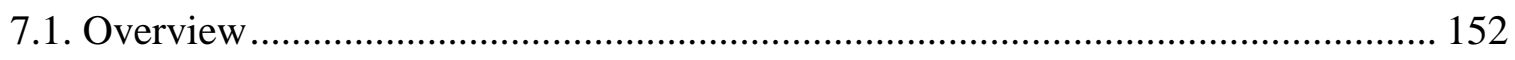

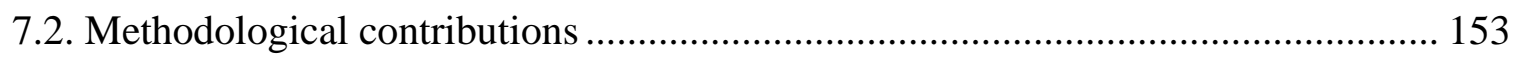

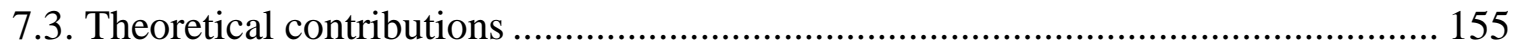

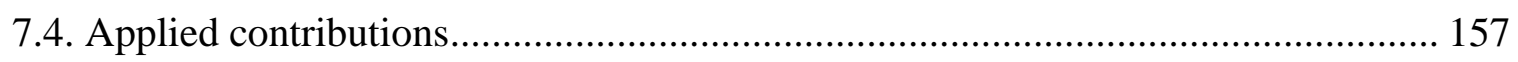

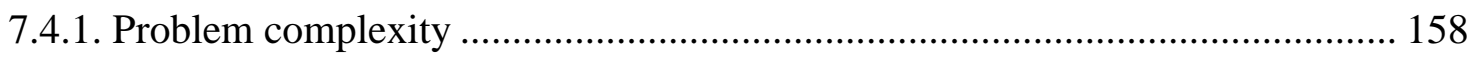

7.4.2. Multiple audiences and messages ......................................................... 159

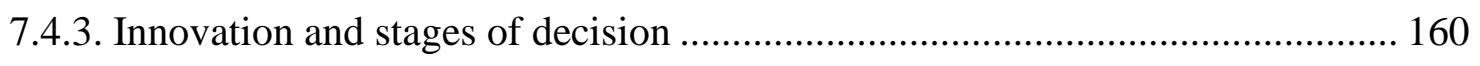

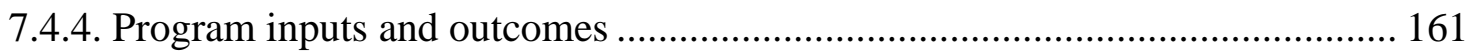

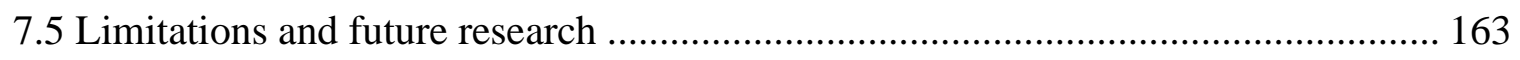

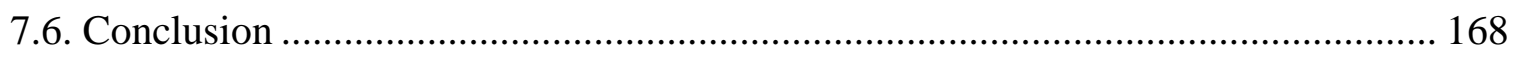

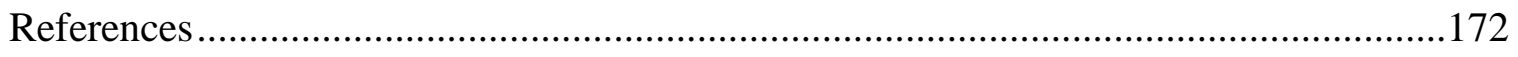

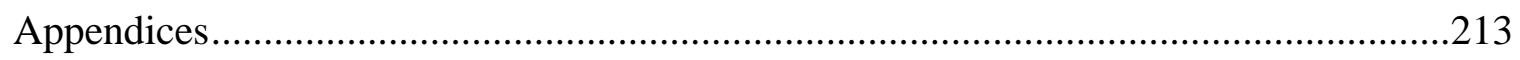

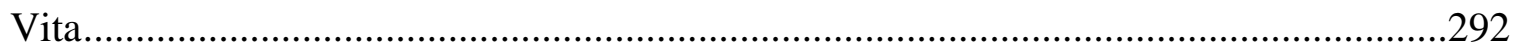




\section{List of Tables}

Table 3.1. Categories and themes from semi-structured interviews. 93

Table 4.1. Characteristics of U.S. Fish and Wildlife Service (USFWS) National Wildlife Refuge (NWR) staff in the Upper Midwest implementing an outreach program encouraging the voluntary use of nonlead hunting ammunition during 2017-2018..... 117

Table 4.2. Attitudes about general mortality threats to bald eagles of U.S. Fish and Wildlife Service (USFWS) National Wildlife Refuge (NWR) staff in the Upper Midwest implementing an outreach program encouraging the voluntary use of nonlead hunting ammunition during 2017-2018

Table 4.3. Attitudes about mortality threats from lead $(\mathrm{Pb})$ poisoning to bald eagles of U.S. Fish and Wildlife Service (USFWS) National Wildlife Refuge (NWR) staff in the Upper Midwest implementing an outreach program encouraging the voluntary use of nonlead hunting ammunition during 2017-2018.

Table 4.4. Attitudes about potential human health risks related to ingestion of lead $(\mathrm{Pb})$ bullet fragments in venison of U.S. Fish and Wildlife Service (USFWS) National Wildlife Refuge (NWR) staff in the Upper Midwest implementing an outreach program encouraging the voluntary use of nonlead hunting ammunition during 2017-2018..... 121 Table 4.5. Attitudes about shooting characteristics of nonlead (nonPb) ammunition and its use of U.S. Fish and Wildlife Service (USFWS) National Wildlife Refuge (NWR) staff in the Upper Midwest implementing an outreach program encouraging the voluntary use of nonlead hunting ammunition during 2017-2018. 122

Table 4.6. Attitudes about socio-economic factors of nonlead (NonPb) ammunition of U.S. Fish and Wildlife Service (USFWS) National Wildlife Refuge (NWR) staff in the Upper Midwest implementing an outreach program encouraging the voluntary use of nonlead hunting ammunition during 2017-2018.

Table 5.1. List of model variables and measurement. 139 
Table 5.2. Characteristics of U.S. Fish and Wildlife Service (USFWS) staff participating

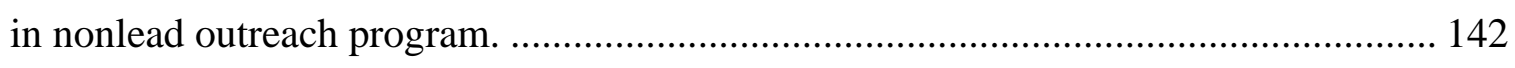

Table 5.3. Descriptive statistics of continuous variables in the model before multiple

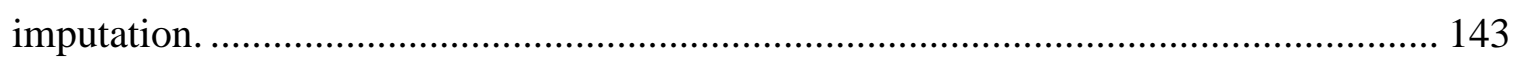

Table 5.4. Linear regression predicting staff support for a nonlead ammunition outreach

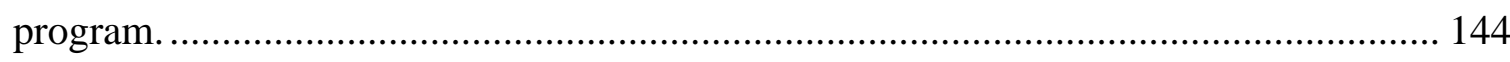

Table 6.1. Summary statistics from structured observation sessions at managed deer hunts with orientation sessions on National Wildlife Refuges participating in the outreach program encouraging hunters to use nonlead ammunition during 2016-2018.............. 151

Table 7.1. Applied contributions from an outreach program encouraging the voluntary use of nonlead ammunition on USFWS NWRs in the Upper Midwest during 2016-2019. 


\section{List of Figures}

Figure 1.1. Lead bullet fragments (yellow circles) in a deer carcass (A) and ingested in a dead bald eagle (B) found in northwestern Iowa during January 2017 (photos Project

SOAR, Saving Our Avian Resources; Kay Neumann). 32

Figure 1.2. Elements of the reasoned action approach and its application to integrated model of behavioral change or the integrated model (Fishbein \& Ajzen, 2010; Montano

\& Kasprzyk, 2015)

Figure 1.3. Cover of tri-fold brochure available at NWRs for hunters emphasizing the voluntary use of nonlead ammunition and recognizing the role hunters play in conservation.

Figure 1.4. Free-standing banner usually placed near entrances of NWR headquarters showing the effects of lead poisoning in bald eagles and the benefits of using nonlead ammunition.

Figure 1.5. Example of epoxy gel blocks used for demonstrating differences in bullet fragmentation characteristics between lead and nonlead rifle ammunition for (A) highpower rifles and (B) shotgun slugs. Both bullets appear similar externally, but the lead bullet (left) has lead core with a copper jacket to control expansion and fragment and dissipate the bullet's energy throughout the animal carcass being about a quick kill. The nonlead bullet (right) is mainly made of solid copper and retains nearly all its initial mass with copper petals peeling backwards upon striking the animal causing fatal hemorrhaging. 36

Figure 1.6. Locations of U.S. Fish and Wildlife Service National Wildlife Refuges in the Midwest Region (Region 3); red dots designate areas entering the outreach program in 2016, green dots in 2017, orange dots in 2018, and blue dots represent refuges not participating in the program.

Figure 2.1. Lead poisoning in wildlife and human health impacts are complex and multifaceted. Different components of the problem are characterized by differing exposure pathways, level of exposure, and relative impact on the wildlife population and the environment. The problem can be categorized by: (1) lead poisoning in the critically endangered California condors eating remains of harvested big game animals, (2) lead 
poisoning impacts on bald eagles and other avian scavengers also feeding big game animal remains on a broader continental scale, (3) possible human health effects from ingestion of lead bullet fragments in game meat, (4) mourning doves and other surfacefeeding songbirds ingesting spent pellets, especially on heavily hunted managed shooting fields, (5) ingestion of unretrieved lead fishing tacking by common loons and swan...... 58 Figure 2.2. Decisions by hunters to use nonlead alternatives involve multiple steps in the decision process. With the diffusion of innovation theory, the process starts with acquiring knowledge about the innovation and the persuasiveness of the information; in this example lead poisoning wildlife and nonlead ammunition. Part of the persuasion process includes information about benefits of nonlead alternatives related to advantages over lead ammunition, compatibility and complexity of changing to nonlead, and opportunities for trialability or test alternatives and observe others. The decision to adopt or reject nonlead alternatives follows with implementation of the continued use of nonlead ammunition or discontinuation depending upon support for long-term continued use or rejection. Even after the decision to use nonlead alternatives has been implemented, confirmation and reinforcement of the behavior is necessary to ensure permanent behavior change. 59

Figure 2.3. People adopting innovations can be based on varying characteristics and impact effectiveness of nonlead hunting ammunition and fishing tackle message campaigns; e.g., (1) innovators, (2) early adopters, (3) early majority, (4) late majority, and (5) laggards or traditionalists. Some of these groups may occur simultaneously or proceed through time with considerable overlap among groups of hunters and anglers.. 60

Figure 5.1. Conceptual model of variables influencing support for a program encouraging voluntary use of nonlead ammunition 145

Figure 7.1. This research draws on a multi-disciplinary approach using literature from human dimensions research including social marketing and public communication campaigns, environmental toxicology and wildlife diseases, and natural resource management. Within the context of outreach programs encouraging voluntary use of 
nonlead hunting ammunition, these four elements interact to relationships among overlapping groups of hunters, nonhunters, and natural resource stakeholders. ............ 171 


\section{List of Appendices}

Appendix 1. Areas participating in outreach program; some areas have both managed hunts and open; i.e., some units of the refuge will have a managed hunt and other portions of the refuge will be open under the respective statewide deer hunting regulations.

Appendix 2. Lead Free Ammunition Hunter Orientation Sessions Observation Form. 217 Appendix 3. Interview Guide for Semi-structured USFWS Staff on National Wildlife

Refuges.

Appendix 4. Questionnaire instrument: USFWS Staff - Lead Free Ammunition

Outreach. 222

Appendix 5. Descriptive summary for each survey question for responses from U.S. Fish and Wildlife Service, National Wildlife Refuge staff, Region 3.

Appendix 6. Summary table of USFWS Staff Interviews followed by themes, subthemes, and example quotes. 


\section{Dissertation abstract}

Lead exposure from spent hunting ammunition affects wildlife populations, human health, and poses challenges to natural resource management. In addition to existing data on this topic spanning >100-years, data from the Upper Midwestern, United States (U.S.) demonstrated bald eagles have greater risk of lead poisoning by ingesting lead bullet fragments in gut piles and unretrieved carcasses related to deer hunting. In response, U.S. Fish and Wildlife Service (USFWS), Region 3 established an outreach program during 2016-2018 encouraging deer hunters to use nonlead ammunition while deer hunting on 54 National Wildlife Refuges (NWRs). This project used a mixed methods approach incorporating 12 structured observations of presentations given at four managed hunts, 29 semi-structured interviews of program staff, and an online survey of 325 NWR staff. Objectives were to (1) examine lead exposure risks and suggest communication strategies, (2) explore attitudes and experiences of NWR staff implementing the program, (3) examine staff attitudes about threats to bald eagles, lead poisoning in bald eagles, human health risks, use of nonlead hunting ammunition, and socio-economic ammunition factors, (4) examine factors influencing program support by staff, and (5) assess structured observations of nonlead presentations. Correspondingly, this research resulted in four manuscripts and an additional research note aligned with the objectives above.

Five key findings were demonstrated by this research. First, the risk of lead exposure from spent hunting ammunition is a multi-dimensional complex issue affecting wildlife and human health with voluntary programs primarily addressing the issue. Although little used in the past, social science theory has the potential to provide a useful framework for evaluating voluntary nonlead ammunition programs. Second, semi- 
structured interviews of USFWS staff resulted in 12 broad themes organized around three categories: (1) challenges within the agency, (2) effects of contextual factors on program implementation, and (3) the effect of different elements observed to be present/absent in successful voluntary conservation programs. Third, an online survey showed differences in attitudes among staff who hunters and nonhunters, lead or nonlead ammunition use by hunters, and likely or unlikely future nonlead use by hunters. Fourth, the survey also demonstrated program support was greatest among refuge staff who strongly agreed with problems related to bald eagles and lead exposure, individuals who strongly agreed with the importance of informational program materials, and individuals with higher levels of innovation characteristics. Fifth, a descriptive assessment of presentations at managed deer hunts showed less than four minutes on average were spent discussing the issue with minimal hunter interest observed.

Findings from this study provide suggestions for improving future nonlead outreach with additional staff training, audience segmentation with targeted messaging for different audiences, broadening the scope of outreach to include human health lead risks, and relevance of nonhunters as stakeholders. Methodologically, this study was the first application mixed methods to explore attitudes and behaviors of natural resource professionals implementing a nonlead outreach program using structured observations, semi-structured interviews, and an online survey. Bridging across multiple disciplines, this study developed a broader theoretical perspective for dealing with a complex sociopolitical landscape with a mixture of competing values, ethics, and worldviews among stakeholders. This study also showed the value of recognizing nonhunters as an important target audience, especially human health lead risks. 


\section{Chapter 1. Introduction and overview}

\subsection{Introduction and background}

A substantial amount of research has documented the effects of spent lead hunting ammunition on wildlife (Haig et al., 2014; Rattner et al., 2008; Tranel \& Kimmel, 2009; R. T. Watson, Fuller, Pokras, \& Hunt, 2009). Exposure has been identified primarily through ingestion of lead shotgun pellets, lead bullet fragments in gut piles, or unretrieved animal carcasses shot with lead bullets (Finkelstein et al., 2012; Haig et al., 2014; Schulz, Gao, Millspaugh, \& Bermudez, 2007; Schulz, Millspaugh, et al., 2006). Although lead poisoning in North American waterfowl has been reduced (Anderson, Havera, \& Zercher, 2000; Schulz, Padding, \& Millspaugh, 2006), the problem persists for avian scavengers like bald eagles (Haliaeetus leucocephalus) and surface-feeding upland birds like mourning doves (Zenaida macroura) and ring-necked pheasants (Phasianus colchicus). In bald eagles, lead poisoning has been linked to ingestion of white-tailed deer (Odocoileus virginianus) gut piles and carcasses containing lead bullet fragments (Warner, Britton, Becker, \& Coffey, 2014) with exposure corresponding to fall firearms deer seasons (Cruz-Martinez, Redig, \& Deen, 2012; Franson \& Russell, 2014; Golden, Warner, \& Coffey, 2016; J. W. Watson, Vekasy, Nelson, \& Orr, 2019); see Figure 1.1. Political realities suggest a regulatory ban on lead hunting ammunition is problematic (Markowitz \& Rosner, 2013b; Oreskes \& Conway, 2010; Smyth, 2020; Snow, 2017), and deer hunters will need to voluntarily switch to nonlead ammunition to reduce lead exposure in wildlife and humans. Many factors, however, influence hunters' ammunition choices. Although considerable information exists on the effects of lead 
poisoning, little research has been conducted on the cognitive and behavioral mechanisms affecting hunters' awareness of the issue, values, beliefs, attitudes, intentions, and behavior of nonlead ammunition use. Existing human dimensions information has focused on attitudes and opinions of hunters concerning the use of nonlead ammunition (Case \& Associates, 2006, 2014; Henry, 2016; Ross-Winslow \& Teel, 2011; RossWinslow, Teel, \& Leong, 2011; Schroeder, Fulton, \& DonCarlos, 2016; Schroeder, Fulton, Penning, \& DonCarlos, 2012; Schulz, Reitz, Sheriff, \& Millspaugh, 2007; Seng, 2005a, 2005b; B. Smith et al., 2017) with limited research evaluating the few existing voluntary programs encouraging hunters to use nonlead ammunition (Bedrosian, Craighead, \& Crandall, 2012; Chase \& Rabe, 2015; Henry, 2016; Seng, 2005a; B. Smith et al., 2017).

\subsubsection{Characteristics of lead}

Lead is both a valuable industrial metal and a dangerous environmental toxin (Eisler, 1988; Markowitz \& Rosner, 2013b; Snow, 2017) affecting wildlife and humans (Markowitz \& Rosner, 2013b; Rattner et al., 2008; R. T. Watson et al., 2009). It is biologically nonessential with all data suggesting no safe level of exposure (Earl, Burns, Nettelbeck, \& Baghurst, 2016; Lanphear et al., 2016). Historians have speculated the widespread use of lead in water pipes, eating utensils, pottery, and cosmetics contributed to the decline of the Roman Empire, and emphasized the critical dangers related to lowlevel human lead exposure (Clarkson, 1987; Delile, Blichert-Toft, Goiran, Keay, \& Albarède, 2014; Järup, 2003; Lanphear, Rauch, Auinger, Allen, \& Hornung, 2018). Monitoring lead concentrations in glacial ice cores has also shown there is no natural 
atmospheric background lead level, and existing environmental lead levels are directly linked to anthropogenic activities of mining, smelting, and using lead (More et al., 2017). Despite this information, modern societies continue grappling with the effects lead exposure due to the toxic legacy of leaded house paint (Markowitz \& Rosner, 2013a, 2013b; Rosen, 1995) and deteriorating water utilities in places like Flint, Michigan, USA (Hanna-Attisha, 2018; Hanna-Attisha, LaChance, Sadler, \& Schnepp, 2016).

\subsubsection{Contentious discourse}

The hunting ammunition industry has developed and marketed nonlead ammunition that is effective and comparatively priced to lead ammunition (Pierce, Roster, Frisbie, Mason, \& Roberson, 2015; V. G. Thomas, 2013) but misinformation continues to pervade the policy discussion about price, availability, and effectiveness (Hunt For Truth Association, 2017b; Southwick, 2014). Further complexity involves comingling the rhetoric of anti-hunting groups using the issue to diminish hunting traditions, gun ownership and connections to $2^{\text {nd }}$ Amendment gun rights, and possible attempts at gun control legislation by controlling the use of ammunition (Baum, 2013; Whitney, 2012). Efforts to address potential human health risks from lead bullet fragments in ground meat remain problematic due to jurisdictional differences among natural resource and human health agencies; i.e., each agency says it is the other's responsibility to address human health issues related to lead exposure from eating meat killed with hunting ammunition.

Dating back to heated policy discussions when nontoxic shot regulations for waterfowl hunting were debated, arguments revolved around ballistic performance of 
nonlead ammunition, lethality or killing effectiveness, and relative cost of nonlead ammunition compared to traditional lead ammunition (Belanger \& Kinnane, 2002; Schulz, Padding, et al., 2006). At the time, many hunters said they would discontinue hunting due to increased ammunition costs, crippling or wounding too many birds, and inability to find sufficient quantities of ammunition. Today, many state agency administrators remain sensitive to these concerns regardless of their factual basis (Pierce et al., 2015; Schulz, Padding, et al., 2006; V. G. Thomas, 2013). The primary reason for inaction stems from declining hunter numbers and participation rates due to multiple changing demographic factors (Enck, Decker, \& Brown, 2000; Schulz, Millspaugh, Zekor, \& Washburn, 2003) leading to state agencies being risk-averse to anything perceived as accelerating these declines and related permit revenues.

Regulatory policy actions, although showing measurable benefits of reducing lead exposure in scavenging birds (Kelly et al., 2011), have also inadvertently caused further polarization of the issue. In other words, the regulatory policy has emboldened gunrights advocates to increase their rhetoric about the "slippery-slope" of perceived gun control legislation, junk science related to lead poisoning in wildlife and human health, and ineffectiveness and cost of nonlead hunting ammunition (Hunt For Truth Association, 2017b). Given the overwhelming data linking wildlife mortality to lead bullet fragments, environmental groups have repeatedly petitioned several federal agencies to ban lead hunting ammunition on public lands. Federal agencies declined to regulate lead ammunition and federal courts ruled against petitioner's requests (Hunt For Truth Association, 2017a), but advocacy groups have persisted. Following is one detailed example. 
During 2010-2013, Center for Biological Diversity (CBD), et al. v. United States Environmental Protection Agency (EPA), et al. (Hunt For Truth Association, 2017a) alleged the EPA is obligated to regulate lead hunting ammunition under the Toxic Substances Control Act of 1976 (TSCA; Public Law 94-469 1976). CBD initiated the lawsuit despite previous lawsuits being denied based on EPA not having authority to regulate ammunition under TSCA; the National Rifle Association, (NRA) and Safari Club International (SCI) petitioned the U.S. District Court in Washington, D.C. to intervene. The suit claimed scavenging birds such as California condors, vultures, and eagles were being poisoned from eating lead bullet fragments in carrion left in the field by hunters. CBD also claimed humans are at risk of lead poisoning by consuming meat containing lead bullet fragments. The U.S. District Court dismissed the case finding EPA acted within its authority when it determined the 2012 petition filed by CBD had based their legal action on a petition for reconsideration rather than a petition for rulemaking, and therefore was insufficient to establish jurisdiction for the suit. In other words, the case was dismissed due to a technicality unrelated to the merits of the case.

\subsubsection{Impacts and policy of lead poisoning in wildife and humans}

\subsubsection{Waterfowl}

Documentation of lead poisoning in waterfowl was first reported near Galveston Bay, Texas, USA (Grinnell, 1894) and later near Misqually Flats, Puget Sound, Washington, USA (Bowles, 1908) and Lake Surprise, Texas, USA north of Galveston Bay (McAtee, 1908). As early as 1919, experimental waterfowl feeding trails revealed the exposure pathway of lead shotgun pellet ingestion and provided detailed descriptions 
and photographs of moribund birds (Wetmore, 1919). Further data documented waterfowl ingesting spent lead shot in shallow water near popular waterfowl feeding and hunting habitats (Anderson, Havera, \& Montgomery, 1987; Simpson, 1989; U.S. Department of the Interior - Fish and Wildlife Service, 1986, 1988). In an attempt to encourage the use of nontoxic shotshells for waterfowl hunting, researchers continued to amass research detailing the effects of lead poisoning in waterfowl with little effect on policy discussions (Bellrose, 1959; Havera, Hine, \& Georgi, 1994; Humburg, Sheriff, Geissler, \& Roster, 1982; Sanderson \& Bellrose, 1986). During this period, policy makers and stakeholders continued disagreeing over the veracity and validity of the available data and called for additional research because of perceived uncertainty or incompleteness of available information. During 1970s and 1980s several states enacted their own waterfowl lead ammunition bans, but these policies were nullified by Stevens Amendment of 1978 (U.S. Department of the Interior - Fish and Wildlife Service, 1988) during development of appropriations bills (Belanger \& Kinnane, 2002); this rider has appeared annually in Interior appropriations language since. These policy efforts were followed by an Environmental Impact Statement (Public Law 91-190, U.S. Department of the Interior - Fish and Wildlife Service 1986), and finally a lawsuit between National Wildlife Federation and USFWS over the death of bald eagles resulting from ingesting lead poisoned waterfowl (51 FR 6012; Belanger and Kinnane 2002). Eventually, state agencies and USFWS agreed to a national policy for a 5-year (1987-1991) phased-in nontoxic-shot regulation for waterfowl hunting (51 FR 42103; U.S. Department of the Interior - Fish and Wildlife Service 1988, Schulz et al. 2006). 
The nontoxic-shot regulation was fully implemented nationally during the 19911992 waterfowl hunting season, but waterfowl hunters were frustrated over federal intrusion and angry over the nontoxic-shot regulation for decades. State and federal agency administrators were battle-worn over the heated political fights and reluctant to deal with the lead poisoning issue more broadly for other species. One of the primary arguments used by hunters at the time against the nontoxic-shot regulation was the increased potential of crippling more ducks and geese because of the perceived poor ballistic performance of nontoxic shotshells (R. L. Smith \& Townsend, 1981). To address this issue, the Cooperative North American Shooting Education Program (CONSEP) was established to promote shotgun shooting education and research on the effectiveness or lethality of nontoxic shot. Since then, hunter harvest surveys completed before, during, and after full implementation of the nontoxic-shot regulation demonstrated the reported crippling rates by waterfowl hunters actually declined after full implementation of the nontoxic-shot regulation (Schulz, Padding, et al., 2006).

Interestingly, many conservation stakeholders today characterize the history of the nontoxic-shot waterfowl regulation as unanimous recognition of lead poisoning in waterfowl, general acceptance of the available scientific information (i.e., "settled science" as a reoccurring phrase), broad agreement upon a regulatory solution, and full support among all parties on effective policy implementation. This portrayal implies current lead poisoning in other wildlife is dissimilar with uncertainty of available data, and lack of a demonstrated population level effect for species such as mourning doves or bald eagles. This mischaracterization distracts, misdirects, and misinforms public discussions surrounding the reduction or elimination of lead poisoning in wildlife 
resulting from spent hunting ammunition. These tactics are similar to those used previously during public discussions of other environmental (e.g., climate change) and social health issues (e.g., cigarette smoking; Oreskes and Conway 2010). Framing the $>100$-year history of waterfowl lead poisoning as a peaceful series of policy discussions and administrative actions distorts the events that occurred at the time (Bean \& Rowland, 1997; Belanger \& Kinnane, 2002; J. Scott Feierabend, 1985; J Scott Feierabend, 1985) and discouraged progress toward improving the health of other wildlife species and human health.

\subsubsection{California condors}

Similar to waterfowl, substantial amounts of data demonstrate the negative effects of lead exposure in California condors (Gymnogyps californianus). Compared to direct ingestion of lead pellets by waterfowl, condors' lead exposure results from ingesting bullet fragments from spent hunting ammunition in animal carcasses and gut piles (Church et al., 2006; Finkelstein et al., 2010; Kelly, Parish, \& Johnson, 2016; B. Smith et al., 2017). In addition to acute levels of lead exposure, sub-lethal lead exposure in California condors may alter blood chemistries and result in negative physiological and behavioral impacts (Glucs et al., 2020; Kelly et al., 2014). In an attempt to increase and expand the California condor population, recovery programs using captive-reared translocated found newly released condors quickly developed feeding behaviors associated with animal carcasses contaminated with lead-based ammunition (Bakker et al., 2017). 
Progress in elevating this issue in the policy agenda has been made, but stakeholders believe more policy action is needed for an endangered species with populations numbering slightly more than 450 birds (Bellinger et al., 2013). A controversial decision was made in 1987 to trap the remaining 27 wild condors and establish a captive breeding program (D'Elia \& Haig, 2013); this was the first step in an incremental policy process. Although still critically endangered under the Endangered Species Act (ESA) of 1973 (Public Law 93-205, 1973), the captive breeding program has allowed condor populations to be reestablished in northern California, northern Arizona, southern Utah, and plans for a population along the Oregon coast (D'Elia \& Haig, 2013).

Because lead poisoning from hunting ammunition is the primary factor contributing to California condor mortality (Church et al., 2006; Finkelstein et al., 2012; Finkelstein et al., 2010; Kelly et al., 2014), California Fish and Game Commission established a regulatory policy by modifying methods-of-take (i.e., a command-andcontrol approach) during 2008 prohibiting the use of lead hunting ammunition for biggame hunting within the primary condor range of southern California (California Department of Fish and Wildlife, 2017). Several environmental nonprofit organizations (e.g., Center for Biological Diversity and San Diego Zoo) attempted to get the issue moved from the general policy agenda to the formal policy agenda, but little progress was made increasing awareness among an interested and attentive public. Despite the 2008 regulation, condor blood lead levels remained high. Data from radio-marked birds indicated condors traveled extensively and scavenged on animal carcasses outside the nonlead ammunition zone (B. Smith et al., 2017). During 2012, California Audubon joined the advocacy coalition by mobilizing their local chapters to affect the legislative 
process by moving the issue to the formal policy agenda. Given limited condor response to the original 2008 policy banning all lead hunting ammunition in southern California, a more extensive and inclusive statewide lead ban was adopted in 2013 for all big-game and small-game hunting (California Assembly Bill 711, 2013) to be fully phased-in by the 2019 hunting seasons (California Department of Fish and Wildlife, 2017).

The statewide ban on lead hunting ammunition in California is currently in the second of three implementation phases. The first phase began 2015 and required nonlead ammunition when hunting on all California Department of Fish and Wildlife (CDFW) properties, and for all bighorn sheep (Ovis canadensis) hunts. Effective 2016, hunters using shotguns were required to use certified nonlead ammunition for upland game hunting (except dove, quail, snipe, and any species taken on licensed game bird clubs), fur-bearing and nongame species, and any species taken with a depredation permit. Shotgun ammunition must be composed of materials approved as nontoxic by USFWS. Effective 2019, certified nonlead ammunition will be required statewide when taking any wildlife. It is currently too early to fully evaluate this regulatory policy approach. However, existing ex-ante evaluation programs tracking condor blood levels, condor reproduction and recruitment, and individual movements have been in place since the late 1990s (B. Smith et al., 2017) and will be useful for monitoring future policy outcomes. In addition to direct measurable policy outcomes related to condor population response, several unique issues have been identified.

In the face of accumulating scientific information linking California condor mortality to ingestion of lead bullet fragments in areas outside of California, environmental nonprofit groups filed petitions against the U.S. Environmental Protection 
Agency, U.S. Forest Service, and Bureau of Land Management during 2010-2012 to expand regulations on all public lands for lead hunting ammunition (Hunt For Truth Association, 2017a). Although federal agencies declined to regulate lead ammunition and federal courts ruled against the petitioners, requests persisted for expanded regulatory policies on public lands (Bellinger et al., 2013; Finkelstein et al., 2012).

The regulatory policy approach adopted in California in the early 2000s motivated stakeholders in Arizona and Utah to adopt a self-regulatory or voluntary policy instrument to avoid a regulatory ban on lead hunting ammunition fearing it would decrease hunting opportunity due primarily to increased ammunition costs (and corresponding declines in hunting permit revenues, hunting guide services, and retail equipment sales). In contrast to the nonhunting stakeholders dominating the policy discussions in California (e.g., California Audubon, Center for Biological Diversity), stakeholders in Arizona and Utah were dominated by hunting groups and associated business interests related to outdoor equipment retailers, and ammunition and firearms manufacturers.

Relying on a self-regulatory or voluntary policy approach, Arizona Game and Fish Department (AGFD) instituted a voluntary nonlead ammunition program in the northern portion of the state during 2005 using a combination of informational materials and shooting demonstrations, and free nonlead hunting ammunition vouchers; i.e., incentives (Chase \& Rabe, 2015; Seng, 2005a, 2005b). A similar voluntary and awareness program about lead poisoning in California condors was established in southern Utah by the Division of Wildlife Resources (UDWR) during 2013. Both Arizona and Utah used "gut-pile raffles" as an incentive with limited success. For each 
gut-pile from an animal shot with lead ammunition and brought to a check station, the hunter would be eligible for a drawing for a new hunting rifle.

The voluntary approach in Arizona and Utah currently uses an ex ante evaluation process. Focus groups were used to test outreach messages along with establishing baseline issue awareness among hunters (Seng, 2005a, 2005b), and mail surveys and hunter interviews to periodically monitor program effectiveness in changing hunter behavior (Chase \& Rabe, 2015; B. Smith et al., 2017). Although current voluntary outreach efforts are established and monitored to measure changes in hunter behavior, hunter populations have an undefined statistical sampling framework providing weak inferences to the broader hunter population.

\subsubsection{Bald eagles}

In contrast to the critically endangered California condors, bald eagles are no longer on the endangered species list (Public Law 93-205, 1973) and populations are increasing (Millsap, Bjerre, Otto, Zimmerman, \& Zimpfer, 2016). However, it remains a violation of the Bald and Golden Eagle Protection Act of 1940 (Public Law 86-70, 1940) to kill eagles by poisoning. Although the issue of lead poisoning in bald eagles was the primary issue behind the nontoxic shot regulation for waterfowl hunting, the proportion of lead poisoning diagnoses for eagles submitted to the National Wildlife Health Center (Madison, Wisconsin, USA) displayed a significant increase after the 1991 waterfowl lead shot ban suggesting broader sources of lead exposure (Russell \& Franson, 2014). This issue was again demonstrated during 2012 when 58 bald eagles were collected across Iowa, Minnesota, and Wisconsin with $60 \%$ of the birds having detectable lead 
concentrations linked to consumption of white-tailed deer gut piles containing lead bullet fragments (Warner et al., 2014). During 1986-2017 in Michigan, lead poisoning was the second leading cause of bald eagle death followed by vehicular trauma demonstrating the long-term and broad scale nature of the problem (Simon et al., 2020). Other research has demonstrated broad scale mortality of bald eagles linked to lead ammunition corresponding to fall firearms deer hunting seasons (Cruz-Martinez et al., 2012; Franson \& Russell, 2014; Golden et al., 2016; Hunt et al., 2006) and other hunting activities (Haig et al., 2014; Herring, Eagles-Smith, \& Wagner, 2016). Carrion-baited camera traps showed eagles visiting these opportunistic feeding sites an average 3.4 times over roughly 2-days until the carcass or gut-pile was totally consumed (J. W. Watson et al., 2019). In areas where lead ammunition was commonly used for big-game hunting, bald eagle blood lead levels $>60 \mu \mathrm{g} / \mathrm{dL}$ (i.e., clinical exposure) were found in $24 \%$ of eagles during the big-game hunting seasons in the Grand Teton National Park and National Elk Refuge during 2005-2010 (Bedrosian et al., 2012). Anecdotal observations from several public land managers where eagles overwinter suggest bald eagles may have learned the visual and auditory cues related to deer hunting as signs of food. Similar observations have been experimentally tested in common ravens (Corvus corax) where the birds fly toward the sounds of gun shots presumably to locate animal gut piles left by hunters (White, 2005).

\subsubsection{Mourning Doves}

Similarly, a considerable amount of research has shown mourning doves (Zenaida macroura) search for lead pellets deposited by hunters (Duguay, Tolson, \& Holt, 2017; 
Plautz, Halbrook, \& Sparling, 2011; Schulz et al., 2002), ingest the pellets, and succumb to lead poisoning (Schulz, Gao, et al., 2007; Schulz, Millspaugh, et al., 2006). Given average pellet ingestion rates of $2.5 \%$ for 4229 mourning doves from 36 public hunting areas in seven states (Franson, Hansen, \& Schulz, 2009), annual estimates of lead mortality likely exceed annual estimates of the legal harvest (Schulz, Padding, et al., 2006). Some stakeholders have argued lead poisoning in mourning doves represents isolated cases of few individuals, however, data from heavily hunted managed fields in Missouri indicate there may be a local population effects (Schulz, Bian, Gao, Mong, \& Millspaugh, 2017).

\subsubsection{Human health and lead exposure from spent ammunition}

Similarly, human health is impacted by lead exposure through ingestion of lead bullet fragments in processed ground venison (Fachehoun et al., 2015; Hunt et al., 2009; Iqbal et al., 2009; Meltzer et al., 2013). Evidence continues to accumulate showing blood lead levels in humans $<5 \mu \mathrm{g} / \mathrm{dL}$ impairs cognition and suggests there is no safe threshold level of human lead exposure (Bellinger et al., 1991; Earl et al., 2016; Lanphear et al., 2016). Not only do low blood lead levels impair cognitive abilities, recent findings demonstrate low-level exposure is a largely overlooked risk factor for cardiovascular disease mortality in the U.S. corresponding to approximately 256,000 annual deaths due to cardiovascular disease and 185,000 a year from ischemic or coronary artery heart disease (Lanphear et al., 2018). Individuals eating game meat shot with lead ammunition are at risk for the chronic and acute effects of lead poisoning (Jones et al., 2009; Knott, Gilbert, Hoccom, \& Green, 2010; Lidsky \& Schneider, 2006; Rosen, 1995). 
Human exposure to lead bullet fragments in game meat can create an environmental injustice by disproportionately and unequally impacting underprivileged racial and social classes (Mohai, Pellow, \& Roberts, 2009; Wenz, 1999). This occurs when state natural resource management agencies partner with local food banks and distribute lead-tainted ground venison to poor and needy families (Missouri Department of Conservation, 2017). Some state agencies provide an lead advisory notice in their big game hunting regulations (Minnesota Department of Natural Resources, 2017) and other states suggest pregnant women and children not consume donated meat (New Hampshire Fish and Game, 2017).

\subsubsection{Hunters' perceptions and behaviors of lead poisoning}

Few human dimensions research studies have documented hunters' attitudes towards nonlead ammunition (Schulz, Reitz, et al., 2007), behavioral mechanisms affecting hunters' voluntarily use of nonlead ammunition (Schroeder et al., 2012), or evaluated existing voluntary programs (Chase \& Rabe, 2015). As mentioned earlier, research has shown mourning doves succumb to lead poisoning (Schulz, Gao, et al., 2007; Schulz, Gao, Millspaugh, \& Bermudez, 2009; Schulz, Millspaugh, et al., 2006; Schulz et al., 2002). Despite this information, approximately 50-53\% of Illinois mourning dove hunters opposed a nontoxic-shot regulation for dove hunting (Anderson \& David, 1994; Levengood, Anderson, \& David, 1999; Miller, McCleary, Stephenson, Harper, \& Campbell, 2013). Similarly, other surveys of dove hunters showed hunters having little awareness of the problem and little desire to change behavior (Case \& Associates, 2006, 2014; Schulz, Reitz, et al., 2007). Small game hunters in Minnesota, 
including dove hunters had little awareness of the lead poisoning in mourning doves but suggested they would be receptive to nonlead ammunition messages from hunter organizations like Ducks Unlimited (Schroeder et al., 2012).

Focus groups and interviews were used to develop a voluntary nonlead ammunition program for California condors in Arizona (Seng, 2005a, 2005b). A followup evaluation assessed the voluntary program's effectiveness with roughly half of the deer hunters in the education-only treatment used nonlead ammunition while about threefourths of the education-voucher group used nonlead ammunition (Chase \& Rabe, 2015). Further voluntary outreach activities occurred in Arizona and Utah to reduce condor lead exposure; an informal survey indicated $88 \%$ of Arizona's Kaibab deer hunters and $80 \%$ of southern Utah's deer hunters participated in some type of lead ammunition reduction activity during 2012-2016 (B. Smith et al., 2017). Another project evaluated education efforts on National Parks to reduce lead deposition related to hunting and fishing and reviewed efforts encouraging voluntary use of nonlead hunting ammunition (RossWinslow \& Teel, 2011; Ross-Winslow et al., 2011). Effectiveness of open-house demonstrations to influence deer hunter behavior to use nonlead ammunition on a single state park in Minnesota were evaluated but due to low participation no conclusions could be drawn (Henry, 2016). A similar small-scale evaluation project is on-going at Great Swamp National Wildlife Refuge in cooperation with U.S. Fish and Wildlife Service, Massachusetts Cooperative Fish and Wildlife Research Unit, and University of Massachusetts (unpublished progress report, 2017). 


\subsubsection{Benefits and uses of theoretical behavioral models}

Public information campaigns are designed to influence a target audience's behavior. Research has shown information campaigns have moderate to strong effects on cognitive outcomes, less on attitudinal outcomes, and still less on specific behaviors (Rice \& Atkin, 2013). Additionally, desired behavioral outcomes may vary by factors such of dose of information, qualitative potency of the information, integration of interpersonal communication processes, and social change strategies (Paisley \& Atkin, 2013). Many of these contemporary campaigns accomplish modest results due to insufficient funding, poorly conceived strategies and objectives, and unsophisticated use of behavioral models or communication theory. Regardless, there has been a growing recognition of the importance of theory in the development of behavior-change interventions in communication programs (Fishbein \& Cappella, 2006), and especially a growing importance in conservation of natural resources (Bennett et al., 2017; Decker, Riley, \& Siemer, 2012; Vaske, 2008). In other words, the more one knows about the contributing factors about a specific behavior the more likely effective communication can be developed and implemented. To ameliorate some of these concerns, this research embraces two broad theoretical frameworks; the reasoned action approach and the diffusion of innovations theory.

\subsubsection{Reasoned action approach}

The reasoned action approach (RAA) is a conceptual framework encouraging the use of varying constructs form widely different disciplines (Figure 1.6). This framework suggests human social behavior is thought to be predicted by a relatively simple and 
limited set of factors or constructs needed to predict and understand almost any behavior (Fishbein \& Ajzen, 2010). A recent formulation of the RAA is the integrated model (IM) or the integrative model of behavioral prediction (Fishbein, 2008; Fishbein \& Ajzen, 2010; Fishbein \& Yzer, 2003; Yzer, 2012). This approach is based upon the earlier models of theory of reasoned action (Fishbein, 1979) and theory of planned behavior (T. J. Madden, Ellen, \& Ajzen, 1992; Montano \& Kasprzyk, 2015). This broad conceptual framework draws on characteristics from the social cognitive theory (Fishbein \& Yzer, 2003; Kelder, Hoelscher, \& Perry, 2015), health belief model (Skinner, Tiro, \& Champion, 2015), and the transtheoretical model (Prochaska, Redding, \& Evers, 2015). Initially, and most importantly, the behavior under consideration must be clearly identified and operationalized with intentions considered the primary construct affecting behavior (Fishbein \& Ajzen, 2010). Next, the fundamental theoretical factors affecting behavior are attitudes toward the behavior (and not the object of the behavior), perceived norms of social conspecifics, and personal agency or self-efficacy (Fishbein, 2008; T. J. Madden et al., 1992). Once attitudes, perceived norms, and self-efficacy are formed they guide intentions and ultimately the resulting behavior. In general, the more favorable the attitude and perceived norm and greater self-efficacy, the stronger a person's behavioral intention. However, the relative weight of the primary constructs vary from one behavior to another and from one group of people to another (Fishbein \& Ajzen, 2010). With this research project, an application of this conceptual framework shows a deer hunter intending to use nonlead ammunition (the intended behavior) with a favorable attitude toward nonlead ammunition, with friends or relatives supportive of using nonlead 
ammunition (perceived norms), and/or feeling confident in their ability to proficiently use nonlead ammunition in hunting situations (self-efficacy).

In addition to behavioral intentions being strongly linked to behavior, the major difference with RAA are four other factors believed to directly affect behavior (Figure 1.5; Jaccard, Dodge, \& Dittus, 2002). First, a person requires the knowledge and skills necessary to perform the intended behavior. For example, a deer hunter would need to have knowledge about effects of potential ballistic differences between nonlead vs. lead ammunition, and the skill to readjust the point of impact of the hunting weapon and differences in barrel rifling. Second, there should be few constraints on conducting the target behavior. The primary factor for hunters in this situation is the availability of nonlead ammunition in the necessary firearm calibers, pricing compared to traditional lead ammunition, and availability in the necessary quantities for hunting and shooting. Third, the behavior must to be salient or important to the individual. For most deer hunters, hunting itself is salient (Black, Jensen, Newman, \& Boulanger, 2018; EbelingSchuld \& Darimont, 2017), but in this example the use of nonlead ammunition and the related ecological benefits must also be salient. Finally, sufficient experience is needed so the target behavior becomes habitual or routine, and thereby making the behavioral intention less important. In the case of a deer hunter routinely using nonlead ammunition, the behavior would likely have to occur over several seasons as previous supplies of lead ammunition are used up or discarded and the hunter learns to specifically acquire and use nonlead ammunition while deer hunting (Note: currently, deer hunting ammunition is not often labeled or marketed as being nonlead or nontoxic). The constructs must work together to effectively predict behavior. Simply addressing one, or 
two, or even three of those factors can lead to the inability to change behavior. This is especially true during implementation of the outreach program intervention. Because each of the four factors affect the behavior, it is important to ensure the intervention strategies address factors affecting knowledge and skills, salience of behavior, environmental constraints, and habit.

The reasoned action approach has a strong tradition for dealing with the human dimensions of contentious natural resource issues (Decker et al., 2012; Vaske, 2008). The theory of reasoned action was used in conjunction with a survey to understand attitudes and beliefs about lethal deer management in Cuyahoga Valley National Park (Fulton, Skerl, Shank, \& Lime, 2004). Beliefs about management outcomes proved to be strong predictors of support for lethal control especially if it was done to prevent human harm (e.g., deer-vehicle collisions, spread of disease), habitat damage, or deer population maintenance. Another application of this framework identified key beliefs using a statewide survey in Minnesota of small-game hunters concerning support/opposition to a ban on lead ammunition (Schroeder et al., 2012). They found factual messages from a trusted hunting organization using a first-person narrative generated the greatest support for a regulatory ban. A different study in Minnesota used the reasoned action approach again, but this time used a multilevel and multivariate approach to clarify how positive and negative beliefs related to attitudes about a ban on lead shot for small-game hunting (Schroeder et al., 2016). Results from this study showed both positive and negative outcomes influence attitudes; positive outcomes were more influential for supporters and negative beliefs for opposers. 


\subsubsection{Diffusion of innovation theoretical framework}

Effective pro-environmental behavioral change, like voluntary use of nonlead hunting ammunition, includes a general framework of (1) carefully selecting behavior to improve environmental quality, (2) determining factors affecting the relevant behavior, (3) designing interventions to encourage the desired behavior, and (4) monitoring outcomes (Steg \& Vlek, 2009). The diffusion of innovation theory (Dingfelder \& Mandell, 2011; Mascia \& Mills, 2017; Rogers, 2003) has the potential of addressing all four of these components by explaining how, why, and the rate at which new ideas or innovations spread. This theoretical framework consists of all activities and effects occurring from the problem, research and development of the innovation, marketing of the innovation, rates of adoption, adopter characteristics, and consequences of adoption (both intended and unintended); i.e., an interconnected set of sub-theories explaining how new ideas and products are adopted and diffused throughout the population. Within the diffusion of innovation framework, four elements influence the spread of new ideas: the innovation itself and its attributes, communication channels, time or progress toward adoption, and the social system relying heavily on human capital.

The first element, innovations, are new ideas or practices characterized by (1) relative advantage, (2) compatibility, (3) complexity, (4) trialability, (5) observability, and (6) reinvention (Greenhalgh, Robert, Macfarlane, Bate, \& Kyriakidou, 2004; Rogers, 2003). In the case of voluntary use of nonlead ammunition, this may include the superior ballistics of nonlead rifle ammunition for big-game hunting (relative advantage), compatibility with modern firearms (compatibility), the relative ease of using nonlead rifle ammunition (complexity), availability of free samples to use on a trial basis (trialability), and shooting demonstrations showing side-by-side comparisons of different 
ammunition types (observability). Another aspect of innovations is reinvention, i.e., modification of the innovation. For example, some hunters may hand-load special (or "wild-cat") rounds of nonlead ammunition, or reinvent a special load, for a specific hunting situation or fill the need for a rifle caliber not commercially available. From the standpoint of a communication program promoting voluntary use of nonlead ammunition, messages should be customized or tailored for specific deer hunting audiences; e.g., understanding the different hunting characteristics and behaviors of different types of deer hunters and weapon types (e.g., rifle, shotgun, muzzleloader rifle, and handgun).

The second element of the theory stresses the importance of communication channels in spreading innovations among group members; e.g., the use of trusted leaders, information sources, or organizations (Barnett, Vasileiou, Djemil, Brooks, \& Young, 2011; Dearing, 2004; Schroeder et al., 2012). It is important to recognize the subtle differences between communication within a person's peer group (homophily) and communication with individuals having different social status, beliefs, or education (heterophily; Rogers 2003). These communication channels play different roles in the innovation-decision process where information from outside a person's regular peer group increases exposure and awareness to the new information. Further along the innovation-decision process, however, peer groups become more important by reinforcing and adding credibility to the new information. Using deer hunting as an example, trusted peer group communicators and outside experts both play a role in increasing awareness and sharing technical details. Social networks of deer hunters can observe firsthand the advantages of nonlead ammunition. Outside experts, viewed as 
credible sources of information, could use shooting demonstrations and provide technical details related to use of nonlead ammunition and compatibility with modern firearms.

The third element, time, includes several components including the innovationdecision process, adopter categories, and the rate of adoption (temporal scale). Although early diffusion of innovation research focused primarily on time of adoption (or rates of adoption), efforts focused on the innovation-decision process and adopter characteristics provide opportunities to tailor communication messages (Mahajan, Muller, \& Srivastava, 1990; G. A. Moore, 2014). The innovation-decision process is characterized by five stages: (1) acquisition of knowledge, (2) persuasion, (3) decision to adopt or reject, (4) implementation of decision, and (5) confirmation or reinforcement (Rogers, 2003). By recognizing these stages, communicators can craft different messages aimed at specific groups of hunters along the nonlead ammunition decision process. Potentially, some messages may focus on acquisition of knowledge by providing technical details of lead poisoning and its effect on wildlife. Other messages would be aimed toward hunters' decision to use nonlead ammunition related ammunition availability, price, or use of nonlead ammunition with existing firearms. Using bald eagles as an example, a multiphase behavioral decision process shows there is more to changing hunter behavior than providing technical information of lead poisoning in a brochure or parking lot kiosk assuming the knowledge deficit model (Brunk, 2006; Sturgis \& Allum, 2004) or cognitive fix model (Heberlein, 2012b). Rather, some voluntary nonlead ammunition programs aimed at reducing lead exposure in condors not only use a brochure but follow up with a persuasive conversation, encouragement to help condor recovery, free samples 
of nonlead ammunition, and further follow-up encouragement (Bedrosian et al., 2012; B. Smith et al., 2017).

Within the five-step decision-making process for adopting innovations from above, the speed of adoption and adopter characteristics have been categorized into groups of: (1) innovators, (2) early adopters, (3) early majority, (4) late majority, and (5) laggards or traditionalists (Hurt, Joseph, \& Cook, 1977; Mahajan et al., 1990; G. A. Moore, 2014). Using deer hunters again as an example, individual hunters can be categorized based on their speed of adoption to use nonlead ammunition and their relative innovativeness characteristics. Innovators are the first deer hunters to experiment with new hunting methods and related outdoor equipment, they have effective methods for dealing with uncertainty about ammunition sources and differences in ballistics between lead and nonlead ammunition and have extensive social networks for communicating what they have learned about their nonlead ammunition experiences. Early adopters of nonlead ammunition are deer hunters who are members of the innovators' social network and usually demonstrate considerable leadership among a much broader group of other deer hunters and have an important role as change agents for speeding the diffusion of nonlead ammunition. Early majority are represented by deer hunters who adopt new ideas before the average deer hunter and have a broad social network but seldom hold leadership positions in hunting organizations, and they will deliberate at some length before completely adopting to nonlead ammunition. Late majority deer hunters are typically skeptical and will adopt nonlead ammunition after the average hunter has already converted. In this example, late majority hunters adopt nonlead ammunition because of increasing peer pressure or because of economic necessity when nonlead 
ammunition is competitively priced. Laggards or traditionalists are the last hunters to adopt nonlead ammunition because of their smaller social networks and suspicious nature concerning nonlead ammunition; e.g., they may believe a voluntary nonlead program is part of a gun control conspiracy or the first step toward a regulatory ban on ammunition. The typology of adopter categories can be expanded beyond an exclusively temporal concept with some groups occurring simultaneously or proceeding through time with considerable overlap among groups of hunters and anglers.

Finally, social systems help establish group behavior patterns where leadership of the innovation is accomplished through change agents or champions (e.g., innovators or early adopters) influencing diffusion of the innovation (Barnett et al., 2011; Dearing, 2009). The primary role of the change agent is to facilitate the flow of innovations from the change agency to the target audience. They must simultaneously be a topical technical expert and effective communicator to groups outside of his/her immediate socioeconomic status. Change agents play a crucial role by being a catalyst for change by helping (1) develop the need for change, (2) develop rapport among a wide range of stake holders (i.e., homophily and heterophily from above), (3) diagnose the problem addressed by the innovation, (4) create motivation to adopt the innovation, (5) facilitate intent into action or adoption, (6) reinforce the adoption behavior, and (7) encourage other innovators and early adaptors to become their own change agents to recruit new adopters (Rogers, 2003). Intuitively, the effectiveness of change agents is a function of their ability to reach out and make meaningful connections to target audiences.

The social systems concept can affect human health and environmental justice issues related to lead bullet fragments in ground game meat, especially when dealing with 
food banks and needy families. The role of change agent is played by multiple individuals with roles being complex and varied. An environmental nonprofit group can be a champion by promoting improved safety of ground venison at food banks by increasing awareness of the issue and the need for hunters to use nonlead ammunition. The food bank director must weigh the social consequences of improved food safety verses availability of protein for clients. State health agency officials can play a change agent role by promoting safety recommendations for at-risk groups like women of childbearing age or young children. State wildlife agency official can change agents by promoting nonlead shooting demonstrations or free ammunition vouchers. State and local hunting organization leaders can play additional change agent roles by promoting the use of nonlead ammunition by their members.

Everett Rogers first popularized the theory in his book Diffusion of Innovations published in 1962 and it is now in its fifth edition (2003). The theory originally tracked the adoption of different agricultural practices in Iowa during the 1930s (e.g., hybrid seed corn, and synthetic fertilizers). Since its inception, the theory has become multidisciplinary, cutting across a variety of scientific fields, with particular emphasis in business and marketing (Chen, Yen, \& Chen, 2009; G. A. Moore, 2014) and human health (Brownson, Takak, Stamatakis, \& Glanz, 2015; Dearing, 2004). The diffusion of innovation theory can provide a useful framework for tracking and documenting the multiple and complex innovation-decision processes of deer hunters who may change their behavior by voluntarily converting to nonlead alternatives after exposure to targeted information programs. As part of a larger program evaluation, human dimensions researchers can use the diffusion of innovation theory to help communicators better 
understand and refine communication strategies over time with formative evaluations and consider monitoring rates of behavior change.

Although DOI theory provides a comprehensive framework, most of its application has been associated with adopter characteristics and rates of adoption associated with marketing a wide range of modern technological innovations like fax machines, cell phones, and personal computers (Chen et al., 2009; G. A. Moore, 2014). Other applications have used DOI and TRA together to understand and predict utilization of information technology by end-users, and showed the most consistent factors affecting use of information technology was ease of use, relative advantaged, and compatibility (G. C. Moore \& Benbasat, 1996). Dearing (2009) reviewed diffusion theory and arrived at seven concepts describing factors affecting the spread of evidence-based practices, programs, and policies in the field of social work (i.e., intervention attributes, intervention clusters, demonstration projects, societal sectors, reinforcing contextual conditions, opinion leadership, and intervention adaptation). Using the innovation decision process construct of DOI theory, Dingfelder \& Mandell (2011) showed how different autism interventions are adopted or successfully implemented by public health and education professionals. The application of DOI in natural resources showed how innovation and adopter characteristics were used to empower managers by improving resource management decisions in Tanzania and locally managed marine areas in the Pacific (Mascia \& Mills, 2017). 


\subsection{Outreach program background}

This project was motivated by research conducted during 2014 demonstrating lead poisoning in bald eagles on U.S. Fish and Wildlife Service (USFWS) National Wildlife Refuges (NWRs) in Upper Midwest, Region 3 (Golden et al., 2016; Warner et al., 2014). These research results prompted the USFWS to explore options for reducing bald eagle lead exposure caused by spent lead ammunition on NWRs. During 2015, a second USFWS team was tasked to develop and implement an outreach program encouraging the voluntary use nonlead ammunition by deer hunters on NWRs. The implementation team developed a set of communication and outreach materials based on consistent messaging about lead poisoning in eagles and nonlead ammunition.

During 2016, the four pilot NWRs received the same set of briefing and outreach materials; i.e., pre-hunting season staff briefing from the implementation team, standardized PowerPoint presentation template, fact sheet, yard signs, free-standing banner for area refuge offices (Figure 1.3), and a brochure or rack card (Figure 1.4). During 2017, the next 17 areas added to the outreach program received the same materials with the addition of a modified presentation for use only on NWRs with managed hunts and a hunter orientation session, and a clear epoxy mold (about 8" x 4" x 2"; Figure 1.5) showing different bullet types and bullet fragmentation characteristics of both lead and nonlead ammunition. The communication materials used during 2018 were slightly edited again for the last 33 areas added to the outreach program for a total of 54 NWRs (Figure 1.6; Appendix 1). Therefore, this project focused on the overall support and perceptions of the program among USFWS refuge staff and not necessarily the efficacy of specific communication strategies, outreach materials, or changes in deer hunter behavior. 
Originally, the USFWS implementation team's goal (or primary outcome), was to measure change in deer hunters' voluntarily using nonlead ammunition while hunting on NWRs. Intuitively, measuring changes deer hunter behavior was logical but impractical for two important reasons. First, the use of federal funds to conduct social science research requires approval from the U.S. Office of Information and Regulatory Affairs (OIRA) with the U.S. Office of Management and Budget (OMB) under the Paperwork Reduction Act of 1980 (Public Law 96-511, 1980). Given the political and social complexities of any issue remotely tangent to control gun and ammunition discussions, the USFWS regional administrative leadership and implementation team decided in late 2017 and early 2018 to forgo applying for a public information request from OIRA and OMB for collecting information from deer hunters. During the pilot phase of the first three years of the program, the USFWS implementation team chose to focus on evaluating effectiveness outcomes from their own refuge field staff which would not require OIRA and OMB approval. Second, the program used a gradual phase-in approach of adding more areas to the outreach program each year along while modifying outreach materials annually. Four NWRs were piloted the 2016-2017 hunting seasons, followed by 17 refuges in 2017-2018, and the remaining refuges entering the program during 2018-2019.

Developing nonlead outreach and communication messages designed to affect deer hunter behavior was challenging because of the complex and controversial nature of the topic. Behind this backdrop, this research was implemented. It was the first of its kind to use different theoretical frameworks methodologies evaluating and exploring mechanisms effecting USFWS staff attitudes, intentions, and behavior regarding 
voluntary use of nonlead ammunition for deer hunting. Previous attempts at monitoring changes in hunter behavior have been primarily subjective (Bedrosian et al., 2012; B. Smith et al., 2017), narrowly focused on a very small subset of hunters (Henry, 2016), or evaluated species like mourning doves which are impacted through different lead exposure pathways (Schroeder et al., 2012). Although a regulatory policy banning lead hunting ammunition may appear on the surface to be most logical and effective (Bellinger et al., 2013; V. G. Thomas \& Guitart, 2003), political realities indicate a regulatory ban on lead ammunition similar to waterfowl hunting was problematic; hunters will need to voluntarily switch to nonlead ammunition to reduce wildlife lead exposure.

\subsection{Research problem and objectives}

Multiple studies have recommended voluntary nonlead hunting ammunition outreach programs to reduce lead poisoning in scavenging birds like bald eagles, vultures, or condors (Chase \& Rabe, 2015; Kelly \& Johnson, 2011; Kelly et al., 2016), but there have been limited assessments exploring factors influencing natural resource professionals' attitudes, perceptions, behavior, and effective messaging strategies. Therefore, the objectives were to (1) examine lead exposure risks and suggest communication strategies, (2) explore attitudes and experiences of NWR staff implementing the program, (3) examine staff attitudes about threats to bald eagles, lead poisoning in bald eagles, human health risks, use of nonlead hunting ammunition, and socio-economic ammunition factors, (4) examine factors influencing program support by staff, and (5) assess structured observations of nonlead presentations. Correspondingly, 
this research resulted in four manuscripts and an additional research note aligned with the objectives above. 


\section{(A)}

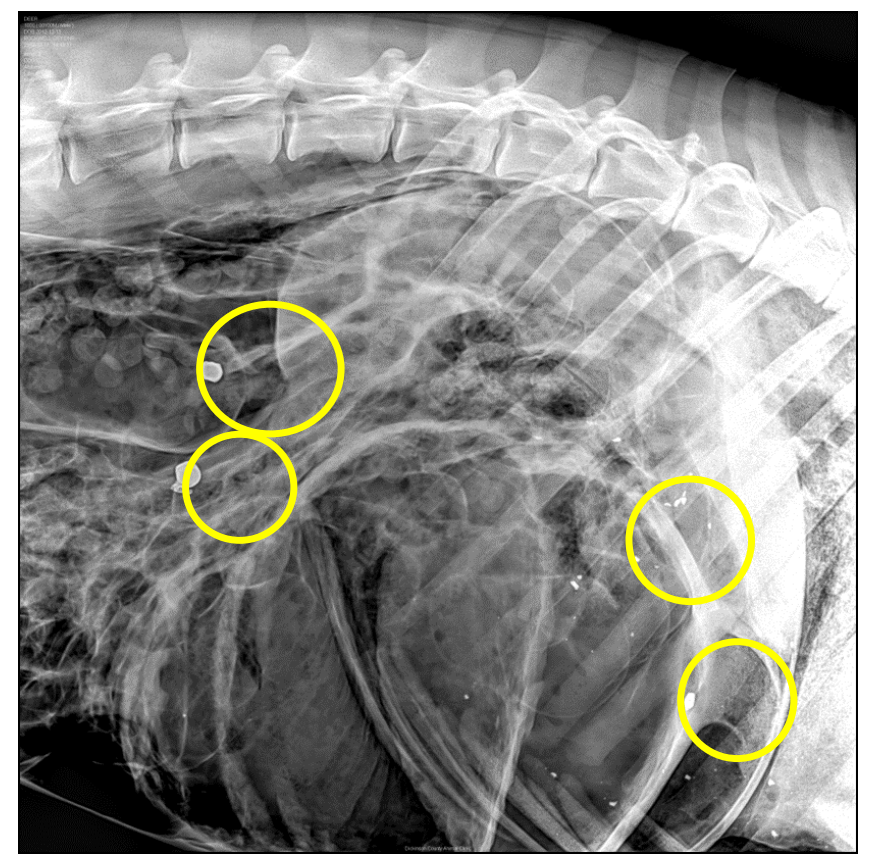

(B)

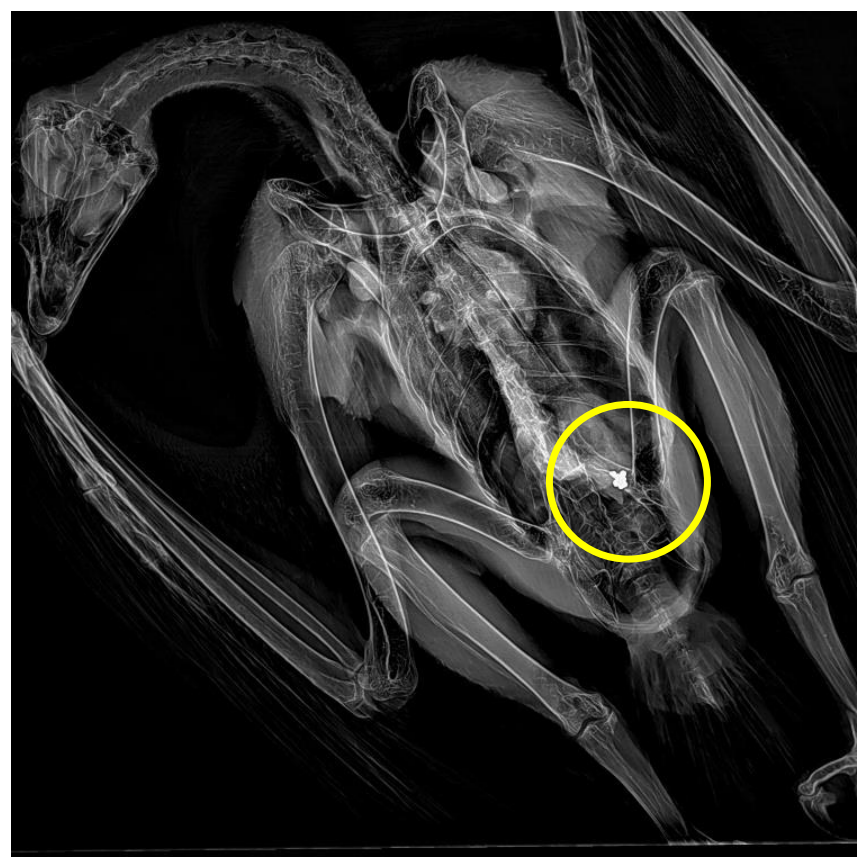

Figure 1.1. Lead bullet fragments (yellow circles) in a deer carcass (A) and ingested in a dead bald eagle (B) found in northwestern Iowa during January 2017 (photos Project SOAR, Saving Our Avian Resources; Kay Neumann). 


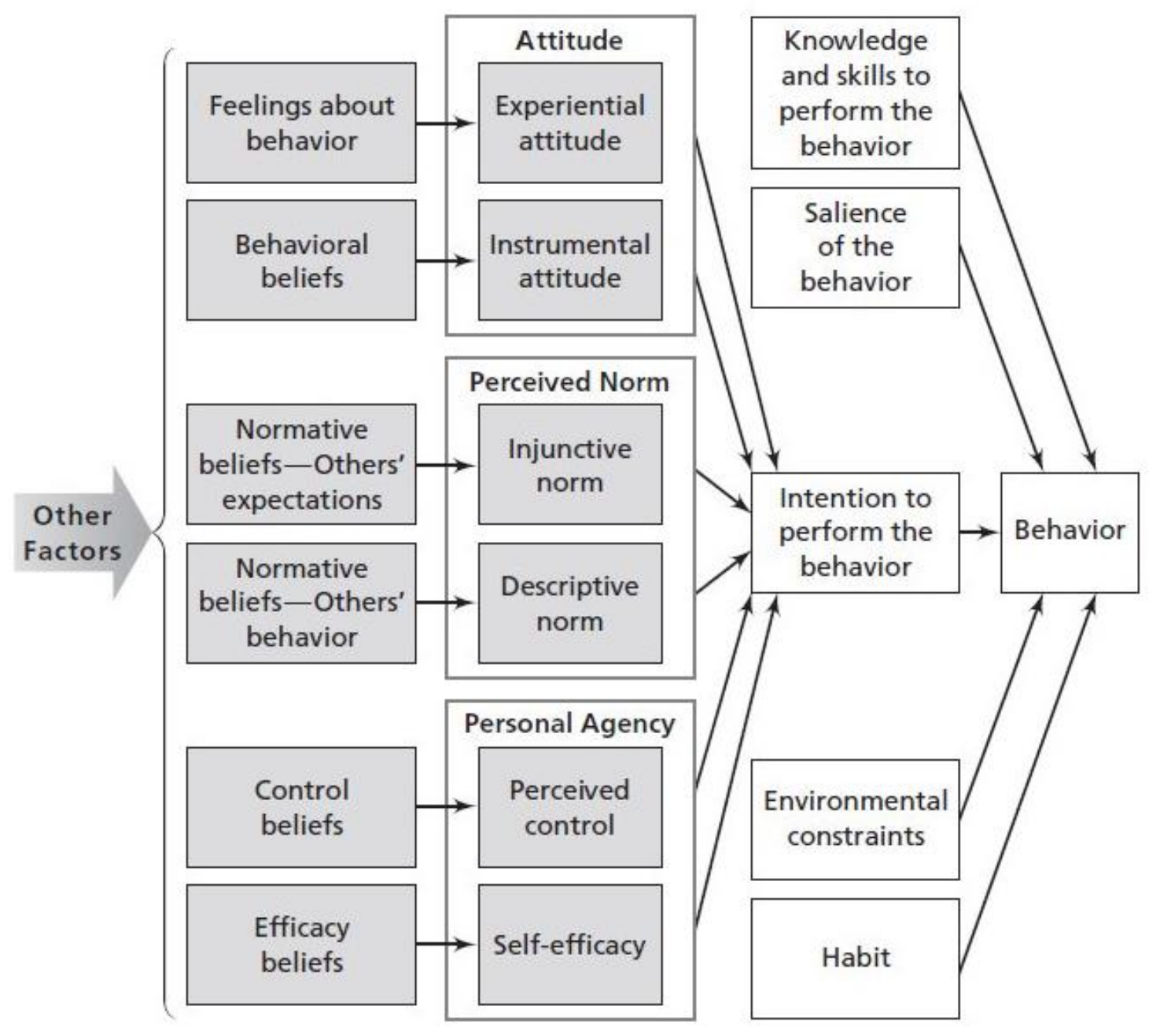

Figure 1.2. Elements of the reasoned action approach and its application to integrated model of behavioral change or the integrated model (Fishbein \& Ajzen, 2010; Montano \& Kasprzyk, 2015). 


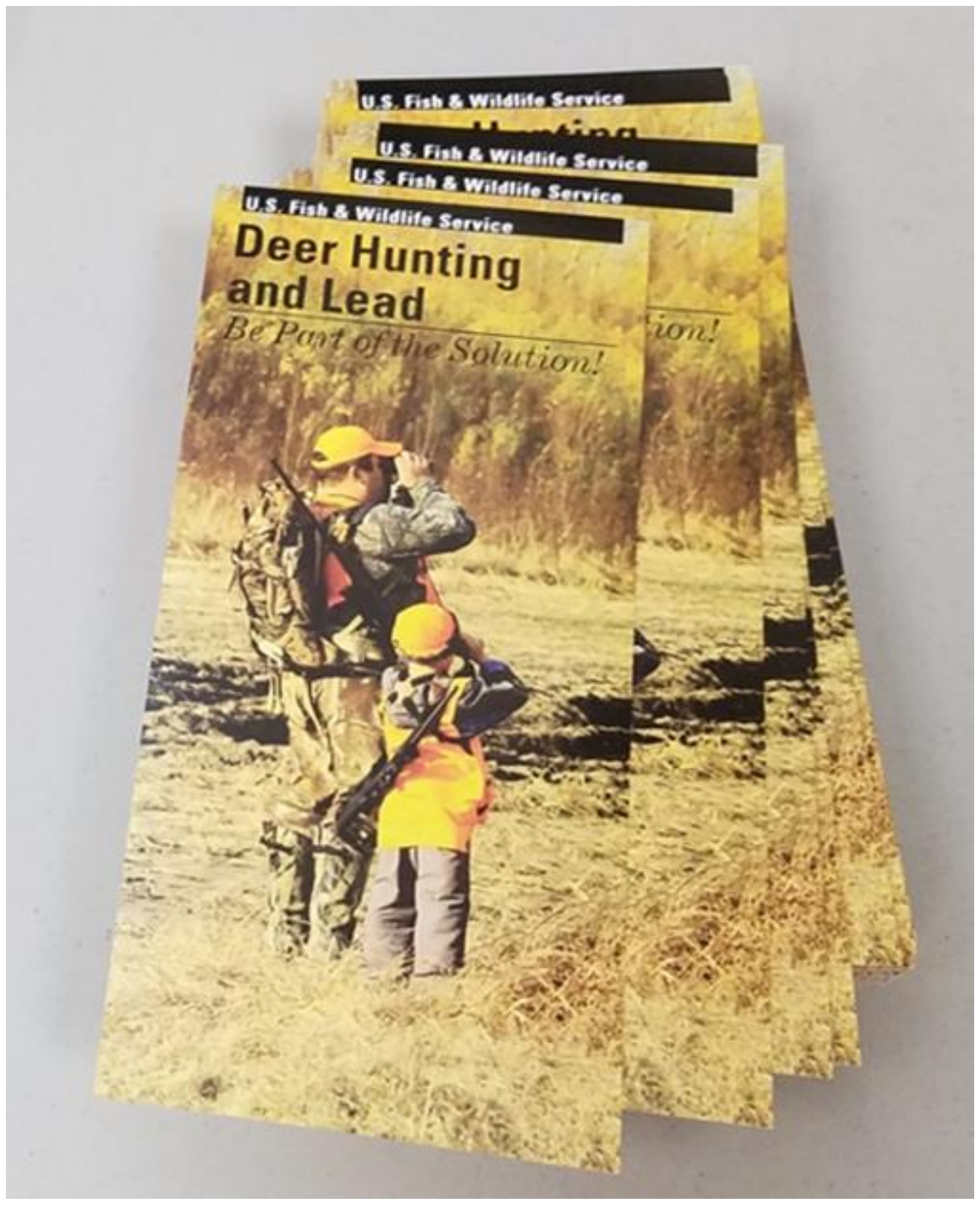

Figure 1.3. Cover of tri-fold brochure available at NWRs for hunters emphasizing the voluntary use of nonlead ammunition and recognizing the role hunters play in conservation. 


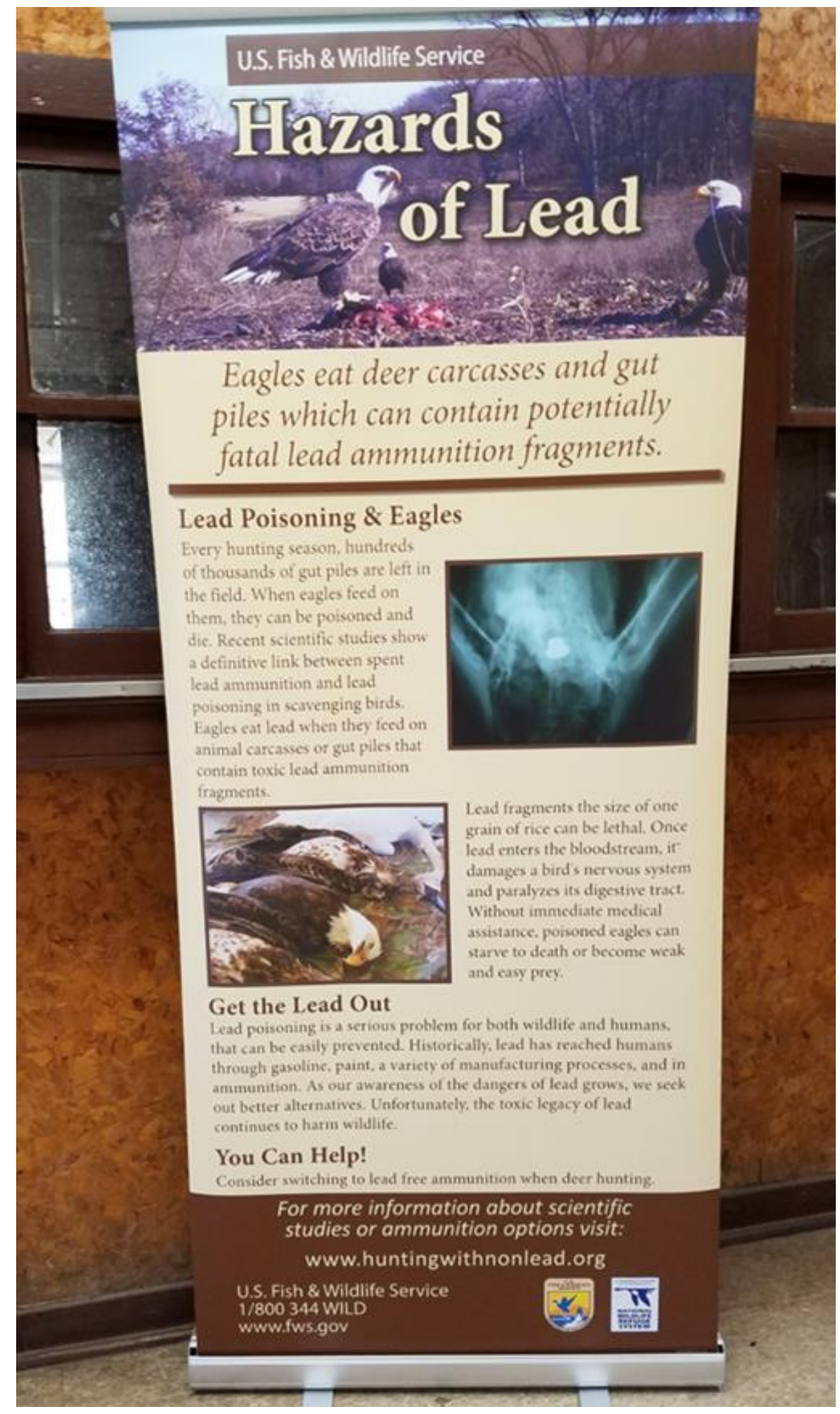

Figure 1.4. Free-standing banner usually placed near entrances of NWR headquarters showing the effects of lead poisoning in bald eagles and the benefits of using nonlead ammunition. 
(A)

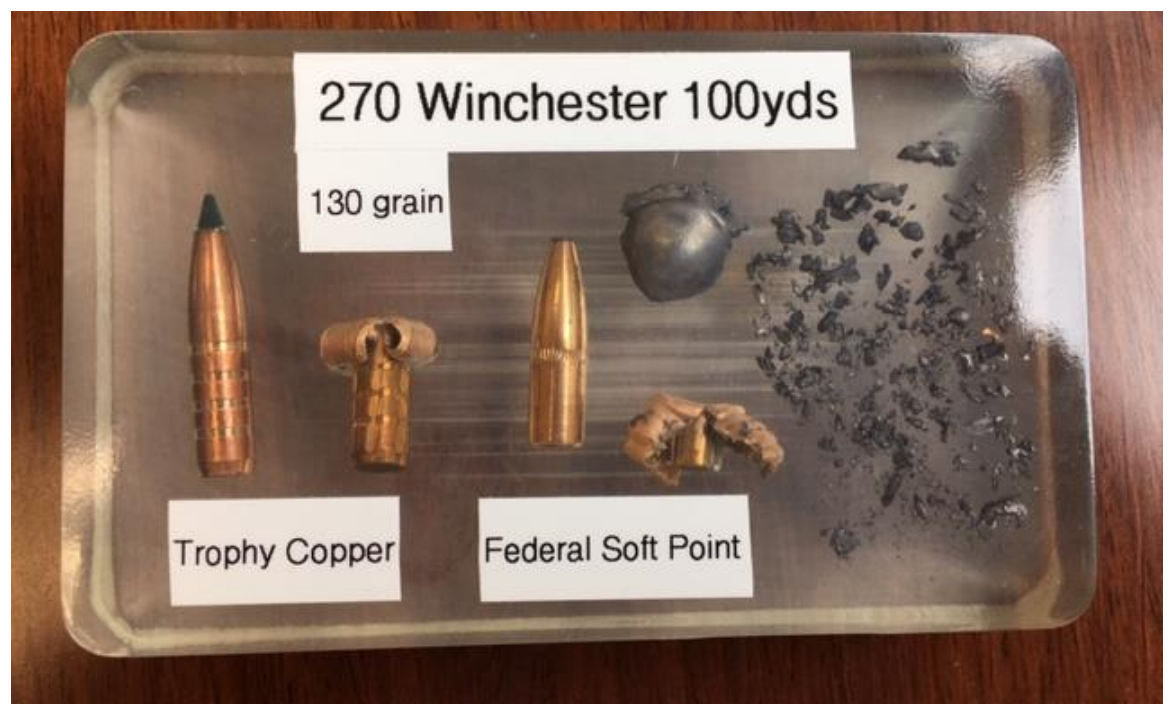

(B)

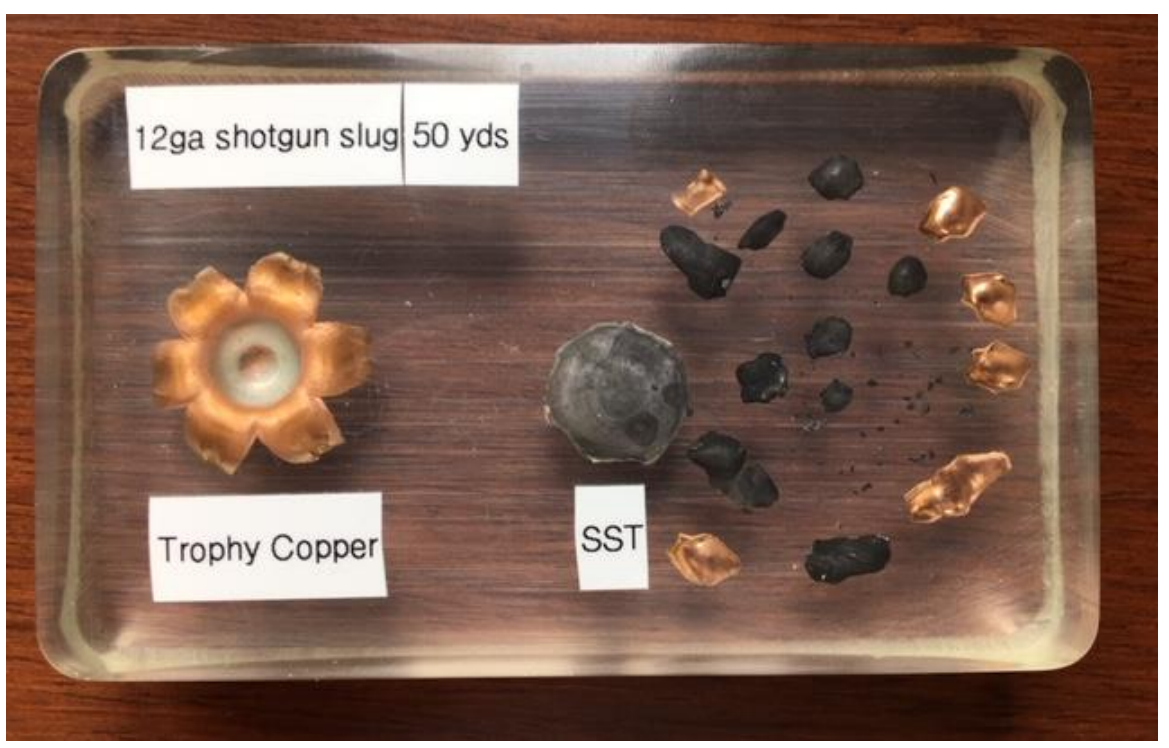

Figure 1.5. Example of epoxy gel blocks used for demonstrating differences in bullet fragmentation characteristics between lead and nonlead rifle ammunition for (A) highpower rifles and (B) shotgun slugs. Both bullets appear similar externally, but the lead bullet (left) has lead core with a copper jacket to control expansion and fragment and dissipate the bullet's energy throughout the animal carcass being about a quick kill. The nonlead bullet (right) is mainly made of solid copper and retains nearly all its initial mass with copper petals peeling backwards upon striking the animal causing fatal hemorrhaging. 


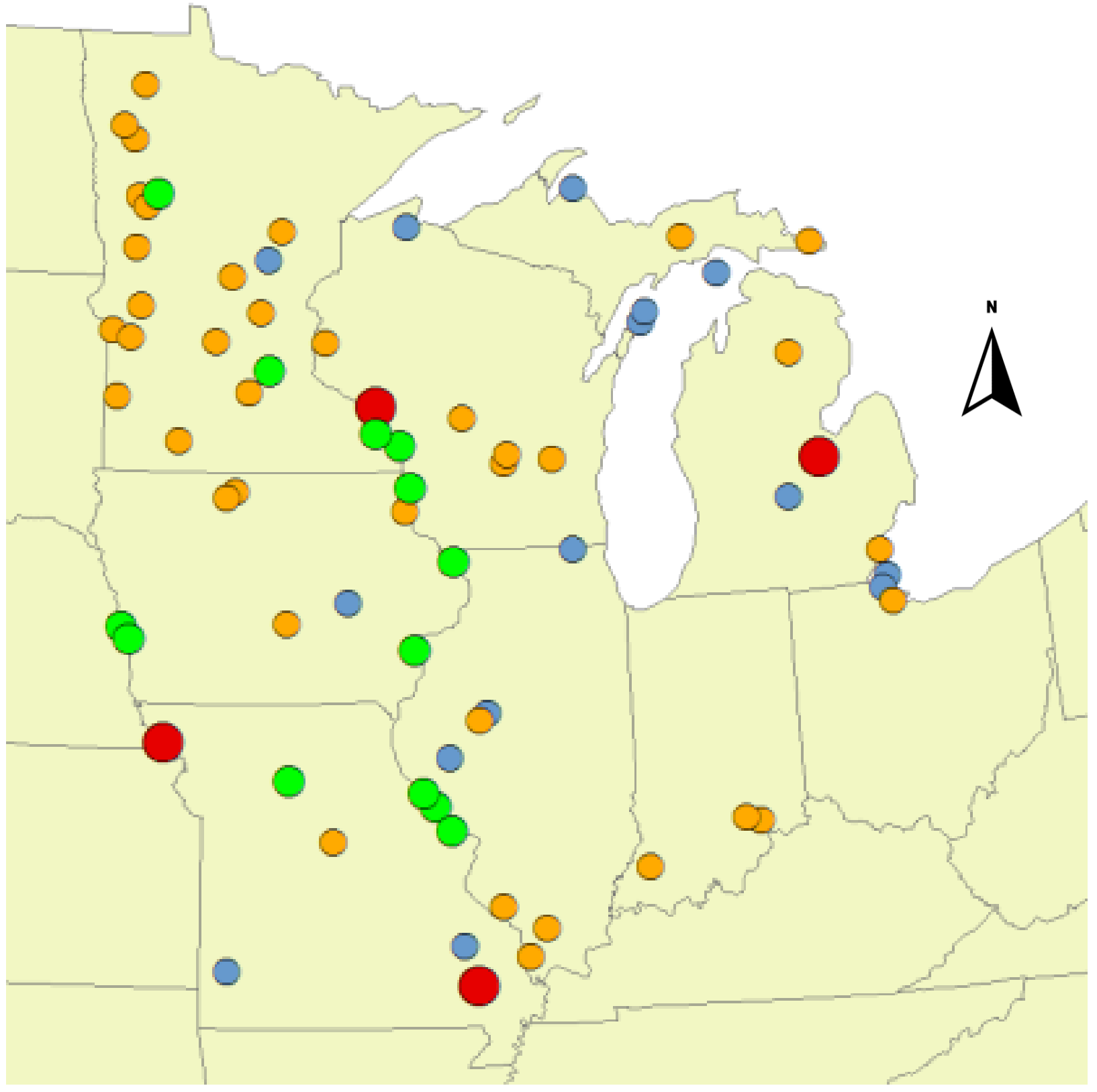

Figure 1.6. Locations of U.S. Fish and Wildlife Service National Wildlife Refuges in the Midwest Region (Region 3); red dots designate areas entering the outreach program in 2016, green dots in 2017, orange dots in 2018, and blue dots represent refuges not participating in the program. 


\title{
Chapter 2. Communication Strategies for Reducing Lead Poisoning in Wildlife and Human Health Risks
}

With Sonja A. Wilhelm Stanis, Elisabeth B. Webb, Christine Jie Li, and Damon M. Hall

Published: Wildlife Society Bulletin; 2019; 43(1):131-140; DOI: 10.1002/wsb.955

\begin{abstract}
Although lead poisoning in North American waterfowl has been reduced, it persists among other wildlife. To address this issue, we review lead poisoning in wildlife and threats to human health, describe the recent socio-political landscape, and develop a framework for reducing lead exposure related to hunting ammunition and fishing tackle. Despite substantial information about lead poisoning in wildlife, an explicit and strategic plan for using existing information to develop an effective communication program is lacking. Local and regional efforts encouraging hunters and anglers to voluntarily use nonlead alternatives could benefit from a nationally coordinated and strategic focus. We propose that the diffusion of innovation theory provides a useful framework for developing and implementing voluntary nonlead hunting ammunition and fishing tackle programs. Further, it can help communicators refine messages, increase efficiencies in developing communication materials, and monitor adoption of nonlead alternatives. The initial step in this process, however, is to engage stakeholders about the importance of the issue and leverage that concern as a catalyst for positive change.
\end{abstract}




\subsection{Introduction}

Research findings accumulated over several decades have documented the effects of spent lead hunting ammunition on numerous wildlife species (Scheuhammer \& Norris, 1995; Tranel \& Kimmel, 2009), identifying exposure primarily through ingestion of lead shotgun pellets, bullet fragments in gut piles, unretrieved animal carcasses, or ingestion of lost fishing tackle (Finkelstein et al., 2012; Grade, Pokras, Laflamme, \& Vogel, 2018; Haig et al., 2014; Schulz, Gao, et al., 2007; Schulz, Millspaugh, et al., 2006). Progress has been made in reducing lead poisoning in North American waterfowl (Anderson et al., 2000; Schulz, Padding, et al., 2006) but the problem persists for other wildlife species, including California condors (Gymnogyps californianus), bald eagles (Haliaeetus leucocephalus), mourning doves (Zenaida macroura), common loons (Gavia immer), and swans (Cygnus spp).

Almost 10 years have passed since The Wildlife Society (TWS) published its technical review on lead poisoning related to hunting ammunition and fishing tackle (Rattner et al., 2008) with additional research documenting the issue (Duguay et al., 2017; Finkelstein et al., 2012; Finkelstein et al., 2010; Haig et al., 2014; Legagneux et al., 2014; Pierce et al., 2015; Warner et al., 2014; R. T. Watson et al., 2009). The issue was further highlighted in The Wildlife Professional on three occasions (Kelly et al., 2016; Schulz, Potts, Cornely, Millspaugh, \& Johnson, 2009; Schulz, Potts, Otis, \& White, 2012). Despite continued concern and voluminous empirical data, limited action has occurred. Conducting more research to substantiate and document lead poisoning in wildlife and related human health effects is providing little new information about the effects of lead poisoning on wildlife and human health. The scientific case is wellestablished. "No more evidence is required . . this is now a socio-political issue" 
(Arnemo et al., 2016). Bridging knowledge with action requires communication strategies that align with dominant social and political narratives (Hall, FeldpauschParker, Peterson, Stephens, \& Wilson, 2017; Lindenfeld, Hall, McGreavy, Silka, \& Hart, 2012). We briefly review lead poisoning in wildlife and human health effects to describe the socio-political landscape and then propose a strategic framework for establishing and evaluating an effective nonlead ammunition communication program.

\subsection{Current Policy Landscape}

Finding that lead poisoning is the primary factor affecting to California condor mortality (Church et al., 2006; Finkelstein et al., 2012; Finkelstein et al., 2010; Kelly et al., 2014), the California Fish and Game Commission prohibited lead hunting ammunition for big-game hunting within the primary condor range of southern California in 2008 (California Department of Fish and Wildlife, 2017). Following limited success of the original policy, a statewide ban was adopted in 2013 (California Assembly Bill 711, 2013) to be phased in by 2019 (California Department of Fish and Wildlife, 2017). Alternatively, Arizona Game and Fish Department (AGFD) instituted a voluntary nonlead ammunition program in the northern portion of the state during 2005 using a combination of informational materials, shooting demonstrations, and free nonlead hunting ammunition vouchers (Chase \& Rabe, 2015; Seng, 2005a, 2005b). A similar program was established in southern Utah by the Division of Wildlife Resources (UDWR) during 2013.

Command-and-control regulations like prohibiting lead hunting ammunition and fishing tackle may appear to be a logical and effective policy option (Bellinger et al., 
2013; V. G. Thomas \& Guitart, 2003), however current political realities indicate implementing a regulatory ban can be complex with positive and negative unintended consequences. The 2008 lead ammunition ban in southern California, and the fully implemented statewide ban in 2019 have provided the hunting ammunition industry a guaranteed nonlead ammunition market. The California hunting and fishing economy generates $>\$ 813.2$ million annually with $>3.4$ million total hunters and $>1.8$ million biggame hunters (U.S. Department of Interior - Fish and Wildlife Service, U.S. Department of Commerce, \& U.S. Census Bureau, 2007). The large number of California hunters provides ammunition manufacturers with a market certainty signaling capital spent on scaling up production of nonlead ammunition will pay for itself over time. Another positive consequence of California's regulation is the increased availability in the amount of nonlead ammunition and the number of calibers available for rifle ammunition (California Department of Fish and Wildlife, 2017). Voluntary programs, although politically attractive by avoiding conflict, do not provide the guaranteed market incentives to ammunition manufacturers, yet these voluntary programs continue to keep the issue on the informal policy agenda.

Alternatively, regulations and accompanying benefits of reducing lead exposure in scavenging birds (Kelly et al., 2011; Kelly \& Johnson, 2011) have caused negative unintended consequences by further polarizing the issue. Regulations "banning" lead hunting ammunition have emboldened gun-rights advocates to increase rhetoric concerning perceived gun control efforts, claim 'junk science' related to lead poisoning in wildlife and human health, suggest ballistic ineffectiveness of nonlead ammunition, emphasize increased cost of nonlead hunting ammunition, and deemphasize 
environmental benefits of nonlead alternatives (Hunt For Truth Association, 2017b). Given the overwhelming data linking wildlife mortality to lead, environmental groups have repeatedly petitioned federal agencies to ban lead hunting ammunition on public lands. Federal agencies have declined to regulate lead ammunition and federal courts have ruled against petitioner's requests (Hunt For Truth Association, 2017a).

In the absence of political leadership via sweeping regulation, hunters and anglers should voluntarily switch to nonlead ammunition and fishing tackle to reduce wildlife lead exposure. However, many socio-economic factors influence hunters' and anglers ammunition and tackle choices including price, availability, ballistics, lethality or effectiveness, and underlying attitudes and beliefs (Pierce et al., 2015; Schroeder et al., 2016; Southwick, 2014; V. G. Thomas, 2013). Given the considerable amount of information on lead poisoning in wildlife (Rattner et al., 2008; R. T. Watson et al., 2009) and related human health effects (Earl et al., 2016; Hanna-Attisha, 2018; Kim, Kwon, \& Hong, 2016; Markowitz \& Rosner, 2013b), little attention has been paid toward developing a national strategy for a coordinated voluntary nonlead ammunition outreach program across North America.

\subsection{Past and Present Issues}

In general, lead is both an important industrial metal and a dangerous environmental poison (Eisler, 1988; Markowitz \& Rosner, 2013b; Snow, 2017). Lead affects a wide range of wildlife species and humans (Markowitz \& Rosner, 2013b; Rattner et al., 2008; R. T. Watson et al., 2009) and empirical data suggest no safe exposure level (Earl et al., 2016; Lanphear et al., 2016; Lanphear et al., 2018). Despite 
the accumulation of this knowledge, society continues grappling with chronic lead exposure from lead ammunition (Iqbal et al., 2009; R. T. Watson et al., 2009) contaminated lead-based house paint (Markowitz \& Rosner, 2013a, 2013b; Rosen, 1995) and deteriorating drinking water infrastructure in places like Flint, Michigan, USA (Hanna-Attisha, 2018; Hanna-Attisha et al., 2016).

This is not a new problem. Lead poisoning in waterfowl was first reported near Galveston Bay, Texas, USA (Grinnell, 1894). Almost 100 years later, a nontoxic-shot regulation for waterfowl hunting was nationally implemented during 1991-1992 (Belanger \& Kinnane, 2002; Schulz, Padding, et al., 2006; U.S. Department of the Interior - Fish and Wildlife Service, 1988). Regardless of environmental benefits, waterfowl hunters were frustrated over federal intrusion and annoyed with the nontoxicshot regulation for decades, causing battle-worn agency administrators to be reluctant to deal with the lead poisoning issue more broadly for other wildlife species like mourning doves (U.S. Department of the Interior - Fish and Wildlife Service, 1988).

Interestingly, many conservation stakeholders today characterize the history of the nontoxic-shot waterfowl regulation by suggesting (1) unanimous recognition of the problem, (2) general acceptance of the available scientific information, (3) broad agreement upon a regulatory solution, and (4) full support among all parties on effective policy implementation. This portrayal implies lead poisoning in other wildlife is dissimilar with insufficient data, and/or lack of a demonstrated population level effect for species such as mourning doves or bald eagles. This characterization has the potential to misinform and bias current policy discussions surrounding lead poisoning in wildlife. Not surprisingly, these misinformation tactics have been used previously on similar 
controversial issues; e.g., climate change (Boykoff, 2013; Michaels, 2008) and social health issues like cigarette smoking (Oreskes \& Conway, 2010). Framing the $>100$-year history of waterfowl lead poisoning as a amiable series of policy and administrative actions distorts the events that actually occurred (Bean \& Rowland, 1997; Belanger \& Kinnane, 2002; J. Scott Feierabend, 1985; J Scott Feierabend, 1985) and impedes progress toward improving wildlife health.

Despite three decades of a lead ammunition ban for waterfowl hunting, the effects of lead poisoning from hunting ammunition persists. For example, bald eagle populations are increasing and no longer endangered (Millsap et al., 2016), but dead and moribund birds resulting from lead ammunition exposure are routinely found (Bedrosian et al., 2012; Yaw et al., 2017). During 2012, 58 dead bald eagles were collected across Iowa, Minnesota, and Wisconsin with $60 \%$ of the birds showing detectable lead concentrations from consumption of white-tailed deer (Odocoileus virginianus) gut piles containing lead bullet fragments (Warner et al., 2014). Additional research has demonstrated extensive bald eagle mortality resulting from ingestion of lead bullet fragments in deer (Cruz-Martinez et al., 2012; Franson \& Russell, 2014; Golden et al., 2016; Yaw et al., 2017).

Following the policy template used for lead poisoning in waterfowl, biologists today rely on the cognitive fix model (Heberlein, 2012a, 2012b) for communicating the technical details of lead poisoning. Wildlife professionals adopting the cognitive fix model believe greater amounts of technical information instills greater awareness, automatically encourages meaningful policy action, and changes hunter or angler behavior. Continued documentation of lead poisoning in wildlife (Rattner et al. 2008, 
Watson et al. 2009) and general lack of public policy discourse on the topic, however, have demonstrated the ineffectiveness of the cognitive fix model demonstrating the need for a more strategic approach based on social theory constructs (Ross-Winslow and Teel 2011). Despite the number of regional voluntary approaches using various outreach strategies (Chase \& Rabe, 2015; Haig et al., 2014; Henry, 2016; Seng, 2005a, 2005b), progress has been limited. The human dimensions component of lead poisoning in wildlife would benefit from a more strategic and organized approach that recognizes the complexity of the issue, uses a theoretical framework for developing and evaluating outreach programs, coordinates efforts across regions, is adequately funded, and measures outcomes through an on-going evaluation with formative and summative recommendations.

It is important to recognize lead poisoning is not only a wildlife health issue. Similar to the wildlife exposure pathway, human health is impacted by lead exposure through ingestion of lead bullet fragments in processed ground venison (Hampton, Laidlaw, Buenz, \& Arnemo, 2018; Hunt et al., 2009; Iqbal et al., 2009). Individuals ingesting game meat shot with lead ammunition are susceptible to chronic and acute effects of lead exposure (Buenz \& Parry, 2018; Jones et al., 2009; Knott et al., 2010; Lidsky \& Schneider, 2006; Mateo et al., 2014; Rosen, 1995). Evidence shows blood lead levels in humans $<5 \mu \mathrm{g} / \mathrm{dL}$ is a biomarker for impaired cognition suggesting no safe level of human lead exposure (Bellinger et al., 1991; Earl et al., 2016; Lanphear et al., 2016). Not only are low blood lead levels a biomarker for impaired cognitive abilities, recent findings demonstrate low-level exposure is a largely overlooked risk factor for cardiovascular disease mortality in the U.S. corresponding to approximately 256,000 
annual deaths due to cardiovascular disease and 185,000 deaths per year from coronary artery heart disease (Lanphear et al., 2018).

Human exposure to lead bullet fragments in game meat also creates an environmental injustice by disproportionately impacting underprivileged racial and social classes (Mohai et al., 2009; Wenz, 1999). The issue of human exposure to led bullet fragments in game meat is exacerbated when state management agencies partner with local food banks and distribute lead tainted ground venison to poor and needy families (Missouri Department of Conservation, 2017). Some state agencies provide a lead advisory notice in their big game hunting regulations (Minnesota Department of Natural Resources, 2017) while other states suggest pregnant women and children not consume donated meat (New Hampshire Fish and Game, 2017). Efforts to address potential human health risks from lead bullet fragments in ground meat remain problematic because of jurisdictional differences among natural resource agencies and human health agencies; i.e., each agency says it is the other's responsibility to address human health issues related to lead exposure from eating meat killed with lead hunting ammunition.

\subsection{Problem Complexity}

Many current environmental issues are complex, and lead poisoning of wildlife and human health are no exception. A useful typology describes complex problems as having dynamic, generative, and social complexity (Kahane, 2007). A problem can be dynamically complex when cause-and-effect relationships are separated by space and time, making it difficult to link causal agents with the resulting environmental effects. Problems can be generatively complex when they evolve in unfamiliar and unpredictable 
ways with little available guidance from previous experience. Problems can also be socially complex when stakeholders perceive the problem differently and from their own perspectives, often leading to gridlock and polarization.

Lead poisoning in wildlife and human health is simultaneously dynamic, generative, and socially complex. The issue is dynamically complex because the ingestion of lead bullet fragments, pellets, or lost fishing tackle usually occur far from where effects of poisoning occur, often days or weeks later. Secondly, the science of lead poisoning is well documented but generatively complex as today's problem landscape is much different than it was during the waterfowl era of the 1970s and 1980s, leaving a future path forward unpredictable and uncertain. Lastly, lead poisoning is socially complex because different stakeholders perceive the problem very differently, which continues to polarize the issue and stifle public debate.

In addition to the above complexity elements, another challenge is the multifaceted nature of lead poisoning. Lead poisoning is composed of at least six different sub-issues each affecting various taxa, different exposure pathways, and population effects (Figure 2.1): (1) Lead poisoning in critically endangered California condors eating remains of harvested big game animals (Finkelstein et al., 2010), (2) lead poisoning impacts on bald eagles and other avian scavengers also feeding on big game animal remains (Behmke et al., 2015; Warner et al., 2014), (3) possible human health effects from ingestion of lead bullet fragments in game meat (Hunt et al., 2009; Iqbal et al., 2009), (4) mourning doves and other surface-feeding songbirds ingesting spent lead pellets, especially on heavily hunted managed shooting fields (Franson et al., 2009; Schulz et al., 2002), (5) ingestion of unretrieved lead fishing tackle by loons and swans 
(Grade et al., 2018; Pokras \& Chafel, 1992), and (6) environmental impacts of spent lead ammunition on inadequately managed outdoor shooting ranges (Laidlaw et al. 2017). These six sub-issues share similar characteristics while demonstrating differences in exposure pathways, tolerances, effects, and stakeholder interests. For example, mourning doves and other surface feeding songbirds directly ingest lead shotgun pellets on managed crop fields designed to attract feeding birds (Plautz et al., 2011; Schulz, Gao, et al., 2007; Schulz, Millspaugh, et al., 2006; Schulz et al., 2002), whereas scavenging birds like eagles and condors indirectly ingest lead bullet fragments in gut piles and carcasses from high-powered rifles (Finkelstein et al., 2012; Herring et al., 2016; Hunt et al., 2006), or loons ingest discarded lead fishing tackle (Grade et al., 2018; Pokras \& Chafel, 1992). Susceptibility varies among avian species with condors, vultures, and ravens seemingly able to tolerate higher blood lead levels (Craighead \& Bedrosian, 2008; Kelly et al., 2014; Kelly \& Johnson, 2011) compared to bald eagles (Bedrosian et al., 2012) and mourning doves (Schulz, Gao, et al., 2007; Schulz, Millspaugh, et al., 2006).

Each situation varies with different exposure risks and pathways. For example, dove hunters shoot dozens to hundreds of rounds of ammunition in a single day compared to rifle hunters firing a few rounds during a season. Further complexity arises when biggame hunters use a combination of firearms including high-powered rifles, handguns, muzzleloading rifles, and shotguns firing slugs or sabots with modern bullets. Each weapon has unique bullet fragmentation and weight retention characteristics with slowermoving projectiles fragmenting less and retaining more mass compared to smaller and higher velocity bullets (Broadway, McCallen, Caudell, \& Stewart, 2020; Sanchez, Epps, \& Taylor, 2016). Also, the ammunition industry has developed effective and economical 
nonlead alternatives (Pierce et al., 2015; V. G. Thomas, 2013) but misinformation about price, availability, and effectiveness continue to permeate the policy discussion (Hunt For Truth Association, 2017b; Southwick, 2014). Further complexity involves the comingling and inadvertent transposing of hunting, diminishing hunting traditions, gun ownership and $2^{\text {nd }}$ Amendment gun rights, and possible gun control legislation by controlling access to ammunition discourses (Baum, 2013; Whitney, 2012). When encouraging hunters to use nonlead alternatives, consideration of these complexities is an important element ensuring the message is perceived as being credible and relevant.

\subsection{Need for a More Strategic Approach}

\subsubsection{Hunters' Perception and Behaviors of Lead Poisoning}

Few human dimensions research studies have documented hunters' attitudes towards nonlead ammunition (Schulz, Reitz, et al., 2007), behavioral mechanisms affecting hunters' voluntarily use of nonlead ammunition (Schroeder et al., 2012), or existing voluntary programs (Bedrosian et al., 2012; Chase \& Rabe, 2015). As mentioned earlier, research has shown mourning doves succumb to lead poisoning (Schulz, Gao, et al., 2007; Schulz, Gao, et al., 2009; Schulz, Millspaugh, et al., 2006; Schulz et al., 2002). Despite this information, approximately $50-53 \%$ of Illinois mourning dove hunters opposed a nontoxic-shot regulation for dove hunting (Anderson \& David, 1994; Levengood et al., 1999; Miller et al., 2013). Similarly, other surveys of dove hunters showed hunters having little awareness of the problem and little desire to change behavior (Case \& Associates, 2006, 2014; Schulz, Reitz, et al., 2007). Small game hunters in Minnesota, including dove hunters, had little awareness of lead 
poisoning in mourning doves but reported they would be receptive to nonlead ammunition messages from hunter organizations like Ducks Unlimited (Schroeder et al., 2012).

Within the context of big-game hunters using nonlead ammunition, focus groups and interviews were used to develop a voluntary nonlead ammunition program for California condors in Arizona (Seng, 2005a, 2005b). A follow-up evaluation assessed the voluntary program's effectiveness with roughly half of the deer hunters in an education-only treatment using nonlead ammunition while about three-fourths of an education-voucher group using nonlead ammunition (Chase \& Rabe, 2015). Further voluntary outreach activities occurred in Arizona and Utah to reduce condor lead exposure; an informal survey indicated $88 \%$ of Arizona's Kaibab deer hunters and $80 \%$ of southern Utah's deer hunters participated in some lead ammunition reduction activity during 2012-2016 (B. Smith et al., 2017). Another project evaluated education efforts on national parks to reduce lead deposition related to hunting and fishing and reviewed efforts encouraging voluntary use of nonlead hunting ammunition (Ross-Winslow \& Teel, 2011; Ross-Winslow et al., 2011). Effectiveness of open-house style demonstrations to influence deer hunter behavior to use nonlead ammunition on a single state park in Minnesota were evaluated but no conclusions could be drawn (Henry, 2016).

\subsubsection{Benefits and Uses of Theoretical Behavioral Models in Evaluation Research}

Public information campaigns are designed to influence a target audience's behavior. However, research has shown communication campaigns have moderate to strong effects on cognitive outcomes, less on attitudinal outcomes, and still less on 
specific behaviors (Rice \& Atkin, 2013). Many of these contemporary campaigns accomplish modest results due to insufficient funding, poorly conceived strategies and objectives, and unsophisticated use of behavioral models or communication theory. Regardless, there has been a growing recognition of the importance of behavioral theory in the development of behavior-change interventions in public communication programs (Fishbein \& Cappella, 2006). In other words, the more one knows about the contributing factors about a specific behavior the more likely effective communication can be developed and implemented.

\subsubsection{Diffusion of Innovation Theoretical Framework}

Effective pro-environmental behavior change, like voluntary use of nonlead hunting ammunition and fishing tackle, includes a general framework of carefully selecting behavior to improve environmental quality, determining factors affecting the relevant behavior, designing interventions to encourage the desired behavior, and monitoring outcomes (Steg \& Vlek, 2009). The diffusion of innovation theory (Rogers, 2003) has the potential of successfully addressing all four of these components within wildlife lead poisoning and related human health. Everett Rogers first popularized the theory in his book Diffusion of Innovations published in 1962, now in its fifth edition (2003). The theory originally tracked the adoption of different agricultural practices in Iowa during the 1930s (e.g., hybrid seed corn, and synthetic fertilizers). Since its inception, the theory has become multidisciplinary, cutting across a variety of scientific fields, with particular emphasis in business and marketing (G. A. Moore, 2014) and human health (Brownson et al., 2015). 
Diffusion of Innovation Theory (Rogers, 2003) attempts to explain how, why, and the rate at which new ideas spread. The theoretical framework consists of all activities and effects occurring from the problem, research and development of the innovation, marketing of the innovation, rates of adoption, and consequences of adoption (both intended and unintended); i.e., an interconnected set of sub-theories explaining how new ideas and products are adopted. Within the diffusion of innovation, four elements influence the spread of new ideas: the innovation itself and its attributes, communication channels, time or progress toward adoption, and the social system relying heavily on human capital.

The first element, innovations, are new ideas or practices characterized by (1) relative advantage, (2) compatibility, (3) complexity, (4) trialability, (5) observability, and (6) reinvention (Greenhalgh et al., 2004; Rogers, 2003). In the case of voluntary use of nonlead ammunition, this may include the superior ballistics of nonlead rifle ammunition for big-game hunting (relative advantage), compatibility with modern firearms (compatibility), the relative ease of using nonlead rifle ammunition (complexity), availability of free samples to use on a trial basis (trialability), and shooting demonstrations showing side-by-side comparisons of different ammunition types (observability). Another aspect of innovations is reinvention, i.e., modification of the innovation. For example, some hunters may hand-load special rounds of nonlead ammunition, or reinvent a special load, for a special hunting situation or rifle caliber not commercially available. From the standpoint of a communication program, messages could be customized for particular hunting audiences; e.g., understanding the different hunting characteristics and behaviors of dove hunters compared to big-game hunters. 
The second element of the theory stresses the importance of communication channels in spreading innovations among group members; e.g., the use of trusted leaders, information sources, or organizations (Barnett et al., 2011; Schroeder et al., 2012). It is important to recognize differences between communication within a person's peer group (homophily) and those with different social status, beliefs, or education (heterophily; Rogers 2003). These communication channels play different roles in the innovationdecision process where information outside a person's regular peer group increases exposure and awareness to the new information. Further along the innovation-decision process, however, peer groups become more important by reinforcing and adding credibility to new information. Using dove hunting as an example, trusted outside experts both play a role in increasing awareness and sharing technical details. Social networks of dove hunters can observe firsthand the advantages of nonlead ammunition. Outside experts, viewed as credible sources of information, could use shooting demonstrations and provide technical details related to use of nonlead ammunition and compatibility with modern shotguns.

The third element, time, includes several components; the innovation-decision process, adopter categories, and the rate of adoption. Although early diffusion research focused primarily on time of adoption (or rates of adoption), other efforts have focused on the innovation-decision process (Figure 2.2) and adopter categories (Figure 2.3) for tailoring different messages (Mahajan et al., 1990; G. A. Moore, 2014). The innovationdecision process is characterized by five stages: (1) acquisition of knowledge, (2) persuasion, (3) decision to adopt or reject, (4) implementation of decision, and (5) confirmation or reinforcement (Figure 2.2; Rogers 2003). By recognizing these stages, 
communicators can craft different messages aimed at specific groups of hunters or anglers. For example, some messages may focus on acquisition of knowledge and provide technical details of lead poisoning and its effect on wildlife while other messages would be aimed toward hunters' decision to use nonlead ammunition related ammunition availability, price, or use of nonlead ammunition with existing firearms. Using condors as an example, a multiphase decision process indicates there is more to changing hunter behavior than providing technical information of lead poisoning in a brochure or parking lot kiosk. Rather, the brochure could be followed up with a persuasive conversation, appeals to help condor recovery, free samples of nonlead ammunition, and follow-up encouragement (B. Smith et al., 2017).

Within the five-step decision-making process for adopting innovations from above, the speed or timing of adoption has been categorized into groups (Figure 2.3) of: (1) innovators, (2) early adopters, (3) early majority, (4) late majority, and (5) laggards or traditionalists (Hurt et al., 1977; Mahajan et al., 1990; G. A. Moore, 2014). Using deer hunters as an example, individual hunters can be categorized based on their speed of adoption to use nonlead ammunition and their relative innovativeness characteristics. Innovators are the first deer hunters to experiment with new hunter methods and related outdoor equipment. They have effective methods for dealing with uncertainty about ammunition sources and differences in ballistics between lead and nonlead ammunition and have extensive social networks for communicating what they have learned about their nonlead ammunition experiences. Early adopters of nonlead ammunition are deer hunters in the innovators' social network who usually demonstrate considerable leadership among a much broader group of other deer hunters and have an important role 
as change agents for speeding the diffusion of nonlead ammunition use. Early majority are represented by deer hunters who adopt new ideas before the average deer hunter. They have a broad social network but seldom hold leadership positions in hunting organizations and deliberate at some length before adopting to nonlead ammunition. Late majority deer hunters are skeptical and will adopt nonlead ammunition after the average hunter has already converted. In this example, late majority hunters adopt nonlead ammunition because of increasing peer pressure or because of economic necessity when nonlead ammunition becomes cheaper. Laggards or traditionalists are the last hunters to adopt nonlead ammunition because of their smaller social networks and suspiciousness of innovators or early adopters encouraging change. Expanding this typology beyond an exclusively temporal concept, some of these groups may occur simultaneously or proceed through time with considerable overlap among groups of hunters and anglers. Outreach programs encouraging voluntary use of nonlead alternatives can frame messages specifically tailored to each group based on adopter categories of hunters or anglers.

Finally, social systems help establish group behavior patterns where leadership of the innovation is accomplished through change agents or champions influencing diffusion of the innovation (Barnett et al., 2011). The primary role of the change agent is to facilitate the flow of innovations from the change agency to the target audience. They must simultaneously be a technical expert and effective communicator to groups outside of their immediate socioeconomic status. Change agents play a crucial role by being a catalyst for change by helping (1) develop the need for change, (2) develop rapport among a wide range of stake holders (i.e., homophily and heterophily from above), (3) diagnose the problem addressed by the innovation, (4) create motivation to adopt the 
innovation, (5) facilitate intent into action or adoption, (6) reinforce adoption behavior, and (7) encourage adaptors to become their own change agents to recruit new adopters (Rogers, 2003). Intuitively, the effectiveness of change agents is a function of their ability to reach out and make meaningful connections to target audiences.

Applying the social systems concept can positively affect human health and environmental justice issues related to lead bullet fragments in ground game meat, especially when dealing with food banks for economically needy families. The role of change agent is played by multiple individuals with roles being complex and varied. An environmental nonprofit group can be a champion promoting the safety of ground venison given away at food banks by increasing awareness of the issue and the need for hunters to use nonlead ammunition. The food bank director must weigh the social consequences of improved food safety verses availability of protein for clients. State health agency officials can act as change agents by promoting safety recommendations for at-risk groups like women of childbearing age or young children. State wildlife agency officials can be change agents by promoting nonlead shooting demonstrations or free ammunition vouchers. State and local hunting organization leaders can play additional change agent roles by promoting the use of nonlead ammunition by their members.

The diffusion of innovation theory can provide a useful framework for tracking and documenting the multiple and complex innovation-decision processes of anglers, small game hunters, and big game hunters who may change their behavior by voluntarily converting to nonlead alternatives after exposure to targeted information programs. As part of a larger program evaluation, human dimensions researchers can use the diffusion 
of innovation theory to help communicators better understand and refine communication strategies over time with evaluations and consider monitoring rates of behavior change.

\subsection{Conclusion and Implications}

As mentioned earlier, conducting more research to substantiate and document lead poisoning in wildlife and related human health effects is providing little new information about the effects of lead poisoning on wildlife and human health; “. . . no more evidence is required. . . this is now a socio-political issue” (Arnemo et al., 2016). A strategic and nationally organized programmatic approach would successfully increase voluntary use of nonlead ammunition and fishing tackle among hunters and anglers. Numerous conservation examples exist demonstrating the effectiveness of meaningful collaboration, coordination, and cooperation across differing levels of agencies and organizations (e.g., greater sage grouse; Centrocercus urophasianus; Copeland et al. 2013, Manier et al. 2013) . Programmatic efforts are more likely to succeed by focusing on the long-term positive benefits of using nonlead alternatives for hunting and fishing, recruiting well-recognized agents of change and champions for the cause, and bringing together representatives from the hunting firearms and shooting industry, outdoor hunting and fishing retailers, and state and federal natural resource organizations. The initial step in this process, however, is to have stakeholders recognize the importance of the issue and use that concern as a catalyst for positive change. 


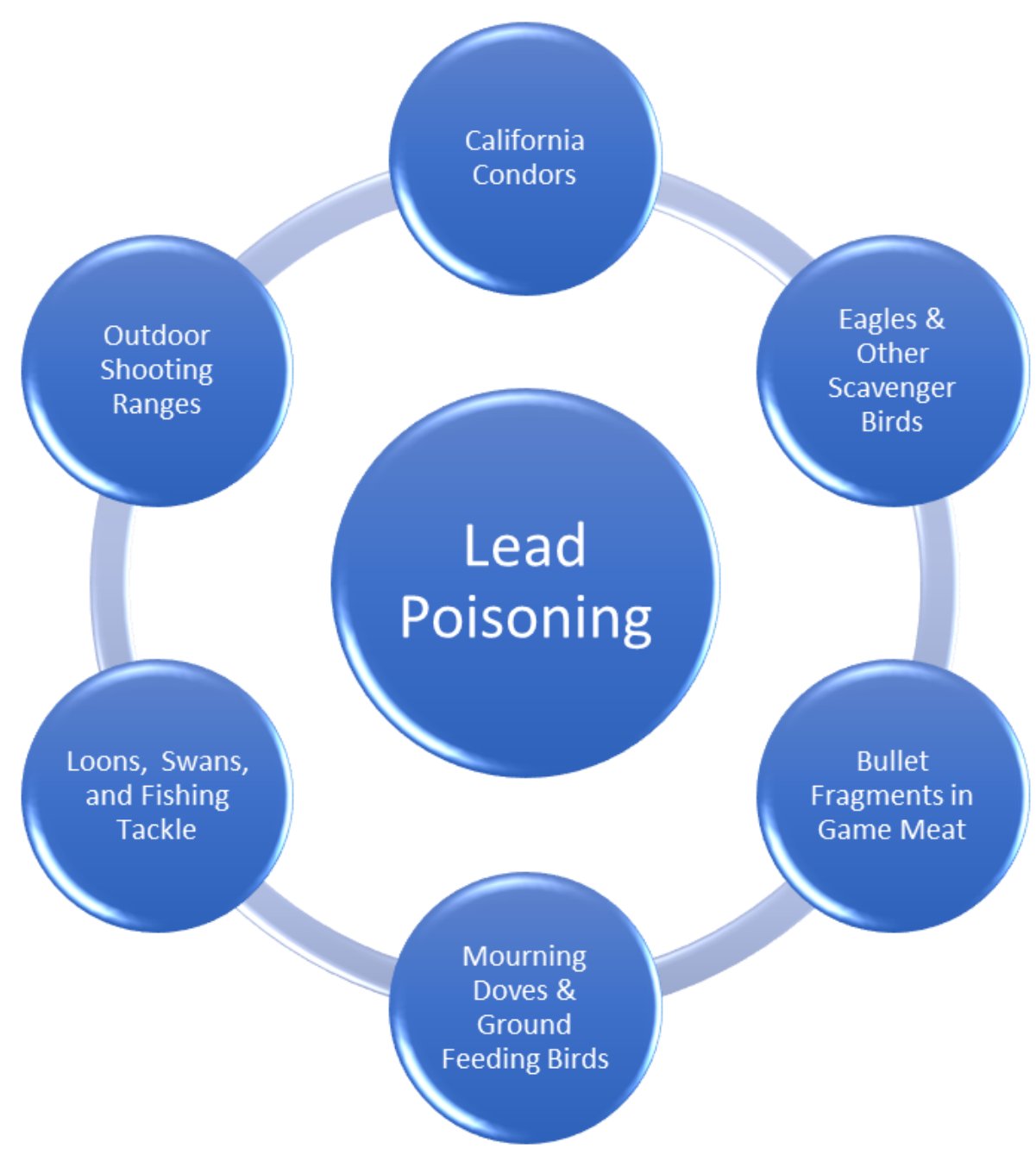

Figure 2.1. Lead poisoning in wildlife and human health impacts are complex and multifaceted. Different components of the problem are characterized by differing exposure pathways, level of exposure, and relative impact on the wildlife population and the environment. The problem can be categorized by: (1) lead poisoning in the critically endangered California condors eating remains of harvested big game animals, (2) lead poisoning impacts on bald eagles and other avian scavengers also feeding big game animal remains on a broader continental scale, (3) possible human health effects from ingestion of lead bullet fragments in game meat, (4) mourning doves and other surfacefeeding songbirds ingesting spent pellets, especially on heavily hunted managed shooting fields, (5) ingestion of unretrieved lead fishing tacking by common loons and swan. 


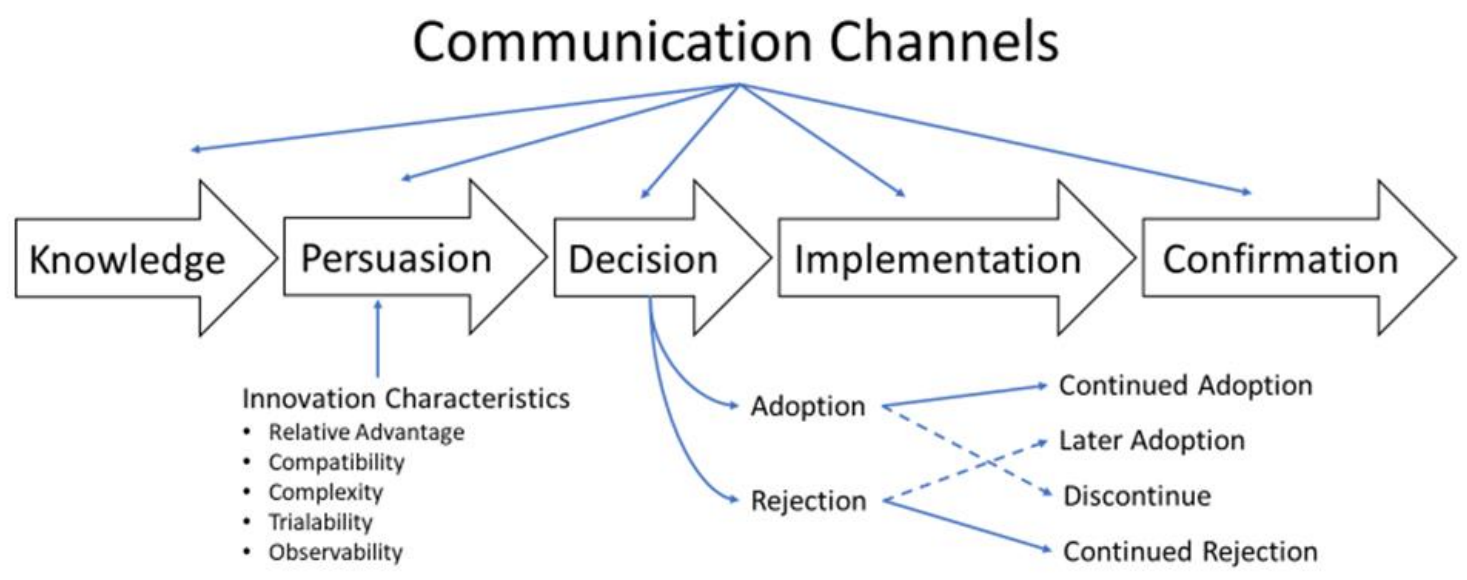

Figure 2.2. Decisions by hunters to use nonlead alternatives involve multiple steps in the decision process. With the diffusion of innovation theory, the process starts with acquiring knowledge about the innovation and the persuasiveness of the information; in this example lead poisoning wildlife and nonlead ammunition. Part of the persuasion process includes information about benefits of nonlead alternatives related to advantages over lead ammunition, compatibility and complexity of changing to nonlead, and opportunities for trialability or test alternatives and observe others. The decision to adopt or reject nonlead alternatives follows with implementation of the continued use of nonlead ammunition or discontinuation depending upon support for long-term continued use or rejection. Even after the decision to use nonlead alternatives has been implemented, confirmation and reinforcement of the behavior is necessary to ensure permanent behavior change. 


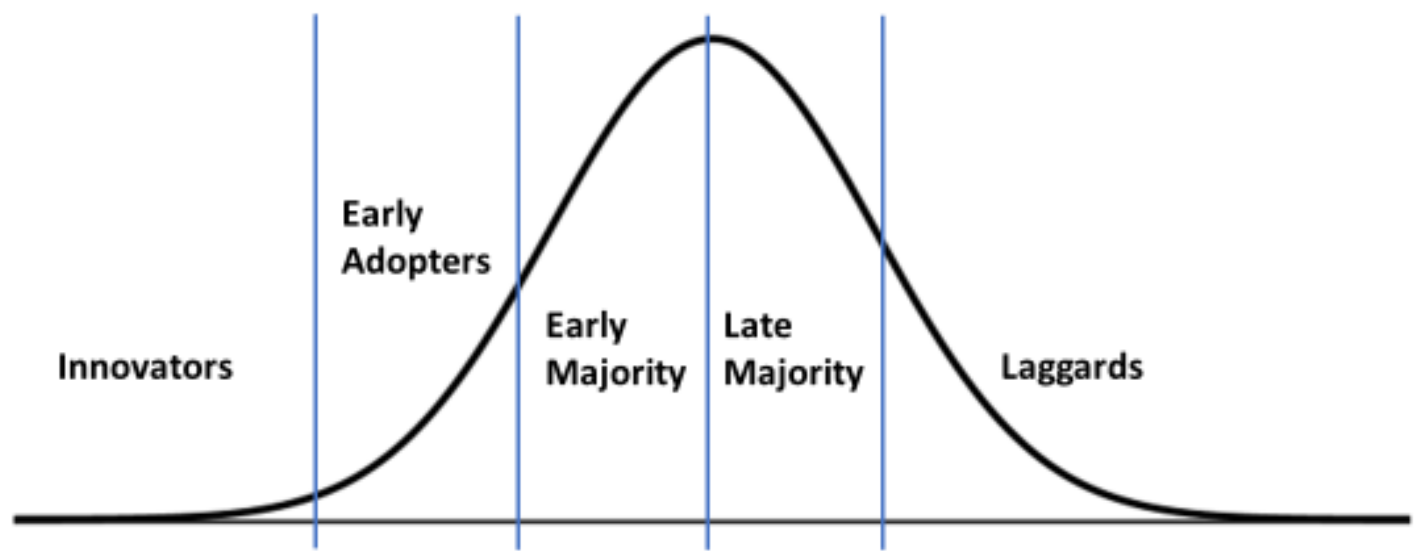

Figure 2.3. People adopting innovations can be based on varying characteristics and impact effectiveness of nonlead hunting ammunition and fishing tackle message campaigns; e.g., (1) innovators, (2) early adopters, (3) early majority, (4) late majority, and (5) laggards or traditionalists. Some of these groups may occur simultaneously or proceed through time with considerable overlap among groups of hunters and anglers. 


\title{
Chapter 3. Until It's a Regulation It's Not My Fight: Complexities of a Voluntary Nonlead Hunting Ammunition Program
}

\author{
With Sonja A. Wilhelm Stanis, Damon M. Hall, and Elisabeth B. Webb
}

Published: Journal of Environmental Management; 2021; 277:111438; DOI:

10.1016/j.jenvman.2020.111438

\begin{abstract}
Wildlife and human health are at risk of lead exposure from spent hunting ammunition. Lead exposure persists for bald eagles due to bullet fragments in game animal gut piles and unretrieved carcasses, and is also a human health risk when wild game is procured using lead ammunition. Programs encouraging the voluntary use of nonlead ammunition have become a popular approach mitigating these effects. This study explored attitudes and experiences of United States Fish and Wildlife Service (USFWS) staff implementing an outreach program encouraging deer hunters to voluntary use nonlead ammunition on 54 National Wildlife Refuges (NWRs) in the Upper Midwest, U.S. to understand factors affecting program implementation. We conducted 29 semi-structured interviews of USFWS staff along with 60 responses from an openended survey question. Twelve themes emerged from the data and were grouped into three broad categories: (1) challenges of dealing with complex issues, (2) importance of messengers and messages, and (3) resistance from staff. Challenges of dealing with complex issues included administrative restraint and uncertainty, scope and scale of program, human health not an agency responsibility, contextual political influences, and
\end{abstract}


public-private collaborations. Importance of messengers and messages included the importance of experience, and salience of human health risk. Finally, resistance from staff included skepticism of the science and motives behind the program, competing priorities for refuge staff, differing perceptions of regulatory and voluntary approaches, cost and availability of nonlead ammunition, and disregard by some about lead ammunition and human health risks. Staff identified numerous challenges implementing the program, many of which were external factors beyond the control of the participants. Understanding the factors affecting program implementation may help guide future efforts encouraging the voluntary use of nonlead ammunition.

\subsection{Introduction}

\subsubsection{Wildlife and human lead exposure from spent hunting ammunition}

Research has demonstrated wildlife and human health are at risk of lead exposure from spent lead hunting ammunition (Delahay \& Spray, 2014; Meltzer et al., 2013; Rattner et al., 2008; V. G. Thomas, Kanstrup, \& Fox, 2019; R. T. Watson et al., 2009). Although lead is a cumulative metabolic poison affecting all vertebrates (Clarkson, 1987; Haig et al., 2014), it is also an important part of the global economy (Rattner et al., 2008; Snow, 2017; Thomson, 2003). Its long tradition for use in hunting ammunition is due to its relatively high density, malleability, low melting point, and ease of availability (Eisler, 1988). Because of these factors, it took more than 100-years of research (Calvert, 1876;

Grinnell, 1894; Sanderson \& Bellrose, 1986) before a ban on lead ammunition for waterfowl hunting in the U.S. was phased-in during 1987-1991 (Schulz, Padding, et al., 2006; U.S. Department of the Interior - Fish and Wildlife Service, 1988). Since then 
various lead ammunition restrictions have been adopted across multiple continents (Avery \& Watson, 2009; Kanstrup, 2019; Kanstrup \& Balsby, 2019; Mateo \& Kanstrup, 2019; Mondain-Monval, Defos du Rau, Guillemain, \& Olivier, 2015; Pain, Fisher, \& Thomas, 2009). Although regulations have reduced lead exposure in North American waterfowl (Anderson et al., 2000; Schulz, Padding, et al., 2006), the problem persists for other avifauna worldwide (Krone, 2018; Pain et al., 2009; Pain, Mateo, \& Green, 2019; Plaza \& Lambertucci, 2019) along with a wide range of other predators and scavengers (Bumann \& Stauffer, 2002; Gomo, Mattisson, Hagen, Moa, \& Willebrand, 2017). Examples include obligate and facultative avian scavengers worldwide including California condors (Gymnogyps californianus; Finkelstein et al., 2012; Finkelstein et al., 2010), Andean condors (Vultur gryphus; Wiemeyer et al., 2017), white-tailed sea eagles (Haliaeetus albicilla; Helander et al., 2009), golden eagles (Aquila chrysaetos; Ecke et al., 2017), and bald eagles (Haliaeetus leucocephalus; Warner, Britton, Becker, \& Coffey, 2014; Cruz-Martinez, Grund, \& Redig, 2015). With the exception of California's statewide ban on all lead hunting ammunition fully implemented during 2019 (California Department of Fish and Wildlife, 2017), there have been few broad scale prohibitions of lead ammunition. Unlike waterfowl which directly ingest spent lead shot in shallow wetlands, avian scavengers indirectly ingest lead bullet fragments in game animal gut piles and carcasses (Finkelstein et al., 2012; Haig et al., 2014; Kelly et al., 2014; Kollander, Widemo, Ågren, Larsen, \& Loeschner, 2016). Bullet fragments vary in size depending upon the prey species, firearm type, bullet construction and material, terminal bullet velocity, and shot placement (Broadway et al., 2020; Martin et al., 2017; Trinogga, Courtiol, \& Krone, 2019; Trinogga, Fritsch, Hofer, \& Krone, 2013). Ingestion of lead 
bullet fragments usually results in mortality for avian scavengers (Golden et al., 2016; Pain, Mateo, et al., 2019; Yaw et al., 2017).

Lead exposure from big-game hunting is not only a wildlife health issue. Humans also ingest lead bullet fragments in venison (Gerofke et al., 2018; Hunt et al., 2009; Iqbal et al., 2009; Pain et al., 2010) with multiple variables affecting the amount and distribution of lead bullet fragments (Grund, Cornicelli, Carlson, \& Butler, 2010; Hunt et al., 2009; Kollander et al., 2016; Trinogga et al., 2013). People ingesting lead-tainted venison are susceptible to chronic and acute effects of lead exposure (Buenz \& Parry, 2018; Jones et al., 2009; Knott et al., 2010; Lidsky \& Schneider, 2006; Mateo et al., 2014; Rosen, 1995). For example, blood lead levels in humans $<5 \mu \mathrm{g} / \mathrm{dL}$ can impair cognition (Bellinger et al., 1991; Earl et al., 2016; Lanphear et al., 2016) and contribute to cardiovascular disease (Lanphear et al., 2018). These issues are magnified when natural resource management agencies establish public-private collaborations with food banks and hunting organizations to distribute lead-tainted venison to families in need (Minnesota Department of Natural Resources, 2020; Missouri Department of Conservation, 2017) with most having some version of a venison donation programs (Congressional Sportsmen's Foundation, 2020; NRA-Explore, 2020).

In the absence of lead ammunition bans, a series of localized and uncoordinated outreach programs have been adopted encouraging hunters to voluntarily use nonlead ammunition (Bedrosian et al., 2012; Chase \& Rabe, 2015; Green, Hunt, Parish, \& Newton, 2008; Haig et al., 2014; Henry, 2016). Voluntary programs, based on publicprivate collaborations, are popular because they reduce socio-political conflict for riskaverse natural resource management agencies facing reduced budgets, mandated staff 
reductions, and declining political support for regulatory policies (Donahue \& Zeckhauser, 2011; Huxham, 2003).

\subsubsection{Voluntary Natural Resource Programs}

Given the vast literature on lead risks to wildlife and humans, many stakeholders have recommended lead ammunition bans based on previous regulatory policies (Bellinger et al., 2013; V. G. Thomas \& Guitart, 2003; V. G. Thomas et al., 2019). Examples include delisting bald eagles as an endangered species (Millsap et al., 2016), the lead ban for waterfowl hunting (Schulz, Padding, et al., 2006; U.S. Department of the Interior - Fish and Wildlife Service, 1988), and the complete lead shotshell ban in Denmark on all hunting and target shooting fully implemented during 1996 (Kanstrup, 2019; Kanstrup \& Balsby, 2019). In contrast to regulatory approaches, however, voluntary programs are becoming a prevailing conservation policy tool (Büscher, Dressler, \& Fletcher, 2014; Heynen \& Robbins, 2005; McCarthy \& Prudham, 2004). Adopting voluntary programs allows policy makers to bypass legislative and administrative rule-making processes allowing for expedient decision making and maximizing discretion for program roll-out, adaptation guidelines, implementation procedures, monitoring, and program termination. Successful examples include farmland soil conservation efforts in the United States (Genskow \& Wood, 2009; Segerson, 2013b), establishment of farmland wildlife habitat (Best et al., 1997; Pabian, Wilson, \& Brittingham, 2013), improved forest habitat management (Kauneckis \& York, 2009; Steelman \& Rivera, 2006), sage grouse (Centrocercus urophasianusas) conservation and habitat management (Copeland et al., 2013; Wollstein \& Davis, 2017), and sustainability 
of marine fisheries (Lent \& Squires, 2017; Segerson, 2010). However, if voluntary programs are to be used for mitigating wildlife lead poisoning, thoughtful design, implementation, and monitoring will be necessary (Alberini \& Segerson, 2002; Prakash \& Potoski, 2012; Rice \& Atkin, 2013).

\subsubsection{Voluntary nonlead ammunition outreach programs}

Voluntary use of nonlead ammunition is affected by a cultural inertia of longestablished use of lead ammunition compared to a novel behavior of using nonlead alternatives. Previous research shows these traditions are influenced by socio-economic factors such as price, availability, ballistics, lethality, and underlying attitudes and beliefs (Pierce et al., 2015; Schroeder et al., 2016; Southwick, 2014; V. G. Thomas, 2013). Differences in cost and availability of lead-based and nonlead ammunition, although slight, are primarily due to differences in bullet materials and manufacturing technologies (V. G. Thomas, 2013). Lead bullets are usually "semi-jacketed" with a lead core surrounded by copper jacket to control bullet expansion and fragmentation (i.e., semijacketed bullets) while nonlead bullets or "monolithic bullets" are often constructed with on a copper alloy designed not to fragment (Gerofke et al., 2018; Krone, 2018; Trinogga et al., 2019). Despite the vast amount of information on lead poisoning in wildlife (Haig et al., 2014; Rattner et al., 2008; R. T. Watson et al., 2009), and related human health risk (Earl et al., 2016; Green \& Pain, 2019; Hanna-Attisha, 2018; Kim et al., 2016; Markowitz \& Rosner, 2013b), few studies have assessed perceptions of nonlead ammunition, outreach encouraging voluntary use of nonlead, or individuals implementing the outreach programs. 
Understanding experiences and perceptions of hunters are critical for the development of successful of voluntary nonlead programs. Newth et al. (2019), for example, found the perceptions of U.K. ammunition users varied based on whether they were open to change or favored the status quo. However, both groups agreed lead is toxic, policy discussions should be inclusive, and persuasive outreach should be presented by the shooting community. Roughly half of the hunters in northern Arizona used nonlead ammunition after receiving only educational materials whereas about threefourths used nonlead when receiving education plus a nonlead voucher (Chase \& Rabe, 2015). Ross-Winslow (2013) identified different attitudes about the use of lead, differences regarding management strategies, and differences associated with tactics for dealing with conflict among stakeholders. Simple factual nonlead messages, messages referencing reputable hunting organizations, and first-person narratives elicited positive attitudes and support for a lead ammunition ban by small game hunters in Minnesota (Schroeder et al., 2012). Furthermore, policy makers may need to consider outreach toward hunters who indicated unlikely support for a lead ban given their opposition to regulations (Schroeder et al., 2016). Perceptions of natural resource professionals implementing voluntary nonlead programs may be critical. For example, proenvironmental behavior is fostered when educators build connections between constituents and natural resources, yet only limited research has examined these factors (Balasubramanyam, Wilhelm Stanis, Morgan, \& Ojewola, 2019). Program representatives' knowledge, awareness, and attitudes could also play an important role influencing pro-environmental behavior among participants (Marion \& Reid, 2007; Taylor \& Caldarelli, 2004). 
Given this background, we explored experiences of hunting and nonhunting United States Fish and Wildlife Service (USFWS) staff implementing a voluntary nonlead ammunition program on National Wildlife Refuges (NWRs), and how staff members' values, beliefs, and attitudes about lead poisoning influenced program implementation. In the following sections we describe our qualitative methodology, summarize interviews, and explore staff perceptions. Twelve themes emerged from our data and were grouped into three general categories; challenges of dealing with complex issues, importance of messengers and messages, and resistance from staff. Next, our findings are compared to characteristics of established voluntary conservation programs and other nonlead outreach programs. Finally, options for encouraging the voluntary use nonlead hunting ammunition are discussed.

\subsection{Methodology}

\subsubsection{Nonlead Outreach Program and data collection}

During 2016-2018, USFWS conducted a phased-in outreach program encouraging hunters to voluntarily use nonlead ammunition while deer hunting on 54 NWRs in Illinois, Iowa, Indiana, Michigan, Minnesota, Missouri, Nebraska, Ohio, and Wisconsin; four NWRs areas piloted during 2016, 17 added in 2017, and 33 in 2018. Deer hunting regulations varied widely among the 54 refuges. Examples included various combinations of statewide regulations, managed hunts with limited number of hunters, use of only shotguns with single projectiles or muzzleloading rifles, and/or mandatory orientation sessions. The outreach program was solely an information campaign. It consisted of outreach materials focused on lead poisoning in bald eagles 
based on publications documenting of lead poisoning in bald eagles in the upper Midwest (Cruz-Martinez et al., 2012; Warner et al., 2014; Yaw et al., 2017). Informational materials designed for hunters included brochures, rack cards, yard signs for parking lots, and free-standing banners for building entrances. Briefing materials for staff included fact sheets, FAQ sheets, and standardized presentations for use on refuges with managed hunts and hunter orientation sessions. Time and effort time implementing the outreach program varied by refuge depending on deer hunting opportunities provided; e.g., refuges open to statewide regulations or different variations of managed hunts limiting the number of hunters.

We conducted semi-structured interviews to explore relationships between USFWS staff implementing voluntary programs and to discover factors affecting staff support or opposition to the program. Potential interview participants were provided by USFWS regional administrators. Participation was voluntary with interviews usually lasting $<60$ min. Following guidelines described by Young et al. (2018), interview questions were developed, pilot tested with eight wildlife biologists from the Missouri Department of Conservation during 2016, and finalized based on feedback from the USFWS regional administrators. The final interview protocol (Appendix 1) contained eight questions concerning participants' awareness of the issue of lead poisoning in wildlife and risk to human health, experiences with the nonlead outreach program, specific program materials used, and status as a deer hunter (Young et al., 2018). Staff who identified as being a deer hunter were asked about the weapon they used, and their choice and rationale for ammunition. Participants were asked about their deer hunting experiences (if they were a hunter) and, efficacy of messages from the USFWS 
implementation team, potential communication barriers and opportunities, and factors influencing their intentions and behaviors related to the outreach program.

Following deer hunting seasons of 2017 and 2018, we conducted semi-structured interviews $(n=29)$ with USFWS field staff with a range of responsibilities for implementing the outreach program and varying levels of public contact on the refuge. For example, participants included refuge managers, assistant managers, visitor services specialists, law enforcement officers, public and private land biologists, administrative support staff, technicians, and maintenance staff. Interview participants averaged 45.4 years of age $(S D=9.9$ years $)$ with ages ranging from 28-66 years, comprising 21 men and eight women. Eleven interviews occurred in-person and 18 were conducted via telephone. In addition to interviews, we used 60 responses of USFWS field staff implementing the program ( $n=12$ from $2018 ; n=48$ from 2019) from one open-ended survey question requesting input on improving the program. The entire survey contained 45 multi-item questions and required $\leq 20 \mathrm{~min}$ to complete with a $52.0 \%$ response rate in $2018(n=167)$ and $62.5 \%$ in $2019(n=197)$; results reported elsewhere (see Chapter 4).

\subsubsection{Qualitative Data Analysis}

The first author had been a wildlife research scientist for nearly 40-years and conducted numerous research projects on lead poisoning in wildlife. This experience provided a deep understanding of the issue and elucidated nuanced perspectives among stakeholders allowing interaction with USFWS field staff on a professional level as a conspecific. Given this experience, all interviews were conducted by the first author. Interviews were audio recorded and transcribed. QSR's NVivo Pro 12 qualitative 
software was used to organize, categorize and summarize the data (Jackson \& Bazeley, 2019). Additional data from the open-ended survey question was added to the transcribed interviews for analysis. Coding of the interview transcripts was done using multiple coders through an interactive process to ensure a robust set of themes (Patton, 2015; D. R. Thomas, 2006). Based on this analysis, themes and categories emerged using participants quotes and expressions. Qualitative research using a thematic approach emphasizes the range, complexity, and depth of ideas, rather than relative importance of each response or theme (Flick, 2014; Riessman, 2008).

\subsection{Results}

Twelve themes emerged from the data and were grouped into three general categories: challenges of dealing with complex issues, importance of messengers and messages, and resistance from staff (Table 3.1).

\subsubsection{Challenges of dealing with complex issues}

\subsubsection{Administrative restraint and uncertainty}

Staff recognized the complexity of trying to change deer hunter behavior to voluntarily adopt nonlead ammunition by noting it will require more than posters and brochures. Failure to embrace complexity appeared to some participants to be a function of agency's modus operandi. "It's been the same way we put out any other information. We fall back of what we traditionally do, and we keep doing it." Failure to grasp this complexity was compounded by a lack of recognition that different audiences may exist within the deer hunter community (Andersen et al., 2014; von Essen, van Heijgen, \& 
Gieser, 2019). Although Segerson (2013b) described successful voluntary programs having a clearly defined target audience, staff recognized target audiences among hunters had not been clearly articulated or identified. "It's [about] knowing your audience in order to have the message prepped for that group."

Given the best of intentions among USFWS administrators, refuge staff recognized the uncertainty among administrators concerning the program with “potentially serious political repercussions." In this situation, internal leadership appeared to stifle engagement with the program. "We're not $100 \%$ sure of where our boundaries are and what we can and can't do." This restraint was echoed by a "need to be careful about not pushing too hard." Other staff said they received mixed messages from administrators. "We know how to get the job done ... the longer we stay in this 'Do as much as you can, but not too much' mode, I think frustration will grow and people will move on to other tasks." Alternatively, one participant said there was no uncertainty about following approved guidelines. "I'm not going outside the box because I don't want to make any trouble." The need for uniformity along with timidity reduced enthusiasm for the program among some staff.

\subsubsection{Scope and scale of program}

One participant commented on the difficulty of local retailers carrying nonlead ammunition for a small niche market given the few hunters exposed to the program and suggested expanding the program beyond NWRs. "We had a very narrow scope of only deer hunting on refuge land. We should have broadened our scope." In addition to the limited spatial scale, some participants questioned the efficacy of focusing informational messages solely on reducing lead exposure to bald eagles and avoiding human health risk 
of lead exposure. "Why is there any concern when the [bald eagle] populations are increasing?" Justification from administrators for emphasizing bald eagles focused on a scientific article showing $60 \%$ of dead eagles had lead exposure with $38 \%$ showing lethal concentrations, and exposure linked to gut piles from harvested deer (Warner et al., 2014). Although bald eagles were the focus of the program, many hunters were likely not exposed to the message or did not have a personal connection with the problem. One participant remarked, "If people see 50 dead birds [from lead poisoning], that opens peoples' eyes. "

\subsubsection{Human health not our responsibility}

Lead exposure in bald eagles was the primary message intended for deer hunters visiting NWRs. During training, however, staff were advised not to talk about human lead exposure from ammunition. The primary reason was the lack of medical expertise in human health issues among staff. However, staff recognized the potential effectiveness of a compelling narrative focused on human health and lead exposure. "The human health aspect would be a game changer, but they advised we're not specialists in that area ... we're a wildlife agency." Other participants stayed on-script, but when asked about human health risks they expressed their personal decision about using nonlead ammunition. "I don't talk about the human health issue. If somebody brings it up, I'd tell I made the switch [to nonlead ammunition], so I don't have worry about it." Other staff deflected the human health risk to medical professionals or partnering with other groups. 'It's definitely worth mentioning [human health risk], but the message would come better from a medical organization." 


\subsubsection{Contextual political influences}

The politics surrounding risks to wildlife and human health from lead exposure were likely impacted by a paradigm of reduced environmental regulation, reduced enforcement of existing regulations, and the desire for slow incremental change (Büscher et al., 2014; Wood, 2014). These factors were manifested through the implementation of the voluntary outreach program on NWRs. "Baby steps and voluntary messages are good first steps. We're doing as much as we can because of the politics." In addition, tangent socio-political issues related to gun control (Baum, 2013; Smyth, 2020), $2^{\text {nd }}$ Amendment rights (Whitney, 2012), and firearms and ammunition excise taxes (Prukop \& Regan, 2005) were implied by many participants. In other words, “politics” was a term having multiple implied meanings related to personal freedoms of gun-related issues imbedded in contextual factors outside of the agency's influence or control. One participant stated the outreach program may be perceived by hunters and gun owners as something more covert than simple attempts to reduce eagle mortality. "Many hunters and gun owners see this as an anti-hunting ploy. We need to do a better job of convincing gun and hunting groups that decisions related to lead are science based, not anti-gun or anti-hunting." Another staff member recognized how the politically charged nature of the issue warranted a voluntary approach that is slow, incremental, deliberate, and designed to avert fanning the political flames of gun-control rhetoric. "Politics of the issue is the main challenge. . we're treading carefully because we know what can happen with the politics." Politics was used in some contexts as dealing with the external administrative layers of federal government and its impacts on implementing the program 
while not drawing unwanted attention. "If we push much harder, [administrators] will tell us to stop or [the program] will get killed."

These explicit and implicit political factors provided uncertainty for staff and administrators. The ambiguous boundaries of this politically volatile issue made program implementation challenging. "It's a touchy issue. It's touchy between us and the state, the politicians, and the lobbyist groups. We're not fully engaging because we're not $100 \%$ sure of where our boundaries are and what we can and can't do." One participant expressed political timing is important and suggested it might be better to wait for a more favorable political climate. "Timing is critical. While I commend the leadership, the foot soldiers in the field recognize the timing is not good politically."

\subsubsection{Public-private collaborations}

Public-private partnerships (Donahue \& Zeckhauser, 2011) have become popular for addressing reduced agency budgets and staffs. Many NWRs have strong relationships with local hunting and fishing stakeholders. "[When] we implemented this voluntary program, I brought it up with all of our partnering rod and gun clubs, a lot of other conservation groups, Trout Unlimited, Pheasants Forever, DU [Ducks Unlimited], all of them." USFWS staff also recognized public-private partnerships could not only help implement the program but they would provide credible messengers from within the hunting community. "I think our state agency partners and organizations such as DU, RMEF [Rocky Mountain Elk Foundation], etc. would be more effective at carrying our message to hunters." It was also suggested partnerships would not only improve communication but provide incentives for ammunition manufacturers. "We could work 
with the ammunition companies to provide incentives for nonlead ammo. Data could be collected for the companies to [improve] nonlead ammo."

\subsubsection{Importance of messengers and messages}

\subsubsection{Experience matters}

Participants described several challenges related to having knowledgeable and credible spokespersons. To be perceived as legitimate and knowledgeable, some staff said it was important to have hunting and shooting experience and be able to effectively communicate their experiences. "Having somebody that cares about eagles is fine, but it is important that they're a hunter." Although staff stressed the importance of deer hunting, hunters are becoming less common among USFWS staff. "It's a reality within our agency that a lot of folks don't hunt and don't have [hunting] experience, [but] make sure you know what you're saying."

Along with hunting and shooting experience, face-to-face communication was emphasized as improving persuasiveness. Dialog among staff and deer hunters, compared to passive messaging through traditional brochures and bulletin board displays, was perceived as being more effective. "Presentations by biologists who hunt will work better than a bunch of brochures and allow audiences to ask questions." This firsthand knowledge gave staff the aura of a nonlead convert with persuasive messages for deer hunters (Levine \& Valle, 1975). However, some participants with hunting experience believed a simpler succinct message may be more persuasive. "It's important for hunters to understand nonlead shoots better than lead ammunition. Ballistic details might help, but dead is dead when it comes to deer hunting." 
Legitimacy of spokespersons was an additional challenge recognized by participants. Staff recognized barriers between federal government employees and the public. “As soon you're in a federal government uniform there's a wall going up between you and the public." This barrier was not just associated with being a federal employee but also may have been additive within the norms of being a natural resource professional. "We look through wildlife lenses all the time; the public doesn't always see things the same way we do." An example of this professional myopathy was demonstrated when the outreach program was scheduled during the autumn hunting seasons when biologists thought it was most appropriate, but hunters were busy deer hunting. From a hunter's point of view, staff who hunted said it would make more sense to conduct outreach prior to the season allowing hunters to acquire nonlead ammunition ahead of time and practice using it. "[We] need to focus on talking to hunters before the season... we're trying to reach hunters when they're in the field and don't want to be distracted."

\subsubsection{Salience of human health risk}

Given the ongoing socio-political discussion of lead exposure in drinking water from public water utilities and lead-based paint in decaying urban housing (Gómez et al., 2018; Hanna-Attisha, 2018), the aspect of linking lead exposure to human health seemed to be an intuitive program message. Many participants expressed the human health issue would be a more efficacious nonlead message by linking family with ingestion of lead bullet fragments. "The fact that tiny lead fragments end up throughout the deer affected me more than the bald eagle information. I do not want to feed that to my family." Staff 
who were also deer hunters often harvested several deer as part of their family's annual meat supply. "There's this study showing venison with lead fragments. I was feeding that to my family. I've got four kids and we put two, three, and sometimes four deer in our freezer every year." Other staff who were not hunters became concerned enough about the human health risk to ask about the type of ammunition used before using venison from family or friends. "If someone was offering me some venison, I'd ask them how they shot it before eating it or giving it to my family." Although staff were instructed not to directly talk about the human health issue, some used humor when dealing with the public. "If I'm talking to the public, I won't say their health is at risk, but I'll ask if they feel comfortable ingesting lead. If the answer's yes, then I tell them they don't need to listen (laughs)."

\subsubsection{Resistance from staff}

\subsubsection{Skeptical of science and motives}

Successful voluntary conservation programs use persuasive messages delivered by credible and experienced program representatives (Corbett, 2006; Rice \& Atkin, 2013). Several participants, however, stressed they believed the science supporting lead poisoning in wildlife was inaccurate, unsubstantiated, or driven by political motivations. "I'm not against nonlead ammo, but do it for the right reason, not some politically skewed ideal." Another participant expressed similar concerns. "I'm not ok with the very biased test results being used [by the program] to push an anti-lead agenda." Other staff stated the information needed to be better supported before publicly talking about the issue. "Ifeel the science needs to be stronger. . I'm not comfortable with the 
information on the impacts of lead from gut piles and eagles... I know there's others that feel that way [within the USFWS]."

Several staff were skeptical of the information based on their firsthand observations. "The nonlead info I saw was very biased showing lead bullets fragmented into hundreds of pieces ... this just isn't my experience." Due to perceived reduced lethality, one experienced deer hunter was concerned nonlead ammunition would unnecessarily cripple more deer. "I cannot in clear conscious hunt with nonlead ammo at this time knowing that I may wound an animal or put the animal through unneeded suffering." These comments were an indication some staff implementing the program on NWRs may do more harm than good.

\subsubsection{Competing priorities and limited resources}

The program was implemented within an agency culture where multiple unmet priorities already existed which in turn created tensions among some field staff. "Why are we focusing on lead poisoning when we have broken infrastructure on our refuges that we can't pay for? We don't have the funds to provide the habitat that's really needed." Not only was the program viewed within the context of funding, staff stressed having too much to do. 'It's one more thing I have to deal with. I just don't have the time to do that. So, I need bullet points [laughs]." Staff also recognized there were competing programs during the same time of year. "We're already working three weekends in a row for waterfowl hunters, then we get a little break, and then kick back into deer hunting season? It's just not a priority." Given reduced budgets and overworked field staff, some participants questioned if the program could be discontinued 
or delayed pending more resources or better socio-political timing. "We have other [refuge] priorities . . . and finite resources . . if now isn't the right time, we should stop and come back when the timing is better."

\subsubsection{Regulatory and voluntary perceptions - a mixed bag}

Varying levels of support were expressed for a nonlead regulation, a voluntary program, or a combination of the two. "If it's a really big priority, we should have gone the regulatory route, but I was quickly told that can't do that because of political realities." Another participant emphasized it was none of their business unless there was a regulation. "Who am I to tell somebody what ammunition to use? Until it's a regulation it's just not my fight." Based on personal experience, another individual suggested a ban on lead ammunition without delay or exceptions. "It's an issue that's been around my whole career. If we're going to require nonlead ammunition for hunting deer on a refuge we should just do it, explain why it's being done, and implement the [regulation]. No exceptions." Referring to the U.S. waterfowl lead ammunition ban phased-in during 1987-1992 (Schulz, Padding, et al., 2006), another participant believed there may be challenges with lead ammunition ban, but they would be manageable. "We broke the ice 30-40 years ago with the steel shot regulation for waterfowl hunting, and we survived. I don't think it's as big a deal as people are making it out to be." Policy options may not simply be dichotomous choices between voluntary and regulatory. One participant stated voluntary programs may provide a policy bridge spanning the political chasm toward a future regulation. "If we said we're doing this voluntary program with a 
pending regulation in ten years I think people would see where we're headed. With just a voluntary program and no long-term objective, I think it's going to just die."

Instead of a ban on lead ammunition, many staff favored a voluntary approach. This perception suggested lead exposure could be mitigated through limited government intervention and adoption of voluntary programs (Castree, 2008; Demirel, Iatridis, \& Kesidou, 2018). Some staff stated that word-of-mouth communication would sufficiently initiate a groundswell of support for nonlead ammunition over the long-term. "It's going to spread by word of mouth. You talk to 500 hunters, and maybe only one will buy nontoxic ammunition and he tells his buddies. With a voluntary program, that's how we have to do it." The importance of implementing the voluntary program slowly and incrementally was compared to a sweeping draconian lead ban. "We're just at that baby stage where we're starting to educate people about the problem. We don't have to make it a law or be heavy handed." Despite the overwhelming science (Arnemo et al., 2016; Bellinger et al., 2013), a participant stated political realities superseded the USFWS's regulatory authority. "The information campaign is the way to go. Even though we have the [regulatory] authority ... it's not politically feasible, so we need to stay the course."

\subsubsection{Nonlead cost and availability perceptions}

Cost and availability of nonlead ammunition were expressed as external factors beyond the influence of the agency. These factors have been reoccurring themes in other lead ammunition policy discussions (Chase \& Rabe, 2015; Kanstrup \& Thomas, 2019; V. G. Thomas, 2013). Cost and availability concerns can be challenging if spokespersons believe using nonlead will reduce hunting and shooting opportunities. "If lead bullets 
are banned the cost for my hunting ammo will double and it will make recreational shooting unaffordable." Even if cost was not an issue, availability at local retail stores provided an obstacle for all but the most determined nonlead ammunition user. "My friend was looking for steel-shot for duck hunting and went to five different stores; none of them had it. If we can't find steel-shot for duck hunting, how are people supposed to find nonlead ammunition for deer hunting?"

Modern hunting is an expensive recreational pastime with ammunition costs a relatively small proportion of the total hunting experience compared to other expenses of a hunting lease, travel, lodging, meals, and equipment (Schulz et al., 2003; von Essen, van Heijgen, \& Gieser, 2019). However, cost was viewed as a binary choice between nonlead vs. lead ammunition, and not within the context of overall hunting expenses. "In the grand scheme of things, it's not that much money but try telling a guy to buy a $\$ 40$ box of [nonlead] ammo when he's used to purchasing a box of lead ammo for \$20."

\subsubsection{Uncertainty of human health risk}

Despite lead exposure from eating animals shot with lead ammunition, several staff expressed the issue was not important if proper butchering techniques were used. "We're cognizant of the wound on the deer and cut a good chunk around that area."

One hunter with considerable hunting and butchering experience suggested there was no problems with lead ammunition. " . . 99.9\% of the deer are shot in the vital organs and the bullet passes through. One time I found a bullet after field dressing and it was only missing a small piece of the cooper jacket covering the bullet." These individuals believed their personal observations in spite of the available evidence describing the 
varying and nonsystematic distribution of lead bullet fragments throughout deer carcasses (Grund et al., 2010; Knott et al., 2010; Kollander et al., 2016).

Natural resource management is inextricably intertwined with socio-cultural factors of politics and economics (Robbins, 2020). Staff perceptions recognized this seemingly intractable comingling of natural resources, politics, and economics. In the other words, they perceived this as a "touchy subject" bounded by complex and uncertain solutions and affected by external forces. Ultimately, staff perceptions described a program with some positive outcomes and an uncertain future.

\subsection{Discussion and conclusions}

\subsubsection{Challenges within the agency}

Factors and challenges within the agency affecting the outreach program reflected multiple deficiencies characteristic of successful voluntary conservation programs. For example, effective voluntary programs need spokespersons who are perceived as knowledgeable and legitimate representatives (Rogers, 2003; Sahin, 2006). Our participants recognized this by suggesting experienced deer hunters and firearms enthusiasts could more persuasively convey nonlead messages than nonhunters. The challenge, however, is the number of deer hunters among the USFWS staff had declined, similar to hunters in the general population (Andersen, Wam, Mysterud, \& Kaltenborn, 2014; Black et al., 2018; Ryan \& Shaw, 2011). The diminishing number of staff with hunting and shooting experience will play an increasingly critical role in program implementation. 
Along with a shortage of knowledgeable hunters and shooters, Rogers (2003)

pointed out agents of change face considerable difficulty if their backgrounds and experiences are substantially different from the target audience. This idea was highlighted when one participant said a type of groupthink mentality (Sunstein \& Hastie, 2015) existed among USFWS professionals that may not be in line with the hunting public. This groupthink substantiates the need for greater training, sensitivity, and insight among USFWS staff for developing persuasive messages. In other words, effective nonlead messages resonating with natural resource professionals may not necessarily be effective for deer hunters (McGuire, 2013).

Additional elements of successful voluntary programs were absent, most importantly participation incentives, regulatory threats for noncompliance, and effective audience targeting (Segerson, 2013b). First, there were no incentives to use nonlead ammunition beyond the satisfaction of doing something altruistic. When ammunition vouchers were provided to big-game hunters in Wyoming, however, bald eagles had significantly reduced blood lead levels (Bedrosian et al., 2012). Second, voluntary compliance without the threat of future regulatory repercussions may encourage freerider behavior (Alberini \& Segerson, 2002) as demonstrated by staff who intended to continue using lead ammunition (see Chapter 4). Without effective compliance monitoring, there is little incentive to use nonlead ammunition (van der Heijden, 2012). Third, deer hunters were considered a homogeneous group with no differential target audiences (McGuire, 2013; Segerson, 2013a). Understanding different motivations for hunting can provide powerful insights (Fulton \& Manfredo, 2004; Schroeder et al., 2012) along with deer hunter typologies to frame messages aimed at each group. For example, 
Andersen et al. (2014) used typologies based on hunter motivation, approach to hunting, and hunter status. Other typologies may include firearms versus archery deer hunters (Black et al., 2018), groups based on support/opposition for recent regulation changes, access to land, current deer population size (K. J. Ward, Stedman, Luloff, Shortle, \& Finley, 2008), or a recognition of dynamic and evolving hunter identities (von Essen et al., 2019).

In addition, successful voluntary programs often provide multiple options for achieving desired outcomes (Segerson, 2013b). To reduce lead exposure on NWRs, however, the only mitigation option was voluntary use of nonlead ammunition. In contrast, voluntary lead reduction efforts in northern Arizona and southern Utah provided hunters a combination of lead abatement practices including use of nonlead bullets, burying or packing out the gut pile, taking a head or neck shot, or electing to use archery or a crossbow during the rifle season (Chase \& Rabe, 2015; B. Smith et al., 2017). The availability of multiple practices likely accounted for the $88 \%$ participation in northern Arizona and $80 \%$ in southern Utah (B. Smith et al., 2017). If the long-term goal is the reduction of lead exposure to wildlife, future outreach programs may consider promoting multiple abatement practices.

Contrary to other successful voluntary conservation programs, nonlead programs based on education-only strategies have rarely proven effective as expressed by several of interviewees. This finding was supported by Grade et al. (2019) who summarized the ineffectiveness of voluntary nonlead fishing tackle programs. Their extensive review showed how well-intentioned nonlead fishing programs based solely on education-only approaches proved largely ineffective throughout Europe and the U.S. One striking 
example reviewed the failure of a 10-year program in Minnesota using a (1) nonlead fishing tackle exchange programs, (2) retail store displays of nonlead fishing tackle, and (3) mass media exposure of the lead poisoning issue (Grade et al., 2019). In another example, Grade et al. (2019) described a 15-year program where outdoor retailers in Sweden refused to sell nonlead fishing tackle unless there was a regulation guaranteeing a market for nonlead fishing tackle.

Several USFWS staff who were also deer hunters said they were either unaware of the vast amount of available scientific data, did not know how access it, did not believe the scientific information, or stated the program may be an anti-hunting ploy. Our findings indicate these participants viewed the outreach program as a regulatory overreach. In the future, the outreach program may want to ensure staff understand the fundamental science before refining program messages for deer hunters. In fact, additional training for staff who are also deer hunters and previous skeptics may help them become more effective communicators as nonlead converts and impassioned proselytizers (Levine \& Valle, 1975).

\subsubsection{Effects of contextual factors on program implementation}

Several contextual factors substantially affected program outcomes. Perceptions of regulatory and voluntary policy approaches, broader political and social influences, cost and availability of nonlead ammunition, and the scope and scale of the program were thought to be influential. As suggested by Thomas and Guitart (2003) and Bellinger et al. (2013), a mandatory ban on all lead hunting ammunition and fishing tackle represents the most effective and efficient policy option. However, staff noted the socio-political 
firearms climate is complex and contentious. It is filled with overlapping issues of lead poisoning in wildlife, human health issues, politics of gun control, $2^{\text {nd }}$ Amendment gun rights, and funding for state and federal agency conservation agencies through firearms and ammunition excise taxes. Given this politically charged climate, voluntary programs provide, at best, a policy instrument for keeping the issue on the informal policy agenda pending a more favorable political climate (Cubbage, O'Laughlin, \& Person, 2017). Within this context, the current approach of voluntary programs has been piecemeal and fragmented with no strategic framework effectively developing and implementing outreach programs with measurable outcomes (Schulz, Wilhelm Stanis, Webb, Li, \& Hall, 2019).

The Association of Fish and Wildlife Agencies (AFWA) and their regional affiliates (e.g., the Midwest Association of Fish and Wildlife Agencies; MAFWA) are likely organizations to spearhead a national and regional voluntary outreach program in the U.S., similar to their humane furbearer trapping standards (Association of Fish \& Wildlife Agencies, 2018). However, the current hyper-sensitive political climate surrounding this issue has affected AFWA and its affiliates to the point where they are unwilling to act and resist any incremental steps. The primary reason for inaction is declining number of hunters due to multiple shifting demographic factors (Enck et al., 2000; Quartuch et al., 2017; Schulz et al., 2003). These declines are the primary reason most state agencies are risk-averse to anything perceived as accelerating these declines and their associated permit revenues (Prukop \& Regan, 2005). For example, in January 2017, the outgoing USFWS Director issued an order to phase-in nonlead ammunition for hunting on NWRs, also known as Director's Order 219. Shortly after the installation of 
the new Secretary of the Department of the Interior during March 2017 the order was rescinded with Secretarial Orders 3346 and 3347 (Association of Fish \& Wildlife Agencies, 2017). The more extensive scale of state natural resource management agencies provides opportunities for future research for monitoring outcomes of state level voluntary nonlead programs. Given the caustic political environment as evidenced by our participants, the greatest contextual challenge is trying to affect meaningful change in a political environment filled with conflict among polarized special interest groups (Coleman, 2003; F. Madden \& McQuinn, 2014, 2015).

Nonlead cost and availability, as recognized by our participants, has been a repeated theme since the lead ammunition ban for waterfowl hunting (J Scott Feierabend, 1985; Havera et al., 1994; Schulz, Padding, et al., 2006) and most recently with nonlead ammunition for big-game hunting (Hunt For Truth Association, 2017b). Consequently, hunters and ammunition manufactures have become accustomed to the externality of not paying the full cost of using lead ammunition and related environmental damage. Other concerns indirectly impacted by cost and availability of nonlead hunting ammunition often include corresponding declines in hunting permit revenues, hunting guide services, and retail equipment sales. Contrary to this negative rhetoric, there has been a positive response from the ammunition industry to produce a greater diversity of nonlead hunting ammunition at lower costs and greater availability (V. G. Thomas, 2013; V. G. Thomas et al., 2019). Much of this positive change can be attributed to ongoing changes in production prompted by the recently adopted statewide ban in California on lead hunting ammunition fully implemented during 2019 (California Department of Fish and Wildlife, 2017). 
Spatially, the nonlead outreach program focused on 54 NWRs scattered across nine upper midwestern states. Given this broad but fragmented scale, the possibility of meaningfully reducing bald eagle lead exposure through voluntary outreach is likely minimal. It would be challenging to affect meaningful change in hunter behavior given the limited number of deer hunters in the region possibly exposed to the nonlead outreach program. With eagles capable of visiting a deer gut pile $>3.0$ times during approximately 2-days (J. W. Watson et al., 2019), the vast number of deer harvested outside of NWR borders ultimately affect lead exposure in bald eagles. As noted by multiple participants, the outreach program's impact on reducing wildlife lead exposure could be greatly multiplied by collaborating with non-federal conservation stakeholders (e.g., state agencies) and related hunting organizations.

With few exceptions, human exposure to lead bullet fragments in venison was overwhelmingly suggested by participants as a persuasive nonlead message. Efforts to address human health risks, however, remain problematic due to jurisdictional differences among natural resource agencies and human health agencies; i.e., each agency says it is the other's responsibility to address human health related to meat killed with lead hunting ammunition. Despite data showing lead is a zero-threshold neurotoxin, especially in young children (Lanphear et al., 2016), many stakeholders believe small amounts are acceptable due to a lack of obvious symptoms of acute poisoning (Hunt For Truth Association, 2017b). Developing future outreach messages targeting deer hunters with families and young children, in cooperation with human health agencies, may provide more impactful messages. Given many participants stressed challenges within the agency and contextual difficulties implementing the program, future research may consider 
examining cultural cognition theory emphasizing the factors of identity affirmation, pluralistic advocacy, and narrative framing (Kahan \& Braman, 2006; Kahan, JenkinsSmith, \& Braman, 2011). Gaining explanations for these underlying political conflicts will be critical in making meaningful reductions in lead exposure for both wildlife and humans.

Relegating sensitive issues to voluntary programs lowers political risk for natural resource management agencies. Voluntary programs may be viewed by some as a logical "first step" in preparation for implementing a new regulation and accompanying enforcement. Alternatively, a political ecology lens (Robbins, 2020) recognizes voluntary programs are a preferred policy tool of the neoliberal conservation paradigm (Büscher et al., 2014; Swaffield, 2016). Neoliberal conservation is generally categorized by support for unencumbered economic growth, continued socio-economic progress, and unbridled individual choice while encouraging slow, incremental change to the current socio-political system or continuance of the status quo (Swaffield, 2016). It is characterized by policies limiting government size, reductions in new environmental regulations, reduced enforcement of existing regulations, decentralized decision making, privatization or commodification of natural resources, and implementation of voluntary programs in lieu of regulatory policies (Brunner et al., 2005; Holmes \& Cavanagh, 2016; Igoe \& Brockington, 2007; McCarthy \& Prudham, 2004). Amid the rhetoric of smaller government, reduced budgets, and voluntary nonlead ammunition programs, further translational research is needed to explore factors limiting the efficacy of existing voluntary nonlead programs as a means to improve future programs across the U.S. and 
Europe using a unifying public communication campaign (Rice \& Atkin, 2013; Schulz et al., 2019).

\subsubsection{Elements of successful voluntary programs}

Staff identified numerous challenges related to the difficulties of a "political issue." Examining these factors along with characteristics of successful programs identify opportunities to guide future outreach. Segerson (2013a) described five elements of successful voluntary conservation programs. First, incentives include factors such as providing a sense of altruism among participants, direct compensation for participation, or regulatory consequences for nonparticipation. Low entry requirements geared toward simply increasing voluntary participation will not likely affect meaningful behavioral change or improved environmental outcomes (Alberini \& Segerson, 2002). Secondly, voluntary programs will be more successful and sustainable if outcomes are monitored. For example, measuring changes of grassland bird nesting success provides more valuable information to policy makers than simply enumerating the number of acres enrolled in a program (Johnson \& Igl, 2001; Reynolds, Shaffer, Sauer, \& Peterjohn, 1994). Third, Segerson (2013a) recommended ease of implementation and delivering the greatest economic or environment benefit. For example, incentives in the form of free nonlead deer hunting ammunition in an area with shotgun-only seasons would be relatively easier compared to areas allowing hunting with high-powered rifles. In other words, most shotgun ammunition would be 12-gauge or 20-gauge nonlead compared to the dozens of different centerfire rifle calibers. Fourth, does the voluntary program provide benefits that would have occurred otherwise, or does the program inadvertently 
cause unintended outcomes in other areas? Does a program cause redirection of a behavior or practice to other areas in the broader landscape causing greater overall harm? The final element of Segerson's (2013a) typology addresses the reduction of free-riders by encouraging participation incentives, while simultaneously creating disincentives for nonparticipation. Although many previous voluntary conservation programs have been successful, these existing program frameworks may not be optimal for many emerging natural resource issues (Steelman \& Rivera, 2006).

Unlike the waterfowl lead poisoning discussions during the 1970s-1980s, a turn towards a neoliberal conservation paradigm since then (Castree, 2008; Igoe \& Brockington, 2007; Swaffield, 2016) has made regulatory bans on lead hunting ammunition problematic while simultaneously making voluntary nonlead programs the default policy option (M. J. Peterson, Hall, Feldpausch-Parker, \& Peterson, 2010; M. N. Peterson, von Essen, Hansen, \& Peterson, 2017). Some voluntary nonlead programs have shown measurable successes in changing hunters' behavior (Bedrosian et al., 2012; Chase \& Rabe, 2015; B. Smith et al., 2017), while others have shown limited reductions in the use of lead ammunition and fishing tackle (Grade et al., 2019; Henry, 2016; Schulz et al., 2019). Our findings demonstrate the difficulty of dealing with this important conservation issue and the need for further social science research aimed at resolving or transforming conservation conflicts (Coleman, 2006; F. Madden \& McQuinn, 2014; Redpath, Gutiérrez, Wood, \& Young, 2015). 
Table 3.1. Categories and themes from semi-structured interviews.

Categories Themes

Challenges of dealing with Administrative restraint and uncertainty complex issues

Scope and scale of program

Human health not our responsibility

Contextual political influences

Public-private collaborations

Importance of messengers and Experience matters messages

Salience of human health risk

Resistance from staff

Skeptical of science and motives

Competing priorities and limited resources

Regulatory and voluntary programs - a mixed bag

Nonlead cost and availability perceptions

Uncertainty of human health risk 


\title{
Chapter 4. Perspectives from natural resource professionals: Attitudes on lead ammunition risks and use of nonlead ammunition
}

With Sonja A. Wilhelm Stanis, Mark Morgan, Christine Jie Li, Damon M. Hall, Elisabeth B. Webb

Published: Journal of Outdoor Recreation and Tourism; 2021; 33:100341; DOI: 10.1016/j.jort.2020.100341

\begin{abstract}
Hunting is a popular activity but continued use of lead ammunition poses risks to wildlife and human health. To inform adoption of the voluntary use of nonlead ammunition, natural resource professionals were surveyed to understand their attitudes about threats to bald eagles, lead poisoning in bald eagles, human health risks from lead bullet fragments in venison, use of nonlead hunting ammunition, and socio-economic nonlead ammunition factors. Differences were examined by hunter status, ammunition type used, and intentions to use nonlead ammunition. Of participants surveyed, $61.0 \%$ were hunters and $39.0 \%$ nonhunters, with $59.5 \%$ of hunters using lead ammunition and $40.5 \%$ using nonlead. Concurrently, $68.5 \%$ of hunters reported likely intentions to continue using nonlead or convert to nonlead in the future, while $31.5 \%$ reported nonlead use was unlikely. Also, some hunters currently using nonlead ammunition indicated they would unlikely continue using nonlead (17.8\%). Nonhunters agreed more strongly than hunters regarding general mortality threats to bald eagles. Additionally, nonhunters, hunters using nonlead, and likely nonlead users more strongly agreed about threats of lead exposure to eagles than their counterparts. Nonhunters and likely nonlead users also more strongly agreed than hunters and unlikely nonlead users about the human health
\end{abstract}


risks of lead ammunition and about shooting characteristics of nonlead. Finally, nonhunters and nonlead users agreed more strongly than their counterparts about the socio-economic factors of using nonlead ammunition. Understanding natural resource professional hunters' attitudes may help with audience segmentation when designing future nonlead outreach messages.

\subsection{Introduction}

\subsubsection{Lead exposure from hunting and fishing}

The dangers of lead hunting ammunition and fishing tackle have been extensively documented (Eisler, 1988; Haig et al., 2014; Rattner et al., 2008). Direct ingestion of unretrieved lead fishing tackle poisons loons, swans, and shorebirds (Grade et al., 2019). Similarly, upland game birds (e.g., mourning doves) often ingest spent lead pellets and succumb to lead poisoning (Schulz, Gao, et al., 2007; Schulz, Millspaugh, et al., 2006). However, lead exposure for avian scavengers like bald eagles (Warner et al., 2014) occurs when lead bullet fragments are indirectly ingested when feeding on big-game animal gut piles or carcasses (Haig et al., 2014). Bullet fragments vary in size depending upon firearm used, terminal bullet velocity, and shot placement (Martin et al., 2017; Trinogga et al., 2019; Trinogga et al., 2013). Without intervention, ingestion of lead bullet fragments by bald eagles almost always results in mortality (Golden et al., 2016; Yaw et al., 2017). Lead exposure from recreational hunting is not only a wildlife health issue but also has human health implications (Jones et al., 2009; Simoni, Gallagher, \& Edwards, 2014). The exposure pathway for humans is similar to wildlife, involving consumption of game meat harvested with lead ammunition (Gerofke et al., 2018; Hunt 
et al., 2009; Iqbal et al., 2009), with low-level lead exposure in young children particularly dangerous (Hanna-Attisha et al., 2016; Lidsky \& Schneider, 2006; Winter \& Sampson, 2017).

Lead exposure and possible environmental contamination has resulted in a number of regulatory and voluntary approaches to limit its effect. For example, a ban in the United States (U.S) on lead shotgun ammunition for waterfowl hunting was phased-in during 1987-1991 (Schulz, Padding, et al., 2006; U.S. Department of the Interior - Fish and Wildlife Service, 1988). However, the ban received little support from hunters and was implemented without consulting them (Belanger \& Kinnane, 2002; Ross-Winslow \& Teel, 2011). Some lead ammunition bans have been adopted across multiple continents (Avery \& Watson, 2009; Kanstrup, 2019; Kanstrup \& Balsby, 2019; Scheuhammer \& Norris, 1995), but most hunting with lead ammunition continues (Pierce et al., 2015; Runia \& Solem, 2016; Schulz et al., 2002). At state and local levels, regulations on certain types and sizes of lead-based fishing tackle have also been adopted (Grade et al., 2019; Ross-Winslow \& Teel, 2011; Scheuhammer \& Thomas, 2011).

In contrast to regulatory approaches, local and regional outreach programs encouraging the voluntary use of nonlead hunting ammunition have become popular (Bedrosian et al., 2012; Chase \& Rabe, 2015; Henry, 2016; B. Smith et al., 2017). This popularity stems primarily from the complex web of socio-political issues surrounding this topic (Schulz et al., 2019). Voluntary nonlead outreach programs, however, are more complex than simply sharing information and expecting hunters to change their behavior (Rice \& Atkin, 2013). Many factors influence hunters' ammunition choices such as price, availability, ballistics, lethality or effectiveness, and underlying hunter attitudes 
and beliefs (Case \& Associates, 2014; Pierce et al., 2015; Southwick, 2014; V. G. Thomas, 2013). In response to these issues, there have been numerous recommendations to integrate social science into voluntary nonlead outreach programs for hunting and angling (Grade et al., 2019; Grade et al., 2018; Ross-Winslow \& Teel, 2011; Ross-

Winslow et al., 2011; Schulz et al., 2019). Given the need for additional social science or human dimensions research, this project attempts to identify attitudes of natural resource professionals implementing a nonlead outreach program and assess those attitudes within the context of general mortality and lead poisoning threats to bald eagles, human health lead risks, use of nonlead ammunition, and socio-economic factors of nonlead ammunition. For purposes of this paper, socio-economic factors of nonlead ammunition is defined as social factors such as underlying hunter attitudes and beliefs that shape economic activity related to price and availability of nonlead ammunition.

\subsubsection{Nonlead alternatives and behavioral change}

Human behavior is composed of multiple complex factors, but attitudes are frequently found among theoretical models predicting behavior: e.g., Theory of Reasoned Action (Fishbein, 1979), Theory of Planned Behavior (Ajzen, 1991), Integrated Behavioral Model (Hagger \& Chatzisarantis, 2014; Montano \& Kasprzyk, 2015), Attitude-to-Behavior Process Model (Fazio, Powell, \& Williams, 1989), and Prototype Willingness Model (Gerrard, Gibbons, Houlihan, Stock, \& Pomery, 2008). Compared to the more deeply held constructs of values and beliefs, attitudes refer to favorable or unfavorable feelings about a person, place, issue, or activity (i.e., attitude object) in regards to the behavior of interest (Fulton, Manfredo, \& Lipscomb, 1996; Kollmuss \& 
Agyeman, 2002; Newhouse, 1990; Vaske \& Manfredo, 2012). In other words, attitudes of a behavior or action are based on a parsimonious description of the benefits and disadvantages to an individual (Ross-Winslow et al., 2011). Within the context of natural resource management and policy, understanding attitudinal differences among different groups, and the basis for those differences, is necessary for designing persuasive messages (Schroeder et al., 2012; Sponarski, Vaske, \& Bath, 2015; Vaske \& Manfredo, 2012).

Encouraging hunters and anglers to use nonlead alternatives can be challenging. For example, hunters and ranchers in Arizona, California, and Utah had limited awareness of lead poisoning in California condors (Ross-Winslow et al., 2011; Seng, 2005a). Studies of mourning dove hunters conducted across the U.S. similarly identified limited awareness of lead ammunition risks as well as limited support for nonlead regulations (Case \& Associates, 2014; Levengood et al., 1999; Miller et al., 2013; Schulz, Reitz, et al., 2007). Other studies have identified obstacles among hunters and anglers such as cost, availability, and performance of nonlead alternatives (Goddard et al., 2008; Ross-Winslow \& Teel, 2011; Ross-Winslow et al., 2011). Although hunters in northern Arizona who participated in a voluntary nonlead ammunition program identified increased cost and lower availability of nonlead ammunition as important considerations (Seng, 2005a), these perceived obstacles could be mitigated by increasing awareness and providing a nonlead ammunition voucher (Chase \& Rabe, 2015). These reoccurring perceptions and concerns appear to be common among both hunters and anglers.

With these challenges in mind, several studies have either investigated or recommended the need to change hunters' and anglers' attitudes and behavior toward 
lead poisoning and nonlead alternatives. In the United Kingdom (U.K.), hunter perspectives towards lead ammunition varied but there was a general consensus that lead is toxic, all stakeholders need to participate in policy discussions, and nonlead messages from the shooting community would be persuasive (Newth et al., 2019). Another study of Minnesota small game hunters found simple factual messages, messages with references to reputable hunting organizations, and first-person narratives elicited positive attitudes and greater support for a lead ammunition ban (Schroeder et al., 2012). Furthermore, Schroeder, Fulton, \& DonCarlos (2016) suggested targeting outreach toward hunters who are unlikely supporters of a lead ammunition ban given their negative attitudes regarding a lead ban and outspoken tendency. The need for further social science research on the use of lead ammunition and fishing tackle and nonlead alternatives is frequently acknowledged (Grade et al., 2019; Ross-Winslow \& Teel, 2011; Schulz et al., 2019; V. G. Thomas, 1997; V. G. Thomas \& Guitart, 2003; Trushenski \& Radomski, 2013), but only a few studies have actually explored hunter and angler awareness of the problem and attitudes (Leszek, 2015; Ross-Winslow, 2013; Twiss \& Thomas, 1998).

\subsubsection{Need for study}

Considerable research has examined the risks of lead hunting ammunition and lead fishing tackle, along with a limited number of human dimensions studies, but no research exists on attitudes of natural resource professionals about deer hunting with nonlead ammunition and lead exposure from spent ammunition. These unique stakeholders are important because they directly implement outreach programs aimed at 
affecting deer hunter behavior; understanding their attitudes may be critical to program success. Natural resource professionals often facilitate connections between environmental resources and user groups, yet only limited research has examined their perceptions and attitudes (Balasubramanyam et al., 2019). Spokespersons' knowledge, awareness, and attitudes about environmental issues could influence the behavior of program participants (Marion \& Reid, 2007; Taylor \& Caldarelli, 2004).

Attitudes of natural resource professionals are not only important but may differ among groups of individuals based on behavioral characteristics. Attempts to forge a monolithic group of like-minded natural resource professionals may be counterproductive, however, due to plurality of values and attitudes associated with resource management (Sandbrook, Scales, Vira, \& Adams, 2011). Understanding these differences among groups may provide suggestions for staff training and insights into attitudes of hunters and nonhunters in the general population. For example, Muth et al. (2006) found North American natural resource professionals held similar conflicting views about leghold traps as did public stakeholders. Previous research conducted in the U.S. has also indicated potential differences in attitudes, motivations, and wildlife value orientations between hunters and nonhunters (Fulton et al., 1996; Messmer \& Enck, 2012). Differences in attitudes among hunters about nonlead ammunition and potential lead ammunition bans have also been used to define groups (Epps, 2014; Schroeder et al., 2016; Schroeder et al., 2012).

In addition to the importance of attitudes, several theories suggest multi-stage decisions where individuals exit and reenter the behavioral decision processes given new information, experiences, and underlying changes in attitudes (Vaske \& Manfredo, 2012). 
Examples of decision theories demonstrating a fluid and multi-stage decision processes include the Transtheoretical Model of Behavior Change (Prochaska \& DiClemente, 1983; Prochaska et al., 2015), Information-Processing Model (Marion \& Reid, 2007), Stage Processing Model (Albarracín, 2002) and Diffusion of Innovation - Decision Process (Rogers, 2003). In the context of hunting, deer hunters adopting nonlead ammunition may not continue its use but may revert to lead ammunition. Examining this decisionmaking process can be useful for understanding the complexity and permanence of hunter behaviors.

To address this need, differences in attitudes among U.S. Fish and Wildlife Service (USFWS) staff were examined related to (1) general mortality threats to bald eagles, (2) mortality threats from lead poisoning to bald eagles, (3) potential human health risks related to ingestion of lead bullet fragments in venison, (4) shooting characteristics of nonlead ammunition and its use, and (5) socio-economic factors of nonlead ammunition. These attitudes were compared between: (1) hunters and nonhunters, (2) hunters using nonlead ammunition and those using lead, and (3) hunters likely and unlikely to use nonlead ammunition in the future. For simplicity, USFWS staff who hunted deer are referred to as 'hunters' and those who were non-deer hunters as 'nonhunters'.

\subsection{Methods}

\subsubsection{Sample and outreach program}

This study was part of a larger project assessing a USFWS pilot outreach program during 2016-2018 on 54 NWRs in Illinois, Iowa, Indiana, Michigan, Minnesota, 
Missouri, Nebraska, Ohio, and Wisconsin. Socio-political factors prevented surveying hunters from the general public, but factors of hunter and nonhunter USFWS NWR field staff were explored concerning beliefs, attitudes, intentions, and behaviors about potential lead risks to wildlife and humans, and nonlead hunting ammunition. Email addresses of potential survey participants were provided by USFWS regional administrators and consisted of all NWR staff from all the participating refuges $(2018 n=321$, and $2019 n=$ 315). Specifically, study participants were considered natural resource professionals which included NWR managers, assistant managers, visitor services specialists, administrative support staff, technicians, and maintenance staff. The only excluded USFWS regional staff were those in the central regional office and those not affiliated with NWRs.

\subsubsection{Survey instrument and implementation}

The survey used items modified from previous research on nonlead ammunition and lead poisoning in wildlife (Case \& Associates, 2006, 2014; Duda, 2004; Seng, 2005a) since no standardized scale was available. Attitudes were examined concerning factors affecting bald eagle mortality (seven items), lead poisoning in bald eagles (eight items), human health risk from ingesting lead fragments in venison (four items), use of nonlead factors (six items), and socio-economics factors of nonlead ammunition (seven items). Each question used a 5-point scale ( $1=$ strongly disagree to $5=$ strongly agree). Participants indicated if they were a hunter, if they currently used nonlead ammunition, and their intention to use nonlead. 
The survey was conducted after the 2017 and 2018 deer hunting seasons via Qualtrics software version 2018, using a modified Dillman technique starting with a prenotification email and ending with five email reminders (Dillman, Smyth, \& Melani Christian, 2014). All email addresses were valid and deliverable. The survey response rate was $52.0 \%$ in $2018(n=167)$ and $62.5 \%$ in $2019(n=197)$. Nonresponse bias was checked using a shortened survey containing eight questions (responses in $2018 n=26$; responses in $2019 n=21$ ) and evaluated at $p<.05$ significance level. For categorical data, no significant differences emerged between respondents to the full survey and respondents to the shortened survey based on deer hunter status $\left(\chi^{2}(1, n=377)=3.260\right.$, $p=.071)$, use of nonlead ammunition $\left(\chi^{2}(1, n=193)=.011, p=.915\right)$, year in the outreach program $\left(\chi^{2}(3, n=377)=2.836, p=.418\right)$, current residence $\left(\chi^{2}(3, n=377)=\right.$ $.629, p=.890)$, or gender $\left(\chi^{2}(2, n=373)=5.994, p=.050\right)$. It is worth noting the significance value for gender was $p=.05$ and may warrant some consideration because females would have been more likely to be nonrespondents. There were no concerns with continuous variables and unequal variances between group means. There were no significant differences between the means of the respondents and nonrespondents for age $(t(409)=1.220, p=.223)$, opinion about effect of ingesting lead bullet fragments by eagles $(t(373)=.803, p=.422)$, and opinion about effect of ingesting lead bullet fragments by people $(t(371)=.695, p=.487)$. Because no significant differences emerged between the 2018 and 2019, analysis used 2019 data unless a respondent only completed the 2018 survey. This resulted in a final sample of $n=235$ ( $n=197$ from 2019 plus $n=38$ from 2018). 


\subsubsection{Data analysis}

All statistical analyses used IBM-SPSS and AMOS version 25 software. Latent variables were created for general mortality threats to bald eagles, lead poisoning in bald eagles, lead exposure risk in people, shooting characteristics of nonlead ammunition, and socio-economic factors related to the use of nonlead. Latent variable items worded in the reverse direction were recoded for consistent directionality. The validity of latent variables were assessed through confirmatory factor analysis using maximum likelihood estimation, missing data (8-10 cases per variable) were replaced using linear trend at point method (Kline, 2016), and error terms were allowed to covary based on examination of modification indices where appropriate (Diamantopoulos, Siguaw, \& Siguaw, 2000; Garson, 2014). Three measures showed acceptable model fit (CabreraNguyen, 2010; Hooper, Coughlan, \& Mullen, 2008): root mean square error of approximation (RMSEA, .053), incremental fit index (IFI, .903) and comparative fit index (CFI, .900). In addition, Cronbach's alpha (Cortina, 1993) showed high internal reliability of the five latent variables $(\alpha=.75-.79)$ except for socio-economic factors of nonlead ammunition $(\alpha=.55)$ but item deletion would not improve reliability.

Although the primary analysis used latent variables, individual items were retained for analysis given the exploratory and applied nature of this study. Independent sample t-tests, using listwise deletion, examined differences in attitudes by hunter status (hunter vs. non-hunter), ammunition use (lead vs. nonlead) and ammunition intensions (unlikely vs. likely nonlead use), and evaluated at $p<.05$. Assumptions for normality were tested and homogeneity of variance with equal variances was not assumed. 


\subsection{Results}

\subsubsection{Respondent characteristics}

The average age of the USFWS staff was 46.6 years $(n=195, S D=10.0$ years), with respondents predominately male $(71.5 \%)$, and most having obtained at least a bachelor's degree (80.5\%; Table 4.1). Of the respondents, $61.0 \%(n=130)$ identified as hunters and 39.0\% $(n=83)$ as nonhunters. Among hunters, 59.5\% $(n=66)$ used lead ammunition while $40.5 \%(n=45)$ reported using nonlead ammunition. Roughly twothirds $(68.5 \% ; n=76)$ of hunters intended to continue or convert to using nonlead ammunition, while $31.5 \%(n=35)$ of hunters indicated they were unlikely to use nonlead.

Although not used for subsequent analysis due to small subgroup sample size, a further breakdown of results from this survey showed intentions sometimes differed from current behavior. Hunters currently using lead ammunition were grouped by nonlead intentions: $59.1 \%$ ( $n=39$ of 66 using lead ammunition) reported positive intentions to convert to nonlead while $40.9 \%$ ( $n=27$ of 66 using lead ammunition) intended to continue using lead. Further, most hunters who reported using nonlead ammunition indicated they would likely continue using it $(82.2 \% ; n=37$ of 45 using nonlead ammunition), yet $17.8 \%$ ( $n=8$ of 45 using nonlead ammunition) said they were unlikely to use nonlead ammunition in the future.

\subsubsection{Mortality threats to bald eagles}

Nonhunters felt more strongly than hunters that bald eagles face mortality threats $(t(190)=-4.17, p<.001)$, but there were no significant differences between hunters' 
nonlead ammunition use, or intentions to use nonlead (Table 4.2). At the item level, nonhunters agreed more strongly than hunters that bald eagle mortality threats include poisoning through illegal use of pesticides or herbicides $(t(189)=-3.58, p<.001)$, ingesting lead bullet fragments in deer gut piles or carcasses $(t(206)=-6.20, p<.001)$, and poaching or illegal shooting $(t(196)=-2.47, p=.01)$. It is worth noting that while not technically meeting the criteria of $p<.05$, nonhunters also agreed more strongly than hunters that bald eagle mortality threats include collisions with wind turbines $(t(170)=-$ $1.99, p=.05)$. In addition, hunters using lead ammunition agreed more strongly than those using nonlead that power line collisions were an important bald eagle threat $(t(85)$ $=-2.90, p<.001)$, while likely nonlead ammunition users agreed more strongly than unlikely nonlead users that ingesting lead bullet fragments in deer gut piles was a serious threat to bald eagles $(t(56)=-3.82, p<.001)$.

\subsubsection{Lead poisoning in bald eagles}

Differences emerged across all three groups regarding attitudes about the risk of lead poisoning in bald eagles: nonhunters felt more strongly than hunters $(t(205)=-6.63$, $p<.001)$, nonlead ammunition users felt more strongly than lead ammunition users $(t$ $(96)=2.41, p=.02)$, and likely nonlead ammunition users felt more strongly than unlikely nonlead users $(t(58)=-3.64, p<.001$; Table 4.3). Specifically, nonhunters agreed more strongly than hunters that ingesting lead bullet fragments was a serious problem for bald eagles $(t(207)=-6.41, p<.001)$, using nonlead ammunition will reduce bald eagle deaths $(t(206)=-6.33, p<.001)$, and small amounts of lead can poison a bald eagle $(t(173)=-2.98, p<.001)$. Hunters, however, agreed more strongly than 
nonhunters that the issue of lead poisoning in bald eagles was a tactic to advance guncontrol regulations $(t(207)=5.85, p<.001)$, some eagles might get sick from lead exposure but most recover $(t(172)=2.38, p=.02)$, and the issue of lead poisoning in bald eagles was being used by some groups to stop hunting $(t(191)=4.31, p<.001)$. Nonlead users agreed more strongly than lead users that nonlead ammunition would reduce bald eagle deaths $(t(92)=2.20, p=.03)$. In addition, nonlead users also agreed more strongly than lead users that small amounts of lead could poison a bald eagle $(t(90)=1.99, p=.053)$, although this finding failed to meet the $p<.05$ threshold. Likely nonlead users agreed more strongly than unlikely nonlead users that ingesting lead bullet fragments is a serious problem for eagles $(t(56)=-3.83, p<.001)$, nonlead ammunition will reduce eagle mortality $(t(58)=-3.95, p<.001)$ and small amounts of lead can poison an eagle $(t(57)=-.394, p<.001)$. Unlikely nonlead users agreed more strongly than likely nonlead users that the issue of lead poisoning in eagles is gun control tactic $(t$ $(52)=2.07, p=.04)$.

\subsubsection{Lead exposure risk in people}

Attitudes about potential human health risks related to ingestion of lead bullet fragments in venison showed nonhunters agreed more strongly than hunters $(t(169)=-$ $3.57, p<.001$ ), and likely nonlead hunters agreed more strongly than unlikely nonlead users $(t(55)=-3.93, p<.001)$ about the importance of the health risks; there were no significant differences between nonlead and lead ammunition users (Table 4.4). Specifically, nonhunters agreed more strongly than hunters that human lead exposure is preventable $(t(182)=-3.17, p<.001)$, lead bullet fragments pose a human health risk $(t$ 
$(139.1)=-3.144, p=.002)$, and small amounts of lead can negatively affect a person $(t$ $(191)=-3.55, p<.001)$. Likely nonlead users, however, agreed more strongly than unlikely nonlead users that lead poisoning in people may not always be obvious $(t(68)=$ $-2.39, p=.02)$, human lead poisoning may be preventable $(t(61)=-2.14, p=.04)$, lead bullet fragments in venison pose a human health risk $(t(53)=-3.62, p<.001)$, and small amounts of lead can negatively affect a person $(t(60)=-2.98, p<.001)$.

\subsubsection{Shooting characteristics of nonlead}

Current nonlead users agreed more strongly than lead users $(t(98)=5.64, p<$ $.001)$ and likely nonlead users agreed more strongly than unlikely nonlead users $(t(60)=$ $-3.92, p=.001)$ about the benefits of using nonlead; there were no significant differences between hunters and nonhunters (Table 4.5). When comparing individual items, nonhunters agreed more strongly than hunters that nonlead was ballistically superior $(t$ $(193)=-2.95, p<.001)$. On the other hand, nonlead users agreed more strongly than lead users that nonlead was ballistically superior $(t(87)=2.74, p=.01)$, nonlead was compatible with modern firearms $(t(98)=4.03, p<.001)$, and there was minimal complexity using nonlead $(t(79)=2.14, p=.04)$. Hunters who used lead ammunition, however, agreed more strongly than nonlead users that nonlead damages firearms $(t$ (102) $=-4.96, p<.001)$, nonlead was not accurate $(t(104)=-4.38, p<.001)$, and lead was more effective in killing deer $(t(102)=-5.07, p<.001)$. Finally, likely nonlead users agreed more strongly than unlikely users that nonlead was ballistically superior $(t(56)=-$ $2.32, p=.02)$, compatible with modern firearms $(t(66)=-2.96, p<.001)$, and minimal complexity using nonlead $(t(63)=-3.65, p<.001)$. Unlikely nonlead users, however, 
agreed more strongly than likely users that lead was more effective killing deer $(t(68)=$ $4.39, p<.001)$.

\subsubsection{Socio-economic nonlead ammunition factors}

Nonhunters $(t(205)=-4.83, p<.001)$ and nonlead users $(t(75)=3.24, p=.002)$ agreed more strongly about socio-economic factors of nonlead ammunition compared to their counterparts; there were no significant differences between likely and unlikely intentions to use nonlead (Table 4.6). Comparisons of individual socio-economic factors of nonlead ammunition showed hunters agreed more strongly than nonhunters that none of their friends or relatives used nonlead $(t(206)=4.73, p<.001)$, it was difficult to find in stores $(t(190)=2.98, p<.001)$, difficult to determine nonlead by looking at the package $(t(199)=2.18, p=.03)$, and lead ammunition was less expensive $(t(185)=$ $2.95, p<.001)$. Alternatively, nonhunters agreed more strongly than hunters that shooting demonstrations would show the benefits of using nonlead $(t(201)=-2.22, p=$ .03). Nonlead users agreed more strongly than lead users that they had no friends or relatives who used nonlead ammunition $(t(86)=-3.73, p<.001)$, nonlead ammunition cost too much $(t(89)=-2.54, p=.01)$, and was difficult to find in stores $(t(75)=-2.28, p$ $=.03$ ). Nonlead users, however, agreed more strongly than hunters that shooting demonstrations would help show the benefits of using nonlead $(t(96)=2.60, p=.01)$. Likely nonlead users agreed more strongly than unlikely users that voucher programs would help encourage the voluntary use of nonlead $(t(71)=-2.19, p=.03)$ along with shooting demonstrations $(t(57)=-2.91, p=.01)$. Alternatively, unlikely nonlead users 
agreed more strongly than likely users that they had no friends or relatives who used nonlead ammunition $(t(68)=2.21, p=.03)$.

\subsection{Discussion}

This exploratory survey focused solely on attitudes of natural resource professionals on NWRs by examining differences among groups based on hunter status, current ammunition use, and ammunition intentions. Compared to hunters, nonhunters more strongly agreed with general mortality threats to bald eagles, suggesting the relative importance of nonhunters as stakeholders in voluntary nonlead outreach programs. Although previous research focused on hunter awareness of lead poisoning in wildlife and factors influencing nonlead use (e.g., Chase \& Rabe, 2015; Duda, 2004), attitudes of nonhunters may be more important than previously considered given the number of nonhunters is more than twice the number of anglers and hunters combined (U.S. Department of Interior - U.S. Fish and Wildlife Service \& U.S. Department of Commerce - U.S. Census Bureau, 2018). Given their relative numbers and increased awareness of the threats to bald eagles, nonhunters may help expand awareness of the issue and greater support for nonlead programs. In addition to general mortality issues for bald eagles nonhunters, nonlead users, and likely nonlead users more strongly agreed than their counterparts about mortality threats from lead ammunition to bald eagles. These findings also demonstrate the importance of including nonhunters as stakeholders in existing typologies (Epps, 2014; Messmer \& Enck, 2012) and may be useful for nonlead outreach efforts in the future. Therefore, nonhunters can play a dual role by being both recipients of information and potentially influencing hunters to use nonlead ammunition. 
Earlier research has documented concerns about human health risk from ingesting lead bullet fragments in venison (Gerofke et al., 2018; Hunt et al., 2009; Iqbal et al., 2009). Concern was expressed by nonhunters, nonlead users, and likely nonlead hunters more strongly in our survey than their counterparts suggesting this topic deserves more attention. Given the importance of nonhunters mentioned above, targeting nonhunting friends and relatives of hunters with nonlead messages about the health benefits of leadfree venison may promote social norms for greater nonlead use among hunters. Widespread concerns about lead exposure from drinking water (Hanna-Attisha, 2018; Hanna-Attisha et al., 2016) may amplify awareness of human health risks from lead ammunition and the health benefits of using nonlead. Current nonlead outreach could be expanded to include venison donations at community food banks by promoting the voluntary use of nonlead ammunition to ensure venison is a healthy food source. However, overlapping jurisdictions of multiple government agencies dealing with human health risk from lead ammunition will require stronger public-private collaborations (Donahue \& Zeckhauser, 2011; Huxham, Vangen, Huxham, \& Eden, 2000) among natural resource managers, hunting organizations, ammunition and firearms manufacturers, hunting-related equipment manufacturers and retailers, public health officials, and local food banks.

Findings from this project also confirm the importance of attitudes about ballistics, cost, and availability of nonlead ammunition found in previous research (Pierce et al., 2015; V. G. Thomas, 2013). Specific attitudes of nonlead users and likely nonlead users were more positive than their counterparts about ballistic superiority of nonlead, compatibility with modern firearms, and simplicity of converting to nonlead. Arizona 
big-game hunters had similar concerns about ballistic performance of nonlead ammunition, difficulty finding it in stores, ambiguous packaging, perceived firearms damage, greater nonlead costs, and less effectiveness killing deer (Chase \& Rabe, 2015). Similar concerns have also been expressed for big-game hunting (Kanstrup \& Thomas, 2019; Ross-Winslow, 2013; Stake, 2019; V. G. Thomas, 2013) and small game hunting (Belanger \& Kinnane, 2002; Case \& Associates, 2014; Pierce et al., 2015; Schulz, Padding, et al., 2006). Also, nonhunters, nonlead users, and likely nonlead users from this survey more strongly agreed about socio-economic factors of nonlead ammunition than their counterparts. Specifically, nonlead vouchers and shooting demonstrations showed stronger agreement among nonhunters, nonlead users, and likely nonlead users These findings are consistent with previous California condor nonlead outreach (B. Smith et al., 2017; Stake, 2019) which showed hunter support for nonlead voucher programs and shooting demonstrations. Results from this survey confirmed previous research demonstrating the importance of friends and family in recognizing hunter satisfactions and motivations (Black et al., 2018; Decker \& Connelly, 1989). Recognizing and addressing attitudes about ballistics, cost, availability, vouchers, demonstrations, and normative relationships may be important considerations for nonlead outreach programs in the future. In other words, the first step in successful outreach programs is identification of potential barriers to achieving the targeted behavior (McKenzie-Mohr, 2000; Schultz, 2002).

These results show the complexity of developing nonlead outreach programs, mainly due to the diversity and overlap of attitudes among groups of natural resource professionals. For example, audience segmentation of the target population is an 
important communication strategy by defining groups by attitudes toward the behavior, behavioral frequency, or demographic characteristics of hunters and nonhunters (Andersen et al., 2014; T. Cheng, Woon, \& Lynes, 2011; Maibach, 1993; K. J. Ward et al., 2008). These findings align with Schroeder et al. (2016) who suggested audiences supportive of a lead ammunition ban more strongly responded to positive behavioral outcomes while negative behavioral outcomes resonated more strongly with hunters opposing a lead ammunition ban. Understanding attitudinal differences and overlap among groups is critical given the inertia of overcoming the long-established tradition of using lead ammunition.

Attitudes among groups from this limited survey of natural resource professionals on NWRs overlapped and showed stronger agreement among nonhunters, hunters using nonlead ammunition, and likely nonlead hunters. Similarly, nonhunters and nonlead users agreed more strongly than their counterparts about the socio-economic factors of using nonlead. While exploring risks associated with lead ammunition among U.K. stakeholders, individuals open to change and those favoring the status quo were able to find consensus among several factors; e.g., all stakeholders should be included in policy decisions (Newth et al., 2019). Recognizing attitudinal similarities and differences among comparison groups may improve the effectiveness of future outreach efforts by helping reach different segments of the target population (Atkin \& Rice, 2013; Dervin \& Foreman-Wernet, 2013).

In addition to audience segmentation based on attitudinal differences, multiple decision-making models (Marion \& Reid, 2007; Prochaska et al., 2015; Rogers, 2003) demonstrate the challenges of making lasting behavioral changes. Roughly one in five 
hunters from our survey of natural resource professionals would unlikely continue using nonlead. This suggests continuing emphasis on the benefits of using nonlead to solidify the behavior over time. The relatively small number of nonlead hunters returning to lead ammunition in this study may represent a larger proportion in the general deer hunter population. From an outreach standpoint, these natural resource professionals who are also hunters may have an unanticipated negative effect on program outcomes. To avoid the possibility of these negative consequences, additional staff training may help convey consistent positive messages about the use of nonlead ammunition to deer hunters in the general population. Also, the relatively large proportion of deer hunters who used nonlead ammunition in this study compared to other studies (Chase \& Rabe, 2015; Duda, 2004) was possibly a best-case scenario given participants had exposure to outreach materials and experience implementing the program.

\subsection{Conclusions and future research}

Our data from natural resource professionals demonstrate the ongoing need to incorporate social science into outreach programs (Manfredo, Teel, Gavin, \& Fulton, 2014), especially those programs attempting to change hunter attitudes, intentions, and behavior toward the use of nonlead ammunition as echoed by others (Cromie, Newth, \& Strong, 2019; Grade et al., 2019; Newth et al., 2019; Ross-Winslow \& Teel, 2011). Contrary to many local or regional nonlead programs (Schulz et al., 2019), future outreach will likely be more complex than simply sharing information or increasing awareness about lead poisoning (Alberini \& Segerson, 2002; Segerson, 2013a) based solely on a lack of understanding and awareness (Burgess, Harrison, \& Filius, 1998; 
Dearing, 2009). Natural resource professionals, both hunters and nonhunters, will play an influential role encouraging hunters in the general population by fostering normative beliefs while being viewed as knowledgeable about lead poisoning and experienced with using nonlead ammunition (Balasubramanyam et al., 2019; Montano \& Kasprzyk, 2015). Limited sample sizes prevented evaluation of predictive behavioral models of deer hunters' voluntary use of nonlead ammunition or further breakdowns of ammunition use and intentions. This study examined on USFWS natural resource professionals on NWRs, so results cannot be generalized to the general hunting or nonhunting publics. A larger and random sample of deer hunters across a broad region of the country would allow researchers to explore relationships among attitudes about nonlead ammunition, norms, self-efficacy, and intentions yielding information to the broader hunting community. A better understanding of these relationships would be helpful to improve the effectiveness of nonlead messages across hunters and nonhunters. Future research could focus on using social psychological theory to explore relationships among independent variables contributing to behavior change; e.g., the Theory of Planned Behavior (Fishbein, 2008; Hrubes, Ajzen, \& Daigle, 2001), Integrated Behavioral Model (Montano \& Kasprzyk, 2015), Transtheoretical Model (Prochaska et al., 2015), or Diffusion of Innovation (Rogers, 2003; Schulz et al., 2019). These frameworks provide a rich research agenda for testing the efficacy of different messages and lasting behavior change by different audiences or adopter categories. Future research into the relative importance of different elements within the stage-of-change models (Albarracín, 2002; Prochaska et al., 2015; Rogers, 2003) also would prove valuable in understanding the decision-making process for using nonlead ammunition, and why some nonlead hunters 
intend to return to using lead ammunition. Researchers may also want to compare values, beliefs, and attitudes toward nonlead ammunition across a broader cross-section of natural resource professionals and hunters in the general public to improve communication strategies and messaging. Also, additional research is needed focusing on further refining scales for latent variables. Within the context of designing new information campaigns, there appears to be a need for multiple messages targeted toward various audiences (i.e., hunters, nonhunters, and likely/unlikely nonlead ammunition users). 
Table 4.1. Characteristics of U.S. Fish and Wildlife Service (USFWS) National Wildlife Refuge (NWR) staff in the Upper Midwest implementing an outreach program encouraging the voluntary use of nonlead hunting ammunition during 2017-2018.

\begin{tabular}{|c|c|}
\hline Characteristic & $n(\%)$ \\
\hline \multicolumn{2}{|l|}{ Gender } \\
\hline Male & $148(71.5)$ \\
\hline Female & $57(27.5)$ \\
\hline Other & $2(1.0)$ \\
\hline \multicolumn{2}{|l|}{ Background } \\
\hline Large city or urban area & $19(9.0)$ \\
\hline Suburban area & $45(21.4)$ \\
\hline Small city or town & $48(22.9)$ \\
\hline Rural area & $98(46.7)$ \\
\hline \multicolumn{2}{|l|}{ Residence } \\
\hline Large city or urban area & $13(6.2)$ \\
\hline Suburban area & $23(11.0)$ \\
\hline Small city or town & $74(35.2)$ \\
\hline Rural area & $100(47.6)$ \\
\hline \multicolumn{2}{|l|}{ Education } \\
\hline Less than high school & $1(0.5)$ \\
\hline Some high school, graduate, or equivalent & $5(2.4$ \\
\hline Some college, no degree & $19(9.0)$ \\
\hline Associates degree & $16(7.6)$ \\
\hline Bachelor's degree & $101(48.1)$ \\
\hline Master's degree & $64(30.5)$ \\
\hline Professional degree & $1(0.5)$ \\
\hline Doctorate degree & $3(1.4)$ \\
\hline \multicolumn{2}{|l|}{ Deer Hunter Status } \\
\hline Yes & $130(61.0)$ \\
\hline No & $83(39.0)$ \\
\hline \multicolumn{2}{|l|}{ Current Ammunition Use } \\
\hline Nonlead & $45(40.5)$ \\
\hline Lead & $66(59.5)$ \\
\hline \multicolumn{2}{|l|}{ Likelihood of nonlead use } \\
\hline Unlikely & $35(31.5)$ \\
\hline Likely & $76(68.5)$ \\
\hline
\end{tabular}


Table 4.2. Attitudes about general mortality threats to bald eagles of U.S. Fish and Wildlife Service (USFWS) National Wildlife Refuge (NWR) staff in the Upper Midwest implementing an outreach program encouraging the voluntary use of nonlead hunting ammunition during 2017-2018.

\begin{tabular}{|c|c|c|c|c|c|c|c|c|c|c|c|c|c|c|c|}
\hline \multirow[t]{3}{*}{ Attitude } & \multicolumn{5}{|c|}{ Deer hunter } & \multicolumn{5}{|c|}{$\mathrm{NonPb}^{1}$ use } & \multicolumn{5}{|c|}{$\mathrm{NonPb}$ intention } \\
\hline & \multirow{2}{*}{$\begin{array}{c}\text { Yes } \\
(n=129) \\
M(S D) \\
\end{array}$} & \multirow{2}{*}{$\begin{array}{c}\text { No } \\
(n=81) \\
M(S D) \\
\end{array}$} & \multicolumn{3}{|c|}{ Test statistic } & \multirow{2}{*}{$\begin{array}{c}\text { Yes } \\
(n=45) \\
M(S D)\end{array}$} & \multirow{2}{*}{$\begin{array}{c}\text { No } \\
(n=65) \\
M(S D)\end{array}$} & \multicolumn{3}{|c|}{ Test statistic } & \multirow{2}{*}{$\begin{array}{l}\text { Unlikely } \\
(n=34) \\
M(S D)\end{array}$} & \multirow{2}{*}{$\begin{array}{l}\text { Likely } \\
(n=76) \\
M(S D)\end{array}$} & \multicolumn{3}{|c|}{ Test statistic } \\
\hline & & & $t$ & $d f$ & $p$ & & & $t$ & $d f$ & $p$ & & & $t$ & $d f$ & $p$ \\
\hline $\begin{array}{l}\text { General mortality threats } \\
(\alpha=.76)\end{array}$ & $3.62(.57)$ & $3.92(.49)$ & -4.17 & 190 & $<.001$ & $3.60(.70)$ & $3.65(.56)$ & -.41 & 81 & .68 & $3.50(.57)$ & $3.68(.64)$ & -1.51 & 71 & .13 \\
\hline $\begin{array}{l}\text { Collisions with wind } \\
\text { turbines }\end{array}$ & $3.47(.80)$ & $3.69(.80)$ & -1.99 & 170 & .05 & $3.42(.89)$ & $3.48(.79)$ & -.33 & 87 & .74 & $3.26(.86)$ & $3.54(.81)$ & -1.57 & 60 & .12 \\
\hline $\begin{array}{l}\text { Flying into windows } \\
\text { on buildings }\end{array}$ & $2.75(.81)$ & $2.98(.82)$ & -1.93 & 168 & .06 & $2.82(.81)$ & $2.75(.83)$ & .43 & 97 & .67 & $2.76(.74)$ & $2.79(.85)$ & -.15 & 73 & .88 \\
\hline Habitat loss & $3.79(1.01)$ & $4.04(.98)$ & -1.76 & 173 & .08 & $3.80(1.14)$ & $3.72(.99)$ & .37 & 86 & .71 & $3.65(1.10)$ & $3.80(1.03)$ & -.70 & 60 & .49 \\
\hline $\begin{array}{l}\text { Poisoning through } \\
\text { illegal use of } \\
\text { pesticides or } \\
\text { herbicides }\end{array}$ & $3.88(.92)$ & $4.31(.78)$ & -3.58 & 189 & $<.001$ & $3.84(1.15)$ & $4.00(.77)$ & -.79 & 71 & .43 & $3.91(.87)$ & $3.95(.98)$ & -.19 & 71 & .85 \\
\hline $\begin{array}{l}\mathrm{Pb} \text { poisoning from } \\
\text { ingesting } \mathrm{Pb} \text { bullet } \\
\text { fragments in deer gut } \\
\text { piles or carcasses }\end{array}$ & $3.95(1.02)$ & $4.63(.58)$ & -6.20 & 206 & $<.001$ & $4.11(1.13)$ & $3.74(1.06)$ & 1.74 & 91 & .09 & $3.29(1.14)$ & $4.16(.98)$ & -3.82 & 56 & $<.001$ \\
\hline $\begin{array}{l}\text { Poaching or illegal } \\
\text { shooting }\end{array}$ & $3.68(.95)$ & $3.98(.76)$ & -2.47 & 196 & .01 & $3.62(.98)$ & $3.82(.93)$ & -1.03 & 92 & .30 & $3.82(.67)$ & $3.70(1.06)$ & .75 & 95 & .45 \\
\hline Power line collisions & $3.80(.82)$ & $3.85(.76)$ & -.48 & 180 & .63 & $3.56(.89)$ & $4.03(.77)$ & -2.90 & 85 & $<.001$ & $3.79(.73)$ & $3.86(.90)$ & -.38 & 78 & .71 \\
\hline
\end{tabular}

Note: $p<.05$ are bolded. Mean scores are based on a five-point scale where $1=$ strongly disagree and $5=$ strongly agree. ${ }^{1} \mathrm{NonPb}=$ nonlead. 
Table 4.3. Attitudes about mortality threats from lead $(\mathrm{Pb})$ poisoning to bald eagles of U.S. Fish and Wildlife Service (USFWS) National Wildlife Refuge (NWR) staff in the Upper Midwest implementing an outreach program encouraging the voluntary use of nonlead hunting ammunition during 2017-2018.

\begin{tabular}{|c|c|c|c|c|c|c|c|c|c|c|c|c|c|c|c|}
\hline \multirow[t]{3}{*}{ Attitude } & \multicolumn{5}{|c|}{ Deer hunter } & \multicolumn{5}{|c|}{$\mathrm{NonPb}^{1}$ use } & \multicolumn{5}{|c|}{ NonPb intention } \\
\hline & \multirow{2}{*}{$\begin{array}{c}\text { Yes } \\
(n=129) \\
M(S D)\end{array}$} & \multirow{2}{*}{$\begin{array}{c}\text { No } \\
(n=80) \\
M(S D)\end{array}$} & \multicolumn{3}{|c|}{ Test statistic } & \multirow{2}{*}{$\begin{array}{c}\text { Yes } \\
(n=45) \\
M(S D)\end{array}$} & \multirow{2}{*}{$\begin{array}{c}\text { No } \\
(n=65) \\
M(S D)\end{array}$} & \multicolumn{3}{|c|}{ Test statistic } & \multirow{2}{*}{$\begin{array}{l}\text { Unlikely } \\
(n=34) \\
M(S D)\end{array}$} & \multirow{2}{*}{$\begin{array}{l}\text { Likely } \\
(n=76) \\
M(S D)\end{array}$} & \multicolumn{3}{|c|}{ Test statistic } \\
\hline & & & $t$ & $d f$ & $p$ & & & $t$ & $d f$ & $p$ & & & $t$ & $d f$ & $p$ \\
\hline $\begin{array}{l}\text { Mortality threats from } \mathrm{Pb} \\
\text { exposure }(\alpha=.77)\end{array}$ & $3.51(.62)$ & $4.00(.43)$ & -6.63 & 205 & $<.001$ & $3.64(.62)$ & $3.35(.63)$ & 2.41 & 96 & .02 & $3.14(.65)$ & $3.62(.58)$ & -3.64 & 58 & .001 \\
\hline $\begin{array}{l}\text { Ingesting } \mathrm{Pb} \text { bullet } \\
\text { fragments is a serious } \\
\text { problem for bald eagles }\end{array}$ & $3.75(1.10)$ & $4.54(.67)$ & -6.41 & 207 & $<.001$ & $3.93(1.18)$ & $3.52(1.15)$ & 1.82 & 93 & .07 & $3.06(1.20)$ & $3.97(1.05)$ & -3.83 & 56 & $<.001$ \\
\hline $\begin{array}{l}\text { NonPb ammunition use will } \\
\text { reduce bald eagle deaths }\end{array}$ & $3.83(.99)$ & $4.51(.57)$ & -6.33 & 206 & $<.001$ & $4.04(1.02)$ & $3.62(.98)$ & 2.20 & 92 & .03 & $3.24(1.02)$ & $4.04(.92)$ & -3.95 & 58 & $<.001$ \\
\hline $\begin{array}{l}\text { Small amounts of } \mathrm{Pb} \text { can } \\
\text { poison a bald eagle }\end{array}$ & $4.21(.70)$ & $4.50(.68)$ & -2.98 & 173 & $<.001$ & $4.36(.74)$ & $4.08(.69)$ & 1.99 & 90 & .05 & $3.79(.73)$ & $4.37(.65)$ & -3.94 & 57 & $<.001$ \\
\hline $\begin{array}{l}\text { There is insufficient } \\
\text { scientific information } \\
\text { supporting lead poisoning of } \\
\text { bald eagles }(\mathrm{R})\end{array}$ & $2.63(1.24)$ & $2.40(1.40)$ & 1.19 & 153 & .24 & $2.62(1.43)$ & $2.75(1.15)$ & -.51 & 81 & .61 & $2.85(1.02)$ & $2.63(1.36)$ & .94 & 84 & .35 \\
\hline $\begin{array}{l}\text { Bald eagle populations are } \\
\text { increasing despite ingesting } \\
\mathrm{Pb} \text { bullet fragments }(\mathrm{R})\end{array}$ & $3.66(.76)$ & $3.49(.66)$ & 1.73 & 185 & .08 & $3.67(.88)$ & $3.75(.69)$ & -.56 & 79 & .58 & $3.76(.89)$ & $3.70(.71)$ & .39 & 53 & .70 \\
\hline $\begin{array}{l}\mathrm{Pb} \text { poisoning in bald eagles } \\
\text { is used to advance gun- } \\
\text { control }(\mathrm{R})\end{array}$ & $2.11(1.10)$ & $1.39(.68)$ & 5.85 & 207 & $<.001$ & $1.91(1.06)$ & $2.29(1.18)$ & -1.77 & 101 & .08 & $2.50(1.31)$ & $1.97(1.03)$ & 2.07 & 52 & .04 \\
\hline $\begin{array}{l}\text { Some eagles might get sick } \\
\text { from } \mathrm{Pb} \text { lead bullet } \\
\text { fragments but most recover } \\
(\mathrm{R})\end{array}$ & $2.57(.90)$ & $2.28(.87)$ & 2.38 & 172 & .02 & $2.44(.94)$ & $2.71(.90)$ & -1.47 & 92 & .15 & $2.79(.73)$ & $2.51(.99)$ & 1.67 & 84 & .10 \\
\hline
\end{tabular}




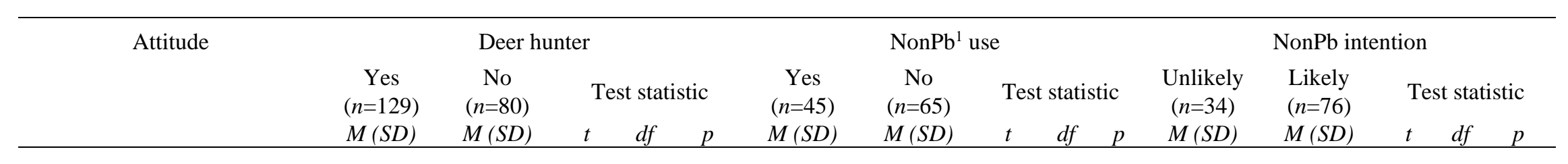

$\mathrm{Pb}$ poisoning in bald eagles is as an attempt to stop

$\begin{array}{llllllllllllll}2.71(1.24) & 2.03(1.02) & 4.31 & 191 & <.001 & 2.56(1.24) & 2.91(1.21) & -1.48 & 93 & .14 & 3.03(1.14) & 2.64(1.25) & 1.59 & 69\end{array}$ hunting

Note: $(\mathrm{R})$ denotes reverse-coded item for the latent variable; $p<.05$ are bolded. Mean scores are based on a five-point scale where $1=$ strongly disagree and $5=$ strongly agree. ${ }^{1} \mathrm{NonPb}=$ nonlead. 
Table 4.4. Attitudes about potential human health risks related to ingestion of lead $(\mathrm{Pb})$ bullet fragments in venison of U.S. Fish and Wildlife Service (USFWS) National Wildlife Refuge (NWR) staff in the Upper Midwest implementing an outreach program encouraging the voluntary use of nonlead hunting ammunition during 2017-2018.

\begin{tabular}{|c|c|c|c|c|c|c|c|c|c|c|c|c|c|c|c|}
\hline \multirow[t]{3}{*}{ Attitude } & \multicolumn{5}{|c|}{ Deer hunter } & \multicolumn{5}{|c|}{$\mathrm{NonPb}^{1}$ use } & \multicolumn{5}{|c|}{ NonPb intention } \\
\hline & \multirow{2}{*}{$\begin{array}{c}\text { Yes } \\
(n=128) \\
M(S D)\end{array}$} & \multirow{2}{*}{ 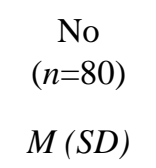 } & \multicolumn{3}{|c|}{ Test statistic } & \multirow{2}{*}{$\begin{array}{c}\text { Yes } \\
(n=45) \\
M(S D)\end{array}$} & \multirow{2}{*}{$\begin{array}{c}\text { No } \\
(n=65) \\
M(S D)\end{array}$} & \multicolumn{3}{|c|}{ Test statistic } & \multirow{2}{*}{$\begin{array}{l}\text { Unlikely } \\
(n=34) \\
M(S D)\end{array}$} & \multirow{2}{*}{$\begin{array}{l}\text { Likely } \\
(n=76) \\
M(S D)\end{array}$} & \multicolumn{3}{|c|}{ Test statistic } \\
\hline & & & $t$ & $d f$ & $p$ & & & $t$ & $d f$ & $p$ & & & $t$ & $d f$ & $p$ \\
\hline $\begin{array}{l}\text { Human } \mathrm{Pb} \text { exposure } \\
(\alpha=.75)\end{array}$ & $3.81(.57)$ & $4.09(.56)$ & -3.57 & 169 & $<.001$ & $3.92(.62)$ & $3.76(.51)$ & 1.42 & 83 & .16 & $3.51(.59)$ & $3.97(.49)$ & -3.93 & 55 & $<.001$ \\
\hline $\begin{array}{l}\text { A person with } \mathrm{Pb} \\
\text { poisoning may not } \\
\text { always appear sick or } \\
\text { show symptoms }\end{array}$ & $3.72(.64)$ & $3.72(.82)$ & -.03 & 136 & .98 & $3.80(.69)$ & $3.70(.63)$ & .74 & 89 & .46 & $3.53(.62)$ & $3.84(.66)$ & -2.39 & 68 & .02 \\
\hline $\begin{array}{l}\mathrm{Pb} \text { poisoning in } \\
\text { people can be } \\
\text { prevented }\end{array}$ & $4.07(.72)$ & $4.38(.64)$ & -3.17 & 182 & $<.001$ & $4.22(.67)$ & $4.02(.75)$ & 1.51 & 101 & .13 & $3.88(.73)$ & $4.20(.70)$ & -2.14 & 61 & .04 \\
\hline $\begin{array}{l}\mathrm{Pb} \text { bullet fragments in } \\
\text { venison could pose a } \\
\text { risk of lead poisoning } \\
\text { in people }\end{array}$ & $3.76(.89)$ & $4.16(.74)$ & -3.55 & 191 & $<.001$ & $3.96(.95)$ & $3.63(.92)$ & 1.81 & 93 & .07 & $3.26(1.02)$ & $3.99(.81)$ & -3.62 & 53 & $<.001$ \\
\hline $\begin{array}{l}\text { A very small amount } \\
\text { of } \mathrm{Pb} \text { can negatively } \\
\text { affect a person }\end{array}$ & $3.68(.77)$ & $4.11(.73)$ & -4.07 & 175 & $<.001$ & $3.71(.89)$ & $3.70(.68)$ & .05 & 78 & .96 & $3.38(.78)$ & $3.85(.73)$ & -2.98 & 60 & $<.001$ \\
\hline
\end{tabular}

Note: $p<.05$ are bolded. Mean scores are based on a five-point scale where $1=$ strongly disagree and $5=$ strongly agree. ${ }^{1} \mathrm{NonPb}=$ nonlead. 
Table 4.5. Attitudes about shooting characteristics of nonlead (nonPb) ammunition and its use of U.S. Fish and Wildlife Service (USFWS) National Wildlife Refuge (NWR) staff in the Upper Midwest implementing an outreach program encouraging the voluntary use of nonlead hunting ammunition during 2017-2018.

\begin{tabular}{|c|c|c|c|c|c|c|c|c|c|c|c|c|c|c|c|}
\hline \multirow[t]{3}{*}{ Attitude } & \multicolumn{5}{|c|}{ Deer hunter } & \multicolumn{5}{|c|}{$\mathrm{NonPb}^{1}$ use } & \multicolumn{5}{|c|}{ NonPb intention } \\
\hline & \multirow{2}{*}{$\begin{array}{c}\text { Yes } \\
(n=128) \\
M(S D)\end{array}$} & \multirow{2}{*}{$\begin{array}{c}\text { No } \\
(n=80) \\
M(S D)\end{array}$} & \multicolumn{3}{|c|}{ Test statistic } & \multirow{2}{*}{$\begin{array}{c}\text { Yes } \\
(n=45) \\
M(S D)\end{array}$} & \multirow{2}{*}{$\begin{array}{c}\text { No } \\
(n=64) \\
M(S D)\end{array}$} & \multicolumn{3}{|c|}{ Test statistic } & \multirow{2}{*}{$\begin{array}{l}\text { Unlikely } \\
(n=34) \\
M(S D)\end{array}$} & \multirow{2}{*}{$\begin{array}{l}\text { Likely } \\
(n=75) \\
M(S D)\end{array}$} & \multicolumn{3}{|c|}{ Test statistic } \\
\hline & & & $t$ & $d f$ & $p$ & & & $t$ & $d f$ & $p$ & & & $t$ & $d f$ & $p$ \\
\hline $\begin{array}{l}\text { Shooting characteristics } \\
\text { of nonPb ammunition } \\
(\alpha=.79)\end{array}$ & $3.50(.57)$ & $3.56(.53)$ & -.81 & 177 & .42 & $3.88(.56)$ & $3.25(.59)$ & 5.64 & 98 & $<.001$ & $3.16(.64)$ & $3.67(.60)$ & -3.92 & 60 & .001 \\
\hline $\begin{array}{l}\text { NonPb ammunition is } \\
\text { ballistically superior } \\
\text { to } \mathrm{Pb} \text { ammunition }\end{array}$ & $2.88(.82)$ & $3.19(.66)$ & -2.95 & 193 & $<.001$ & $3.16(.95)$ & $2.67(.84)$ & 2.74 & 87 & .01 & $2.56(.99)$ & $3.01(.85)$ & -2.32 & 56 & .02 \\
\hline $\begin{array}{l}\text { NonPb ammunition is } \\
\text { compatible with most } \\
\text { modern firearms }\end{array}$ & $3.77(.78)$ & $3.88(.74)$ & -1.02 & 175 & .31 & $4.13(.79)$ & $3.50(.84)$ & 4.03 & 98 & $<.001$ & $3.41(.82)$ & $3.92(.85)$ & -2.96 & 66 & $<.001$ \\
\hline $\begin{array}{l}\text { There is minimal } \\
\text { complexity converting } \\
\text { to nonPb ammunition }\end{array}$ & $3.57(.94)$ & $3.65(.78)$ & -.66 & 190 & .51 & $3.80(1.12)$ & $3.38(.86)$ & 2.14 & 79 & .04 & $3.06(.95)$ & $3.77(.94)$ & -3.65 & 63 & $<.001$ \\
\hline $\begin{array}{l}\text { NonPb ammunition } \\
\text { damages firearms }(\mathrm{R})\end{array}$ & $2.37(.83)$ & $2.53(.80)$ & -1.36 & 167 & .18 & $1.89(.71)$ & $2.63(.83)$ & -4.96 & 102 & $<.001$ & $2.50(.86)$ & $2.24(.85)$ & 1.46 & 63 & .15 \\
\hline $\begin{array}{l}\text { Deer hunting guns } \\
\text { will not shoot nonPb } \\
\text { ammunition } \\
\text { accurately (R) }\end{array}$ & $2.22(.81)$ & $2.28(.78)$ & -.53 & 170 & .60 & $1.82(.72)$ & $2.48(.85)$ & -4.38 & 104 & $<.001$ & $2.44(.93)$ & $2.11(.81)$ & 1.81 & 57 & .08 \\
\hline $\begin{array}{l}\text { Traditional } \mathrm{Pb} \\
\text { ammunition is more } \\
\text { effective in killing } \\
\text { deer }(\mathrm{R})\end{array}$ & $2.63(.87)$ & $2.51(.78)$ & 1.08 & 178 & .28 & $2.09(.79)$ & $2.92(.91)$ & -5.07 & 102 & $<.001$ & $3.12(.84)$ & $2.33(.91)$ & 4.39 & 68 & $<.001$ \\
\hline
\end{tabular}

Note: $(\mathrm{R})$ denotes reverse-coded item for the latent variable; $p<.05$ are bolded. Mean scores are based on a five-point scale where $1=$ strongly disagree and $5=$ strongly agree. ${ }^{1} \mathrm{NonPb}=$ nonlead. 
Table 4.6. Attitudes about socio-economic factors of nonlead (NonPb) ammunition of U.S. Fish and Wildlife Service (USFWS) National Wildlife Refuge (NWR) staff in the Upper Midwest implementing an outreach program encouraging the voluntary use of nonlead hunting ammunition during 2017-2018.

\begin{tabular}{|c|c|c|c|c|c|c|c|c|c|c|c|c|c|c|c|}
\hline \multirow[t]{3}{*}{ Attitude } & \multicolumn{5}{|c|}{ Deer hunter } & \multicolumn{5}{|c|}{ NonPb $^{1}$ use } & \multicolumn{5}{|c|}{ NonPb intention } \\
\hline & \multirow{2}{*}{$\begin{array}{c}\text { Yes } \\
(n=128) \\
M(S D)\end{array}$} & \multirow{2}{*}{$\begin{array}{c}\text { No } \\
(n=80) \\
M(S D)\end{array}$} & \multicolumn{3}{|c|}{ Test statistic } & \multirow{2}{*}{$\begin{array}{c}\text { Yes } \\
(n=45) \\
M(S D)\end{array}$} & \multirow{2}{*}{$\begin{array}{c}\text { No } \\
(n=64) \\
M(S D)\end{array}$} & \multicolumn{3}{|c|}{ Test statistic } & \multirow{2}{*}{$\begin{array}{l}\text { Unlikely } \\
(n=34) \\
M(S D)\end{array}$} & \multirow{2}{*}{$\begin{array}{l}\text { Likely } \\
(n=75) \\
M(S D)\end{array}$} & \multicolumn{3}{|c|}{ Test statistic } \\
\hline & & & $t$ & $d f$ & $p$ & & & $t$ & $d f$ & $p$ & & & $t$ & $d f$ & $p$ \\
\hline $\begin{array}{l}\text { NonPb ammunition socio- } \\
\text { economic factors } \\
(\alpha=.55)\end{array}$ & $2.96(.50)$ & $3.24(.34)$ & -4.83 & 205 & $<.001$ & $3.16(.57)$ & $2.84(.42)$ & 3.24 & 75 & .002 & $2.83(.50)$ & $3.03(.51)$ & -1.94 & 64 & .57 \\
\hline $\begin{array}{l}\text { Voucher programs would be } \\
\text { helpful for hunters to try } \\
\text { nonPb ammunition }\end{array}$ & $3.78(.94)$ & $3.95(.70)$ & -1.47 & 198 & .14 & $3.98(.89)$ & $3.66(1.03)$ & 1.74 & 102 & .08 & $3.50(.90)$ & $3.92(1.00)$ & -2.19 & 71 & .03 \\
\hline $\begin{array}{l}\text { None of my friends or } \\
\text { relatives use nonPb } \\
\text { ammunition }(\mathrm{R})\end{array}$ & $3.27(1.08)$ & $2.69(.69)$ & 4.73 & 206 & $<.001$ & $2.73(1.14)$ & $3.52(.99)$ & -3.73 & 86 & $<.001$ & $\begin{array}{c}3.53 \\
(1.05)\end{array}$ & $3.04(1.12)$ & 2.21 & 68 & .03 \\
\hline $\begin{array}{l}\text { Shooting demonstrations } \\
\text { would show the benefits of } \\
\text { nonPb ammunition }\end{array}$ & $3.63(.94)$ & $3.88(.68)$ & -2.22 & 201 & .03 & $3.93(.91)$ & 3.47 (.93) & 2.60 & 96 & .01 & $3.26(.99)$ & $3.84(.87)$ & -2.91 & 57 & .01 \\
\hline $\begin{array}{l}\text { NonPb deer hunting } \\
\text { ammunition costs too much } \\
\text { (R) }\end{array}$ & $3.06(.99)$ & $3.03(.80)$ & .30 & 194 & .76 & $2.73(1.05)$ & $3.23(.96)$ & -2.54 & 89 & .01 & $3.21(.95)$ & $2.95(1.05)$ & 1.28 & 70 & .21 \\
\hline $\begin{array}{l}\text { NonPb ammunition is } \\
\text { difficult to find in stores }(\mathrm{R})\end{array}$ & $3.63(.94)$ & $3.28(.78)$ & 2.98 & 190 & $<.001$ & $3.42(1.14)$ & $3.88(.83)$ & -2.28 & 75 & .03 & $3.62(.82)$ & $3.72(1.06)$ & -.55 & 81 & .58 \\
\hline $\begin{array}{l}\text { It is difficult to determine } \\
\text { nonPb ammunition by } \\
\text { looking at the package }(\mathrm{R})\end{array}$ & $3.23(1.03)$ & $2.96(.76)$ & 2.18 & 199 & .03 & $3.29(1.31)$ & $3.23(.83)$ & .25 & 69 & .81 & $3.12(.77)$ & $3.32(1.15)$ & -1.08 & 92 & .28 \\
\hline $\begin{array}{l}\mathrm{Pb} \text { ammunition is } \\
\text { significantly cheaper than } \\
\text { nonPb alternatives }(\mathrm{R})\end{array}$ & $3.48(.83)$ & $3.16(.71)$ & 2.95 & 185 & $<.001$ & $3.60(.84)$ & $3.41(.95)$ & 1.12 & 102 & .26 & $3.47(.90)$ & $3.49(.92)$ & -.12 & 65 & .90 \\
\hline
\end{tabular}

Note: $(\mathrm{R})$ denotes reverse-coded item for the latent variable; $p<.05$ are bolded. Mean scores are based on a five-point scale where $1=$ strongly disagree and $5=$ strongly agree. ${ }^{1} \mathrm{NonPb}=$ nonlead. 


\title{
Chapter 5. Factors Affecting Staff Support of a Voluntary Nonlead Ammunition Outreach Program
}

With Sonja A. Wilhelm Stanis, Mark Morgan, Christine Jie Li, Damon M. Hall, Elisabeth B. Webb

Under review in Applied Environmental Education and Communication

\begin{abstract}
Due to lead poisoning in bald eagles, we explored possible factors influencing program support among U.S. Fish and Wildlife Service staff, including the use of nonlead ammunition and lead poisoning in wildlife. Results from regression with multiple imputation showed attitudes toward eagles' lead risk and importance of informational materials had the strongest effect on program support, followed by an individual's innovation score. Although previous studies have focused on influencing hunter behavior, our findings suggest staff attributes and support for nonlead outreach may be important. To enhance program support, different types of staff training might be necessary.
\end{abstract}

\subsection{Introduction}

Deer hunting has historically used lead ammunition due to its availability, cost, and lethality (Arnemo et al., 2016; V. G. Thomas, Gremse, \& Kanstrup, 2016). A large body of research, however, has demonstrated risk to wildlife and human health from exposure to spent lead ammunition (Gerofke et al., 2018; Rattner et al., 2008). Unlike wetland and upland game birds which directly ingest lead shotgun pellets (Bellrose, 
1959; Schulz et al., 2002), facultative and obligate avian scavengers indirectly ingest lead bullet fragments from big-game animal gut piles or carcasses (Haig et al., 2014; Slabe et al., 2020). Of particular concern is lead poisoning in bald eagles (Cruz-Martinez et al., 2012; Warner et al., 2014). In Michigan, mortality by ingestion of lead bullet fragments was the second leading cause of death among bald eagles during 1986-2017 (Simon et al., 2020). Despite concern for bald eagles, the complexity and polarization surrounding firearms and ammunition (Smyth, 2020; Whitney, 2012) has fostered a climate of trepidation among natural resource decision-makers (Cromie et al., 2019; Schulz et al., 2019). Given the importance of this issue, we addressed relative support among natural resource staff implementing an outreach program that encouraged deer hunters to use nonlead ammunition voluntarily.

\subsubsection{Characteristics of voluntary conservation programs}

Some stakeholders have recommended banning lead hunting ammunition (Bellinger et al., 2013; V. G. Thomas, 2019), while others have promoted the voluntary use of nonlead alternatives (Green et al., 2008; Haig et al., 2014). Information campaigns encouraging pro-environmental behavior, however, can be challenging (Rice \& Atkin, 2013). Considerations include existing regulations, objectives, incentives, penalties, environmental benefits, identification of target audiences, and monitoring participation and outcomes (Randall, 2002; Segerson, 2013a). Some voluntary conservation programs have been successful; e.g., farmland wildlife habitat (Pabian et al., 2013) and private forest management (Kauneckis \& York, 2009). However, voluntary policies may not be 
optimal for many emerging natural resource issues (Dietz, 2002; Steelman \& Rivera, 2006).

Despite these complexities, several voluntary nonlead programs have been implemented. Use of nonlead ammunition by big-game hunters near Jackson Hole, Wyoming, U.S. corresponded with significantly reduced blood lead levels in eagles (Bedrosian et al., 2012). In northern Arizona and southern Utah, 80-88\% of big-game hunters participated in voluntary nonlead ammunition programs aimed at reducing lead exposure for California condors (B. Smith et al., 2017). In another study of Arizona biggame hunters, perceived barriers of using nonlead ammunition were mitigated with factual information along with a nonlead ammunition voucher (Chase \& Rabe, 2015). A common feature of these programs was reliance on information encouraging hunters to voluntarily use nonlead ammunition. Achieving this outcome, however, is more complex than sharing information. Persistent behavioral changes result from a dynamic interaction among target audiences, content and delivery of the material, setting and context, and attributes of the program staff or spokespersons (Powell \& Stern, 2013).

\subsubsection{Factors effecting program staff}

Individuals who deliver outreach programs may have different backgrounds and training, but they play similar roles as knowledgeable and trusted messengers (Corner et al., 2015; McBride \& Burgman, 2012). Attitudes and perceptions toward the program among these individuals may provide insights into outreach efficacy. For example, attitudes toward mandated outreach among inexperienced educators may be influenced by social norms among staff who are more experienced (J. C.-H. Cheng \& Monroe, 
2010). In other situations, experienced educators who were skeptical about climate change avoided the issue and did not provide instruction on the topic (Liu, Roehrig, Bhattacharya, \& Varma, 2015). Prior research suggests environmental knowledge and ideology of educators may also affect attitudes and beliefs toward instruction (Guy, Kashima, Walker, \& O'Neill, 2014) and subsequently program support. In Missouri, interpreters at state parks were comfortable discussing climate change when they had sufficient training and resources (Balasubramanyam et al., 2019). Therefore, perceptions about an environmental issue, training, and informational materials may influence educators' attitudes toward an outreach program, which in turn, may impact outcomes.

Although a set of common predictors may not exist for a range of proenvironmental behaviors, several factors may affect support for outreach (McKenzieMohr, Nemiroff, Beers, \& Desmarais, 1995). Ideally, educators should possess knowledge and experience, be trustworthy sources of information, and be enthusiastic. These characteristics suggest nonlead program staff may be more effective if they are experienced hunters and possess knowledge about firearms and ammunition. These individuals, acting as trusted and knowledgeable messengers, can be scientists, refuge managers, administrative assistants, technicians, or peers.

Program staff may also act as change agents by influencing hunter behavior when discussing lead poisoning and adopting nonlead ammunition. For example, Rogers' (2003) theory of innovation suggests behavioral change is related to the effort, empathy, credibility, and innovativeness of program staff. Staff, acting as change agents, tend to be more effective if they have favorable attitudes toward the innovation, positively identify with it, and have administrative support (Wejnert, 2002). Other research has 
suggested behavioral change at the organizational scale will only occur if there is support for an initiative at the individuals' level (Frambach \& Schillewaert, 2002). Passion, enthusiasm, and other characteristics have influenced effectiveness of information delivery and interpretive program outcomes (C. W. Ward \& Wilkinson, 2006). For example, spokespersons' attributes and program characteristics interacted to influence visitor outcomes at 24 U.S. National Parks (Powell \& Stern, 2013).

When natural resource professionals are asked to deliver a nonlead outreach program, they, in turn, become potential adopters within the innovation process (Dearing, 2009). Therefore, staff may act as both change agents and opinion leaders. In fact, training may be tailored for individuals at different stages of the decision-making process and different levels of innovativeness, which may improve program outcomes among deer hunters.

Even robust scientific information demonstrating lead poisoning wildlife, adoption of new behaviors like using nonlead hunting ammunition can be complicated. Definitions of what constitutes credible evidence may be uncertain and debated among program staff, especially within local networks (Hunter et al., 2015). Therefore, attitudes about the importance of outreach materials may affect program support among staff. Given differences of opinions toward the credibility of scientific information about lead poisoning in bald eagles (Schulz, Wilhelm Stanis, Hall, \& Webb, 2021), perceptions and attitudes among staff about the risk of lead exposure to wildlife may also affect program support. The level of training received by staff may affect their ability to communicate with hunters. Hunting experience may also influence program outcomes where staff who are hunters not only are change agents, but also act as trusted opinion leaders. 


\subsubsection{Research objective}

Given the importance of staff to influence program outcomes, it is useful to understand factors which might affecting behavioral changes and nonlead program support. However, previous research has focused on increasing hunter awareness of lead poisoning in wildlife and use of nonlead ammunition, while overlooking the importance of staff conducting the programs. Earlier research essentially assumed program staff were engaged, informed, and supportive of the nonlead outreach activities (Bedrosian et al., 2012; Chase \& Rabe, 2015). Yet, without the full support of staff, program outcomes may not be achieved.

After documenting lead poisoning in bald eagles (Warner et al., 2014), an outreach program was initiated on Upper Midwestern U.S. Fish and Wildlife Service (USFWS) National Wildlife Refuges (NWRs) encouraging deer hunters to voluntarily use nonlead ammunition. For this paper, program support was defined as factors reflecting an individual's agreement with the goals and supporting information of the outreach program, and agreement with the importance of materials and tools for encouraging deer hunters to adopt nonlead ammunition. Additionally, program staff are defined as individuals with some level of outreach responsibility. Our research objective, therefore, was to identify potential factors influencing program support among staff conducting a nonlead information campaign. Identifying and assessing factors related to staff support of this outreach program can provide suggestions for improving future nonlead ammunition initiatives and related efforts of hunter recruitment, retention and 
reactivation (Price Tack, McGowan, Ditchkoff, Morse, \& Robinson, 2018; Responsive Management \& National Shooting Sports Foundation, 2017).

\subsection{Methods}

\subsubsection{Study area and nonlead program}

This study was part of a larger project assessing a nonlead outreach program at 54 NWRs in Illinois, Iowa, Indiana, Michigan, Minnesota, Missouri, Nebraska, Ohio, and Wisconsin. The program was phased-in over a three-year period with additional NWRs added each year; four NWRs during 2016, 17 added in 2017, and 33 in 2018. A variety of outreach materials provided information about lead poisoning in bald eagles (Warner et al., 2014) and suggested voluntary use of nonlead ammunition when deer hunting on NWRs. Outreach materials for hunters included brochures, parking lot signs, and banners located in USFWS offices. During 2016, NWRs received the same briefing and outreach materials; i.e., fact sheets, yard signs, and brochures. In 2017, NWRs received the same materials along with a clear plastic block (about 8" x 4" x 2" of clear epoxy resin) showing bullet fragmentation characteristics followed by minimal updates in the outreach materials for the 2018 hunting season. Deer hunting opportunities varied among refuges; e.g., statewide regulations, use of only shotguns or muzzleloading rifles, and managed hunts with limited number of hunters.

Along with the materials designed for deer hunters, materials for staff included fact sheets, FAQs, and standardized presentations for use with managed hunt presentations for deer hunters. Staff participation ranged from professional educational specialists delivering oral presentations to hunters while other staff simply addressed questions from hunters encountered on the refuge. Although some staff had formal 
training in pedagogy, most had no teaching experience. Respondents included refuge managers, assistant managers, visitor services specialists, law enforcement officers, public and private land biologists, administrative support staff, technicians, and maintenance staff.

\subsubsection{Survey design and implementation}

After the 2017 and 2018 deer hunting seasons, we conducted an online survey of USFWS program staff. The survey addressed issues related to nonlead ammunition, lead poisoning in wildlife, human health risks from spent lead ammunition, and items focused on implementing and supporting the program. Because no standardized scale was available, we selected relevant issues from items in previous research about lead poisoning in wildlife (Duda, 2004; Seng, 2005a). The survey contained 45 multi-item questions requiring $\leq 20 \mathrm{~min}$ to complete. A list of email addresses was provided by USFWS administrators consisting of potential participants conducting the outreach program. We used a modified Dillman technique starting with a prenotification email and concluding with five reminders to nonrespondents (Dillman et al., 2014) via Qualtrics software version 2018.

The survey resulted in a 52.0\% response rate in $2018(n=167)$ and $62.5 \%$ in $2019(n=197)$. To check for nonresponse bias, we used a shortened version of the survey (responses in $2018 n=26$; responses in $2019 n=21$ ). No significant differences emerged between respondents in the full survey and those in a shortened version for any of the variables except gender $\left(\chi^{2}(2, n=373)=5.994, p=.050\right)$ indicating females were more likely to be nonrespondents than males. Because there were no differences between 
years, we used 2019 data unless a respondent only completed the 2018 survey. These data resulted in a total sample of $n=235$ ( $n=197$ from 2019 plus $n=38$ from 2018).

\subsubsection{Regression model variables}

We used linear regression to determine if program support could be predicted by six independent variables (Figure 1; Table 5.1). Program support was based on four questions $(\alpha=.71)$, each using a 5-point scale (1=low program support). Items included agreement on the voluntary program being an optimal approach, compatibility with the agency's goals and objectives, incentives to use nonlead ammunition, and the use of shooting demonstrations showing benefits of nonlead ammunition. We used six independent variables in the model; five were continuous and one dichotomous.

Continuous independent variables included perceived eagles' lead risk, sufficient training and resources, satisfaction with program implementation, importance of informational program materials, and innovation score; each was measured on a 5-point scale (1=low importance, agreement, or satisfaction); deer hunter status was dichotomous. Items worded in the reverse direction were recoded for consistent directionality.

Perceived eagles' lead risk was based on three indicators: lead poisoning in eagles resulting from ingestion of bullet fragments, ingesting lead bullet fragments by bald eagles, and use of nonlead ammunition reducing bald eagle deaths $(\alpha=.87)$. The variable, sufficient training and resources, consisted of four factors: sufficient training, necessary administrative support, ample time to review material, and ample time to become familiar with the topic of lead poisoning in eagles $(\alpha=.93)$. We used six indicators for satisfaction with program implementation which included: conference calls 
with the implementation team, on-site training sessions, usefulness of materials on a secure server, organization of materials on the secure server, summary notes from implementation team meetings, and supply and availability of program materials $(\alpha=$ .87). Importance of informational and program materials was based on 14 factors that addressed a variety of information and materials in the outreach program $(\alpha=.97)$; e.g., brochures, banners, parking lot signs. Innovation score was a continuous variable $(\alpha=$ .89) based on an existing scale using 20 indicators of innovativeness (Hurt et al., 1977).

We acknowledge an existing relationship between attitudes about lead risks in human health and bald eagles (Haig et al., 2014). Consequently, we developed a latent variable of perceived human health risk and used it in original modeling exercises. It consisted of four indicators; a person with lead poisoning may not appear sick, lead poisoning in people can be prevented, lead fragments in venison pose a health risk, and small amounts of lead can negatively affect a person $(\alpha=.75)$. However, we removed this variable from the final model due to multicollinearity issues with bald eagles' lead risk (Lewis-Beck \& Lewis-Beck, 2016).

\subsubsection{Analysis and multiple imputation}

We used IBM-SPSS version 25 for conducting multiple imputation to handle missing values (Wayman, 2003) and subsequent linear regression. Multiple imputation addressed missing data issues that would have greatly reduced sample size if casewise or listwise deletion were used (Rubin, 1987). Multiple imputation generated values for missing observations mimicking the uncertainty in the original data (Song, Aguilar, \& Butler, 2013). This created multiple datasets by replacing missing values using a 
separate regression model (Hendee \& Flint, 2013). Next, we pooled the imputed datasets to generate representative and robust results. After multiple imputation, we conducted linear regression to determine the predictive values of factors affecting program support. Regression results compared relationships between the original complete-case results with the pooled values from multiple imputation based on recommendations from Pedersen et al. (2017).

\subsection{Results}

Program staff were middle-aged, predominantly male, most having at least a bachelor's degree, and most identifying as a deer hunter (Table 5.2). Table 5.3 provides a summary of descriptive statistics for the latent variables. A regression model with the complete-case dataset was significant $\left(F(6,74)=15.60, p<.001, \eta_{\mathrm{p}}=.56\right)$ and represented a large effect $\left(R^{2} a d j=.52\right)$ accounting for variance in program support (Table 5.4). Missing value analysis, however, showed $83.0 \%$ of survey responses contained missing cases. Little's MCAR test (Little, 1988) indicated missing cases occurred at random $\left(\chi^{2}(70)=70.55, p=.46\right)$ so we used multiple imputation (Wayman, 2003) to estimate missing values resulting in multiple datasets $(m=25)$.

We compared complete-case results and pooled values from multiple imputation

(Table 3). The model with complete-case data showed attitudes about eagles' lead risk ( $p$ $<.001)$ and importance of informational program materials $(p=.002)$ were significant predictors of program support among staff. This finding was similar to results from pooled imputation values for perceived eagles' lead risk $(p<.001)$ and importance of informational program materials $(p=.001)$. In addition, regression results from pooled imputation values showed innovation score $(p=.017)$ significantly predicted program 
support along with perception of eagles' lead risk and importance of informational materials. Standardized results from pooled multiple imputation showed attitudes of perceived lead risk to eagles $(\beta=.45)$ and importance of informational materials $(\beta=.27)$ had the strongest effect on program support, followed by innovativeness $(\beta=.17)$. In other words, a one unit increase in perceived lead risk to eagles led to a $45 \%$ increase in program support, a one unit increase in importance of informational materials led to a $27 \%$ increase in program support, and a one unit increase in innovation led to a $17 \%$ increase in program support, while controlling for other variables in the model.

\subsection{Discussion}

We found USFWS staff were affected by perceptions of eagles' lead risks, attitudes about the importance of informational materials, and attributes of personal innovativeness. Although this study examined a small sample of natural resource professionals and their level of support for a nonlead ammunition outreach program, our findings may improve future efforts related to ongoing recruitment, retention, and reactivation activities (Price Tack et al., 2018; Responsive Management \& National Shooting Sports Foundation, 2017). Unlike previous research about factors influencing hunters' attitudes and behavior about lead and nonlead ammunition (Chase \& Rabe, 2015; Schroeder et al., 2016), this study explored attributes of staff support for nonlead outreach.

Program support was greater among staff agreeing about the harmful effects of lead poisoning in bald eagles. This is consistent with previous research where program staff were assumed to agree with the effects of spent lead ammunition on wildlife (Haig 
et al., 2014), and specifically bald eagles (Warner et al., 2014). Designers of the USFWS nonlead outreach assumed staff implementing the program agreed with the information and supported the program. This assumption appears to be consistent with similar nonlead programs aimed at changing hunter behavior (Bedrosian et al., 2012; B. Smith et al., 2017). Observations from other environmental outreach programs, however, showed inconsistent support among staff. For example, environmental educators differed on various aspects of climate change which impacted their decisions to address specific topics in the classroom (Liu et al., 2015). Also, some natural resource professionals who were also deer hunters were skeptical of some scientific information about lead poisoning in bald eagles that was included in the nonlead ammunition program (Schulz, Wilhelm Stanis, Hall, et al., 2021). In other studies, program staff simply ignored discussing some environmental information if they thought the material was unacceptable or inappropriate (Maibach, 1993).

Program staff also supported the outreach program when they agreed more strongly about the importance of informational materials. Materials used were similar to those in other nonlead outreach programs (Chase \& Rabe, 2015; B. Smith et al., 2017). Attitudes about the importance of outreach materials may increase program support among staff by message framing. Previous research showed the importance of message framing and its relationship between how the information is delivered and how it is received (T. Cheng et al., 2011; Gamson \& Modigliani, 1989). Program staff often act as gatekeepers because they can ignore information they disagree with (Maibach, 1993), similar to the way some teachers address global climate change. If educators agree with informational materials about climate change, then students are likely to learn about its 
causes and effects. If skeptical about the topic, teachers avoided discussing it with their students (Liu et al., 2015). Disagreement among program staff over information credibility, however, could be mitigated by framing it in ways that increase personal relevance and emotional engagement (Myers, Nisbet, Maibach, \& Leiserowitz, 2012).

Our results also showed innovativeness predicted support for the nonlead outreach program. Innovation refers to an individual's receptivity to behavioral change based on new information (Dearing, 2009). This finding agrees with earlier research across disciplines (Barnett et al., 2011; Dingfelder \& Mandell, 2011; Wisdom, Chor, Hoagwood, \& Horwitz, 2014). Specifically, program staff who are more innovative may be more effective in communicating the benefits of nonlead ammunition. Innovativeness is also important because program staff who tend to adopt new products or behaviors are perceived as more knowledgeable and experienced (Frambach \& Schillewaert, 2002).

\subsection{Limitations and future research}

We were unable to explore lead impacts on human health as a predictor of program support due to multicollinearity with perceptions of lead risk to eagles. Earlier research, however, has documented human health risk of ingesting lead bullet fragments in venison (Gerofke et al., 2018). This concern was expressed by natural resource professionals who were nonhunters, nonlead users, and likely nonlead hunters (Schulz, Wilhelm Stanis, Morgan, et al., 2021), suggesting the need for greater attention to this issue. With recent concerns about declining hunter participation rates and recruitment, retention, and reactivation efforts (Responsive Management \& National Shooting Sports Foundation, 2017), messages about human health risk from lead bullet fragments in 
venison may resonate more with younger new hunters (Hinrichs et al., 2020; Price Tack et al., 2018). Given the importance of human health risk, future research could start with developing specific scales that decouple human health lead risks from those of bald eagles.

Although there was uniformity in outreach materials and messages among refuges, each manager had flexibility to implement the program. There were also differences among refuges in hunting regulations, number of deer hunters per area, and experience and training of refuge staff. Given these challenges, outreach coordinators may consider different types of staff training based on the importance of program materials, staff innovativeness, and perceptions of health risks from lead ammunition in bald eagles and humans. 
Table 5.1. List of model variables and measurement.

Variable Measurement

Program support (Dependent variable)

Innovation score (Independent variable)

Perceived eagles' lead risk (Independent variable)
Continuous scale ranging from 1 to 5 (low score $=$ low program support)

Scale constructed based on agreement of four indicators of program support: Program is an optimal approach to reduce lead poisoning in bald eagles; program is compatible with the goals and objectives of my agency and cooperating conservation organizations; voucher incentives would encourage nonlead use; shooting demonstrations would show nonlead benefits. Scale reliability $\alpha=.71$

Continuous scale ranging from 1 to 5 (low score $=$ low innovation)

Scale constructed based on agreement of 20 indicators of innovativeness: Peers often ask for advice or information; enjoy trying new ideas; seek out new ways to do things; am generally cautious about accepting new ideas; frequently improvise methods for solving a problem when an answer is not apparent; suspicious of new inventions and new ways of thinking; rarely trust new ideas until the vast majority of people accept them; an influential member of my peer group; creative and original in my thinking and behavior; one of the last people in my group to accept something new; inventive kind of person; enjoy taking part in the leadership responsibilities of my group; reluctant to adopt new ways of doing things until seeing them working for other people; stimulating to be original in thinking and behavior; tend to feel the old way of living and doing things is the best way; challenged by ambiguities and unsolved problems; must see other people using new innovations before considering them; receptive to new ideas; challenged by unanswered questions; often skeptical of new ideas. Scale reliability $\alpha=.89$

Continuous scale ranging from 1 to 5 (low score $=$ low agreement about lead risks to eagles)

Scale constructed based on agreement of three indicators of agreement about lead risk to eagles: Lead poisoning from ingesting lead bullet fragments in deer gut piles or carcasses; ingesting lead bullet fragments from deer gut piles or carcasses is 
Variable

Sufficient training

and resources

(Independent

variable)

Satisfaction with

program

implementation

(Independent

variable)

Importance of

informational

program materials

(Independent

variable)
Measurement

a serious problem for bald eagles; use of nonlead ammunition will reduce bald eagle deaths. Scale reliability $\alpha=.87$

Continuous scale ranging from 1 to 5 (low score $=$ low agreement)

Scale constructed based on agreement of four indicators of agreement about sufficient training and resources: I had sufficient training to become knowledgeable about the topic; I felt I had the necessary administrative support to freely discuss the topic with deer hunters; I was given ample time and opportunity to review the available materials; I was given ample time and opportunity to learn about the topic. Scale reliability $\alpha=.93$

Continuous scale ranging from 1 to 5 (low score $=$ low satisfaction)

Scale constructed based on agreement of six indicators of satisfaction with program implementation: Conference calls with the regional implementation team; on-site training by regional implementation team; usefulness of informational materials on Google drive; organization of materials on the Google drive; summary notes from the regional implementation team meetings; supply of outreach program materials. Scale reliability $\alpha=.87$

Continuous scale ranging from 1 to 5 (low score $=$ low importance)

Scale constructed based on agreement of 14 indicators of importance of informational program materials: Information from the FWS Implementation Team (e.g., conference calls, meeting summary notes, on-site training); posters and banners at refuge visitors' centers and offices; fliers, pamphlets, bookmarks, and brochures; signs or kiosks on refuges; information enclosed with managed hunt notification letter; presentations at orientation sessions at refuges with managed hunts; information on refuge websites; FWS news releases; news or media stories (e.g., newspaper, online, TV, radio); information at non-hunting events (e.g., Eagle Days); information at local retailers and partners (e.g., Pheasants Forever chapter meeting); social media (e.g., Facebook, Twitter); Conversation with an FWS employee about lead free ammunition; conversation with an FWS volunteer about lead free ammunition. Scale reliability $\alpha=.97$ 
Variable

Deer hunter status

(Independent

variable)

*Perceived human health lead risk
Measurement

Dichotomous variable: Do you consider yourself to be a deer hunter?

Continuous scale ranging from 1 to 5 (low score $=$ low agreement)

Scale constructed based on agreement of four indicators of agreement about perceived human health risk: A person with lead poisoning may not always appear sick or show symptoms of poisoning; Lead poisoning in people can be prevented; Lead bullet fragments in venison could pose a risk of lead poisoning in people; A very small amount of lead can negatively affect a person. Scale reliability $\alpha=.75$ 
Table 5.2. Characteristics of U.S. Fish and Wildlife Service (USFWS) staff participating in nonlead outreach program.

\begin{tabular}{|c|c|}
\hline Characteristic & $n(\%)$ \\
\hline \multicolumn{2}{|l|}{ Gender } \\
\hline Male & $148(71.5)$ \\
\hline Female & $57(27.5)$ \\
\hline Other & $2(1.0)$ \\
\hline \multicolumn{2}{|l|}{ Background } \\
\hline Large city or urban area & $19(9.0)$ \\
\hline Suburban area & $45(21.4)$ \\
\hline Small city or town & $48(22.9)$ \\
\hline Rural area & $98(46.7)$ \\
\hline \multicolumn{2}{|l|}{ Residence } \\
\hline Large city or urban area & $13(6.2)$ \\
\hline Suburban area & $23(11.0)$ \\
\hline Small city or town & $74(35.2)$ \\
\hline Rural area & $100(47.6)$ \\
\hline \multicolumn{2}{|l|}{ Education } \\
\hline Less than high school & $1(0.5)$ \\
\hline $\begin{array}{l}\text { Some high school, graduate, or } \\
\text { equivalent }\end{array}$ & $5(2.4$ \\
\hline Some college, no degree & $19(9.0)$ \\
\hline Associates degree & $16(7.6)$ \\
\hline Bachelor's degree & $101(48.1)$ \\
\hline Master's degree & $64(30.5)$ \\
\hline Professional degree & $1(0.5)$ \\
\hline Doctorate degree & $3(1.4)$ \\
\hline \multicolumn{2}{|l|}{ Deer Hunter Status } \\
\hline Yes & $130(61.0)$ \\
\hline No & $83(39.0)$ \\
\hline \multicolumn{2}{|l|}{ Current Ammunition Use } \\
\hline Nonlead & $45(40.5)$ \\
\hline Lead & $66(59.5)$ \\
\hline \multicolumn{2}{|l|}{ Likelihood of nonlead use } \\
\hline Unlikely & $35(31.5)$ \\
\hline Likely & $76(68.5)$ \\
\hline
\end{tabular}


Table 5.3. Descriptive statistics of continuous variables in the model before multiple imputation.

\begin{tabular}{lccccc}
\hline & \multicolumn{3}{c}{ Original data } & \multicolumn{2}{c}{ Pooled imputed data } \\
& $n$ & $M$ & $S D$ & $n$ & $M$ \\
\hline Program support & 142 & 3.80 & .63 & 232 & 3.77 \\
Innovation score & 208 & 3.70 & .42 & 232 & 3.69 \\
Perceived eagles' lead risk & 228 & 4.10 & .91 & 232 & 4.10 \\
Sufficient training and resources & 146 & 3.33 & .89 & 232 & 3.29 \\
$\begin{array}{l}\text { Satisfaction with program } \\
\text { implementation }\end{array}$ & 104 & 3.44 & .59 & 232 & 3.37 \\
$\begin{array}{l}\text { Importance of informational } \\
\text { program materials }\end{array}$ & 114 & 3.69 & .79 & 232 & 3.67 \\
\hline
\end{tabular}

*SD not available from pooled values from imputed datasets. 
Table 5.4. Linear regression predicting staff support for a nonlead ammunition outreach program.

\begin{tabular}{|c|c|c|c|c|c|c|c|c|}
\hline \multirow[b]{2}{*}{ Variable } & \multicolumn{4}{|c|}{$\begin{array}{l}\text { Complete Case Analysis } \\
\qquad(n=81)\end{array}$} & \multicolumn{4}{|c|}{$\begin{array}{l}\text { Multiple Imputation } \\
\quad(n=232 ; m=25)\end{array}$} \\
\hline & $b(95 \% C I)$ & $S E_{b}$ & $\beta$ & $p$ & $b(95 \% C I)$ & $S E_{b}$ & $\beta$ & $p$ \\
\hline $\begin{array}{l}\text { Program support } \\
\text { (Constant) }\end{array}$ & $.989(-.018,1.997)$ & .506 & & .054 & $.722(-.079,1.523)$ & .405 & & .077 \\
\hline Innovation score & $.068(-.196, .333)$ & .133 & .043 & .609 & $.248(.045, .452)$ & .103 & .169 & .017 \\
\hline $\begin{array}{l}\text { Perceived eagles' } \\
\text { lead risk }\end{array}$ & $.376(.242, .509)$ & .067 & .541 & .000 & $.313(.211, .415)$ & .052 & .453 & $<.001$ \\
\hline $\begin{array}{l}\text { Sufficient training } \\
\text { and resources }\end{array}$ & $-.045(-.210, .121)$ & .083 & -.054 & .592 & $-.041(-.155, .074)$ & .058 & -.056 & .482 \\
\hline $\begin{array}{l}\text { Satisfaction with } \\
\text { program } \\
\text { implementation }\end{array}$ & $.048(-.180, .276)$ & .115 & .044 & .677 & $.043(-.130, .216)$ & .087 & .042 & .626 \\
\hline $\begin{array}{l}\text { Importance of } \\
\text { program } \\
\text { informational } \\
\text { materials }\end{array}$ & $.270(.105, .434)$ & .082 & .312 & .002 & $.225(.088, .362)$ & .069 & .266 & .001 \\
\hline Deer hunter? & $-.031(-.266, .203)$ & .118 & -.023 & .790 & $.010(-.154, .492)$ & .083 & .008 & .906 \\
\hline
\end{tabular}




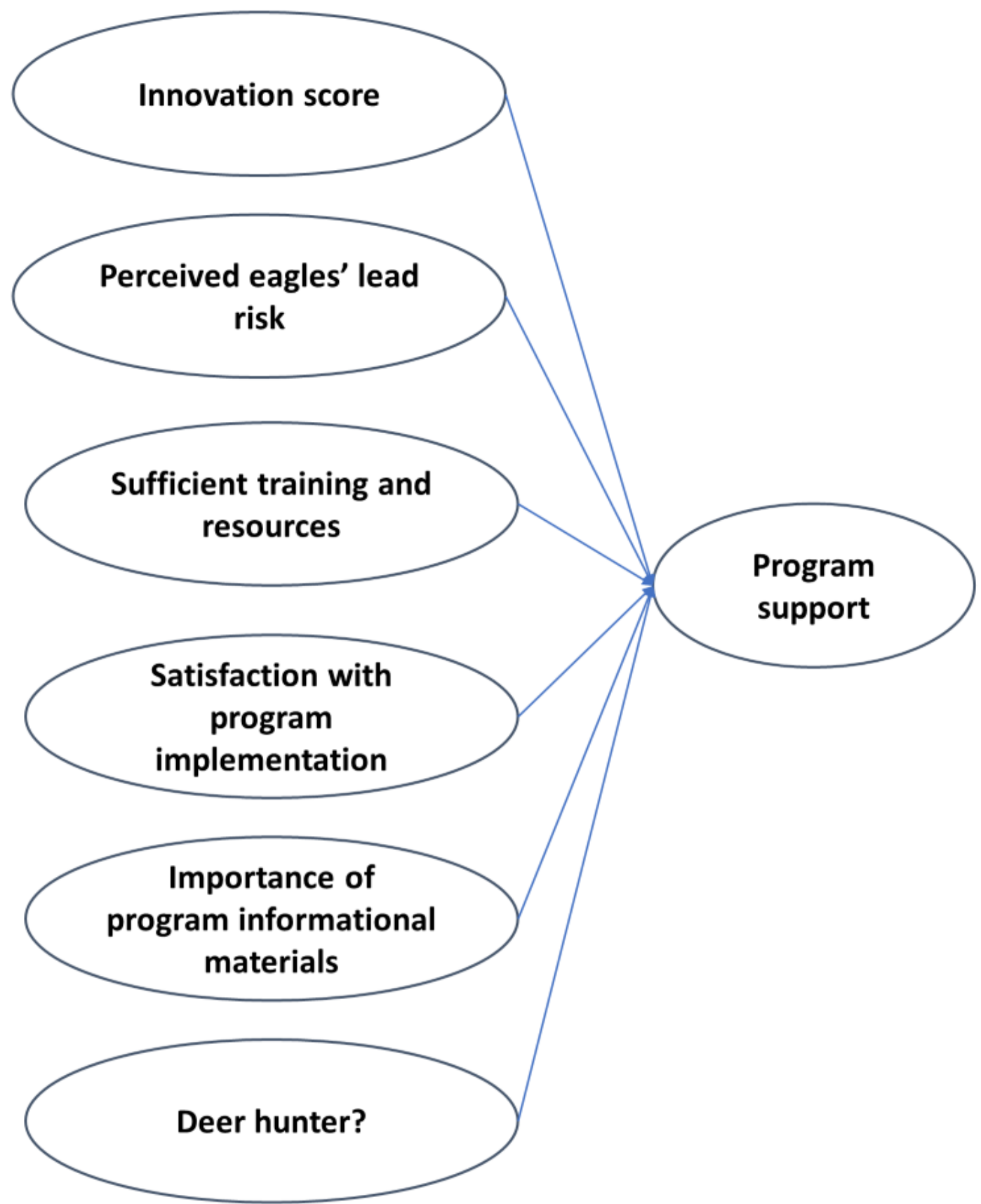

Figure 5.1. Conceptual model of variables influencing support for a program encouraging voluntary use of nonlead ammunition. 


\title{
Chapter 6. Structured Observations at Hunt Orientation Sessions
}

\author{
With Sonja A. Wilhelm Stanis and Elisabeth B. Webb
}

To be submitted as a research note to Human Dimensions of Natural Resources

\subsection{Introduction}

While considerable research has documented the negative effects of lead ammunition on bald eagles and other wildlife (Haig et al., 2014; Rattner et al., 2008), little research has been conducted on behavioral mechanisms affecting the voluntary use of nonlead ammunition by deer hunters or program staff implementing outreach programs. Based on research documenting lead poisoning bald eagles resulting from the ingestion lead bullets in deer gut piles and carcasses (Warner et al., 2014), the U.S. Fish and Wildlife Service (USFWS), Midwest Region, developed an outreach program encouraging hunters to voluntarily use nonlead ammunition on National Wildlife Refuges (NWR).

The voluntary nonlead outreach program was implemented on 54 NWRs in Illinois, Iowa, Indiana, Michigan, Minnesota, Missouri, Nebraska, Ohio, and Wisconsin; 4 NWRs began during the hunting seasons of 2016, 17 areas added in 2017, and the remaining 33 areas added in 2018. The outreach program consisted of FAQ sheets, color brochures, parking lot signs, free-standing banners at refuge headquarters, examples of spent lead and nonlead hunting ammunition, and oral presentations at managed deer hunts with orientation sessions. As part of a larger mixed-methods research project assessing the regional nonlead outreach program, our objective was to observe interactions between USFWS staff and hunters during the oral presentations. 


\subsection{Methods}

Structured observations (Sommer \& Sommer, 2002) were conducted at managed deer hunts with nonlead ammunition presentations during hunt orientation sessions $(n=$ 12) during 2016 and 2017 hunting seasons (Table 6.1). Presentations at managed deer hunts were conducted to primarily provide details about managed hunt regulations and refuge specific information. Information about lead poisoning in eagles and nonlead ammunition was combined with the managed hunt presentations and was contained on four slides. Orientation sessions occurred before hunters were allowed to go scouting or hunting on the refuge. The senior author conducted all observations at the managed hunt presentations by sitting in the back of the room and blending in with other hunters. A structured observation form was used to ensure the same information was collected during each presentation (Appendix 2).

\subsection{Results and discussion}

During the first two hunting seasons of the nonlead outreach program, we conducted 12 observations on four different NWRs with 193 hunters attending presentations (Table 6.1). Average length of managed hunt presentations was 24.8 min $(S D=9.0)$ with time devoted to discussing lead poisoning in bald eagles and voluntary use of nonlead ammunition $3.7 \mathrm{~min}(S D=1.4 \mathrm{~min})$ or $14.7 \%$ of total presentation time. Hunters attending presentations averaged 16.1 hunters per session ( $S D=14.6$ hunters). With one exception (a student intern), oral presentations were delivered by natural resource professionals; e.g., refuge manager or visitor services specialist. All but one 
presentation used the same four PowerPoint slides and corresponding script describing lead poisoning in eagles resulting from spent ammunition along with a message to voluntarily use nonlead ammunition when hunting on the refuge. Two presentations contained slight modifications to the PowerPoint presentation template by adding 1-2 slides about potential human health risks from ingesting lead bullet fragments processed venison. Deer hunters asked questions after only two of the presentations: one hunter inquired about the material used to make nonlead ammunition, and another was about the cost of nonlead ammunition compared to lead ammunition.

Our data highlighted a missed opportunity due to the very short amount of time allocated for presentations. From an outreach program standpoint, the relative lack of time allotted for presenting the information and little time given for questions/answers limits the program's overall potential effect on changing hunter behavior. In other words, the information provided to hunters was factual and concise to avoid potential conflict, but may have been at such a small dose it had little impact (Atkin \& Rice, 2013). Potentially, structured observations could have provided information about how hunters react to information about lead poisoning and nonlead ammunition, insights about hunters' attitudes and behavior from question/answer sessions, and observations of how staff delivered the information.

Given this limited discussion during orientation sessions, it would have been difficult to have a meaningful effect on changing hunter behavior. The topic of lead poisoning in wildlife (and specifically bald eagles) can be complex, nuanced, and contextual. Ideally, messages could have been developed to stress bald eagle populations are increasing in many areas across North America, but the birds still face a series of 
threats and are protected by multiple statutes prohibiting activities that threaten bald eagles (Public Law 85-585, 1958; Public Law 86-70, 1940; Public Law 86-732, 1918; Public Law 93-205, 1973; Public Law 94-469, 1976). These nuanced and complex issues, in addition to potential human health risks, can be difficult to discuss in a public setting; this can be especially difficult with limited time to discuss nuanced details.

Additional time allocated for more in-depth presentations would not only increase hunters' familiarity with the technical details related to lead poisoning and use of nonlead ammunition, but cold also provide time for developing normative connections (Cialdini et al., 2006) and message framing (T. Cheng et al., 2011). The limited amount of time given to presentations provided little opportunity for hunters to thoroughly consider the impacts of using lead ammunition and the benefits of using nonlead ammunition. Within the context of the multi-stage decision process, the decision process had barely started beyond the first stage of knowledge acquisition (Prochaska et al., 2015; Rogers, 2003). In other words, observation data highlighted the potentially minimal effect on changing hunter behavior due to the small "dose" of information provided during the hunt orientation sessions.

Another factor was the timing of orientation sessions; i.e., they occurred immediately before hunters were allowed to go scouting or to go hunting. On one area, orientation occurred 60 min before sunrise and the start of legal hunting. Deer hunters observed during these orientation sessions asked very few questions in the nonlead portions of the presentations and quickly left so they could go scouting or hunting (this was confirmed by casual comments overheard by hunters afterwards). From a practical standpoint, hunters may have been hesitant to ask questions about nonlead ammunition as 
it could be perceived by other hunters as prolonging the presentation and lengthening delays that would otherwise cut into time spent hunting in the field.

Structured observations conducted during this investigation occurred at only four managed deer hunts with orientation sessions (Note - refuges with managed hunts occurred at only $7.4 \%$ of the 54 refuges implementing the program). Although findings were limited, the observations were complimentary to other information collected assessing the outreach program. Given the limited social science research on this topic, this may be the first use of structured observation methods to gather observational data about interactions between natural resource professionals and hunters during oral presentations about lead poisoning in wildlife and nonlead ammunition. Previously, only two nonlead programs conducted anecdotal observations of hunters during public meetings about lead poisoning and nonlead ammunition (Henry, 2016; Seng, 2005a). This limited but valuable observational research demonstrates the importance and usefulness of structured observations for use in future nonlead outreach programs. 
Table 6.1. Summary statistics from structured observation sessions at managed deer hunts with orientation sessions on National Wildlife Refuges participating in the outreach program encouraging hunters to use nonlead ammunition during 2016-2018.

\begin{tabular}{|c|c|c|c|c|c|c|c|}
\hline Year & Area & Presenter & $\begin{array}{c}\text { No. } \\
\text { hunters }\end{array}$ & $\begin{array}{c}\text { Overall } \\
\text { presentation } \\
\text { time (min) }\end{array}$ & $\begin{array}{l}\text { Lead presentation } \\
\text { time (min) }\end{array}$ & $\begin{array}{c}\text { PowerPoint } \\
\text { used? }\end{array}$ & $\begin{array}{c}\text { Questions } \\
\text { asked }\end{array}$ \\
\hline \multirow[t]{6}{*}{2016} & Loess Bluffs $^{\text {a }}$ & Visitor services specialist & 7 & 9 & 6 & Yes & $1^{\mathrm{b}}$ \\
\hline & Mingo (8AM) & Refuge manager & 54 & 39 & 4 & Yes & 0 \\
\hline & Mingo (9AM) & Refuge manager & 9 & 35 & 3 & Yes & 0 \\
\hline & Mingo (12PM) & Assistant refuge manager & 6 & 29 & 3 & Yes & 0 \\
\hline & Mingo (5PM) & Assistant refuge manager & 14 & 20 & 3 & Yes & 0 \\
\hline & Mingo (6PM) & Assistant refuge manager & 3 & 17 & 4 & Yes & $1^{\mathrm{c}}$ \\
\hline \multirow[t]{5}{*}{2017} & Swan Lake & Intern & 9 & 20 & 7 & Yes & 0 \\
\hline & Mingo (8AM) & Refuge manager & 30 & 30 & 3 & Yes & 0 \\
\hline & Mingo (9AM) & Refuge manager & 5 & 30 & 3 & Yes & 0 \\
\hline & Mingo (12PM) & Assistant refuge manager & 26 & 31 & 3 & Yes & 0 \\
\hline & Mingo (6PM) & Visitor services specialist & 12 & 24 & 3 & Yes & 0 \\
\hline 2018 & Clarence Cannon & Refuge manager & 18 & 14 & 2 & $\mathrm{No}^{\mathrm{d}}$ & 0 \\
\hline
\end{tabular}

${ }^{a}$ Squaw Creek NWR name changed in 2017 Loess Bluffs NWR.

${ }^{\mathrm{b}}$ One question was asked concerning the material used made to make nonlead ammunition.

${ }^{c}$ One question was asked concerning cost, and whether it costs more than lead ammunition.

${ }^{\mathrm{d}}$ A PowerPoint presentation was not given during the orientation session, but it was available on a laptop if any hunters wanted to view it later during the day; no one viewed the presentation while the observer was present. 


\section{Chapter 7. Contributions and Future Research}

\subsection{Overview}

Before discussing the contributions of this research and the need for further study, it is critical to acknowledge how multiple factors affected the USFWS, Region 3 nonlead program. Within a broader context of the current political and cultural climate surrounding guns, ammunition, and hunting., it is a remarkable achievement the nonlead program exists. Increasing cultural polarization (Bageant, 2007; Clark \& Teachout, 2012; Feinberg \& Willer, 2013), distrust of scientific information (McGarity \& Wagner, 2010; Michaels, 2008; Oreskes \& Conway, 2010), politization of natural resource management (Cohen, 2006; Nordhaus \& Shellenberger, 2009; Steingraber, 2010), and shifts in economic policies (CORE Team., 2019; Harvey, 2007; Igoe \& Brockington, 2007; Prugh, 1999) provided multiple external pressures on the program. To keep the program viable and reduce negative attention, the USFWS focused on information about bald eagles, avoided discussing human health risks, and discontinued surveying deer hunters on NWRs. Although not optimal for reducing the use of lead ammunition, this

narrow focus avoided conflict and kept the issue on the informal policy agenda (Cubbage et al., 2017; Sterner \& Coria, 2012) pending greater public support in the future. Contributions of this study and suggestions for future research, therefore, need to be viewed through this lens of socio-political complexity. 


\subsection{Methodological contributions}

Since the adoption of nontoxic-shot for North American waterfowl hunting, a large body of research has documented the effects of lead exposure on wildlife and human health (Buenz \& Parry, 2018; Felsmann, Szarek, Felsmann, \& Gulda, 2016; Goguen, Riley, Organ, \& Rudolph, 2018; Haig et al., 2014; Rattner et al., 2008), hunters' attitudes about lead ammunition regulations (Miller et al., 2013; Schroeder et al., 2016; Schroeder et al., 2012; Schulz, Reitz, et al., 2007), and factors related to the use of nonlead ammunition (Chase \& Rabe, 2015; McCann, Whitworth, \& Newman, 2016; Pierce et al., 2015; B. Smith et al., 2017; Stokke, Arnemo, \& Brainerd, 2019; V. G. Thomas, 2019). Often acknowledged is the need for increased human dimensions research (Arnemo et al., 2016; Arnemo et al., 2019; V. G. Thomas et al., 2019), but its use in natural resource management remains scarce (Bennett et al., 2017; Manfredo, Sullivan, Salerno, \& Berger, 2020).

To help remedy this deficiency, we used a convergent parallel mixed method research design (Creswell, 2014; Creswell \& Plano Clark, 2011) where quantitative and qualitative findings are integrated and compared after data collection (Patton, 2015).

Although not new (Creswell, 2014; Creswell \& Plano Clark, 2011), this is the first project to use a mixed-methods approach to explore attitudes and behaviors of natural resource professionals implementing a nonlead outreach program. This project used (1) structured observations of presentations given at managed hunts, (2) semi-structured interviews of USFWS staff implementing the program, and (3) an online survey of all USFWS staff on NWRs.

USFWS staff attitudes and perceptions were examined about lead poisoning in bald eagles, human health risks, availability and use of nonlead ammunition, differences 
between hunters and nonhunters, and factors affecting program support. In some circumstances, qualitative and quantitative methods provided complimentary results demonstrating how nonlead ammunition cost and availability were major issues affecting hunters decisions. In this example, quantitative survey results showed relative proportions of hunters using nonlead and lead ammunition in regard to attitudes about cost and availability. In a complimentary fashion, qualitative findings used participants' own words and experiences to describe their personal difficulties finding nonlead ammunition, and how cost was an impediment to their recreational shooting activities.

Alternatively, mixed methods provided unique perspectives not found otherwise. Structured observations demonstrated staff used a very limited amount of time to discuss lead poisoning during orientation sessions. This finding was corroborated with semistructured interviews by staff suggesting other refuge priorities may be more important. The complimentary value of these qualitative results also raised issues not addressed in the quantitative online survey and added context to issues raised superficially in the survey (e.g., the importance of human health and safety of friends and family when sharing lead contaminated venison). Quantitative survey data, however, showed how individuals' attitudes about lead poisoning in eagles, attitudes about information materials, and innovativeness predicted program support.

In addition to a mixed-methods research design, this project used multiple imputation for dealing with incomplete cases in survey data (Hayati Rezvan, Lee, \& Simpson, 2015; Mackinnon, 2010). If missing cases are completely random (Little, 1988), multiple imputation can address missing data issues better than casewise or listwise deletion methods (Rubin, 1987; Wayman, 2003). Multiple imputation creates 
datasets by replacing missing values with numbers mimicking the uncertainty in the original data (Hendee \& Flint, 2013; Song et al., 2013). The multiple imputation datasets can be pooled and compared with the complete-case results based on recommendations from Pedersen et al. (2017). In this study, the use of multiple imputation, in combination with linear regression, showed an additional variable was a significant predictor of program support.

\subsection{Theoretical contributions}

This study contributes to theory by bridging existing knowledge from environmental toxicology (Beyer, Heinz, \& Redmon-Norwood, 1996), wildlife diseases (Friend \& Laitman, 1987), and natural resource management (Soule \& Orians, 2001) to understand factors affecting behavioral changes while not only integrating human dimensions of natural resources (Decker et al., 2012), but also drawing on the multiple theories of social marketing (McKenzie-Mohr, 2000), public communication campaigns (Rice \& Atkin, 2013), and human health behavior (Glanz, Rimer, \& Viswanath, 2015). Numerous researchers have suggested using human dimensions research for addressing the lead poisoning issue (Arnemo et al., 2019; Cromie et al., 2014; Newth et al., 2019; Pain, Dickie, Green, Kanstrup, \& Cromie, 2019), but so far few studies have accomplished this goal (e.g., Henry, 2016). By connecting multiple disciplinary theories, this study developed a broader perspective of behavior change when dealing with competing values, ethics, and worldviews among stakeholders (Redpath et al., 2015; Sidaway, 2005). 
Although there was nearly 100-years of scientific information about lead poisoning in waterfowl, there was little support for a nontoxic-shot regulation at that time because policy makers did not have an understanding of hunter attitudes and perceptions about the issue or policy options (Ross-Winslow et al., 2011). Despite the U.S. waterfowl lead ammunition ban implemented during 1987-1991 (Schulz, Padding, et al., 2006; U.S. Department of the Interior - Fish and Wildlife Service, 1988), lead ammunition continues to affect wildlife and human health. Human dimensions research, however, can bridge between what is already known about toxicological aspects of lead poisoning and integrate that information in public communication campaigns, social marketing, human health behavior, and environmental program evaluation. Within the context of nonlead outreach programs, this research showed how multiple technical, social, economic, and political factors interact while affecting overlapping groups of hunters, nonhunters, and natural resource stakeholders (Figure 7.1).

This study also reaffirmed the theoretical importance of understanding attitudes spanning multiple behavioral models. Previous research has shown how attitudes are an important element in numerous behavioral models: e.g., Theory of Reasoned Action (Fishbein, 1979), Theory of Planned Behavior (Ajzen, 1991), Integrated Behavioral Model (Hagger \& Chatzisarantis, 2014; Montano \& Kasprzyk, 2015), Attitude-toBehavior Process Model (Fazio et al., 1989), and Prototype Willingness Model (Gerrard et al., 2008). Our findings show the importance of attitudes in understanding factors influencing changes in behavior. In this research, hunters having more favorable attitudes towards nonlead ammunition were more likely to use nonlead or have intentions to use it in the future. Similarly, attitudes of nonhunters were generally more favorable 
compared to deer hunters concerning attitudes about socio-economic factors related to nonlead ammunition. This study also reinforced findings from previous theoretical research showing the value of understanding attitudinal differences among different groups when designing persuasive outreach messages (Schroeder et al., 2012; Sponarski et al., 2015; Vaske \& Manfredo, 2012).

This research affirmed the complexity of the lead poisoning issue and the importance of adopter characteristics (Dearing, 2004) by showing how increases in innovativeness predicted greater program support by staff. Diffusion of innovation theory has a rich history spanning multiple disciplines and supported by a substantial body of research (Fitzgerald, Ferlie, \& Hawkins, 2003; Frambach \& Schillewaert, 2002; Ntemana \& Olatokun, 2012; Tidd \& Bessant, 2009). In addition to innovation, this research also used elements of the diffusion decision-process sub-model (Rogers, 2003) to highlight the need of reinforcing initial behavioral changes. This demonstrated the importance of recognizing decisions about purchasing and using nonlead ammunition involve a multi-step process; e.g., knowledge acquisition, persuasion to change behavior, decision to make a behavioral change, implementation of the new behavior, and confirmation and reinforcement of the behavior for long-term change. Recognition of a multiple stage decision process could help inform future outreach efforts and provide insights into outreach messages that reinforce hunters' long-term use of nonlead ammunition.

\subsection{Applied contributions}

Results from this project support multiple recommendations for improving future outreach efforts encouraging the voluntary use of nonlead ammunition (Table 7.1). 


\subsubsection{Problem complexity}

Traditionally, voluntary nonlead programs have relied on information campaigns to increase awareness and affect behavior change among hunters; i.e., application of the knowledge deficit model (Burgess et al., 1998; Redpath \& Sutherland, 2015; Sturgis \& Allum, 2004). However, results from this project showed efforts to influence hunter behavior may be more complex than simply sharing information. External socioeconomic factors related to cost and availability of nonlead ammunition likely affected staff support for the program (e.g., several staff remarked it was difficult to find nonlead ammunition at local retail stores). Also, long-term declines in hunting participation (Larson, Stedman, Decker, Siemer, \& Baumer, 2014; Quartuch et al., 2017) impacted the program with corresponding declines in hunting experience among USFWS staff and an inability of nonhunters to effectively communicate with hunters. This finding suggests nonlead materials and messaging need to adapt to changing conditions and situations. Staff recognized that changing hunter behavior requires more than brochures and standardized presentations. Additionally, staff recognized different audiences may exist within the deer hunter community, and some staff suggested nonhunters may be an important stakeholder in future outreach. Intertwined with this outreach program was a volatile mixture of overlapping socio-political firearms issues adding further complexity (e.g., $2^{\text {nd }}$ Amendment rights, gun control, and firearms excise taxes).

Information alone can sometimes address simple problems (Balint, Stewart, Desai, \& Walters, 2011; Dietz \& Stern, 2002) but complex problems (e.g., lead exposure in wildlife and human health) require additional changes at organizational and individual scales (Frambach \& Schillewaert, 2002). Future outreach could recognize these different 
scales of change to ensure the desired outcomes among different target audiences. It is also important to recognize that not all USWS staff were supportive of the outreach program; some believed the information used in the outreach materials was biased and not factual.

\subsubsection{Multiple audiences and messages}

Nonlead outreach has been previously directed toward hunters (Bedrosian et al., 2012; Chase \& Rabe, 2015). Recognizing other audiences, however, may help with developing multiple messages for specific groups. For example, USFWS staff who were nonhunters reported stronger attitudes than hunters about the negative effects of ingesting lead bullet fragments in venison. Results also showed differences in attitudes about nonlead cost and availability among staff who were hunters. These findings suggest groups of natural resource professionals who were hunters, nonhunters, nonlead ammunition users, and lead ammunition users may be influenced by different messages. Hunters currently using nonlead ammunition, for example, may respond more favorable to information reinforcing the improved ballistics of nonlead ammunition. Alternatively, hunters using lead ammunition may not be aware of the negative effects of lead ammunition and disagree with the available scientific information. Also, hunters using lead ammunition may be more responsive to shooting demonstrations conducted by opinion leaders.

Although the use of nonlead ammunition may be the most effective solution, hunters may be more engaged if they are provided a range of mitigating options. For example, the use of nonlead ammunition was the focus of outreach programs in northern 
Arizona and southern Utah (B. Smith et al., 2017) but these efforts also provided multiple mitigation options (e.g., burying gut the pile, taking a head or neck shot). Due to negative factors like cost and availability of nonlead ammunition identified by USFWS staff during this study, a similar approach recommending multiple mitigation options may improve future program outcomes.

Additionally, messages thought to be persuasive to some stakeholders may not be as effective with others, especially depending upon the timing of message delivery. For example, several staff indicated nonlead messaging aimed at hunters may be more effective if delivered months before hunting season, so hunters have time to adjust rifle scopes and acquire nonlead ammunition. As implemented, it is likely hunters were not aware of the nonlead program until they arrived at the refuge. Alternatively, one participant in the study stated their entire family were recreational shooters and pursued their hobby all year. Compared to hunters, recreational shooters may be more receptive to nonlead messages throughout the year. Future outreach may implement multiple strategies before and during the hunting season thereby allowing hunters to practice using nonlead before the hunting season and then reinforcing the behavior during the season.

\subsubsection{Innovation and stages of decision}

When natural resource professionals are requested to voluntarily participate in disseminating information about nonlead ammunition they become potential adopters of the nonlead innovation (Albarracín, 2002; Prochaska \& DiClemente, 1983). Our findings confirm this by showing how relative innovativeness among USFWS program staff was one of the factors affecting program support. Staff innovativeness, in turn, likely effects 
their role of change agents within the outreach program which further impacts information dissemination. Although the results from our research have limited external validity, we found innovativeness a useful construct for developing specific messages for groups defined by adopter categories; i.e., innovators, early adopters, early majority, late majority, and traditionalists or laggards. Our results have additional applications by showing the importance of innovativeness and stage of decision-making in future nonlead outreach. For example, messages tailored to an individuals' stage in the decision process and their innovativeness may improve support for the program.

\subsubsection{Program inputs and outcomes}

USFWS regional leaders developed the informational materials while refuge managers implemented the program at the local level. We found NWR staff with the greatest potential to interact with the public played support roles on the refuge (e.g., administrative assistants or technicians) or staff who were hunters with experience using nonlead ammunition. Although all staff had the potential to be a nonlead spokesperson, it is important to recognize individuals developing outreach materials played different roles than individuals implementing the program (Corner et al., 2015; McBride \& Burgman, 2012). Results showed that staff implementing the program on NWRs recognized they were confronted by different challenges at the local level compared to those individuals who developed the outreach materials at the regional level.

Although orientation sessions about lead poisoning and nonlead ammunition occurred at a limited number of NWRs, the results were emblematic of missed opportunities. Data showed presentations averaged less than four minutes which may 
have been perceived by hunters that the issue was a low priority. Another likely explanation is that presentations were designed to avoid possible conflict with this sensitive issue and quickly present only factual information about eagles and nonlead ammunition. These efficient efforts, however, limited opportunities to discuss the complex issues surrounding lead poisoning in bald eagles. Also, orientation sessions at managed hunters were held before hunters were allowed to go scouting or to go hunting on the refuge (e.g., 60 min before sunrise and the start of hunting) with hunters showing minimal interest in the presentations. The lack of time and the timing of the oral presentations precluded meaningful dialog among staff and hunters.

The need for additional training was demonstrated when staff expressed skepticism of the science and motives behind the program, discussed competing priorities on the refuge, differing perceptions of regulatory and voluntary approaches, differences in cost and availability of lead and nonlead ammunition, and disregard by some about lead ammunition being human health risk. Although there were numerous challenges that could be addressed with additional training, USFW staff identified numerous external political factors (e.g., $2^{\text {nd }}$ Amendment rights and gun control issues; Smyth, 2020; Whitney 2012) effecting the program that were beyond the control of the administrators or participants.

Last, program support was affected by attitudes toward eagles' lead risk, importance of informational materials, and an individual's innovativeness. Although previous studies have focused on influencing hunter behavior (Chase \& Rabe, 2015; B. Smith et al., 2017), this research showed how program support among staff could be improved by enhanced staff training based on perceived eagles' lead risk, importance of 
informational materials, and individuals' innovativeness. Innovative staff who are hunters, for example, may be more attuned to messages about the improved ballistics and lethality of nonlead while staff who are nonhunters may be more influenced by messages about lead exposure from spent ammunition in wildlife and humans.

\subsection{Limitations and future research}

Although original objectives included evaluation components for monitoring changes in hunter behavior, USFWS regional leadership decided during January 2018 not to apply for a public information request through the U.S. Office of Management and Budget and U.S. Office of Information and Regulatory Affairs. This decision resulted in our inability to communicate with deer hunters about the voluntary use of nonlead ammunition. Thus, inferences from this research can only be made to USFWS staff participating in the nonlead program. It is important not overlook this limitation because big-game hunting, dominated by white-tailed deer, supports $\$ 9.6$ billion in equipment sales and $\$ 7.3$ billion in trip-related expenses (U.S. Department of the Interior - Fish and Wildlife Service, U.S. Department of Commerce, \& Bureau, 2011). Therefore, attitudes and behaviors of USFWS staff who are hunters and nonhunters may not necessarily be representative of the general population.

Attempting to influence this social culture and economic enterprise was not inconsequential or without limitations. As a group, deer hunters are not homogeneous with demographic and behavioral characteristics varying by region. In the upper Midwest, for example, most deer hunters are white males, and many states require the use of shotguns with slugs compared to other regions of the country where high-powered 
rifles are allowed (U.S. Department of the Interior - Fish and Wildlife Service et al., 2011). Future nonlead voluntary programs should recognize these potential regional differences among deer hunters' attitudes, perceptions, and behaviors (e.g., hunting traditions and weapons choice vary regionally which in turn may affect persuasiveness of different messages and ultimately attitudes and behavior). Recognizing the importance of different audiences based on hunter backgrounds and regional variation will be critical in the success of future program development, implementation, and evaluation.

Because this project only assessed USFWS staff, future research is needed to understand broader audiences of deer hunters to obtain generalizable information. To fully assess nonlead outreach programs, future research should (1) secure funding for nonfederal sources to avoid political interference at the national level (while recognizing the problem of gun politics will not totally disappear with broader funding), (2) design a series of linked studies testing persuasive messages and materials targeted at different audiences, and (3) develop a long-term research strategy where multiple projects provide a series of summative assessments of voluntary programs over time.

Another factor related to the previously mentioned socio-political realities limiting research on deer hunters was our inability to randomly assign treatments, conduct before-and-after intervention measurements, or provide input for message development or implementation strategies. In addition, the program added more NWRs each year; four areas were piloted during 2016, 17 added in 2017, and another 33 added in 2018. Although shorter-term formative evaluations may have been possible given the constraints we had, the pilot nature of this expanding outreach effort precluded a comprehensive summative evaluation. Difficulties included our inability to measure 
effects of staff training materials across different hunting frameworks, effects caused by differences in the number of hunters among areas, variation in staff training, and amount of public contact among staff.

Future research could also consider exploring characteristics of individual program staff to identify the most effective individuals to represent the program based on their communication abilities and level of innovativeness. Previously, limited research on program support has focused on trained environmental educators or interpreters (Balasubramanyam et al., 2019; Corner et al., 2015; Liu et al., 2015). In our study, a limited number of NWR staff had some educational or outreach training whereas the vast majority were natural resource professionals responsible for a wide variety of public land management activities. The amount of staff training varied during the program but generally involved exposure to outreach materials and conference calls prior to the fall hunting season. Given the results of this project, future nonlead outreach programs would benefit from research building upon those factors affecting program support and staff training (e.g., training of all refuge staff, not just managers as suggested by some staff). There are also opportunities for future projects that integrate nonlead outreach with current efforts to recruit and retain hunters (Larson et al., 2014; Price Tack et al., 2018; Quartuch et al., 2017; Responsive Management \& National Shooting Sports Foundation, 2017). As new cohorts and demographic groups of hunters are recruited, it may be easier to encourage these new hunters to use nonlead ammunition than attempting to change existing hunters' behavior.

It is also important to recognize the implied or underlying purpose of the nonlead program was to keep the issue of lead poisoning in wildlife on the policy agenda, and not 
necessarily to affect a significant change in deer hunter behavior to voluntarily use nonlead ammunition or affect mortality in bald eagle populations. Compared to the total number deer hunters across the region, a relatively small number of them use NWRs. In addition to limited number of hunters exposed to the outreach message, the relative dose or exposure to the outreach messages was limited. The outreach program on 50 of the 54 relied solely on passive messaging during the hunting season using parking lot signs, rack cards on bulletin boards, and free-standing banners at area headquarters. Given this limited exposure to messages about lead poisoning and nonlead ammunition, it would have been difficult to measure a change in hunter behavior given the change would have been likely minimal.

Future research might consider a more robust evaluation framework linking frontend, formative, and summative evaluations (Ernst, Monroe, \& Simmons, 2012). For example, a series of refuges with similar types of hunts (e.g., managed deer hunts with inperson orientation sessions) may provide opportunities to build greater program support among staff by using focus groups to test the efficacy of different outreach materials and training techniques. Once staff are comfortable with the program messages, these can then be tested on different audiences of hunters across a broad region followed by formative evaluations. This initial work could then be used in a longer-term summative evaluation which would include monitoring changes in hunters' voluntary use of nonlead ammunition based on different hunter audiences and regions of the country. Front-end and formative evaluations could also explore attributes of program staff to identify their relative strengths and weaknesses as program representatives. Previously, limited research on program support has focused on environmental educators or interpreters 
(Balasubramanyam et al., 2019; Corner et al., 2015; Liu et al., 2015). In our study, a limited number of NWR staff had formal training in education or communication and there was inconsistent training on how to effectively share information to affect a change in deer hunter behavior.

Finally, the risk of human lead exposure from bullet fragments in venison was expressed by USFWS staff as a serious concern, suggesting this topic deserves more attention in future outreach. Although several staff recognized human health is not a USFWS responsibility or area of expertise, staff emphasized its importance in communicating with hunters. To avoid being "out of their lane”, future outreach coordinators may want to follow-up on suggestions by staff to build collaborative relationships with other natural resources management agencies and stakeholders to deal with the human health issue. For example, these partnerships could build upon the strengths of the different groups involved. Food banks and medical practitioners could focus on human health risks of lead exposure and the benefits of using nonlead ammunition while natural resource agencies could focus on wildlife impacts. Ammunition manufacturers may also play a key stakeholder role by marketing and packaging nonlead as a safe and environmentally friendly ammunition alternative. All stakeholders would collaborate in a multi-pronged communication strategy to affect hunter behavior.

Because of long-term trend declines in hunter participation (Fulton \& Manfredo, 2004; Larson et al., 2014), a concerted effort is underway across the U.S. to understand hunter motivations and behaviors, and use that information to recruit, retain, or reactivate lapsed hunters, or more commonly known as R3 (Responsive Management \& National 
Shooting Sports Foundation, 2017). Future research on human health risks related to lead ammunition could build upon this R3 framework by focusing on newer or younger hunters who could be more concerned about the quality of the meat they acquire (Stedman, Larson, Tidball, Tidball, \& Curtis, 2017). Additional research could also compare the efficacy of different nonlead messages between newer and experienced hunters to develop more effective and targeted messages (Larson et al., 2014; Quartuch et al., 2017). Given the importance of human health risk from lead ammunition, future research also needs to consider developing specific scales decoupling human health lead risks from perceived eagles' lead risk mitigating the multicollinearity issues we experienced (see Chapter 5).

\subsection{Conclusion}

Grappling with the issue of lead poisoning in North American waterfowl involved nearly 100 years of research and policy discussions before the culminating ban on lead shotshell ammunition in the U.S. was fully implemented in 1991 (Schulz, Padding, et al., 2006; U.S. Department of the Interior - Fish and Wildlife Service, 1988). In similar fashion, dealing with the dangerous environmental impacts of lead poisoning resulting from hunting other wildlife (Delahay \& Spray, 2014; Rattner et al., 2008), and related human health impacts (Goguen et al., 2018; Knott et al., 2010), appears to be following a similar trajectory of slow incremental progress. This project adds one additional piece of information in this continuing environmental saga examining a single regional-scale program on 54 NWRs encouraging hunters to use nonlead hunting information provide useful information for improving future programs. 
Although the issue of lead exposure from spent hunting ammunition requires environmental toxicological information to document the problem, effectively dealing with this complex environmental problem requires knowledge and expertise found in the social sciences, otherwise known as human dimensions (Bennett et al., 2017; F. Madden \& McQuinn, 2014; Robinson, Fuller, Stedman, Siemer, \& Decker, 2019). As stated earlier, we have sufficient information showing the ongoing negative impacts of using lead hunting ammunition. However, we need to make better use of this documenting information to affect behavior change among hunters (Arnemo et al., 2016), especially if voluntary programs are the default policy option (Schulz et al., 2019). Although not new, this project has demonstrated again that simply sharing technical and factual information rarely changes behavior. Similar to a considerable body of earlier social science research on this topic, this research project demonstrated the need for a more inclusive, coordinated, and well-funded public communication campaign recognizing contributions by using tools of conflict resolution and the importance developing and evaluating outreach efforts aimed at different audiences. 
Table 7.1. Applied contributions from an outreach program encouraging the voluntary use of nonlead ammunition on USFWS NWRs in the Upper Midwest during 2016-2019.

\begin{tabular}{|c|c|}
\hline Applied contributions & Recommendations \\
\hline Problem complexity & $\begin{array}{l}\text { Information sharing alone has limited effects on } \\
\text { changing behavior due to socio-economic and } \\
\text { socio-political factors of nonlead ammunition. } \\
\text { Complex problems require change at organizational } \\
\text { and individual scales. }\end{array}$ \\
\hline $\begin{array}{l}\text { Multiple audiences and } \\
\text { messages }\end{array}$ & $\begin{array}{l}\text { Recognize different groups of hunters may be } \\
\text { responsive to different messages, and nonhunters } \\
\text { are also an important stakeholder. } \\
\text { Provide multiple nonlead mitigation options for } \\
\text { hunters beyond using nonlead ammunition. } \\
\text { Timing of messages needs to reflect characteristics } \\
\text { of the target audience. }\end{array}$ \\
\hline $\begin{array}{l}\text { Innovation and stages of } \\
\text { decision }\end{array}$ & $\begin{array}{l}\text { Develop different messages for program staff and } \\
\text { hunters using innovativeness and decision- } \\
\text { making categories as a framework. }\end{array}$ \\
\hline Program inputs and outcomes & $\begin{array}{l}\text { Recognize that staff developing outreach materials } \\
\text { face different challenges than staff implementing } \\
\text { the program. } \\
\text { Oral presentations have the potential to initiate } \\
\text { dialog between staff and hunters, but additional } \\
\text { time and resources are needed. } \\
\text { Future efforts would benefit from additional training } \\
\text { recognizing differences among groups of staff } \\
\text { (e.g., hunters and nonhunters, nonlead users and } \\
\text { lead users). }\end{array}$ \\
\hline
\end{tabular}




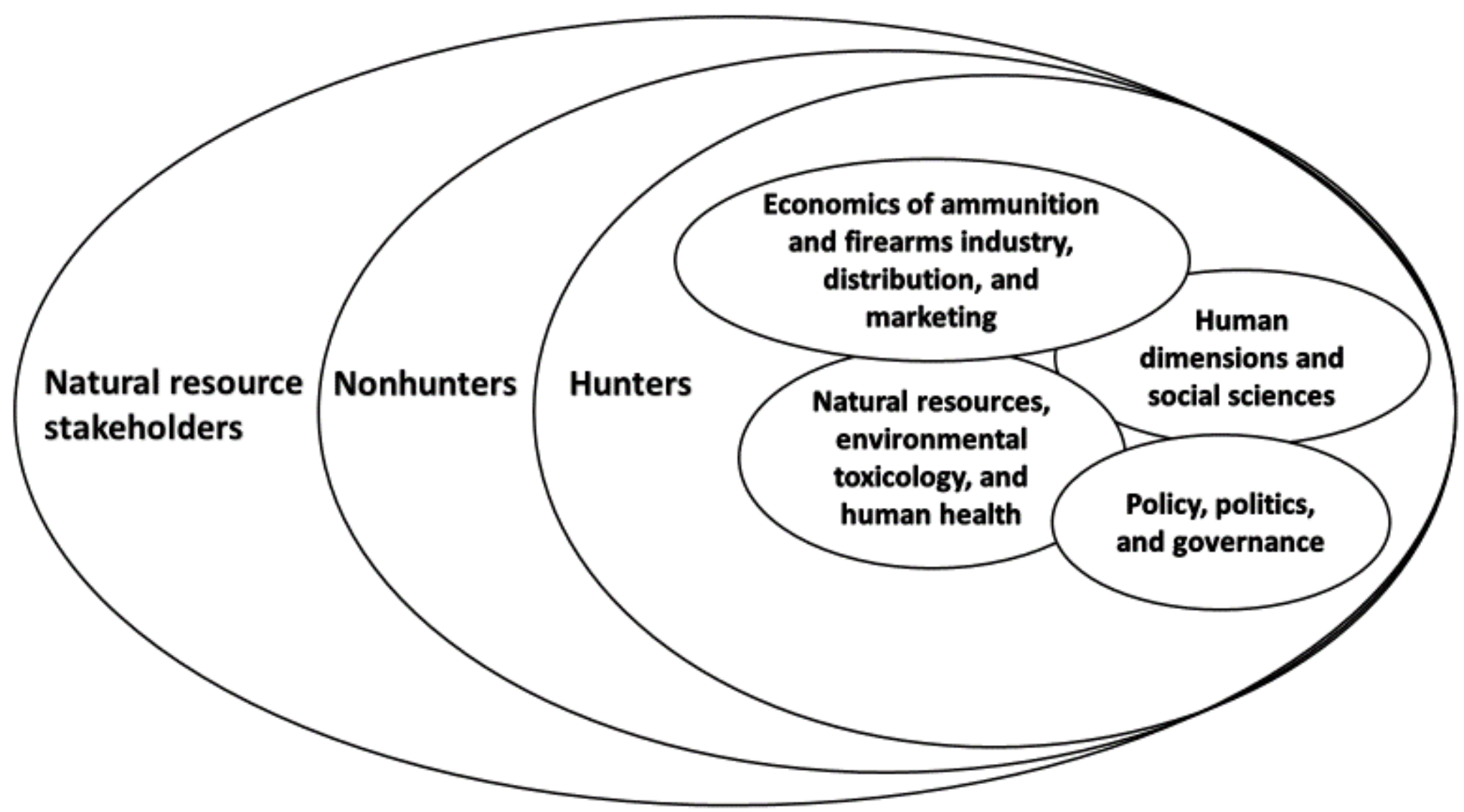

Figure 7.1. This research draws on a multi-disciplinary approach using literature from human dimensions research including social marketing and public communication campaigns, environmental toxicology and wildlife diseases, and natural resource management. Within the context of outreach programs encouraging voluntary use of nonlead hunting ammunition, these four elements interact to relationships among overlapping groups of hunters, nonhunters, and natural resource stakeholders. 


\section{References}

Ajzen, I. (1991). The theory of planned behavior. Organizational Behavior and Human Decision Processes, 50(2), 179-211. doi:10.1016/0749-5978(91)90020-T

Albarracín, D. (2002). Cognition in persuasion: an analysis of information processing in response to persuasive communications. Advances in Experimental Social Psychology, 34, 61-130. doi:10.1016/S0065-2601(02)80004-1

Alberini, A., \& Segerson, K. (2002). Assessing voluntary programs to improve environmental quality. Environmental and Resource Economics, 22(1), 157-184. doi:10.1023/a:1015519116167

Andersen, O., Wam, H. K., Mysterud, A., \& Kaltenborn, B. P. (2014). Applying typology analyses to management issues: deer harvest and declining hunter numbers. Journal of Wildlife Management, 78(7), 1282-1292. doi:10.1002/jwmg.770

Anderson, W. L., \& David, L. M. (1994). Results of the 1992 Illinois mourning dove hunter survey. (W-112-R). Springfield, Illinois, USA: Illinois Department of Conservation-Division of Wildlife Resources.

Anderson, W. L., Havera, S. P., \& Montgomery, R. A. (1987). Incidence of ingested shot in waterfowl in the Mississippi Flyway, 1977-1979. Wildlife Society Bulletin, 15(2), 181-188. doi:10.2307/3782599

Anderson, W. L., Havera, S. P., \& Zercher, B. W. (2000). Ingestion of lead and nontoxic shotgun pellets by ducks in the Mississippi Flyway. Journal of Wildlife Management, 64(3), 848-857. doi:10.2307/3802755

Arnemo, J. M., Andersen, O., Stokke, S., Thomas, V. G., Krone, O., Pain, D. J., \& Mateo, R. (2016). Health and environmental risks from lead-based ammunition: science versus socio-politics. EcoHealth, 13(4), 618-622. doi:10.1007/s10393016-1177-X

Arnemo, J. M., Cromie, R., Fox, A. D., Kanstrup, N., Mateo, R., Pain, D. J., \& Thomas, V. G. (2019). Transition to lead-free ammunition benefits all. Ambio. doi:10.1007/s13280-019-01221-x

Association of Fish \& Wildlife Agencies. (2017). Statement from the Association of Fish and Wildlife Agencies applauding Secretary Zinke in issuing secretarial orders on 
day one. Retrieved from http://www.fishwildlife.org/index.php?section=pressroom7\&prid $=334$

Association of Fish \& Wildlife Agencies. (2018). Research, data, reports, white papers, and best practices. Retrieved from https://www.fishwildlife.org/afwainforms/research

Atkin, C. K., \& Rice, R. E. (2013). Theory and principles of public communication campaigns. In R. E. Rice \& C. K. Atkin (Eds.), Public communication campaigns (4th ed., pp. 3-19). Thousand Oaks, California, USA: SAGE.

Avery, D., \& Watson, R. T. (2009). Regulation of lead-based ammunition around the world. In R. T. Watson, M. Fuller, M. A. Pokras, \& W. G. Hunt (Eds.), Ingestion of lead from spent ammunition: implications for wildlife and humans (pp. 161168). Boise, Idaho, USA: Peregrine Fund.

Bageant, J. (2007). Deer hunting with Jesus: dispatches from America's class war. New York, New York, USA: Three River Press.

Bakker, V. J., Smith, D. R., Copeland, H., Brandt, J., Wolstenholme, R., Burnett, J., . . . Finkelstein, M. E. (2017). Effects of Lead Exposure, Flock Behavior, and Management Actions on the Survival of California Condors (Gymnogyps californianus). EcoHealth, 14(1), 92-105. doi:10.1007/s10393-015-1096-2

Balasubramanyam, V., Wilhelm Stanis, S. A., Morgan, M., \& Ojewola, O. (2019). Climate change communication in the Midwestern United States: perceptions of state park interpreters. Environmental Management, 63(5), 615-628. doi:10.1007/s00267-019-01142-1

Balint, P. J., Stewart, R. E., Desai, A., \& Walters, L. C. (2011). Wicked environmental problems: managing uncertainty and conflict. Washington, D.C., USA: Island Press.

Barnett, J., Vasileiou, K., Djemil, F., Brooks, L., \& Young, T. (2011). Understanding innovators' experiences of barriers and facilitators in implementation and diffusion of healthcare service innovations: a qualitative study. BMC Health Services Research, 11(1), 342. doi:10.1186/1472-6963-11-342

Baum, D. (2013). Gun guys: a road trip. New York, New York, USA: Alfred A. Knopf. 
Bean, M. J., \& Rowland, M. J. (1997). The evolution of national wildlife law (3rd ed.). Westport, Connecticut, USA: Greenwood Publishing Group.

Bedrosian, B., Craighead, D., \& Crandall, R. (2012). Lead exposure in bald eagles from big game hunting, the continental implications and successful mitigation efforts. PLOS ONE, 7(12), e51978. doi:10.1371/journal.pone.0051978

Behmke, S., Fallon, J., Duerr, A. E., Lehner, A., Buchweitz, J., \& Katzner, T. (2015). Chronic lead exposure is epidemic in obligate scavenger populations in eastern North America. Environment International, 79, 51-55.

doi:10.1016/j.envint.2015.03.010

Belanger, D. O., \& Kinnane, A. (2002). Managing American wildlife: a history of the International Association of Fish and Wildlife Agencies. Rockville, MD: Montrose Press.

Bellinger, D. C., Bradman, A., Burger, J., Cade, T. J., Cory-Slechta, D. A., Doak, D., . . . Wright, R. (2013). Health risks from lead-based ammunition in the environment a consensus statement of scientists. Environmental Health Perspectives, 121(6), A178-A179. doi:10.1289/ehp.1306945

Bellinger, D. C., Leviton, A., Sloman, J., Rabinowitz, M., Needleman, H., \& Waternaux, C. (1991). Low-level lead exposure and children's cognitive function in the preschool years. Pediatrics, 87(2), 219-227.

Bellrose, F. C. (1959). Lead poisoning as a mortality factor in waterfowl populations. Illinois Natural History Survey Bulletin, 27(3), 236-288.

Bennett, N. J., Roth, R., Klain, S. C., Chan, K., Christie, P., Clark, D. A., . . Wyborn, C. (2017). Conservation social science: understanding and integrating human dimensions to improve conservation. Biological Conservation, 205, 93-108. doi:10.1016/j.biocon.2016.10.006

Best, L. B., Campa, H., III, Kemp, K. E., Robel, R. J., Ryan, M. R., Savidge, J. A., . . Winterstein, S. R. (1997). Bird abundance and nesting in CRP fields and cropland in the Midwest: a regional approach. Wildlife Society Bulletin, 25(4), 864-877. doi: $10.2307 / 3783737$ 
Beyer, W. N., Heinz, G. H., \& Redmon-Norwood, A. W. (Eds.). (1996). Environmental contaminants in wildlife: interpreting tissue concentrations. Boca Raton, Florida, USA: CRC - Lewis Publishers.

Black, K. E., Jensen, W. F., Newman, R., \& Boulanger, J. R. (2018). Motivations and satisfaction of North Dakota deer hunters during a temporal decline in deer populations. Human-Wildlife Interactions, 12(3), 427-443. doi:10.26077/zb6s$4 \mathrm{~m} 87$

Bowles, J. H. (1908). Lead poisoning in ducks. Auk, 25, 312-313. doi: doi:10.2307/4070529

Boykoff, M. T. (2013). Public enemy no. 1?: understanding media representations of outlier views on climate change. American Behavioral Scientist, 57(6), 796-817. doi:10.1177/0002764213476846

Broadway, M. S., McCallen, E. B., Caudell, J., \& Stewart, C. M. (2020). Ammunition type and shot placement determine lead fragmentation in deer. Journal of Wildlife Management, 84(7), 1406-1414. doi:10.1002/jwmg.21917

Brownson, R. C., Takak, R. G., Stamatakis, K. A., \& Glanz, K. (2015). Implementation, dissemination, and diffusion of public health interventions. In K. Glanz, B. K. Rimer, \& K. Viswanath (Eds.), Health behavior: theory, research, and practice (5th ed., pp. 301-325). San Francisco, California USA: Jossey-Bass.

Brunk, C. G. (2006). Public knowledge, public trust: understanding the 'knowledge deficit'. Public Health Genomics, 9(3), 178-183.

Brunner, R. D., Steelman, T. A., Coe-Juell, L., Cromley, C. M., Edwards, C. M., \& Tucker, D. W. (2005). Adaptive governance: integrating science, policy, and decision making. New York, USA: Columbia University Press.

Buenz, E. J., \& Parry, G. J. (2018). Chronic lead intoxication from eating wild-harvested game. American Journal of Medicine, 131(5), e181-e184. doi:10.1016/j.amjmed.2017.11.031

Bumann, G. B., \& Stauffer, D. F. (2002). Scavenging of ruffed grouse in the Appalachians: influences and implications. Wildlife Society Bulletin (1973-2006), 30(3), 853-860. 
Burgess, J., Harrison, C. M., \& Filius, P. (1998). Environmental communication and the cultural politics of environmental citizenship. Environment and Planning A: Economy and Space, 30(8), 1445-1460. doi:10.1068/a301445

Büscher, B., Dressler, W., \& Fletcher, R. (Eds.). (2014). Nature Inc. Environmental conservation in the neoliberal age. Tucson, Arizona, USA: University of Arizona Press.

Cabrera-Nguyen, P. (2010). Author guidelines for reporting scale development and validation results in the Journal of the Society for Social Work and Research. Journal of the Society for Social Work and Research, 1(2), 99-103. doi:10.5243/jsswr.2010.8

California Assembly Bill 711. (2013). Hunting: nonlead ammunition. Retrieved from http://leginfo.legislature.ca.gov/faces/billNavClient.xhtml?bill_id=201320140AB $\underline{711}$

California Department of Fish and Wildlife. (2017). Nonlead ammunition in California. Retrieved from https://www.wildlife.ca.gov/hunting/nonlead-ammunition

Calvert, J. H. (1876). Pheasants poisoned by swallowing shots. The Field, 47(1,208), 189. Case, D. J., \& Associates. (2006). Non-toxic shot regulation inventory of the Unitied States and Canada. Mishawaka, Indiana, USA: D.J. Case and Associates.

Case, D. J., \& Associates. (2014). National dove hunting survey 2013: national and dove management unit descriptive statistics. Mishawaka, Indiana, USA: D.J. Case and Associates.

Castree, N. (2008). Neoliberalising nature: the logics of deregulation and reregulation. Environment and Planning A: Economy and Space, 40(1), 131-152. doi:10.1068/a3999

Chase, L., \& Rabe, M. J. (2015). Reducing lead on the landscape: anticipating hunter behavior in absence of a free nonlead ammunition program. PLOS ONE, 10(6), e0128355. doi:10.1371/journal.pone.0128355

Chen, J. V., Yen, D. C., \& Chen, K. (2009). The acceptance and diffusion of the innovative smart phone use: a case study of a delivery service company in logistics. Information \& Management, 46(4), 241-248.

doi:10.1016/j.im.2009.03.001 
Cheng, J. C.-H., \& Monroe, M. C. (2010). Examining Teachers' Attitudes Toward a Required Environmental Education Program. Applied Environmental Education \& Communication, 9(1), 28-37. doi:10.1080/15330150903566463

Cheng, T., Woon, D. K., \& Lynes, J. K. (2011). The use of message framing in the promotion of environmentally sustainable behaviors. Social Marketing Quarterly, 17(2), 48-62. doi:10.1080/15245004.2011.570859

Church, M. E., Gwiazda, R., Risebrough, R. W., Sorenson, K., Chamberlain, C. P., Farry, S., ... Smith, D. R. (2006). Ammunition is the principal source of lead accumulated by California condors re-introduced to the wild. Environmental Science \& Technology, 40(19), 6143-6150. doi:10.1021/es060765s

Cialdini, R. B., Demaine, L. J., Sagarin, B. J., Barrett, D. W., Rhoads, K., \& Winter, P. L. (2006). Managing social norms for persuasive impact. Social Influence, 1(1), 315. doi:10.1080/15534510500181459

Clark, S., \& Teachout, W. (2012). Slow democracy: rediscovering community, bringing decision making back home. White River, Vermont, USA: Chelsea Green Publishing.

Clarkson, T. W. (1987). Metal toxicity in the central nervous system. Environmental Health Perspectives, 75, 59-64.

Cohen, M. J. (2006). "The death of environmentalism": introduction to the symposium. Organization \& Environment, 19(1), 74-81. doi:10.1177/1086026605285586

Coleman, P. T. (2003). Characteristics of protracted, intractable conflict: toward the development of a metaframework-I. Peace and Conflict: Journal of Peace Psychology, 9(1), 1-37. doi:10.1207/S15327949PAC0901_01

Coleman, P. T. (2006). Conflict, complexity, and change: a meta-framework for addressing protracted, intractable conflicts-III. Peace and Conflict: Journal of Peace Psychology, 12(4), 325-348. doi:10.1207/s15327949pac1204_3

Congressional Sportsmen's Foundation. (2020). Game meat donation programs. Retrieved from http://congressionalsportsmen.org/policies/state/game-meatdonation-programs

Copeland, H. E., Pocewicz, A., Naugle, D. E., Griffiths, T., Keinath, D., Evans, J., \& Platt, J. (2013). Measuring the effectiveness of conservation: a novel framework 
to quantify the benefits of sage-grouse conservation policy and easements in Wyoming. PLOS ONE, 8(6), e67261. doi:10.1371/journal.pone.0067261

Corbett, J. B. (2006). Communicating nature: how we create and understand environmental messages. Washington, D.C., USA: Island Press.

CORE Team. (2019). Economy, society, and public poliyc. New York, New York, USA: Oxford University Press.

Corner, A., Roberts, O., Chiari, S., Völler, S., Mayrhuber, E. S., Mandl, S., \& Monson, K. (2015). How do young people engage with climate change? The role of knowledge, values, message framing, and trusted communicators. WIREs Climate Change, 6(5), 523-534. doi:10.1002/wcc.353

Cortina, J. M. (1993). What is coefficient alpha? An examination of theory and applications. Journal of applied psychology, 78(1), 98. doi:0021-90I0/93

Craighead, D., \& Bedrosian, B. (2008). Blood lead levels of common ravens with access to big-game offal. Journal of Wildlife Management, 72(1), 240-245. doi:10.2193/2007-120

Creswell, J. W. (2014). Research design: qualitative, quantitative, and mixed methods approaches (4th ed.). Los Angeles, California, USA: SAGE.

Creswell, J. W., \& Plano Clark, V. L. (2011). Designing and conducting mixed methods research (2nd ed.). Los Angles, California, USA: SAGE.

Cromie, R., Newth, J., Reeves, J., O’Brien, M., Beckmann, K., \& Brown, M. (2014). The sociological and political aspects of reducing lead poisoning from ammunition in the UK: why the transition to non-toxic ammunition is so difficult. In R. J. Delahay \& C. J. Spray (Eds.), Lead ammunitioin: Understanding and Minimising the Risks to Human and Environmental Health (pp. 104-124). University of Oxford, UK: Edward Grey Institude.

Cromie, R., Newth, J., \& Strong, E. (2019). Transitioning to non-toxic ammunition: making change happen. Ambio, 48(9), 1079-1096. doi:10.1007/s13280-01901204-y

Cruz-Martinez, L., Redig, P. T., \& Deen, J. (2012). Lead from spent ammunition: a source of exposure and poisoning in bald eagles. Human-Wildlife Interactions, 6(1), 94-104. 
Cubbage, F., O'Laughlin, J., \& Person, M. N. (2017). Natural resource policy. Long Grove, Illinois, USA: Waveland Press.

D'Elia, J., \& Haig, S. M. (2013). California condors in the Pacific Northwest. Corvallis, OR: Oregon State University Press.

Dearing, J. W. (2004). Improving the state of health programming by using diffusion theory. Journal of Health Communication, 9(sup1), 21-36. doi:10.1080/10810730490271502

Dearing, J. W. (2009). Applying diffusion of innovation theory to intervention development. Research on Social Work Practice, 19(5), 503-518. doi:10.1177/1049731509335569

Decker, D. J., \& Connelly, N. A. (1989). Motivations for deer hunting: implications for antlerless deer harvest as a management tool. Wildlife Society Bulletin, 17(4), 455-463.

Decker, D. J., Riley, S. J., \& Siemer, W. F. (Eds.). (2012). Human dimensions of wildlife management (2nd ed.). Baltimore, Maryland, USA: Johns Hopkins University Press.

Delahay, R. J., \& Spray, C. J. (2014). Proceedings of the Oxford lead symposium. Paper presented at the Lead ammunition: understanding and minimising the risks to human and environmental health, University of Oxford, UK.

Delile, H., Blichert-Toft, J., Goiran, J.-P., Keay, S., \& Albarède, F. (2014). Lead in ancient Rome's city waters. Proceedings of the National Academy of Sciences, 111(18), 6594-6599. doi:10.1073/pnas.1400097111

Demirel, P., Iatridis, K., \& Kesidou, E. (2018). The impact of regulatory complexity upon self-regulation: evidence from the adoption and certification of environmental management systems. Journal of Environmental Management, 207, 80-91. doi:10.1016/j.jenvman.2017.11.019

Dervin, B., \& Foreman-Wernet, L. (2013). Sense-making methodology as an apporach to understanding and designing for campaign audiences. In R. E. Rice \& C. K. Atkin (Eds.), Public communication campaigns (4th ed.). Los Angeles, California, USA: SAGE. 
Diamantopoulos, A., Siguaw, J. A., \& Siguaw, J. A. (2000). Introducing LISREL: a guide for the uninitiated. London, UK: SAGE.

Dietz, T. (2002). Understanding voluntary measures. In T. Dietz \& P. C. Stern (Eds.), New tools for environmental protection: education, information, and voluntary measures (pp. 319-333). Washington, D.C., USA: National Academy Press.

Dietz, T., \& Stern, P. C. (2002). Exploring new tools for environmental protection. In T. Dietz \& P. C. Stern (Eds.), New tools for environmental protection: education, information, and voluntary measures (pp. 1-15). Washington, D.C., USA: National Acdemy Press.

Dillman, D. A., Smyth, J. D., \& Melani Christian, L. (2014). Internet, phone, mail, and mixed-mode survey: the tailored design method (4th ed.). Hoboken, New Jersey, USA: John Wiley \& Sons.

Dingfelder, H. E., \& Mandell, D. S. (2011). Bridging the research-to-practice gap in autism intervention: an application of diffusion of innovation theory. Journal of Autism and Developmental Disorders, 41(5), 597-609. doi:10.1007/s10803-0101081-0

Donahue, J. D., \& Zeckhauser, R. J. (2011). Collaborative governance: private roles for public goals in turbulent times. Princeton, New Jersey, USA: Princeton University Press.

Duda, M. D. (2004). California hunters' knowledge of and attitudes toward threats to California condors. Harisburg, Virginia, USA: Responsive Management.

Duguay, J. P., Tolson, K. M., \& Holt, J. (2017). Lead shot concentrations in and adjacent to fields managed for mourning doves and effects of tillage on shot concentrations in Tangipahoa Parish, Louisiana. Journal of the Southeastern Association of Fish and Wildlife Agencies, 4, 68-72.

Earl, R., Burns, N., Nettelbeck, T., \& Baghurst, P. (2016). Low-level environmental lead exposure still negatively associated with children's cognitive abilities. Australian Journal of Psychology, 68(2), 98-106. doi:10.1111/ajpy.12096

Ebeling-Schuld, A. M., \& Darimont, C. T. (2017). Online hunting forums identify achievement as prominent among multiple satisfactions. Wildlife Society Bulletin, 41(3), 523-529. doi:10.1002/wsb.796 
Ecke, F., Singh, N. J., Arnemo, J. M., Bignert, A., Helander, B., Berglund, Å. M. M., . . . Hörnfeldt, B. (2017). Sublethal lead exposure alters movement behavior in freeranging golden eagles. Environmental Science \& Technology, 51(10), 5729-5736. doi:10.1021/acs.est.6b06024

Eisler, R. (1988). Lead hazards to fish, wildlife, and invertebrates: a snoptic review. (Report No. 14). Laurel, MD USA: U.S. Fish and Wildlife Service.

Enck, J. W., Decker, D. J., \& Brown, T. L. (2000). Status of hunter recruitment and retention in the United States. Wildlife Society Bulletin, 28(4), 817-824.

Epps, C. W. (2014). Considering the switch: challenges of transitioning to non-lead hunting ammunition. Condor, 429-434. doi:10.1650/CONDOR-14-78.1

Ernst, J. A., Monroe, M. C., \& Simmons, B. (2012). Evaluating your environmental education programs: a workbook for practices (2nd ed.). Washington, D.C., USA: North American Association for Environmental Education.

Fachehoun, C. R., Lévesque, B., Dumas, P., St-Louis, A., Dubé, M., \& Ayotte, P. (2015). Lead exposure through consumption of big game meat in Québec (Canada): risk assessment and perception. Food Additives \& Contaminants: Part A, 1501-1511. doi:10.1080/19440049.2015.1071921

Fazio, R. H., Powell, M. C., \& Williams, C. J. (1989). The role of attitude accessibility in the Attitude-to-Behavior Process. Journal of Consumer Research, 16(3), 280-288. doi:10.1086/209214

Feierabend, J. S. (1985). Comment: impacts of current federal policy on National Wildlife Refuges nontoxic shot zones. Wildlife Society Bulletin, 13(1), 88-92. doi: $10.2307 / 3781958$

Feierabend, J. S. (1985). Legal challenges to nontoxic (steel) shot regulations. Proceedings of the Annual Conference of the Southeastern Association of Fish and Wildlife Agencies, 39, 452-458.

Feinberg, M., \& Willer, R. (2013). The moral roots of environmental attitudes. Psychological Science, 24(1), 56-62. doi:10.1177/0956797612449177

Felsmann, M. Z., Szarek, J., Felsmann, M., \& Gulda, D. (2016). Lead in game bird meat as a risk to public health: new aspects in the light of physical phenomena 
generated by a projectile. Journal of Elementology, 21(2), 595-607.

doi:10.5601/jelem.2015.20.3.989

Finkelstein, M. E., Doak, D. F., George, D., Burnett, J., Brandt, J., Church, M., . .

Smith, D. R. (2012). Lead poisoning and the deceptive recovery of the critically endangered California condor. Proceedings of the National Academy of Sciences, USA, 109(28), 11449-11454. doi:10.1073/pnas.1203141109

Finkelstein, M. E., George, D., Scherbinski, S., Gwiazda, R., Johnson, M., Burnett, J., . . . Smith, D. R. (2010). Feather lead concentrations and 207Pb/206Pb ratios reveal lead exposure history of California condors (Gymnogyps californianus). Environmental Science \& Technology, 44(7), 2639-2647. doi:10.1021/es903176w

Fishbein, M. (1979). A theory of reasoned action: some applications and implications. Nebraska Symposium on Motivation, 27, 65-116.

Fishbein, M. (2008). A reasoned action approach to health promotion. Medical Decision Making, 28(6), 834-844. doi:10.1177/0272989x08326092

Fishbein, M., \& Ajzen, I. (2010). Predicting and changing behavior: the reasond action approach. New York, New York, USA: Psychology Press - Taylor \& Francis Group.

Fishbein, M., \& Cappella, J. N. (2006). The role of theory in developing effective health communications. Journal of Communication, 56, S1-S17. doi:10.1111/j.14602466.2006.00280.x

Fishbein, M., \& Yzer, M. C. (2003). Using theory to design effective health behavior interventions. Communication Theory, 13(2), 164-183. doi:10.1111/j.14682885.2003.tb00287.x

Fitzgerald, L., Ferlie, E., \& Hawkins, C. (2003). Innovation in healthcare: How does credible evidence influence professionals? Health Social Care in the Community, 11(3), 219-228. doi:10.1046/j.1365-2524.2003.00426.x

Flick, U. (2014). An introduction to qualitative research (5th ed.). Thousand Oaks, California, USA: SAGE.

Frambach, R. T., \& Schillewaert, N. (2002). Organizational innovation adoption: a multilevel framework of determinants and opportunities for future research. Journal of Business Research, 55(2), 163-176. doi:10.1016/S0148-2963(00)00152-1 
Franson, J. C., Hansen, S. P., \& Schulz, J. H. (2009). Ingested shot and tissue lead concentrations in mourning doves. In R. T. Watson, M. Fuller, M. A. Pokras, \& G. Hunt (Eds.), Ingestion of Lead from Spent Ammunition: Implications for Wildlife and Humans (pp. 175-186). Boise, Idaho, USA: The Peregrine Fund.

Franson, J. C., \& Russell, R. (2014). Lead and eagles: demographic and pathological characteristics of poisoning, and exposure levels associated with other causes of mortality. Ecotoxicology, 23(9), 1722-1731. doi:10.1007/s10646-014-1337-0

Friend, M., \& Laitman, C. J. (Eds.). (1987). Field guide to wildlife diseases: volume 1 general field procedures and diseases of migratory birds. Washington, D.C., USA: U.S. Department of Interior - Fish and Wildlife Serive.

Fulton, D. C., \& Manfredo, M. J. (2004). A panel design to assess the effects of regulatory induced reductions in opportunity on deer hunters' satisfaction. Human Dimensions of Wildlife, 9(1), 35-55. doi:10.1080/10871200490272160

Fulton, D. C., Manfredo, M. J., \& Lipscomb, J. (1996). Wildlife value orientations: a conceptual and measurement approach. Human Dimensions of Wildlife, 1(2), 2447. doi:10.1080/10871209609359060

Fulton, D. C., Skerl, K., Shank, E. M., \& Lime, D. W. (2004). Beliefs and attitudes toward lethal management of deer in Cuyahoga Valley National Park. Wildlife Society Bulletin, 32(4), 1166-1176. doi:doi:10.2193/00917648(2004)032[1166:BAATLM]2.0.CO;2

Gamson, W. A., \& Modigliani, A. (1989). Media discourse and public opinion on nuclear power: a constructionist approach. American Journal of Sociology, 95(1), 1-37. doi:10.1086/229213

Garson, G. D. (2014). Structural equation modeling. Asheboro, North Carolina, USA: Statistical Publishing Associates.

Genskow, K. D., \& Wood, D. M. (2009). Measurement, learning, and adaptation in planning and implementing voluntary nonpoint source watershed programs. Journal of Planning Literature, 24(2), 137-154. doi:10.1177/0885412209358049

Gerofke, A., Ulbig, E., Martin, A., Müller-Graf, C., Selhorst, T., Gremse, C., . . Hensel, A. (2018). Lead content in wild game shot with lead or non-lead ammunition - 
does "state of the art consumer health protection" require non-lead ammunition? PLOS ONE, 13(7), e0200792. doi:10.1371/journal.pone.0200792

Gerrard, M., Gibbons, F. X., Houlihan, A. E., Stock, M. L., \& Pomery, E. A. (2008). A dual-process approach to health risk decision making: the prototype willingness model. Developmental Review, 28(1), 29-61. doi:10.1016/j.dr.2007.10.001

Glanz, K., Rimer, B. K., \& Viswanath, K. (Eds.). (2015). Health behavior: theory, research, and practice (5th ed.). San Francisco, California, USA: Jossey-Bass.

Glucs, Z. E., Smith, D. R., Tubbs, C. W., Bakker, V. J., Wolstenholme, R., Dudus, K., . . . Finkelstein, M. E. (2020). Foraging behavior, contaminant exposure risk, and the stress response in wild California condors (Gymnogyps californianus).

Environmental Research, 189, 109905. doi:10.1016/j.envres.2020.109905

Goddard, C. I., Leonard, N. J., Stang, D. L., Wingate, P. J., Rattner, B. A., Franson, J. C., \& Sheffield, S. R. (2008). Management concerns about known and potential impacts of lead use in shooting and in fishing activities. Fisheries, 33(5), 228-236. doi:10.1577/1548-8446-33.5.228

Goguen, A. D., Riley, S. J., Organ, J. F., \& Rudolph, B. A. (2018). Wild-harvested venison yields and sharing by Michigan deer hunters. Human Dimensions of Wildlife, 23(3), 197-212. doi:10.1080/10871209.2017.1409372

Golden, N., Warner, S., \& Coffey, M. (2016). A review and assessment of spent lead ammunition and its exposure and effects to scavenging birds in the United States. In W. P. de Voogt (Ed.), Reviews of Environmental Contamination and Toxicology Volume 237 (Vol. 237, pp. 123-191): Springer International Publishing Switzerland.

Gomo, G., Mattisson, J., Hagen, B. R., Moa, P. F., \& Willebrand, T. (2017). Scavenging on a pulsed resource: quality matters for corvids but density for mammals. $B M C$ Ecology, 17(1), 22. doi:10.1186/s12898-017-0132-1

Grade, T. J., Campbell, P., Cooley, T., Kneeland, M., Leslie, E., MacDonald, B., . . . Pokras, M. (2019). Lead poisoning from ingestion of fishing gear: a review. Ambio, 48, 1023-1038. doi:10.1007/s13280-019-01179-w 
Grade, T. J., Pokras, M. A., Laflamme, E. M., \& Vogel, H. S. (2018). Population-level effects of lead fishing tackle on common loons. Journal of Wildlife Management, 82(1), 155-164. doi:10.1002/jwmg.21348

Green, R. E., Hunt, W. G., Parish, C. N., \& Newton, I. (2008). Effectiveness of action to reduce exposure of free-ranging California condors in Arizona and Utah to lead from spent ammunition. PLOS ONE, 3(12), e4022. doi:10.1371/journal.pone.0004022

Green, R. E., \& Pain, D. J. (2019). Risks to human health from ammunition-derived lead in Europe. Ambio, 48(9), 954-968. doi:10.1007/s13280-019-01194-X

Greenhalgh, T., Robert, G., Macfarlane, F., Bate, P., \& Kyriakidou, O. (2004). Diffusion of innovations in service organizations: systematic review and recommendations. Milbank Quarterly, 82(4), 581-629. doi:10.1111/j.0887-378X.2004.00325.x

Grinnell, G. (1894). Lead poisoning. Forest and Stream, 42(6), 117-118.

Grund, M. D., Cornicelli, L., Carlson, L. T., \& Butler, E. A. (2010). Bullet fragmentation and lead deposition in white-tailed deer and domestic sheep. Human-Wildlife Interactions, 4(2), 257-265.

Guy, S., Kashima, Y., Walker, I., \& O'Neill, S. (2014). Investigating the effects of knowledge and ideology on climate change beliefs. European Journal of Social Psychology, 44(5), 421-429. doi:10.1002/ejsp.2039

Hagger, M. S., \& Chatzisarantis, N. L. D. (2014). An integrated behavior change model for physical activity. Exercise and Sport Sciences Reviews, 42(2), 62-69.

Haig, S. M., D'Elia, J., Eagles-Smith, C., Fair, J. M., Gervais, J., Herring, G., . . Schulz, J. H. (2014). The persistent problem of lead poisoning in birds from ammunition and fishing tackle. Condor, 116, 408-428. doi:10.1650/CONDOR-14-36.1

Hall, D. M., Feldpausch-Parker, A., Peterson, T. R., Stephens, J. C., \& Wilson, E. J. (2017). Social-ecological system resonance: a theoretical framework for brokering sustainable solutions. Sustainability Science, 12(3), 381-392. doi:10.1007/s11625-017-0424-6

Hampton, J. O., Laidlaw, M., Buenz, E., \& Arnemo, J. M. (2018). Heads in the sand: public health and ecological risks of lead-based bullets for wildlife shooting in Australia. Wildlife Research, 45(4), 287-306. doi:10.1071/WR17180 
Hanna-Attisha, M. (2018). What the eyes don't see: a story of crisis, resistance, and hope in an American city. New York, New York, USA: Random House.

Hanna-Attisha, M., LaChance, J., Sadler, R. C., \& Schnepp, A. C. (2016). Elevated blood lead levels in children associated with the Flint drinking water crisis: a spatial analysis of risk and public health response. American Journal of Public Health, 106(2), 283-290. doi:10.2105/ajph.2015.303003

Harvey, D. (2007). Neoliberalism as creative destruction. ANNALS of the American Academy of Political and Social Science, 610(1), 21-44. doi:10.1177/0002716206296780

Havera, S. P., Hine, C. S., \& Georgi, M. M. (1994). Waterfowl hunter compliance with nontoxic shot regulations in Illinois. Wildlife Society Bulletin, 22, 454-460.

Hayati Rezvan, P., Lee, K. J., \& Simpson, J. A. (2015). The rise of multiple imputation: a review of the reporting and implementation of the method in medical research. BMC Medical Research Methodology, 15(1), 30. doi:10.1186/s12874-015-0022-1

Heberlein, T. A. (2012a). Navigating environmental attitudes. New York, New York, USA: Oxford University Press.

Heberlein, T. A. (2012b). Navigating environmental attitudes. Conservation Biology, 26(4), 583-585. doi:10.1111/j.1523-1739.2012.01892.x

Helander, B., Axelsson, J., Borg, H., Holm, K., \& Bignert, A. (2009). Ingestion of lead from ammunition and lead concentrations in white-tailed sea eagles (Haliaeetus albicilla) in Sweden. Science of the Total Environment, 407(21), 5555-5563. doi:10.1016/j.scitotenv.2009.07.027

Hendee, J. T., \& Flint, C. G. (2013). Managing private forestlands along the publicprivate interface of Southern Illinois: Landowner forestry decisions in a multijurisdictional landscape. Forest Policy and Economics, 34, 47-55. doi:10.1016/j.forpol.2013.04.009

Henry, K. (2016). Examining the effect of the Hunter's Choice: Alternative Ammunition project on Minnesota deer hunters' knowledge, attitudes, behavioral intentions, and behaviors regarding lead ammunition. (Master of Environmental Education Master's Plan B), University of Minnesota, St. Paul, Minnesota, USA. 
Herring, G., Eagles-Smith, C. A., \& Wagner, M. T. (2016). Ground squirrel shooting and potential lead exposure in breeding avian scavengers. PLOS ONE, 11(12), e0167926. doi:10.1371/journal.pone.0167926

Heynen, N., \& Robbins, P. (2005). The neoliberalization of nature: governance, privatization, enclosure and valuation. Capitalism Nature Socialism, 16(1), 5-8. doi:10.1080/1045575052000335339

Hinrichs, M. P., Price, N. B., Gruntorad, M. P., Pope, K. L., Fontaine, J. J., \& Chizinski, C. J. (2020). Understanding sportsperson retention and reactivation through license purchasing behavior. Wildlife Society Bulletin, 44(2), 383-390. doi:10.1002/wsb.1088

Holmes, G., \& Cavanagh, C. J. (2016). A review of the social impacts of neoliberal conservation: formations, inequalities, contestations. Geoforum, 75, 199-209. doi:10.1016/j.geoforum.2016.07.014

Hooper, D., Coughlan, J., \& Mullen, M. R. (2008). Structural equation modelling: guidelines for determining model fit. Electronic journal of business research methods, 6(1), 53-60.

Hrubes, D., Ajzen, I., \& Daigle, J. (2001). Predicting hunting intentions and behavior: an application of the Theory of Planned Behavior. Leisure Sciences, 23(3), 165-178. doi:10.1080/014904001316896855

Humburg, D. D., Sheriff, S. L., Geissler, P. H., \& Roster, T. (1982). Shotshell and shooter effectiveness: lead vs. steel shot for duck hunting. Wildlife Society Bulletin, 10(2), 121-126. doi:10.2307/3781729

Hunt For Truth Association. (2017a). Litigation and petitions. Retrieved from http://www.huntfortruth.org/legal/litigation-and-petitions/

Hunt For Truth Association. (2017b). The truth behind the assault on hunting. Retrieved from http://www.huntfortruth.org/

Hunt, W. G., Burnham, W., Parish, C. N., Burnham, K. K., Mutch, B., \& Oaks, J. L. (2006). Bullet fragments in deer remains: implications for lead exposure in avian scavengers. Wildlife Society Bulletin, 34(1), 167-170. doi:10.2193/00917648(2006)34[167:BFIDRI]2.0.CO;2 
Hunt, W. G., Watson, R. T., Oaks, J. L., Parish, C. N., Burnham, K. K., Tucker, R. L., . . . Hart, G. (2009). Lead bullet fragments in venison from rifle-killed deer: potential for human dietary exposure. PLOS ONE, 4(4), e5330.

doi:10.1371/journal.pone.0005330

Hunter, R. F., McAneney, H., Davis, M., Tully, M. A., Valente, T. W., \& Kee, F. (2015). "Hidden" social networks in behavior change interventions. American Journal of Public Health, 105(3), 513-516. doi:10.2105/AJPH.2014.302399

Hurt, H. T., Joseph, K., \& Cook, C. D. (1977). Scales for the measurement of innovativeness. Human Communication Research, 4, 58-65.

Huxham, C. (2003). Theorizing collaboration practice. Public Management Review, 5(3), 401-423. doi:10.1080/1471903032000146964

Huxham, C., Vangen, S., Huxham, C., \& Eden, C. (2000). The challenge of collaborative governance. Public Management: An International Journal of Research and Theory, 2(3), 337-358. doi:10.1080/14719030000000021

Igoe, J., \& Brockington, D. (2007). Neoliberal conservation: a brief introduction. Conservation and Society, 5(4), 432-449.

Iqbal, S., Blumenthal, W., Kennedy, C., Yip, F. Y., Pickard, S., Flanders, W. D., . . Jean Brown, M. (2009). Hunting with lead: association between blood lead levels and wild game consumption. Environmental Research, 109(8), 952-959. doi:10.1016/j.envres.2009.08.007

Jaccard, J., Dodge, T., \& Dittus, P. (2002). Parent-adolescent communication about sex and birth control: a conceptural framework. New Direcrtions in Child and Adolescent Development, 97, 9-42.

Jackson, K., \& Bazeley, P. (2019). Qualitative data analysis with NVivo (3rd ed.). Thousand Oaks, California, USA: SAGE.

Järup, L. (2003). Hazards of heavy metal contamination. British Medical Bulletin, 68(1), 167-182. doi:10.1093/bmb/ldg032

Johnson, D. H., \& Igl, L. D. (2001). Area requirements of grassland birds: a regional perspective. Auk, 118(1), 24-34. doi:10.1642/00048038(2001)118[0024:AROGBA]2.0.CO;2 
Jones, R. L., Homa, D. M., Meyer, P. A., Brody, D. J., Caldwell, K. L., Pirkle, J. L., \& Brown, M. J. (2009). Trends in blood lead levels and blood lead testing among U.S. children aged 1 to 5 years, 1988-2004. Pediatrics, 123(3), e376-e385. doi:10.1542/peds.2007-3608

Kahan, D. M., \& Braman, D. (2006). Cultural cognition and public policy. Yale Law \& Policy Review, 24(1), 147-170.

Kahan, D. M., Jenkins-Smith, H., \& Braman, D. (2011). Cultural cognition of scientific consensus. Journal of Risk Research, 14(2), 147-174. doi:10.1080/13669877.2010.511246

Kahane, A. (2007). Solving tough problems: an open way of talking, listening, and creating new realities. San Francisco, California, USA: Berrett-Koehler.

Kanstrup, N. (2019). Lessons learned from 33 years of lead shot regulation in Denmark. Ambio, 48(9), 999-1008. doi:10.1007/s13280-018-1125-9

Kanstrup, N., \& Balsby, T. J. S. (2019). Danish pheasant and mallard hunters comply with the lead shot ban. Ambio, 48(9), 1009-1014. doi:10.1007/s13280-019-011527

Kanstrup, N., \& Thomas, V. G. (2019). Availability and prices of non-lead gunshot cartridges in the European retail market. Ambio, 48(9), 1039-1043. doi:10.1007/s13280-019-01151-8

Kauneckis, D., \& York, A. M. (2009). An empirical evaluation of private landowner participation in voluntary forest conservation programs. Environmental Management, 44(3), 468-484. doi:10.1007/s00267-009-9327-3

Kelder, S. H., Hoelscher, D., \& Perry, C. L. (2015). How individuals, environments, and health behaviors interact: social cognitive theory. In K. Glanz, B. K. Rimer, \& K. Viswanath (Eds.), Health behavior: theory, research, and practice (pp. 159-181). San Francisco, California, USA: Jossey-Bass, Wiley.

Kelly, T. R., Bloom, P. H., Torres, S. G., Hernandez, Y. Z., Poppenga, R. H., Boyce, W. M., \& Johnson, C. K. (2011). Impact of the California lead ammunition ban on reducing lead exposure in golden eagles and turkey vultures. PLOS ONE, 6(4), e17656. doi:10.1371/journal.pone.0017656 
Kelly, T. R., Grantham, J., George, D., Welch, A., Brandt, J., Burnett, L. J., . . Johnson, C. K. (2014). Spatiotemporal patterns and risk factors for lead exposure in endangered California condors during 15 years of reintroduction. Conservation Biology, 28(6), 1721-1730. doi:10.1111/cobi.12342

Kelly, T. R., \& Johnson, C. K. (2011). Lead exposure in free-flying turkey vultures is associated with big game hunting in California. PLOS ONE, 6(4), e15350. doi:10.1371/journal.pone.0015350

Kelly, T. R., Parish, C. N., \& Johnson, C. K. (2016). Tackling California condor recovery: difficult transitions along a clear path. Wildlife Professional, 10(4), 3437.

Kim, K. N., Kwon, H. J., \& Hong, Y. C. (2016). Low-level lead exposure and autistic behaviors in school-age children. Neurotoxicology, 53, 193-200. doi:10.1016/j.neuro.2016.02.004

Kline, R. B. (2016). Principles and practice of structural equation modeling (4th ed.). New York, New York, USA: Guilford Press.

Knott, J., Gilbert, J., Hoccom, D. G., \& Green, R. E. (2010). Implications for wildlife and humans of dietary exposure to lead from fragments of lead rifle bullets in deer shot in the UK. Science of the Total Environment, 409(1), 95-99. doi:10.1016/j.scitotenv.2010.08.053

Kollander, B., Widemo, F., Ågren, E., Larsen, E. H., \& Loeschner, K. (2016). Detection of lead nanoparticles in game meat by single particle ICP-MS following use of lead-containing bullets. Analytical and Bioanalytical Chemistry, 1-9. doi:10.1007/s00216-016-0132-6

Kollmuss, A., \& Agyeman, J. (2002). Mind the gap: why do people act environmentally and what are the barriers to pro-environmental behavior? Environmental Education Research, 8(3), 239-260. doi:10.1080/13504620220145401

Krone, O. (2018). Lead poisoning in birds of prey. In J. H. Sarasola, J. M. Grande, \& J. J. Negro (Eds.), Birds of prey: biology and conservation in the XXI century (pp. 251-272). Cham, Switzerland: Springer International 
Laidlaw, M. A. S., Filippelli, G., Mielke, H., Gulson, B., \& Ball, A. S. (2017). Lead exposure at firing ranges - a review. Environmental Health, 16(1), 34. doi:10.1186/s12940-017-0246-0

Lanphear, B. P., Lowry, J. A., Ahdoot, S., Baum, C. R., Bernstein, A. S., Bole, A., . . Trasande, L. (2016). Prevention of childhood lead toxicity. Pediatrics, 138(1), e20161493. doi:10.1542/peds.2016-1493

Lanphear, B. P., Rauch, S., Auinger, P., Allen, R. W., \& Hornung, R. W. (2018). Lowlevel lead exposure and mortality in U.S. adults: a population-based cohort study. Lancet - Public Health, 3(4), e177-e184. doi:10.1016/s2468-2667(18)30025-2

Larson, L. R., Stedman, R. C., Decker, D. J., Siemer, W. F., \& Baumer, M. S. (2014). Exploring the social habitat for hunting: toward a comprehensive framework for understanding hunter recruitment and retention. Human Dimensions of Wildlife, 19(2), 105-122. doi:10.1080/10871209.2014.850126

Legagneux, P., Suffice, P., Messier, J.-S., Lelievre, F., Tremblay, J. A., Maisonneuve, C., ... Bêty, J. (2014). High risk of lead contamination for scavengers in an area with high moose hunting success. PLOS ONE, 9(11), e111546. doi:10.1371/journal.pone.0111546

Lent, R., \& Squires, D. (2017). Reducing marine mammal bycatch in global fisheries: an economics approach. Deep-Sea Research Part II - Topical Studies in Oceanography, 140, 268-277. doi:10.1016/j.dsr2.2017.03.005

Leszek, M. L. (2015). Changing angler behavior to reduce the impacts of lead fishing tackle in New Hampshire: Applied social science using community-based social marketing. (M.S.), Plymouth State University, Plymouth, New Hampshire.

Retrieved from

http://proxy.mul.missouri.edu/login?url=https://search.proquest.com/docview/177 $\underline{8102379 ? \text { accountid }=14576}$

Levengood, J. M., Anderson, W. L., \& David, L. M. (1999). Results of the 1997 Illinois mourning dove hunter survey. (W-112-R). Springfield, Illinois, USA: Illinois Department of Natural Resources - Division of Wildlife Resources. 
Levine, J. M., \& Valle, R. S. (1975). The convert as a credible communicator. Social Behavior and Personality: an international journal, 3(1), 81-90. doi:10.2224/sbp.1975.3.1.81

Lewis-Beck, C., \& Lewis-Beck, M. (2016). Applied regression: an introduction (2nd ed. Vol. 22). Thousand Oaks, California, USA: SAGE.

Lidsky, T. I., \& Schneider, J. S. (2006). Adverse effects of childhood lead poisoning: the clinical neuropsychological perspective. Environmental Research, 100(2), 284293. doi:10.1016/j.envres.2005.03.002

Lindenfeld, L. A., Hall, D. M., McGreavy, B., Silka, L., \& Hart, D. (2012). Creating a Place for Environmental Communication Research in Sustainability Science. Environmental Communication, 6(1), 23-43. doi:10.1080/17524032.2011.640702

Little, R. J. A. (1988). A test of missing completely at random for multivariate data with missing values. Journal of the American Statistical Association, 83(404), 11981202. doi:10.1080/01621459.1988.10478722

Liu, S., Roehrig, G., Bhattacharya, D., \& Varma, K. (2015). In-service teachers' attitudes, knowledge and classroom teaching of global climate change. Science Educator, 24(1), 12-22.

Mackinnon, A. (2010). The use and reporting of multiple imputation in medical research - a review. Journal of Internal Medicine, 268(6), 586-593. doi:10.1111/j.13652796.2010.02274.x

Madden, F., \& McQuinn, B. (2014). Conservation's blind spot: the case for conflict transformation in wildlife conservation. Biological Conservation, 178, 97-106. doi:10.1016/j.biocon.2014.07.015

Madden, F., \& McQuinn, B. (2015). Conservation conflict transformation: the missing link in conservation. In S. M. Redpath, R. J. Gutiérrez, K. A. Wood, \& J. C. Young (Eds.), Conflicts in conservation: navigating towards solutions (pp. 257267). Cambridge, UK: Cambridge University Press.

Madden, T. J., Ellen, P. S., \& Ajzen, I. (1992). A comparison of the theory of planned behavior and the theory of reasoned action. Personality and Social Psychology Bulletin, 18(1), 3-9. 
Mahajan, V., Muller, E., \& Srivastava, R. K. (1990). Determination of adopter categories by using innovation diffusion models. Journal of Marketing Research, 27(1), 3750. doi:10.2307/3172549

Maibach, E. (1993). Social marketing for the environment: using information campaigns to promote environmental awareness and behavior change. Health Promotion International, 8(3), 209-224. doi:10.1093/heapro/8.3.209

Manfredo, M. J., Sullivan, L., Salerno, J., \& Berger, J. (2020). Looking forward, not backward in considering the needs for social science in wildlife management. Bioscience, 70(7), 529-530. doi:10.1093/biosci/biaa054

Manfredo, M. J., Teel, T. L., Gavin, M. C., \& Fulton, D. (2014). Considerations in representing human individuals in social-ecological models. In Understanding society and natural resources: forging new strands of integration across the social sciences (pp. 137-158). Heidelberg, New York, USA: Springer, Dordrecht.

Manier, D. J., Wood, D. J. A., Bowen, Z. H., Donovan, R. M., Holloran, M. J., Juliusson, L. M., . . Titolo, A. J. (2013). Summary of science, activities, programs, and policies that influence the rangewide conservation of greater sage-grouse (Centrocercus urophasianus). (Open-File Report 2013-1098). Reston, Virginia, USA: U.S. Geological Survey Retrieved from http://pubs.er.usgs.gov/publication/ofr20131098.

Marion, J. L., \& Reid, S. E. (2007). Minimising visitor impacts to protected areas: the efficacy of low impact education programmes. Journal of Sustainable Tourism, 15(1), 5-27. doi:10.2167/jost593.0

Markowitz, G., \& Rosner, D. (2013a). Deceit and denial: the deadly politics of industrial pollution (2nd ed.). Berkeley, California, USA: University of California Press.

Markowitz, G., \& Rosner, D. (2013b). Lead wars: the politics of science and the fate of America's children. New York, New York USA: University of California Press.

Martin, A., Gremse, C., Selhorst, T., Bandick, N., Müller-Graf, C., Greiner, M., \& Lahrssen-Wiederholt, M. (2017). Hunting of roe deer and wild boar in Germany: is non-lead ammunition suitable for hunting? PLOS ONE, 12(9), e0185029. doi:10.1371/journal.pone.0185029 
Mascia, M. B., \& Mills, M. (2017). When conservation goes viral: The diffusion of innovative biodiversity conservation policies and practices. Conservation Letters, O(0), e12442. doi:doi:10.1111/conl.12442

Mateo, R., \& Kanstrup, N. (2019). Regulations on lead ammunition adopted in Europe and evidence of compliance. Ambio, 48(9), 989-998. doi:10.1007/s13280-019$01170-5$

Mateo, R., Vallverdú-Coll, N., López-Antia, A., Taggart, M. A., Martínez-Haro, M., Guitart, R., \& Ortiz-Santaliestra, M. E. (2014). Reducing Pb poisoning in birds and $\mathrm{Pb}$ exposure in game meat consumers: the dual benefit of effective $\mathrm{Pb}$ shot regulation. Environment International, 63(Supplement C), 163-168. doi:10.1016/j.envint.2013.11.006

McAtee, W. L. (1908). Lead poisoning in ducks. Auk, 25(4), 472. doi:10.2307/4070657 McBride, M. F., \& Burgman, M. A. (2012). What Is expert knowledge, how Is such knowledge gathered, and how do we use it to address questions in landscape ecology? In A. H. Perera, C. A. Drew, \& C. J. Johnson (Eds.), Expert Knowledge and Its Application in Landscape Ecology (pp. 11-38). New York, NY: Springer New York.

McCann, B. E., Whitworth, W., \& Newman, R. A. (2016). Efficacy of non-lead ammunition for culling elk at Theodore Roosevelt National Park. Human-Wildlife Interactions, 10(2), 268-282.

McCarthy, J., \& Prudham, S. (2004). Neoliberal nature and the nature of neoliberalism. Geoforum, 35(3), 275-283. doi:10.1016/j.geoforum.2003.07.003

McGarity, T. O., \& Wagner, W. E. (2010). Bending science: how special interests correupt public health research. Cambridge, Massachusetts, USA: Harvard University Press.

McGuire, W. J. (2013). McGuire's classic input-output framework for constructing persuasive messages. In R. E. Rice \& C. K. Atkin (Eds.), Public communication campaigns (4th ed., pp. 133-145). Thousand Oaks, California, USA: SAGE.

McKenzie-Mohr, D. (2000). New ways to promote proenvironmental behavior: promoting sustainable behavior: an introduction to community-based social 
marketing. Journal of Social Issues, 56(3), 543-554. doi:10.1111/00224537.00183

McKenzie-Mohr, D., Nemiroff, L. S., Beers, L., \& Desmarais, S. (1995). Determinants of responsible environmental behavior. Journal of Social Issues, 51(4), 139-156. doi:10.1111/j.1540-4560.1995.tb01352.x

Meltzer, H. M., Dahl, H., Brantsæter, A. L., Birgisdottir, B. E., Knutsen, H. K., Bernhoft, A., ... Y Ydersbond, T. A. (2013). Consumption of lead-shot cervid meat and blood lead concentrations in a group of adult Norwegians. Environmental Research, 127(Supplement C), 29-39. doi:10.1016/j.envres.2013.08.007

Messmer, T. A., \& Enck, J. W. (2012). Human dimensions of wildlife management. In D. J. Decker, S. J. Riley, \& W. F. Siemer (Eds.), Human dimensions of wildlife management (2nd ed., pp. 203-219). Baltimore, Maryland, USA: John Hopkins University.

Michaels, D. (2008). Doubt is their product: how industry's assault on science threatens your health. New York, New York, USA: Oxford University Press.

Miller, C. A., McCleary, M. E., Stephenson, A. L., Harper, E. E., \& Campbell, L. K. (2013). Assessment of Illinois dove hunter satisfaction, retention, and attitudes toward non-toxic shot. (Study 101 - Job No. 101.4). Champaign, Illinois, USA: Illinois Natural History Survey.

Millsap, B. A., Bjerre, E. R., Otto, M. C., Zimmerman, G. S., \& Zimpfer, N. L. (2016). Bald and golden eagles: population demographics and estimation of sustainable take in the United States, 2016 update. Washington, D.C., USA: U.S. Department of Interior - Fish and Wildlife Service - Division of Migratory Bird Management. Minnesota Department of Natural Resources. (2017). Lead information for hunters. Retrieved from http://www.dnr.state.mn.us/hunting/ammo/lead.html Minnesota Department of Natural Resources. (2020). Share the harvest. Retrieved from https://www.health.state.mn.us/diseases/coronavirus/index.html Missouri Department of Conservation. (2017). Share the harvest - deer. Retrieved from https://huntfish.mdc.mo.gov/hunting-trapping/species/deer/deer-share-harvest 
Mohai, P., Pellow, D., \& Roberts, J. T. (2009). Environmental justice. Annual Review of Environment and Resources, 34(1), 405-430. doi:doi:10.1146/annurev-environ082508-094348

Mondain-Monval, J.-Y., Defos du Rau, P., Guillemain, M., \& Olivier, A. (2015). Switch to non-toxic shot in the Camargue, France: effect on waterbird contamination and hunter effectiveness. European Journal of Wildlife Research, 61(2), 271-283. doi:10.1007/s10344-014-0897-x

Montano, D. E., \& Kasprzyk, D. (2015). Theory of reasoned action, theory of planned behavior, and the integrated behavioral model. In K. Glanz, B. K. Rimer, \& K. Viswanath (Eds.), Health Behavior: Theory, Research and Practice (5th ed.). San Francisco, California, USA: Jossey-Bass.

Moore, G. A. (2014). Crossing the chasm: marketing and selling disruptive products to mainstream customers (3rd ed.). New York, New York, USA: Harper Business.

Moore, G. C., \& Benbasat, I. (1996). Integrating Diffusion of Innovations and Theory of Reasoned Action models to predict utilization of information technology by endusers. In K. Kautz \& J. Pries-Heje (Eds.), Diffusion and Adoption of Information Technology: Proceedings of the first IFIP WG 8.6 working conference on the diffusion and adoption of information technology, Oslo, Norway, October 1995 (pp. 132-146). Boston, MA: Springer US.

More, A. F., Spaulding, N. E., Bohleber, P., Handley, M. J., Hoffmann, H., Korotkikh, E. V., . . Mayewski, P. A. (2017). Next-generation ice core technology reveals true minimum natural levels of lead $(\mathrm{Pb})$ in the atmosphere: Insights from the Black Death. GeoHealth, 1(4), 211-219. doi:10.1002/2017gh000064

Muth, R. M., Zwick, R. R., Mather, M. E., Organ, J. F., Daigle, J. J., \& Jonker, S. A. (2006). Unnecessary source of pain and suffering or necessary management tool: attitudes of conservation professionals toward outlawing leghold traps. Wildlife Society Bulletin, 34(3), 706-715. doi:10.2193/0091-

7648(2006)34[706:Usopas]2.0.Co;2

Myers, T. A., Nisbet, M. C., Maibach, E. W., \& Leiserowitz, A. A. (2012). A public health frame arouses hopeful emotions about climate change. Climatic Change, 113(3), 1105-1112. doi:10.1007/s10584-012-0513-6 
New Hampshire Fish and Game. (2017). Information about possible lead in venison. Retrieved from http://www.wildlife.state.nh.us/hunting/deer-lead.html

Newhouse, N. (1990). Implications of attitude and behavior research for environmental conservation. Journal of Environmental Education, 22(1), 26-32. doi:10.1080/00958964.1990.9943043

Newth, J. L., Lawrence, A., Cromie, R. L., Swift, J. A., Rees, E. C., Wood, K. A., . . McDonald, R. A. (2019). Perspectives of ammunition users on the use of lead ammunition and its potential impacts on wildlife and humans. People and Nature, 1(3), 347-361. doi:10.1002/pan3.30

Nordhaus, T., \& Shellenberger, M. (2009). Break through: why we can't leave saving the planet to environmentalists. Boston, Massachusetts, USA: Mariner Books.

NRA-Explore. (2020). Hunters for the hungry. Retrieved from https://hfth.nra.org/

Ntemana, T. J., \& Olatokun, W. (2012). Analyzing the influence of diffusion of innovation attributes on lecturers' attitudes toward information and communication technologies. Human Technology, 8(2), 179-197.

Oreskes, N., \& Conway, E. M. (2010). Merchants of doubt: how a handful of scientists obscured the truth on issues from tobacco smoke to global warming. New York, New York, USA: Bloomsbury Press.

Pabian, S. E., Wilson, A. M., \& Brittingham, M. C. (2013). Mixed responses of farmland birds to the Conservation Reserve Enhancement Program in Pennsylvania. Journal of Wildlife Management, 77(3), 616-625. doi:10.1002/jwmg.514

Pain, D. J., Cromie, R. L., Newth, J., Brown, M. J., Crutcher, E., Hardman, P., . . Green, R. E. (2010). Potential hazard to human health from exposure to fragments of lead bullets and shot in the tissues of game animals. PLOS ONE, 5(4), e10315. doi:10.1371/journal.pone.0010315

Pain, D. J., Dickie, I., Green, R. E., Kanstrup, N., \& Cromie, R. (2019). Wildlife, human and environmental costs of using lead ammunition: an economic review and analysis. Ambio, 48(9), 969-988. doi:10.1007/s13280-019-01157-2

Pain, D. J., Fisher, I. J., \& Thomas, V. G. (2009). A global update of lead poisoning in terrestrial birds from ammunition sources. In R. T. Watson, M. Fuller, M. A. Pokras, \& W. G. Hunt (Eds.), Ingestion of lead from spent ammunition: 
implications for wildlife and humans (pp. 99-118). Boise, Idaho, USA: Peregrine Fund.

Pain, D. J., Mateo, R., \& Green, R. E. (2019). Effects of lead from ammunition on birds and other wildlife: a review and update. Ambio, 48(9), 935-953. doi:10.1007/s13280-019-01159-0

Paisley, W., \& Atkin, C. K. (2013). Public communication campaigns - the American experience. In R. E. Rice \& C. K. Atkin (Eds.), Public communication campaigns (4th ed., pp. 21-33). Thousand Oaks, California, USA: SAGE.

Patton, M. Q. (2015). Qualitative evaluation and research methods (4th ed.). Newbury Park, CA: SAGE.

Pedersen, A. B., Mikkelsen, E. M., Cronin-Fenton, D., Kristensen, N. R., Pham, T. M., Pedersen, L., \& Petersen, I. (2017). Missing data and multiple imputation in clinical epidemiological research. Clinical epidemiology, 9, 157-166. doi:10.2147/CLEP.S129785

Peterson, M. J., Hall, D. M., Feldpausch-Parker, A. M., \& Peterson, T. R. (2010). Obscuring ecosystem function with application of the ecosystem services concept. Conservation Biology, 24(1), 113-119. doi:10.1111/j.1523-1739.2009.01305.x

Peterson, M. N., von Essen, E., Hansen, H. P., \& Peterson, T. R. (2017). Illegal fishing and hunting as resistance to neoliberal colonialism. Crime, Law and Social Change, 67(4), 401-413. doi:10.1007/s10611-016-9664-0

Pierce, B. L., Roster, T. A., Frisbie, M. C., Mason, C. D., \& Roberson, J. A. (2015). A comparison of lead and steel shot loads for harvesting mourning doves. Wildlife Society Bulletin, 39(1), 103-115. doi:10.1002/wsb.504

Plautz, S. C., Halbrook, R. S., \& Sparling, D. W. (2011). Lead shot ingestion by mourning doves on a disked field. Journal of Wildlife Management, 75(4), 779785. doi:10.1002/jwmg.105

Plaza, P. I., \& Lambertucci, S. A. (2019). What do we know about lead contamination in wild vultures and condors? A review of decades of research. Science of the Total Environment, 654, 409-417. doi:10.1016/j.scitotenv.2018.11.099 
Pokras, M. A., \& Chafel, R. (1992). Lead toxicosis from ingested fishing sinkers in adult common loons (Gavia immer) in New England. Journal of Zoo and Wildlife Medicine, 23(1), 92-97. doi:10.2307/20460274

Powell, R. B., \& Stern, M. J. (2013). Is it the program or the interpreter? Modeling the influence of program characteristics and interpreter attributes on visitor outcomes. Journal of Interpretation Research, 18(2), 45-60.

Prakash, A., \& Potoski, M. (2012). Voluntary environmental programs: a comparative perspective. Journal of Policy Analysis and Management, 31(1), 123-138. doi:10.1002/pam.20617

Price Tack, J. L., McGowan, C. P., Ditchkoff, S. S., Morse, W. C., \& Robinson, O. J. (2018). Managing the vanishing North American hunter: a novel framework to address declines in hunters and hunter-generated conservation funds. Human Dimensions of Wildlife, 23(6), 515-532. doi:10.1080/10871209.2018.1499155

Prochaska, J. O., \& DiClemente, C. C. (1983). Stages and processes of self-change of smoking: toward an integrative model of change. Journal of Consulting and Clinical Psychology, 51(3), 390-395. doi:10.1037/0022-006X.51.3.390

Prochaska, J. O., Redding, C. A., \& Evers, K. E. (2015). The transtheoretical model and stages of change. In K. Glanz, B. K. Rimer, \& K. Viswanath (Eds.), Health behavior: theory, research, and practice (pp. 125-148). San Fransisco, California, USA: Jossey-Bass, Wiley.

Prugh, T. (1999). Natural capital and human economic survival (2nd ed.). Boca Raton, Florida, USA: CRC Press and International Society for Ecological Economics.

Prukop, J., \& Regan, R. J. (2005). The value of the North American model of wildlife conservation - an International Association of Fish and Wildlife Agencies position. Wildlife Society Bulletin, 33(1), 374-377. doi:10.2193/00917648(2005)33[374:IMOTVO]2.0.CO;2

Public Law 85-585. (1958). Migratory Bird Conservation Act of 1958. Retrieved from https://www.fws.gov/birds/policies-and-regulations/laws-legislations/migratorybird-hunting-and-conservation-stamp-act.php

Public Law 86-70. (1940). Bald and golden eagle protection act of 1940. Retrieved from https://www.fws.gov/midwest/MidwestBird/EaglePermits/bagepa.html 
Public Law 86-732. (1918). Migratory Bird Treaty Act of 1918. Retrieved from https://www.fws.gov/laws/lawsdigest/migtrea.html

Public Law 91-190. (1969). National Environmental Policy Act of 1969. Retrieved from https://ceq.doe.gov/laws-regulations/laws.html

Public Law 93-205. (1973). Endangered Species Act of 1973. Retrieved from https://www.fws.gov/endangered/

Public Law 94-469. (1976). Toxic Substances Control Act of 1976. Retrieved from https://www.epa.gov/laws-regulations/summary-toxic-substances-control-act

Public Law 96-511. (1980). Paperwork Reduction Act of 1980. Retrieved from https://www.gpo.gov/fdsys/pkg/STATUTE-94/pdf/STATUTE-94-Pg2812.pdf

Quartuch, M. R., Stedman, R. C., Decker, D. J., Larson, L. R., Siemer, W. F., \& Baumer, M. S. (2017). Exploring nontraditional pathways into hunting in New York state: implications for recruitment and retention. Human Dimensions of Wildlife, 22(5), 391-405. doi:10.1080/10871209.2017.1334247

Randall, A. (2002). The policy context for flexible, negotiated, and voluntary measures. In T. Dietz \& P. C. Stern (Eds.), New tools for environmental protection: education, information, and voluntary measures (pp. 311-333). Washington, D.C., USA: National Academy Press.

Rattner, B. A., Franson, J. C., Sheffield, S. R., Goddard, C. I., Leonard, N. J., Stang, D., \& Wingate, P. J. (2008). Sources and implications of lead ammunition and fishing tackle on natural resources. Bethesda, MD: Wildlife Society.

Redpath, S. M., Gutiérrez, R. J., Wood, K. A., \& Young, J. C. (Eds.). (2015). Conflicts in conservation: navigating towards solutions. Cambridge, UK: Cambridge University Press.

Redpath, S. M., \& Sutherland, W. J. (2015). The value of ecological information in conservation conflict. In S. M. Redpath, R. J. Gutiérrez, K. A. Wood, \& J. C. Young (Eds.), Conflicts in conservation: navigating towards solutions (pp. 3645). Cambridge, U.K.: Cambridge University Press.

Responsive Management, \& National Shooting Sports Foundation. (2017). Hunting, fishing, sport shooting, and archery recruitment, retention, and reactivation: a 
practitioner's guide. Harrisonburg, Virginia, USA: Association of Fish and Wildlife Agencies and U.S. Fish and Wildlife Service.

Reynolds, R. E., Shaffer, T. L., Sauer, J. R., \& Peterjohn, B. G. (1994). Conservation reserve program: benefit for grassland birds in the northern plains. Transactions of the North American Wildlife and Natural Resources Conference, 59, 328-336.

Rice, R. E., \& Atkin, C. K. (Eds.). (2013). Public communication campaigns (4th ed.). Thousand Oaks, California, USA: SAGE.

Riessman, C. K. (2008). Narrative methods for the human sciences. Thousand Oaks, California, USA: SAGE.

Robbins, P. (2020). Political ecology: a critical introduction (3rd ed.). Hoboken, New Jersey, USA: John Wiley \& Sons.

Robinson, K. F., Fuller, A. K., Stedman, R. C., Siemer, W. F., \& Decker, D. J. (2019). Integration of social and ecological sciences for natural resource decision making: challenges and opportunities. Environmental Management, 63(5), 565-573. doi:10.1007/s00267-019-01141-2

Rogers, E. M. (2003). Diffusion of innovations (5th ed.). New York, New York, USA: Free Press.

Rosen, J. F. (1995). Adverse health effects of lead at low exposure levels: trends in the management of childhood lead poisoning. Toxicology, 97(1-3), 11-17. doi:10.1016/0300-483X(94)02963-U

Ross-Winslow, D. J. (2013). Human dimensions of lead in the environment from ammunition and fising tackle. (M.S. Thesis M.S. Thesis), Colorado State University, Fort Collins, Colorado, USA.

Ross-Winslow, D. J., \& Teel, T. L. (2011). The quest to eliminate lead from units of the National Park System: understanding and reaching out to audiences. George Wright Forum, 28(1), 34-77.

Ross-Winslow, D. J., Teel, T. L., \& Leong, K. M. (2011). Understanding audiences to eliminate lead in NPS environments: literature synthesis report (updated May 2011). (NPS/NRPC/BRMD/NRR—2011/398). Fort Collins, Colorado, USA: U.S. Department of Interior - National Park Service. 
Rubin, D. B. (1987). Multiple Imputation for Nonresponse in Surveys. New York, NY: John Wiley \& Sons.

Runia, T. J., \& Solem, A. J. (2016). Spent lead shot availability and ingestion by ringnecked pheasants in South Dakota. Wildlife Society Bulletin, n/a-n/a. doi:10.1002/wsb.681

Russell, R. E., \& Franson, J. C. (2014). Causes of mortality in eagles submitted to the National Wildlife Health Center 1975-2013. Wildlife Society Bulletin, 38(4), $697-$ 704. doi:10.1002/wsb.469

Ryan, E. L., \& Shaw, B. (2011). Improving hunter recruitment and retention. Human Dimensions of Wildlife, 16(5), 311-317. doi:10.1080/10871209.2011.559530

Sahin, I. (2006). Detailed review of Rogers' diffusion of innovations theory and educational technology-related studies based on Rogers' theory. Turkish Online Journal of Educational Technology, 5(2), 14-23.

Sanchez, D. M., Epps, C. W., \& Taylor, D. S. (2016). Estimating lead fragmentation from ammunition for muzzleloading and black powder cartridge rifles. Journal of Fish and Wildlife Management, 7(2), 467-479. doi:10.3996/092015-jfwm-086

Sandbrook, C., Scales, I. R., Vira, B., \& Adams, W. M. (2011). Value plurality among conservation professionals. Conservation Biology, 25(2), 285-294. doi:10.1111/j.1523-1739.2010.01592.x

Sanderson, G. C., \& Bellrose, F. C. (1986). A review of the problem of lead poisoning in waterfowl. (4). Champaign, IL: Illinois Natural History Survey.

Scheuhammer, A. M., \& Norris, S. L. (1995). A review of the environmental impacts of lead shotshell ammunition and lead fishing weights in Canada. (88). Ottawa, Ontario, Canada: Environment Canada, Canadian Wildlife Service.

Scheuhammer, A. M., \& Thomas, V. G. (2011). Eliminating lead from recreational shooting and angling: relating wildlife science to environmental policy and regulation in North America. In J. E. Elliott, C. A. Bishop, \& C. A. Morrissey (Eds.), Wildlife Ecotoxicology (Vol. 3, pp. 359-382): Springer New York.

Schroeder, S. A., Fulton, D. C., \& DonCarlos, K. (2016). Clarifying beliefs underlying hunter intentions to support a ban on lead shot. Society \& Natural Resources, 29(7), 852-867. doi:10.1080/08941920.2015.1107792 
Schroeder, S. A., Fulton, D. C., Penning, W., \& DonCarlos, K. (2012). Using persuasive messages to encourage hunters to support regulation of lead shot. Journal of Wildlife Management, 76(8), 1528-1539. doi:10.1002/jwmg.420

Schultz, P. W. (2002). Knowledge, information, and household recycling: examining the knowledge-deficit model and behavior change. In T. Dietz \& P. C. Stern (Eds.), New tools for environmental protection: education, information, and voluntary measures (pp. 67-82). Washington, D.C., USA: National Academy Press.

Schulz, J. H., Bian, Y., Gao, X., Mong, T. W., \& Millspaugh, J. J. (2017). Mourning dove period and annual survival in west-central Missouri. Wildlife Society Bulletin, 41(2), 249-255. doi:10.1002/wsb.764

Schulz, J. H., Gao, X., Millspaugh, J. J., \& Bermudez, A. J. (2007). Experimental lead pellet ingestion in mourning doves (Zenaida macroura). American Midland Naturalist, 158(1), 177-190. doi:10.1674/00030031(2007)158[177:elpiim]2.0.co;2

Schulz, J. H., Gao, X., Millspaugh, J. J., \& Bermudez, A. J. (2009). Acute lead toxicosis and experimental lead pellet ingestion in mourning doves. In R. T. Watson, M. Fuller, M. A. Pokras, \& G. Hunt (Eds.), Ingestion of lead from spent ammunition: implications for wildlife and humans (pp. 187-189). Boise, Idaho, USA: Peregrine Fund.

Schulz, J. H., Millspaugh, J. J., Bermudez, A. J., Gao, X., Bonnot, T. W., Britt, L. G., \& Paine, M. (2006). Acute lead toxicosis in mourning doves. Journal of Wildlife Management, 70(2), 413-421. doi:10.2193/0022541X(2006)70[413:ALTIMD]2.0.CO;2

Schulz, J. H., Millspaugh, J. J., Washburn, B. E., Wester, G. R., Lanigan III, J. T., \& Franson, J. C. (2002). Spent-shot availability and ingestion on areas managed for mourning doves. Wildlife Society Bulletin, 30(1), 112-120.

Schulz, J. H., Millspaugh, J. J., Zekor, D. T., \& Washburn, B. E. (2003). Enhancing sport-hunting opportunities for urbanites. Wildlife Society Bulletin, 31(2), 565573. doi: $10.2307 / 3784340$ 
Schulz, J. H., Padding, P. I., \& Millspaugh, J. J. (2006). Will mourning dove crippling rates increase with nontoxic-shot regulations? Wildlife Society Bulletin, 34(3), 861-865. doi:10.2193/0091-7648(2006)34[861:WMDCRI]2.0.CO;2

Schulz, J. H., Potts, G. E., Cornely, J. E., Millspaugh, J. J., \& Johnson, M. A. (2009). The question of lead: considerations for mourning dove nontoxic-shot regulation. Wildlife Professional, 3(2), 46-49.

Schulz, J. H., Potts, G. E., Otis, D. L., \& White, G. C. (2012). The ongoing debate over lead: moving from discord to action. Wildlife Professional, 6(2), 62-63.

Schulz, J. H., Reitz, R. A., Sheriff, S. L., \& Millspaugh, J. J. (2007). Attitudes of Missouri small game hunters toward nontoxic-shot regulations. Journal of Wildlife Management, 71(2), 628-633. doi:10.2193/2006-352

Schulz, J. H., Wilhelm Stanis, S. A., Hall, D. M., \& Webb, E. B. (2021). Until it's a regulation it's not my fight: complexities of a voluntary nonlead hunting ammunition program. Journal of Environment Management, 277, 111438. doi:10.1016/j.jenvman.2020.111438

Schulz, J. H., Wilhelm Stanis, S. A., Morgan, M., Li, C. J., Hall, D. M., \& Webb, E. B. (2021). Perspectives from natural resource professionals: staff attitudes on lead ammunition risks and use of nonlead ammunition. Journal of Outdoor Recreation and Tourism, 33, 100341. doi:10.1016/j.jort.2020.100341

Schulz, J. H., Wilhelm Stanis, S. A., Webb, E. B., Li, C. J., \& Hall, D. M. (2019). Communication strategies for reducing lead poisoning in wildlife and human health risks. Wildlife Society Bulletin, 43(1), 131-140. doi:10.1002/wsb.955

Segerson, K. (2010). Can voluntary programs reduce sea turtle bycatch? Insights from the literature in environmental economics. In R. Q. Grafton, R. Hilborn, D. Squires, M. Tait, \& M. J. Williams (Eds.), Handbook of marine fisheries conservation and management (pp. 618-629). New York, New York, USA: Oxford University Press.

Segerson, K. (2013a). Voluntary approaches to environmental protection and resource management. Annual Review of Resource Economics, 5(1), 161-180. doi:10.1146/annurev-resource-091912-151945 
Segerson, K. (2013b). When Is reliance on voluntary approaches in agriculture likely to be effective? Applied Economic Perspectives and Policy, 35(4), 565-592. doi:10.1093/aepp/ppt030

Seng, P. (2005a). Communicating with hunters and ranchers to reduce lead availability to California condors: final report. Mishawaka, Indiana USA: D.J. Case \& Associates.

Seng, P. (2005b). Communicating with hunters and ranchers to reduce lead available to California condors: implementation phase and final report. Mishawaka, Indiana USA: D.J. Case \& Associates.

Sidaway, R. (2005). Resolving environmental disputes: from conflict to consensus. London, UK: Earthscan.

Simon, K. L., Best, D. A., Sikarskie, J. G., Pittman, H. T., Bowerman, W. W., Cooley, T. M., \& Stolz, S. (2020). Sources of mortality in bald eagles in Michigan, 19862017. Journal of Wildlife Management, 84(3), 553-561. doi:10.1002/jwmg.21822

Simoni, T., Gallagher, D., \& Edwards, M. (2014). Assessing risk with increasingly stringent public health goals: the case of water lead and blood lead in children. Journal of Water and Health, 12(1), 57-68. doi:10.2166/wh.2013.067

Simpson, S. G. (1989). Compliance by waterfowl hunters with nontoxic shot regulations in central South Dakota. Wildlife Society Bulletin, 17(3), 245-248. doi: $10.2307 / 3782378$

Skinner, C. S., Tiro, J., \& Champion, V. L. (2015). The health belief model. In K. Glanz, B. K. Rimer, \& K. Viswanath (Eds.), Health behavior: theory, research, and practice (pp. 75-94). San Francisco, Calfornia, USA: Jossey-Bass, Wiley.

Slabe, V. A., Anderson, J. T., Cooper, J., Miller, T. A., Brown, B., Wrona, A., . . Katzner, T. (2020). Feeding ecology drives lead exposure of facultative and obligate avian scavengers in the eastern United States. Environmental Toxicology and Chemistry, 39(4), 882-892. doi:10.1002/etc.4680

Smith, B., Graham, S., Parish, C. N., Hauch, T., Zufelt, A., Day, K., . . Allard, R. (2017). California condor recovery program in the Southwest-fourth review (2012-2016) Retrieved from Flagstaff, Arizona USA: 
https://www.fws.gov/southwest/es/arizona/Documents/SpeciesDocs/CA_Condor/ Fourth\%205yr\%20review\%20final.pdf

Smith, R. L., \& Townsend, T. W. (1981). Attitudes of Ohio hunters toward steel shot. Wildlife Society Bulletin, 9(1), 4-7.

Smyth, F. (2020). The NRA: the unauthorized history. New York, New York, USA: Flatiron Books.

Snow, B. D. (2017). Living with lead: an environmental history Idaho's Coeur D'Alenes, 1885-2011. Pittsburgh, Pennsylvania USA: University of Pittsburgh Press.

Sommer, R., \& Sommer, B. (2002). A practical guide to behavioral research: tools and techniques (5th ed.). New York, New York, USA: Oxfor University Press.

Song, N., Aguilar, F. X., \& Butler, B. J. (2013). Conservation aasements and management by family forest owners: a propensity score matching approach with multi-imputations of survey data. Forest Science, 60(2), 298-307. doi:10.5849/forsci.12-107

Soule, M. E., \& Orians, G. H. (Eds.). (2001). Conservation biology: research priorities for the next decade. Washington, D.C., USA: Island Press.

Southwick, R. (2014). Effects of the ban on traditional ammunition for hunting in California on hunting participation and associated economic measures. Fernandina Beach, Florida, USA: Southwick Associates, Inc.

Sponarski, C. C., Vaske, J. J., \& Bath, A. J. (2015). Attitudinal differences among residents, park staff, and visitors toward coyotes in Cape Breton Highlands National Park of Canada. Society \& Natural Resources, 28(7), 720-732. doi:10.1080/08941920.2015.1014595

Stake, M. (2019). Lethal ingestion: non-lead ammunition is now required for hunting in California, so why are California condors still at risk of lead poisoning? Wildlife Professional, 13, 52-55.

Stedman, R. C., Larson, L. R., Tidball, K. G., Tidball, M., \& Curtis, P. D. (2017). Hunting and the local food movement: insights from central New York state. Wildlife Society Bulletin, 41(4), 720-728. doi:10.1002/wsb.802 
Steelman, T. A., \& Rivera, J. (2006). Voluntary environmental programs in the United States: whose interests are served? Organization \& Environment, 19(4), 505-526. doi:10.1177/1086026606296393

Steg, L., \& Vlek, C. (2009). Encouraging pro-environmental behaviour: An integrative review and research agenda. Journal of Environmental Psychology, 29(3), 309317. doi:10.1016/j.jenvp.2008.10.004

Steingraber, S. (2010). Living downstream: an ecologist's personal investigation of cancer and the environment (2nd ed.). Cambridge, Massachusetts, USA: Da Capo Press.

Sterner, T., \& Coria, J. (2012). Policy instruments for environmental and natural resource management (2nd edition ed.). New York, New York, USA: Resources for the Future Press.

Stokke, S., Arnemo, J. M., \& Brainerd, S. (2019). Unleaded hunting: are copper bullets and lead-based bullets equally effective for killing big game? Ambio, 48(9), 10441055. doi:10.1007/s13280-019-01171-4

Sturgis, P., \& Allum, N. (2004). Science in society: re-evaluating the deficit model of public attitudes. Public Understanding of Science, 13(1), 55-74. doi:10.1177/0963662504042690

Sunstein, C. R., \& Hastie, R. (2015). Wiser: getting beyond groupthink to make groups smarter. Boston, Massachusetts, USA: Harvard Business Review Press.

Swaffield, J. (2016). After a decade of critique: neoliberal environmentalism, discourse analysis and the promotion of climate-protecting behaviour in the workplace. Geoforum, 70, 119-129. doi:10.1016/j.geoforum.2016.02.014

Taylor, E. W., \& Caldarelli, M. (2004). Teaching beliefs of non-formal environmental educators: a perspective from state and local parks in the United States. Environmental Education Research, 10(4), 451-469. doi:10.1080/1350462042000291001

Thomas, D. R. (2006). A general inductive approach for analyzing qualitative evaluation data. American Journal of Evaluation, 27(2), 237-246. doi:10.1177/1098214005283748 
Thomas, V. G. (1997). Attitudes and issues preventing bans on toxic lead shot and sinkers in North America and Europe. Environmental Values, 6(2), 185-199. doi:10.3197/096327197776679176

Thomas, V. G. (2013). Lead-free hunting rifle ammunition: product availability, price, effectiveness, and role in global wildlife conservation. Ambio, 42(6), 737-745. doi:10.1007/s13280-012-0361-7

Thomas, V. G. (2019). Rationale for the regulated transition to non-lead products in Canada: a policy discussion paper. Science of the Total Environment, 649, 839845. doi:10.1016/j.scitotenv.2018.08.363

Thomas, V. G., Gremse, C., \& Kanstrup, N. (2016). Non-lead rifle hunting ammunition: issues of availability and performance in Europe. European Journal of Wildlife Research, 62(6), 633-641. doi:10.1007/s10344-016-1044-7

Thomas, V. G., \& Guitart, R. (2003). Lead pollution from shooting and angling, and a common regulative approach. Environmental Policy and Law, 33(3), 143-149.

Thomas, V. G., Kanstrup, N., \& Fox, A. D. (2019). The transition to non-lead sporting ammunition and fishing weights: review of progress and barriers to implementation. Ambio, 48, 925-934. doi:10.1007/s13280-018-1132-x

Thomson, V. E. (2003). Grab bag ethics and policymaking for leaded gasoline: a pragmatist's view. In A. Light \& A. de-Shalit (Eds.), Moral and Political Reasoning in Environmental Practice (pp. 259-279). Cambridge, Massachusetts, USA: MIT Press.

Tidd, J., \& Bessant, J. (2009). Managing innovation: integrating technological market and organizational change. Chichester, West Sussex UK: John Wiley \& Sons, Ltd.

Tranel, M. A., \& Kimmel, R. O. (2009). Impacts of lead ammunition on wildlife, the environment, and human health — a literature review and implications for Minnesota. In R. T. Watson, M. Fuller, M. A. Pokras, \& G. Hunt (Eds.), Ingestion of Lead from Spent Ammunition: Implications for Wildlife and Humans (pp. 318337). Boise, Idaho, USA: The Peregrine Fund. 
Trinogga, A. L., Courtiol, A., \& Krone, O. (2019). Fragmentation of lead-free and leadbased hunting rifle bullets under real life hunting conditions in Germany. Ambio, 48(9), 1056-1064. doi:10.1007/s13280-019-01168-z

Trinogga, A. L., Fritsch, G., Hofer, H., \& Krone, O. (2013). Are lead-free hunting rifle bullets as effective at killing wildlife as conventional lead bullets? A comparison based on wound size and morphology. Science of the Total Environment, 443, 226-232. doi:10.1016/j.scitotenv.2012.10.084

Trushenski, J., \& Radomski, P. (2013). American Fisheries Society adopts new policy, encourages efforts to understand and limit effects of lead in sport fishing tackle on fish and wildlife. Fisheries, 38(1), 38-38. doi:10.1080/03632415.2013.750141

Twiss, M. P., \& Thomas, V. G. (1998). Preventing fishing-sinker-induced lead poisoning of common loons through Canadian policy and regulative reform. Journal of Environmental Management, 53(1), 49-59. doi:10.1006/jema.1998.0190

U.S. Department of Interior - Fish and Wildlife Service, U.S. Department of Commerce, \& U.S. Census Bureau. (2007). National survey of fishing, hunting, and wildlifeassociated recreation - 2006. Washington, D.C., USA

U.S. Department of Interior - U.S. Fish and Wildlife Service, \& U.S. Department of Commerce - U.S. Census Bureau. (2018). 2016 National survey of fishing, hunting, and wildlife associated recreation. Washington, D.C., USA.

U.S. Department of the Interior - Fish and Wildlife Service. (1986). Final supplemental environmental impact statement on the use of lead shot for hunting of migratory birds in the United States. Washington, D.C. USA: U.S. Department of Interior Fish and Wildlife Service.

U.S. Department of the Interior - Fish and Wildlife Service. (1988). Appendix 13: a synopsis of the nontoxic shot issue. In Final supplemental environmental impact statement: issuance of annual regulations permitting the sport hunting of migratory birds (SEIS 88) (pp. 317-319). Washington, D.C. USA: U.S. Department of Interior - Fish and Wildlife Service.

U.S. Department of the Interior - Fish and Wildlife Service, U.S. Department of Commerce, \& Bureau, U. S. C. (2011). National survey of fishing, hunting, and wildlife-associated recreation. Washington, D.C. USA: U.S. Department of 
Interior - Fish and Wildlife Service, U.S. Department of Commerce, U.S. Census Bureau Retrieved from https://www.census.gov/prod/2012pubs/fhw11-nat.pdf (January 2016).

van der Heijden, J. (2012). Voluntary environmental governance arrangements. Environmental Politics, 21(3), 486-509. doi:10.1080/09644016.2012.671576

Vaske, J. J. (2008). Survey research and anlysis: applications in parks, recreation, and human dimensions. State College, Pennsylvania, USA: Venture Publishing. Vaske, J. J., \& Manfredo, M. J. (2012). Social psychological considerations in wildlife management. In D. J. Decker, S. J. Riley, \& W. F. Siemer (Eds.), Human dimensions of wildlife management (2nd ed., pp. 43-57). Baltimore, Maryland: Johns Hopkins University Press.

von Essen, E., van Heijgen, E., \& Gieser, T. (2019). Hunting communities of practice: factors behind the social differentiation of hunters in modernity. Journal of Rural Studies, 68, 13-21. doi:10.1016/j.jrurstud.2019.03.013

Ward, C. W., \& Wilkinson, A. E. (2006). Conducting meaningful interpretation: a field guide for success. Golden, Colorado, USA: Fulcrum Publishing.

Ward, K. J., Stedman, R. C., Luloff, A. E., Shortle, J. S., \& Finley, J. C. (2008). Categorizing deer hunters by typologies useful to game managers: a latent-class model. Society \& Natural Resources, 21(3), 215-229. doi:10.1080/08941920701831913

Warner, S. E., Britton, E. E., Becker, D. N., \& Coffey, M. J. (2014). Bald eagle lead exposure in the upper Midwest. Journal of Fish and Wildlife Management, 5(2), 208-216. doi:10.3996/032013-JFWM-029

Watson, J. W., Vekasy, M. S., Nelson, J. D., \& Orr, M. R. (2019). Eagle visitation rates to carrion in a winter scavenging guild. Journal of Wildlife Management, 83, 1735-1743. doi:10.1002/jwmg.21760

Watson, R. T., Fuller, M., Pokras, M. A., \& Hunt, G. (Eds.). (2009). Ingestion of lead from spent ammunition: implications for wildlife and humans. Boise, Idaho USA: Peregrine Fund. 
Wayman, J. C. (2003). Multiple imputation for missing data: what is it and how can I use it. Paper presented at the Annual Meeting of the American Educational Research Association, Chicago, IL.

Wejnert, B. (2002). Integrating models of diffusion of innovations: a conceptual framework. Annual Review of Sociology, 28, 297-326.

Wenz, P. (1999). The importance of environmental justice. In C. Merchant (Ed.), Ecology: key concepts in critical theory (pp. 248-253). Amherst, New York, USA: Humanity Books.

Wetmore, A. (1919). Lead poisoning in waterfowl. (Bulletin No. 793). Washington, D.C., USA: U.S. Department of Agriculture.

White, C. (2005). Hunters ring dinner bell for ravens: experimental evidence of a unique foraging strategy. Ecology, 86(4), 1057-1060. doi:10.1890/03-3185

Whitney, C. R. (2012). Living with guns: a liberal's case for the Second Amendment. New York, New York USA: Public Affairs - Perseus Group.

Wiemeyer, G. M., Pérez, M. A., Torres Bianchini, L., Sampietro, L., Bravo, G. F., Jácome, N. L., . . Lambertucci, S. A. (2017). Repeated conservation threats across the Americas: high levels of blood and bone lead in the andean condor widen the problem to a continental scale. Environmental Pollution, 220, 672-679. doi:10.1016/j.envpol.2016.10.025

Winter, A. S. A. M., \& Sampson, R. J. P. M. A. (2017). From lead exposure in early childhood to adolescent health: a Chicago birth cohort. American Journal of Public Health, 107(9), 1496-1501. doi:10.2105/AJPH.2017.303903

Wisdom, J. P., Chor, K. H. B., Hoagwood, K. E., \& Horwitz, S. M. (2014). Innovation Adoption: A Review of Theories and Constructs. Administration and policy in mental health, 41(4), 480-502. doi:10.1007/s10488-013-0486-4

Wollstein, K. L., \& Davis, E. J. (2017). A "hammer held over their heads": voluntary conservation spurred by the prospect of regulatory enforcement in Oregon. Human-Wildlife Interactions, 11(3), 258-273. doi:10.26077/wrwp-f416

Wood, M. C. (2014). Nature's trust: environmental law for a new ecological age. New York, New York, USA: Cambridge University Press. 
Yaw, T., Neumann, K., Bernard, L., Cancilla, J., Evans, T., Martin-Schwarze, A., \& Zaffarano, B. (2017). Lead poisoning in bald eagles admitted to wildlife rehabilitation facilities in Iowa, 2004-2014. Journal of Fish and Wildlife Management, 8(2), 465-473. doi:10.3996/122015-JFWM-124

Young, J. C., Rose, D. C., Mumby, H. S., Benitez-Capistros, F., Derrick, C. J., Finch, T., ... Mukherjee, N. (2018). A methodological guide to using and reporting on interviews in conservation science research. Methods in Ecology and Evolution, 9(1), 10-19. doi:doi:10.1111/2041-210X.12828

Yzer, M. C. (2012). The Integrative Model of Behavioral Prediction as a tool for designing health messages. In H. Cho (Ed.), Health Communication Message Design: Theory and Practice. Thousand Oaks, California, USA: SAGE. 


\section{Appendices}

Appendix 1. Areas participating in outreach program; some areas have both managed hunts and open; i.e., some units of the refuge will have a managed hunt and other portions of the refuge will be open under the respective statewide deer hunting regulations.

\begin{tabular}{|c|c|c|c|c|c|}
\hline $\begin{array}{l}\text { Entry } \\
\text { Year }\end{array}$ & $\begin{array}{l}\text { Hunt } \\
\text { Type }\end{array}$ & Refuge & State & $\begin{array}{c}\text { Estimated } \\
\text { Annual } \\
\text { Hunters }\end{array}$ & $\begin{array}{c}\text { Outreach } \\
\text { Intensity } \\
\text { Level a }^{\text {L }}\end{array}$ \\
\hline \multirow[t]{4}{*}{2016} & Managed & $\begin{array}{l}1 \text { - Mingo NWR (October through December } \\
\text { hunts) }\end{array}$ & MO & 135 & $*$ \\
\hline & Managed & 2 - Shiawassee NWR & MI & 156 & $*$ \\
\hline & Managed & 3 - Loess Bluffs NWR & MO & 7 & $*$ \\
\hline & Managed & 4 - Trempealeau NWR & WI & 45 & $*$ \\
\hline \multirow[t]{13}{*}{2017} & Open & 5 - Boyer Chute NWR & $\mathrm{NE}$ & 100 & $* *$ \\
\hline & Managed & $\begin{array}{l}6 \text { - Clarence Cannon NWR (October and } \\
\text { January hunts; } 12 \text { hunters each) }\end{array}$ & MO & 24 & $* *$ \\
\hline & Open & 7 - DeSoto NWR & NE, IA & 150 & $* *$ \\
\hline & Open & 8 - Driftless Area NWR & IA & 50 & $* *$ \\
\hline & Managed & 9a - Great River NWR - Delair Unit & IL & 40 & $* *$ \\
\hline & Open & 9b - Great River NWR - Long Island Division & IL & 2,800 & $* *$ \\
\hline & Open & 10a - Minnesota Valley NWR & $\mathrm{MN}$ & 5,000 & $* *$ \\
\hline & Managed & 10b - Minnesota Valley NWR & $\mathrm{MN}$ & 44 & $* *$ \\
\hline & Open & 11 - Port Louisa NWR & IA & 350 & $* *$ \\
\hline & Managed & 12 - Swan Lake NWR & MO & 10 & $* *$ \\
\hline & Open & 13 - Tamarac NWR & $\mathrm{MN}$ & 3,500 & $* *$ \\
\hline & Open & $\begin{array}{l}14 \text { - Two Rivers NWR - Apple Creek \& } \\
\text { Calhoun Divisions }\end{array}$ & IL & 60 & $* *$ \\
\hline & Open & $\begin{array}{l}\text { 15a-Upper Mississippi River NW\&FR } \\
\text { LaCrosse District }\end{array}$ & $\begin{array}{c}\mathrm{MN}, \\
\mathrm{WI}\end{array}$ & 2,700 & $* *$ \\
\hline
\end{tabular}




\begin{tabular}{|c|c|c|c|c|c|}
\hline $\begin{array}{l}\text { Entry } \\
\text { Year }\end{array}$ & $\begin{array}{l}\text { Hunt } \\
\text { Type }\end{array}$ & Refuge & State & $\begin{array}{c}\text { Estimated } \\
\text { Annual } \\
\text { Hunters }\end{array}$ & $\begin{array}{c}\text { Outreach } \\
\text { Intensity } \\
\text { Level a }^{\text {a }}\end{array}$ \\
\hline & Open & $\begin{array}{l}\text { 15b-Upper Mississippi River NW\&FR } \\
\text { McGregor District }\end{array}$ & IA, WI & 3,500 & $* *$ \\
\hline & Open & $\begin{array}{l}\text { 15c-Upper Mississippi River NW\&FR } \\
\text { Savanna District }\end{array}$ & IA, IL & 4,200 & $* *$ \\
\hline & Open & $\begin{array}{l}\text { 15d-Upper Mississippi River NW\&FR } \\
\text { Winona District }\end{array}$ & $\begin{array}{l}\mathrm{MN}, \\
\mathrm{WI}\end{array}$ & 3,200 & $* *$ \\
\hline \multirow[t]{17}{*}{2018} & Open & 16 - Agassiz NWR & $\mathrm{MN}$ & 1,000 & Low \\
\hline & Open & 17 - Big Muddy NF\&WR & MO & 4,000 & Medium \\
\hline & Managed & 18 - Big Oaks NWR & IN & 4,455 & High \\
\hline & Open & 19 - Big Stone NWR & $\mathrm{MN}$ & 400 & Low \\
\hline & Open & 20 - Big Stone WMD & $\mathrm{MN}$ & 1,900 & Low \\
\hline & $\begin{array}{l}\text { Open \& } \\
\text { Managed }\end{array}$ & 21 - Crab Orchard NWR & IL & 6,300 & High \\
\hline & Managed & 22 - Crane Meadows NWR & $\mathrm{MN}$ & 10 & Low \\
\hline & Open & 23 - Cypress Creek NWR & $\mathrm{IL}$ & 4,100 & Medium \\
\hline & Open & 24 - Detroit Lakes WMD & $\mathrm{MN}$ & 2,225 & Low \\
\hline & Open & 25 - Detroit River IWR & MI & 540 & Medium \\
\hline & Open & 26 - Emiquon NWR & IL & 150 & Low \\
\hline & Open & 27 - Fergus Falls WMD & $\mathrm{MN}$ & 7,750 & Low \\
\hline & Open & 28 - Fox River NWR & WI & 100 & Low \\
\hline & Open & 29 - Glacial Ridge NWR & $\mathrm{MN}$ & 60 & Low \\
\hline & & 30 - Hackmatack NWR & IL, WI & $\mathrm{n} / \mathrm{a}$ & Low \\
\hline & Open & 31 - Hamden Slough NWR & $\mathrm{MN}$ & 100 & Low \\
\hline & Open & 32 - Harbor Island NWR & MI & 30 & Low \\
\hline
\end{tabular}




\begin{tabular}{|c|c|c|c|c|c|}
\hline $\begin{array}{c}\text { Entry } \\
\text { Year }\end{array}$ & $\begin{array}{l}\text { Hunt } \\
\text { Type }\end{array}$ & Refuge & State & $\begin{array}{c}\text { Estimated } \\
\text { Annual } \\
\text { Hunters }\end{array}$ & $\begin{array}{c}\text { Outreach } \\
\text { Intensity } \\
\text { Level a }^{\text {L }}\end{array}$ \\
\hline & $\begin{array}{l}\text { Open \& } \\
\text { Managed }\end{array}$ & 33 - Horicon NWR & WI & 1,100 & Medium \\
\hline & Open & 34 - Iowa WMD & IA & 5,100 & Low \\
\hline & Open & 35 - Kankakee NWR & $\mathrm{IL}$ & $\mathrm{n} / \mathrm{a}$ & Low \\
\hline & Open & 36 - Kirtland's Warbler WMA & MI & 100 & Low \\
\hline & Open & 37 - Leopold WMD & WI & 9,250 & Low \\
\hline & Open & 38 - Litchfield WMD & $\mathrm{MN}$ & 17,000 & Low \\
\hline & Open & 39 - Middle Mississippi River NWR & IL, MO & 100 & Low \\
\hline & Open & 40 - Minnesota Valley WMD & $\mathrm{MN}$ & 800 & Low \\
\hline & Open & 41 - Morris WMD & $\mathrm{MN}$ & 5,400 & Low \\
\hline & Managed & 42 - Muscatatuck NWR & IN & 550 & Medium \\
\hline & Open & 43 - Neal Smith NWR & IA & 928 & Medium \\
\hline & Open & 44 - Necedah NWR & WI & 2,348 & High \\
\hline & Open & 45 - Northern Tallgrass Prairie NWR & $\mathrm{MN}$ & 120 & Low \\
\hline & Managed & 46 - Ottawa NWR & $\mathrm{OH}$ & 143 & Medium \\
\hline & Open & 47 - Patoka River NWR & IN & 2,385 & Medium \\
\hline & Managed & 48 - Rice Lake NWR & $\mathrm{MN}$ & 400 & Low \\
\hline & Managed & 49 - Rydell NWR & $\mathrm{MN}$ & 32 & Low \\
\hline & Open & 50 - Seney NWR & MI & 475 & Medium \\
\hline & Open & 51 - Sherburne NWR & $\mathrm{MN}$ & 5,100 & Medium \\
\hline & Open & 52 - St. Croix WMD & WI & 5,100 & Low \\
\hline
\end{tabular}




\begin{tabular}{|c|l|l|c|c|c|}
\hline $\begin{array}{c}\text { Entry } \\
\text { Year }\end{array}$ & $\begin{array}{c}\text { Hunt } \\
\text { Type }\end{array}$ & Refuge & State & $\begin{array}{c}\text { Estimated } \\
\text { Annual } \\
\text { Hunters }\end{array}$ & $\begin{array}{c}\text { Outreach } \\
\text { Intensity } \\
\text { Level a }\end{array}$ \\
\hline & Open & 53- Union Slough NWR & IA & 310 & Low \\
\hline & Open & 54 - Windom WMD & MN & 4,725 & Low \\
\hline
\end{tabular}

* Refuges in 2016 all received the same level of outreach material including

** Refuges in 2017 all received the same level of outreach material including everything from 2016 plus epoxy gel blocks showing bullet fragmentation characteristics.

${ }^{a}$ Low outreach level: updated refuge website, refuge staff meeting informational toolbox, printable fact sheets, new release language templates, brochures or rack cards, and free-standing banner and epoxy bullet molds available on loan. Medium outreach level: all elements from low outreach level plus permanently assigned free-standing banners and epoxy molds, and temporary yards during deer season.

High outreach: All items from medium intensity level plus signs for notice boards or kiosks at major access points. 
Appendix 2. Lead Free Ammunition Hunter Orientation Sessions Observation Form

Date

Area

Hunt Type (youth, handicapped, muzzleloader, etc.)

Number of hunters

Are printed materials available?

Visitors area: YES NO Orientation session room: YES NO

Are posters or banners present and visible?:

Visitors area: YES NO Orientation session room: YES NO

Who gave the orientation (level or position)?

Total time of orientation session

Time spent on lead free ammunition during orientation session

Was standard PowerPoint presentation from Google drive used? YES NO

If yes, was is tailored/adapted to the local refuge? YES NO

If yes, describe how it was adapted:

Were staff prepared and knowledgeable about the lead free portion of the orientation?

NOT AT ALL MODERATELY VERY

Answer questions assertively

Reference available FWS materials

Project confidence

Offer additional resources

Comments: 
Did hunters seem engaged and pay attention?
SOMEWHAT NO
Sleeping
$\square$ Checking Cell phones
Reading other material

Nodding in agreement

Asking Questions

Not paying attention

Comments:

Did hunters ask questions? YES NO

List/describe deer hunter questions:

Were staff able to answer hunters' questions correctly? NONE

SOME

ALL

Describe staff/hunter interchange: 
This table provides a second check at the end of the orientation session on the availability of the material at the orientation.

\begin{tabular}{|l|l|}
\hline Information Materials Used & $\begin{array}{l}\text { Material Used by } \\
\text { Staff? }\end{array}$ \\
\hline $\begin{array}{l}\text { Letter to hunter (e.g., was it mentioned during } \\
\text { orientation or did some hunters have a copy with } \\
\text { them?) }\end{array}$ & \\
\hline PowerPoint presentation & \\
\hline $\begin{array}{l}\text { Lead poisoning fact sheet (w/ picture father-son } \\
\text { hunting) }\end{array}$ & \\
\hline FAQ sheet (w/ picture of sick eagle and gut pile) & \\
\hline Free-standing banners & \\
\hline Sandwich board signs at area headquarters & \\
\hline Yard signs at area headquarters or parking lots & \\
\hline Rack cards & \\
\hline Other material used (list below): & \\
\hline
\end{tabular}

Other hunter or staff observations: 
Appendix 3. Interview Guide for Semi-structured USFWS Staff on National Wildlife Refuges.

Qualitative Research Questions: How do USFWS staff experiences and opinions of the Lead Free Ammunition Outreach Program influence staff awareness of lead poisoning in wildlife and human health, and implementation of the program at the refuge level?

Interview Questions (probes or follow-ups listed below primary questions):

1. Tell me about how you got started in your career with USFWS. What do you enjoy about your job?

a. About how many years have work for USFWS?

b. In general terms, describe your job title and duties?

2. Describe how much public contact is a part of your daily activities, especially during hunting seasons, and provide examples.

3. Are you a deer hunter?

a. If yes, describe what deer hunting means to you and why it's important to you?

i. Do you use lead free ammunition when deer hunting? Why/why not?

b. If no, have you ever thought about going deer hunting? Why/why not?

4. Tell me about your thoughts regarding lead poisoning in bald eagles or other wildlife?

a. Describe what you know about how lead effects the health of bald eagles and other wildlife?

5. Tell me about your thoughts regarding lead poisoning in people?

a. Describe what you know about how lead effects the health of people?

6. Tell me about your involvement and experiences with USFWS Region 3 Lead Free Outreach communication program encouraging the voluntarily use lead free ammunition. 
a. Describe how you used the information on the Google drive?

b. Describe how you found the information helpful or organized.

c. What information did you find to be useful or persuasive?

d. Describe your participation and use of other parts of the program; e.g., regular phone conferences, visits and on-site presentations from the implementation team, informational materials, etc.

e. Did you modify any of the available materials to suit your particular needs or circumstance? If yes, why was it modified and how?

f. Tell me about what worked, what you liked, or what you thought was most effective?

g. Tell me about what needs to be improved? What would you change, improve, or add in the future?

7. Describe some of your experiences when you shared information about lead free ammunition with deer hunters on the refuge.

a. What parts of the conversation were easy or fun?

b. What parts were difficult or challenging?

c. Tell me what you may have learned from these experiences that my help other USFWS staff talking with hunter about lead free ammunition.

8. What else would you like to say about communication program, deer hunting, or lead free ammunition that hasn't been covered? 


\section{Appendix 4. Questionnaire instrument: USFWS Staff - Lead Free Ammunition Outreach.}

Q1 Thank you for your willingness to participate in this survey. We are interested in learning more about your attitudes and opinions concerning lead poisoning in wildlife and the U.S. Fish and Wildlife Service (FWS) Lead Free Ammunition Outreach Program. Please read through and answer all questions in the survey. Your time and input are appreciated.

\section{Q2 THIS FIRST SECTION DEALS WITH YOUR HUNTING EXPERIENCES AND ACTIVITIES}

Q3 Do you consider yourself a deer hunter?

Yes (1)

No (2)

Q4 Have you hunted the following types game at least once in the past 5 years?

White-tailed deer (1)
Other big-game hunting (mule deer,
elk, bear, moose, etc.) (2)
Upland birds (pheasants, quail,
grouse, doves, woodcock, etc.) (3)
Other small game (rabbits, squirrels,
etc.) (4)
Waterfowl (ducks and geese) (5)

Q5 Think back to when you started deer hunting. How many years has it been since you started?

1-2 years (1)

3-5 years (2)

6-10 years (3)

$11-15$ years $(4$

$16-20$ years (5)

$21-25$ years $(6)$ 
more than 25 years (7)

Q6 When deer hunting, where do you typically hunt?

Only on public land (1)

Mostly on public land (2)

Mostly on private land (3)

Only on private land (4)

Q7 During this past deer hunting season, did you deer hunt on a U.S. Fish and Wildlife Service National Wildlife Refuge (NWR), National Fish \& Wildlife Refuge (NFWR), Wetland Management District (WMD), or U.S. Fish and Wildlife Service Wildlife Management Area (WMA)?

Yes (1)

No (2)

Skip To: Q10 If During this past deer hunting season, did you deer hunt on a U.S. Fish and Wildlife Service Natio... = No

Display This Question:

If During this past deer hunting season, did you deer hunt on a U.S. Fish and Wildlife Service Natio... = Yes

Q8 During the past deer hunting season, did you hunt on any of the National Wildlife Refuges (NWR), National Fish \& Wildlife Refuges (NFWR), Wetland Management Districts (WMD), or U.S. Fish and Wildlife Service Wildlife Management Areas (WMA)listed below? (Select all that apply) (NOTE - Only two areas are shown for example purposes)

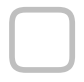

$$
\text { Agassiz NWR (1) }
$$

Big Muddy NF\&WR (2)

Q9 How many deer did you harvest on the refuge(s) you hunted this past deer hunting season? (NOTE - Only two areas are shown for example purposes)

\begin{tabular}{c|ccc} 
& $\begin{array}{c}\text { I did not harvest a } \\
\text { deer on the refuge } \\
(1)\end{array}$ & 1 deer (2) & 2 deer (3) or more deer (4) \\
\hline Agassiz NWR (1) & \\
Big Muddy NF\&WR & \\
(2) &
\end{tabular}


Q10 During the past deer hunting season, did you use a firearm? (rifle, handgun, shotgun, muzzleloader)

Yes (1)

No (2)

Skip To: Q11 If During the past deer hunting season, did you use a firearm? (rifle, handgun, shotgun, muzzleloader) = Yes

Skip To: Q21 If During the past deer hunting season, did you use a firearm? (rifle, handgun, shotgun, muzzleloader) = No

Q11 Which firearms do you currently use while deer hunting? (Select all that apply)

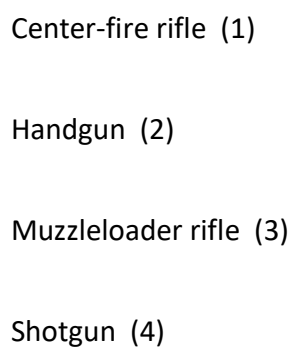

Q12 About how many shots do you typically shoot practicing prior to the deer hunting season?

I do not target practice before deer hunting (1)

$1-5$ shots (2)

$6-20$ shots (3)

21-40 shots (4)

More than 40 shots (5)

Q13 About how many shots do you typically shoot while hunting during one deer hunting season?

$1-5$ shots (1)

$6-20$ shots (2)

21-40 shots (3)

More than 40 shots (4)

Q14 On average, how much do you typically spend on hunting ammunition for one deer hunting season?

Less than $\$ 10(1)$

$\$ 10$ to $\$ 19$ (2)

$\$ 20$ to $\$ 29$ (3) 
$\$ 30$ to $\$ 50(4)$

$\$ 51$ to $\$ 100(5)$

More than $\$ 100(6)$

Q15 Where do your purchase the majority of your deer hunting ammunition?

Big-box or discount chain store (1)

Large sporting goods stores (e.g., Cabela's, Bass Pro, Gander Mountain, etc.) (6)

Local hunting and fishing store (2)

Gas station convenience store (3)

Internet website or mail-order catalog (4)

Other (please fill-in): (5)

Q16 Do you currently use lead free ammunition while deer hunting?

Yes (1)

No (2)

Skip To: Q17 If Do you currently use lead free ammunition while deer hunting? = Yes

Skip To: Q19 If Do you currently use lead free ammunition while deer hunting? = No

Q17 How unlikely or likely will you continue using lead free ammunition for deer hunting?

Very unlikely (1)

Unlikely (2)

Neither likely nor unlikely (3)

Likely (4)

Very likely (5) 
Q18 How unimportant or important were the following factors in your use of lead free ammunition for deer hunting?

\begin{tabular}{|c|c|c|c|c|c|}
\hline & $\begin{array}{c}\text { Very } \\
\text { unimportant (1) }\end{array}$ & Unimportant (2) & $\begin{array}{c}\text { Neither } \\
\text { unimportant or } \\
\text { important (3) }\end{array}$ & Important (4) & $\begin{array}{c}\text { Very important } \\
\text { (5) }\end{array}$ \\
\hline $\begin{array}{l}\text { Potential } \\
\text { negative health } \\
\text { effects on } \\
\text { people from } \\
\text { lead } \\
\text { ammunition (1) }\end{array}$ & & & & & \\
\hline $\begin{array}{c}\text { Potential } \\
\text { negative effects } \\
\text { on wildlife from } \\
\text { lead } \\
\text { ammunition (2) }\end{array}$ & & & & & \\
\hline $\begin{array}{c}\text { Similar or better } \\
\text { performance of } \\
\text { lead free } \\
\text { ammunition } \\
\text { compared to } \\
\text { traditional lead } \\
\text { ammunition (3) }\end{array}$ & & & & & \\
\hline $\begin{array}{l}\text { Availability of } \\
\text { lead free } \\
\text { ammunition in } \\
\text { stores or } \\
\text { internet } \\
\text { retailers (4) }\end{array}$ & & & & & \\
\hline $\begin{array}{l}\text { Cost difference } \\
\text { between lead } \\
\text { free ammunition } \\
\text { and lead } \\
\text { ammunition (5) }\end{array}$ & & & & & \\
\hline
\end{tabular}

Q19 How unlikely or likely would you use lead free ammunition for deer hunting?

Very unlikely (1)

Unlikely (2)

Neither likely nor unlikely (3)

Likely (4)

Very likely (5) 
Q20 How unlikely or likely would you be willing to use lead free ammunition given the following information?

\begin{tabular}{|c|c|c|c|c|c|}
\hline & Very unlikely (1) & Unlikely (2) & $\begin{array}{c}\text { Neither likely } \\
\text { nor unlikely ( } 3 \text { ) }\end{array}$ & Likely (4) & Very likely (5) \\
\hline $\begin{array}{l}\text { If there was } \\
\text { evidence of lead } \\
\text { ammunition } \\
\text { having negative } \\
\text { health effects on } \\
\text { people (1) }\end{array}$ & & & & & \\
\hline $\begin{array}{l}\text { If there was } \\
\text { evidence of lead } \\
\text { ammunition } \\
\text { having negative } \\
\text { effects on bald } \\
\text { eagles (2) }\end{array}$ & & & & & \\
\hline $\begin{array}{l}\text { If lead free } \\
\text { ammunition } \\
\text { performed } \\
\text { similar to } \\
\text { traditional lead } \\
\text { ammunition } \\
\text { (e.g., accuracy, } \\
\text { killing efficiency, } \\
\text { and sight-in) (3) }\end{array}$ & & & & & \\
\hline $\begin{array}{l}\text { If there was } \\
\text { greater } \\
\text { availability of } \\
\text { lead free } \\
\text { ammunition in } \\
\text { stores (4) }\end{array}$ & & & & & \\
\hline $\begin{array}{l}\text { If the cost was } \\
\text { the same or no } \\
\text { more than } \\
\text { traditional lead } \\
\text { ammunition (5) }\end{array}$ & & & & & \\
\hline $\begin{array}{l}\text { If a coupon or } \\
\text { voucher was } \\
\text { available } \\
\text { offsetting the } \\
\text { additional cost of } \\
\text { lead free } \\
\text { ammunition (6) }\end{array}$ & & & & & \\
\hline
\end{tabular}

Q21 THIS SECTION EXAMINES YOUR ATTITUDES AND OPINIONS ABOUT THE IMPACTS OF LEAD AMMUNITION

Q22 How much do you disagree or agree that each of the following threats affect bald eagles? 


\begin{tabular}{|c|c|c|c|c|c|}
\hline & $\begin{array}{c}\text { Strongly } \\
\text { disagree (1) }\end{array}$ & Disagree (2) & $\begin{array}{c}\text { Neither agree } \\
\text { nor disagree (3) }\end{array}$ & Agree (4) & $\begin{array}{c}\text { Strongly agree } \\
\text { (5) }\end{array}$ \\
\hline $\begin{array}{l}\text { Collisions with } \\
\text { wind turbines } \\
\text { (1) }\end{array}$ & & & & & \\
\hline $\begin{array}{l}\text { Flying into } \\
\text { windows on } \\
\text { buildings (2) }\end{array}$ & & & & & \\
\hline Habitat loss (3) & & & & & \\
\hline $\begin{array}{l}\text { Poisoning } \\
\text { through illegal } \\
\text { use of pesticides } \\
\text { or herbicides (4) }\end{array}$ & & & & & \\
\hline $\begin{array}{l}\text { Lead poisoning } \\
\text { from ingesting } \\
\text { lead bullet } \\
\text { fragments in } \\
\text { deer gut piles or } \\
\text { carcasses (5) }\end{array}$ & & & & & \\
\hline $\begin{array}{l}\text { Poaching or } \\
\text { illegal shooting } \\
\text { (6) }\end{array}$ & & & & & \\
\hline $\begin{array}{l}\text { Power line } \\
\text { collisions (7) }\end{array}$ & 0 & & & & \\
\hline $\begin{array}{l}\text { Other (please } \\
\text { describe): (8) }\end{array}$ & & & & & \\
\hline
\end{tabular}

Q23 To what extent do you disagree or agree with each statement below about lead poisoning in bald eagles?

\begin{tabular}{|c|c|c|c|c|c|}
\hline & $\begin{array}{c}\text { Strongly } \\
\text { disagree (1) }\end{array}$ & Disagree (2) & $\begin{array}{c}\text { Neither agree } \\
\text { nor disagree (3) }\end{array}$ & Agree (4) & $\begin{array}{c}\text { Strongly agree } \\
\text { (5) }\end{array}$ \\
\hline $\begin{array}{l}\text { Ingesting lead } \\
\text { bullet fragments } \\
\text { from deer gut } \\
\text { piles or carcasses } \\
\text { is a serious } \\
\text { problem for bald } \\
\text { eagles. (1) }\end{array}$ & & & & & \\
\hline $\begin{array}{l}\text { Use of lead free } \\
\text { hunting } \\
\text { ammunition will } \\
\text { reduce bald } \\
\text { eagle deaths. (2) }\end{array}$ & & $\cap$ & & (a) & \\
\hline
\end{tabular}




\begin{tabular}{|c|c|c|c|c|c|}
\hline & $\begin{array}{c}\text { Strongly } \\
\text { disagree (1) }\end{array}$ & Disagree (2) & $\begin{array}{c}\text { Neither agree } \\
\text { nor disagree (3) }\end{array}$ & Agree (4) & $\begin{array}{c}\text { Strongly agree } \\
\text { (5) }\end{array}$ \\
\hline $\begin{array}{l}\text { A very small } \\
\text { amount of lead } \\
\text { can poison a } \\
\text { bald eagle. (3) }\end{array}$ & & & & & \\
\hline $\begin{array}{l}\text { There is } \\
\text { insufficient } \\
\text { scientific } \\
\text { information } \\
\text { supporting lead } \\
\text { poisoning of bald } \\
\text { eagles. (4) }\end{array}$ & & & & & \\
\hline $\begin{array}{c}\text { Bald eagle } \\
\text { populations are } \\
\text { increasing } \\
\text { despite ingesting } \\
\text { lead bullet } \\
\text { fragments. (5) }\end{array}$ & & & & & \\
\hline $\begin{array}{l}\text { The issue of lead } \\
\text { poisoning in bald } \\
\text { eagles is a tactic } \\
\text { to advance gun- } \\
\text { control } \\
\text { regulations. (6) }\end{array}$ & & & & & \\
\hline $\begin{array}{l}\text { Some eagles } \\
\text { might get sick } \\
\text { from eating lead } \\
\text { bullet fragments } \\
\text { but most } \\
\text { recover. (7) }\end{array}$ & & & & & \\
\hline $\begin{array}{l}\text { The issue of lead } \\
\text { poisoning in bald } \\
\text { eagles is used by } \\
\text { some groups as } \\
\text { an attempt to } \\
\text { stop hunting. (8) }\end{array}$ & & & & & \\
\hline
\end{tabular}

Q24 To what extent do you disagree or agree with each statement below about lead poisoning in people?

\begin{tabular}{c|cccc} 
Strongly & Disagree (2) & $\begin{array}{c}\text { Neither agree } \\
\text { nor disagree (3) }\end{array}$ & Agree (4) & $\begin{array}{c}\text { Strongly agree } \\
\text { disagree (1) }\end{array}$ \\
\hline $\begin{array}{c}\text { A person with } \\
\text { lead poisoning } \\
\text { may not always } \\
\text { appear sick or } \\
\text { show symptoms } \\
\text { of poisoning. (1) }\end{array}$ & & & \\
$\begin{array}{c}\text { Lead poisoning } \\
\text { in people can be } \\
\text { prevented. (2) }\end{array}$ & & & \\
\end{tabular}




\begin{tabular}{|c|c|c|c|c|c|}
\hline & $\begin{array}{c}\text { Strongly } \\
\text { disagree (1) }\end{array}$ & Disagree (2) & $\begin{array}{c}\text { Neither agree } \\
\text { nor disagree (3) }\end{array}$ & Agree (4) & $\begin{array}{c}\text { Strongly agree } \\
\text { (5) }\end{array}$ \\
\hline $\begin{array}{l}\text { Lead bullet } \\
\text { fragments in } \\
\text { venison could } \\
\text { pose a risk of } \\
\text { lead poisoning in } \\
\text { people. (3) }\end{array}$ & & & & & \\
\hline $\begin{array}{c}\text { A very small } \\
\text { amount of lead } \\
\text { can negatively } \\
\text { affect a person. } \\
\text { (4) }\end{array}$ & & & & & \\
\hline
\end{tabular}

Q25 To what extent do you disagree or agree with each of the following statements about using lead free ammunition for deer hunting?

\begin{tabular}{|c|c|c|c|c|c|}
\hline & $\begin{array}{c}\text { Strongly } \\
\text { disagree (1) }\end{array}$ & Disagree (2) & $\begin{array}{c}\text { Neither agree } \\
\text { nor disagree (3) }\end{array}$ & Agree (4) & $\begin{array}{l}\text { Strongly agree } \\
\text { (5) }\end{array}$ \\
\hline $\begin{array}{l}\text { Lead free } \\
\text { ammunition is } \\
\text { ballistically } \\
\text { superior to } \\
\text { traditional lead } \\
\text { ammunition. (1) }\end{array}$ & & & & & \\
\hline $\begin{array}{l}\text { Lead free } \\
\text { ammunition is } \\
\text { compatible with } \\
\text { most modern } \\
\text { firearms used for } \\
\text { deer hunting. (2) }\end{array}$ & & & & & \\
\hline $\begin{array}{l}\text { There is minimal } \\
\text { complexity } \\
\text { converting to } \\
\text { lead free } \\
\text { ammunition (e.g., } \\
\text { sighting in my } \\
\text { firearm). (3) }\end{array}$ & & & & & \\
\hline $\begin{array}{l}\text { Voucher } \\
\text { programs would } \\
\text { be helpful for } \\
\text { hunters to try } \\
\text { lead free } \\
\text { ammunition for } \\
\text { themselves. (4) }\end{array}$ & & & & & \\
\hline $\begin{array}{l}\text { None of my } \\
\text { friends or } \\
\text { relatives use lead } \\
\text { free deer hunting } \\
\text { ammunition. (5) }\end{array}$ & & & & & \\
\hline
\end{tabular}




\begin{tabular}{|c|c|c|c|c|c|}
\hline & $\begin{array}{c}\text { Strongly } \\
\text { disagree (1) }\end{array}$ & Disagree (2) & $\begin{array}{c}\text { Neither agree } \\
\text { nor disagree (3) }\end{array}$ & Agree (4) & $\begin{array}{c}\text { Strongly agree } \\
\text { (5) }\end{array}$ \\
\hline $\begin{array}{c}\text { Shooting } \\
\text { demonstrations } \\
\text { would show deer } \\
\text { hunters the } \\
\text { benefits of lead } \\
\text { free ammunition } \\
\text { and dangers of } \\
\text { lead poisoning. } \\
\text { (6) }\end{array}$ & & & & & \\
\hline $\begin{array}{l}\text { Lead free deer } \\
\text { hunting } \\
\text { ammunition costs } \\
\text { too much } \\
\text { compared to lead } \\
\text { ammunition. (7) }\end{array}$ & & & & & \\
\hline $\begin{array}{c}\text { Lead free } \\
\text { ammunition is } \\
\text { difficult to find at } \\
\text { local retail stores. } \\
\text { (8) }\end{array}$ & & & & & \\
\hline $\begin{array}{l}\text { It is difficult to } \\
\text { determine lead } \\
\text { free ammunition } \\
\text { by looking at the } \\
\text { package. (9) }\end{array}$ & & & & & \\
\hline $\begin{array}{l}\text { Lead free deer } \\
\text { hunting } \\
\text { ammunition } \\
\text { damages } \\
\text { firearms. (10) }\end{array}$ & & & & & \\
\hline $\begin{array}{l}\text { Deer hunting } \\
\text { guns will not } \\
\text { shoot lead free } \\
\text { ammunition } \\
\text { accurately. (11) }\end{array}$ & & & & & \\
\hline $\begin{array}{l}\text { Lead ammunition } \\
\text { is significantly } \\
\text { cheaper than } \\
\text { lead free } \\
\text { alternatives. (12) }\end{array}$ & & & & & \\
\hline $\begin{array}{l}\text { Traditional lead } \\
\text { ammunition is } \\
\text { more effective in } \\
\text { killing deer. (13) }\end{array}$ & & & & & \\
\hline
\end{tabular}


Q26 From which of the following sources do you receive information regarding the effects of deer hunting ammunition?

\begin{tabular}{|c|c|c|}
\hline & \multicolumn{2}{|c|}{ Source of information about effects of deer hunting ammunition? } \\
\hline & Yes (1) & No $(2)$ \\
\hline \multicolumn{3}{|l|}{ Family and friends (405) } \\
\hline \multicolumn{3}{|l|}{$\begin{array}{l}\text { Major outdoor or wildlife } \\
\text { organization (e.g., Ducks Unlimited, } \\
\text { Pheasants Forever, or Safari Club } \\
\text { International) (406) }\end{array}$} \\
\hline \multicolumn{3}{|l|}{$\begin{array}{l}\text { Shooting sports organization (e.g., } \\
\text { National Rifle Association (NRA), } \\
\text { National Shooting Sports Foundation } \\
\text { (NSSF), local gun club or shooting } \\
\text { range) (407) }\end{array}$} \\
\hline \multicolumn{3}{|l|}{ Hunter safety course (408) } \\
\hline \multicolumn{3}{|l|}{$\begin{array}{l}\text { Hunting magazines or periodicals } \\
\qquad(409)\end{array}$} \\
\hline \multicolumn{3}{|l|}{$\begin{array}{l}\text { Local hunting or sporting goods store } \\
\qquad(410)\end{array}$} \\
\hline \multicolumn{3}{|l|}{ State wildlife agency website (411) } \\
\hline \multicolumn{3}{|l|}{ Federal agency website (412) } \\
\hline \multicolumn{3}{|l|}{$\begin{array}{c}\text { Television stories, public service } \\
\text { announcements (413) }\end{array}$} \\
\hline \multicolumn{3}{|l|}{$\begin{array}{l}\text { Scientific journals or technical } \\
\text { reports }(414)\end{array}$} \\
\hline $\begin{array}{l}\text { Nature center or museum displays } \\
\qquad(415)\end{array}$ & & \\
\hline
\end{tabular}


Q27 Given the information you received regarding deer hunting ammunition, how unimportant or important was each source to you? (NOTE - only two items are shown for example purposes)

\begin{tabular}{|c|c|c|c|c|}
\hline $\begin{array}{c}\text { Very } \\
\text { unimportant (1) }\end{array}$ & Unimportant (2) & $\begin{array}{c}\text { Neither } \\
\text { unimportant or } \\
\text { important (3) }\end{array}$ & Important (4) & $\begin{array}{c}\text { Very important } \\
\text { (5) }\end{array}$ \\
\hline
\end{tabular}

Family and
friends (1)
Major outdoor
or wildlife
organization
(e.g., Ducks
Unlimited,
Pheasants
Forever, or Safari
Club
International) (2)

\section{Q28 THIS SECTION DEALS WITH THE FWS LEAD FREE AMMUNITION OUTREACH PROGRAM}

Q29 Are you aware of the U.S. Fish and Wildlife Service (FWS) Lead Free Ammunition Outreach Program encouraging hunters to voluntarily use lead free ammunition while deer hunting on national wildlife refuges?

Yes (1)

No (2)

Skip To: Q30 If Are you aware of the U.S. Fish and Wildlife Service (FWS) Lead Free Ammunition Outreach Program e... = Yes

Skip To: Q38 If Are you aware of the U.S. Fish and Wildlife Service (FWS) Lead Free Ammunition Outreach Program e... = No

Q30 From which of the following sources in the U.S. Fish and Wildlife Service (FWS) Lead Free Ammunition Outreach Program do you receive information regarding the effects of lead ammunition on bald eagles?

$$
\text { | Source of information about effects of lead ammunition? }
$$

Yes (1) No (2)

Information from the FWS

Implementation Team (e.g.,

conference calls, meeting summary

notes, on-site training) (506)

Posters and banners at refuge

visitors' centers and offices (507)

Fliers, pamphlets, bookmarks, and brochures (508) 


Signs or kiosks on refuges (509)
$\begin{gathered}\text { Information enclosed with managed } \\ \text { hunt notification letter (510) }\end{gathered}$
Presentations at orientation sessions
at refuges with managed hunts (511)
Information on refuge websites
(512)
FWs news releases (513)
News or media stories (e.g.,
newspaper, online, TV, radio) (514)
Information at non-hunting events
(e.g., Eagle Days) (515)
Information at local retailers and
partners (e.g., Pheasants Forever
chapter meeting) (516)
Social media (e.g., Facebook,
Twitter) (517)
about lead free ammunition (518)
about lead free ammunition (519)

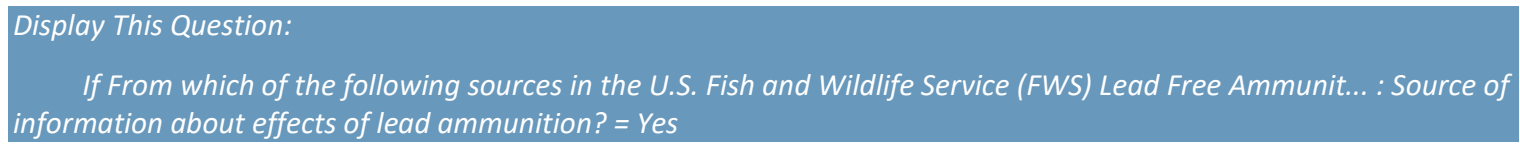


Q31 Of the FWS Lead Free Ammunition Outreach Program information sources used, how unimportant or important was each source of information to you for your own learning about the effects of lead free ammunition on bald eagles? (NOTE - Only two items are shown for example purposes)

\begin{tabular}{c|cccc} 
& $\begin{array}{c}\text { Very } \\
\text { unimportant (1) }\end{array}$ & $\begin{array}{c}\text { Neither } \\
\text { Unimportant or } \\
\text { important (3) }\end{array}$ & Important (4) & $\begin{array}{c}\text { Very important } \\
\text { (5) }\end{array}$ \\
\hline $\begin{array}{c}\text { Information from } \\
\text { the FWS } \\
\text { Implementation } \\
\text { Team (e.g., } \\
\text { conference calls, } \\
\text { meeting }\end{array}$ & & \\
summary notes, \\
on-site training) \\
(1)
\end{tabular}

Q32 Is your field station participating in the FWS Lead Free Ammunition Outreach Program?

Yes, started in 2016 (1)

Yes, started in 2017 (2)

Yes, to start in 2018 (3)

No, not participating in program (4)

Skip To: Q33 If Is your field station participating in the FWS Lead Free Ammunition Outreach Program? = Yes, started in 2016

Skip To: Q33 If Is your field station participating in the FWS Lead Free Ammunition Outreach Program? = Yes, started in 2017

Skip To: Q38 If Is your field station participating in the FWS Lead Free Ammunition Outreach Program? = Yes, to start in 2018

Skip To: Q38 If Is your field station participating in the FWS Lead Free Ammunition Outreach Program? = No, not participating in program 
Q33 As a staff person working at a field station participating in the FWS Lead Free Ammunition Outreach Program, how dissatisfied or satisfied were you with each of the following to help you implement the program on your refuge?

\begin{tabular}{|c|c|c|c|c|c|c|}
\hline & $\begin{array}{l}\text { Strongly } \\
\text { dissatisfied } \\
\text { (1) }\end{array}$ & $\begin{array}{l}\text { Dissatisfied } \\
\text { (2) }\end{array}$ & $\begin{array}{c}\text { Neither } \\
\text { dissatisfied } \\
\text { nor satisfied } \\
\text { (3) }\end{array}$ & Satisfied (4) & $\begin{array}{c}\text { Strongly } \\
\text { satisfied (5) }\end{array}$ & $\begin{array}{l}\text { I did not use } \\
\text { or participate } \\
\text { (6) }\end{array}$ \\
\hline $\begin{array}{l}\text { Conference } \\
\text { calls with the } \\
\text { Regional } \\
\text { Implementation } \\
\text { Team (1) }\end{array}$ & & $C$ & C & & & ) \\
\hline $\begin{array}{l}\text { On-site training } \\
\text { by Regional } \\
\text { Implementation } \\
\text { Team (e.g., } \\
\text { videos and } \\
\text { PowerPoint } \\
\text { presentations) } \\
\text { (2) }\end{array}$ & & & & & & \\
\hline $\begin{array}{l}\text { Usefulness of } \\
\text { informational } \\
\text { materials on } \\
\text { the Google } \\
\text { drive (3) }\end{array}$ & & & & & & \\
\hline $\begin{array}{l}\text { Organization of } \\
\text { materials on } \\
\text { the Google } \\
\text { drive (4) }\end{array}$ & & & & & & \\
\hline $\begin{array}{l}\text { Summary notes } \\
\text { from the } \\
\text { Regional } \\
\text { Implementation } \\
\text { Team meetings } \\
\text { (5) }\end{array}$ & & $\cap$ & & 8 & $\bigcirc$ & \\
\hline $\begin{array}{l}\text { Supply of } \\
\text { Outreach } \\
\text { Program } \\
\text { information } \\
\text { materials (6) }\end{array}$ & & & & & & \\
\hline
\end{tabular}


Q34 To what extent do you disagree or agree with each of the following statements about your ability to implement the FWS Lead Free Ammunition Outreach Program?

\begin{tabular}{|c|c|c|c|c|c|}
\hline & $\begin{array}{c}\text { Strongly } \\
\text { disagree (1) }\end{array}$ & Disagree (2) & $\begin{array}{c}\text { Neither agree } \\
\text { nor disagree (3) }\end{array}$ & Agree (4) & $\begin{array}{c}\text { Strongly agree } \\
\text { (5) }\end{array}$ \\
\hline $\begin{array}{l}\text { I had sufficient } \\
\text { training to } \\
\text { become } \\
\text { knowledgeable } \\
\text { about the topic. } \\
\text { (1) }\end{array}$ & & & & & \\
\hline $\begin{array}{c}\text { I felt I had the } \\
\text { necessary } \\
\text { administrative } \\
\text { support to freely } \\
\text { discuss the topic } \\
\text { with deer } \\
\text { hunters. (2) }\end{array}$ & & & & & \\
\hline $\begin{array}{l}\text { I was given ample } \\
\text { time and } \\
\text { opportunity to } \\
\text { review the } \\
\text { available } \\
\text { materials. (3) }\end{array}$ & & & & & \\
\hline $\begin{array}{l}\text { I was given ample } \\
\text { time and } \\
\text { opportunity to } \\
\text { learn about the } \\
\text { topic. }(4)\end{array}$ & & & & & \\
\hline
\end{tabular}

Q35 In your opinion, how unimportant or important were each of the following information materials from the FWS Lead Free Ammunition Outreach Program in persuading hunters to use lead free ammunition?

\begin{tabular}{|c|c|c|c|c|c|c|}
\hline & $\begin{array}{c}\text { Very } \\
\text { unimportant } \\
\text { (1) }\end{array}$ & $\begin{array}{c}\text { Unimportant } \\
\text { (2) }\end{array}$ & $\begin{array}{c}\text { Neither } \\
\text { unimportant } \\
\text { or important } \\
\text { (3) }\end{array}$ & $\begin{array}{l}\text { Important } \\
\text { (4) }\end{array}$ & $\begin{array}{c}\text { Very } \\
\text { important } \\
\text { (5) }\end{array}$ & $\begin{array}{c}\text { Not } \\
\text { applicable } \\
(6)\end{array}$ \\
\hline $\begin{array}{c}\text { Information } \\
\text { from the FWS } \\
\text { Implementation } \\
\text { Team (e.g., } \\
\text { conference } \\
\text { calls, meeting } \\
\text { summary notes, } \\
\text { on-site training) } \\
\text { (1) }\end{array}$ & & & & & & \\
\hline $\begin{array}{l}\text { Posters and } \\
\text { banners at } \\
\text { refuge visitors' } \\
\text { centers and } \\
\text { offices (2) }\end{array}$ & & & & & & \\
\hline
\end{tabular}




\begin{tabular}{|c|c|c|c|c|c|c|}
\hline & $\begin{array}{c}\text { Very } \\
\text { unimportant } \\
\text { (1) }\end{array}$ & $\begin{array}{c}\text { Unimportant } \\
\text { (2) }\end{array}$ & $\begin{array}{c}\text { Neither } \\
\text { unimportant } \\
\text { or important } \\
\text { (3) }\end{array}$ & $\begin{array}{l}\text { Important } \\
\text { (4) }\end{array}$ & $\begin{array}{c}\text { Very } \\
\text { important } \\
\text { (5) }\end{array}$ & $\begin{array}{c}\text { Not } \\
\text { applicable } \\
(6)\end{array}$ \\
\hline $\begin{array}{c}\text { Fliers, } \\
\text { pamphlets, } \\
\text { bookmarks, and } \\
\text { brochures (3) }\end{array}$ & & & & & & \\
\hline $\begin{array}{l}\text { Signs or kiosks } \\
\text { on refuges (4) }\end{array}$ & & & & & & \\
\hline $\begin{array}{l}\text { Information } \\
\text { enclosed with } \\
\text { managed hunt } \\
\text { notification } \\
\text { letter (5) }\end{array}$ & & & & & & \\
\hline $\begin{array}{l}\text { Presentations } \\
\text { at orientation } \\
\text { sessions at } \\
\text { refuges with } \\
\text { managed hunts } \\
\text { (6) }\end{array}$ & & & & & & \\
\hline $\begin{array}{l}\text { Information on } \\
\text { refuge websites } \\
\text { (7) }\end{array}$ & & & & & & \\
\hline $\begin{array}{l}\text { FWS news } \\
\text { releases ( } 8 \text { ) }\end{array}$ & & & & & & \\
\hline $\begin{array}{l}\text { News or media } \\
\text { stories (e.g., } \\
\text { newspaper, } \\
\text { online, TV, } \\
\text { radio) (9) }\end{array}$ & & & & & & \\
\hline $\begin{array}{l}\text { Information at } \\
\text { non-hunting } \\
\text { events (e.g., } \\
\text { Eagle Days) (10) }\end{array}$ & & & & & & \\
\hline $\begin{array}{l}\text { Information at } \\
\text { local retailers } \\
\text { and partners } \\
\text { (e.g., Pheasants } \\
\text { Forever chapter } \\
\text { meeting) (11) }\end{array}$ & $\cap$ & & & & & \\
\hline $\begin{array}{c}\text { Social media } \\
\text { (e.g., Facebook, } \\
\text { Twitter) (12) }\end{array}$ & & & & & & \\
\hline
\end{tabular}




\begin{tabular}{|c|c|c|c|c|c|c|}
\hline & $\begin{array}{c}\text { Very } \\
\text { unimportant } \\
\text { (1) }\end{array}$ & $\begin{array}{l}\text { Unimportant } \\
\text { (2) }\end{array}$ & $\begin{array}{c}\text { Neither } \\
\text { unimportant } \\
\text { or important } \\
\text { (3) }\end{array}$ & $\begin{array}{l}\text { Important } \\
\text { (4) }\end{array}$ & $\begin{array}{c}\text { Very } \\
\text { important } \\
\text { (5) }\end{array}$ & $\begin{array}{c}\text { Not } \\
\text { applicable } \\
(6)\end{array}$ \\
\hline $\begin{array}{l}\text { Conversation } \\
\text { with an FWS } \\
\text { employee } \\
\text { about lead free } \\
\text { ammunition } \\
\text { (13) }\end{array}$ & & & & & & \\
\hline $\begin{array}{l}\text { Conversation } \\
\text { with an FWS } \\
\text { volunteer about } \\
\text { lead free } \\
\text { ammunition } \\
\text { (14) }\end{array}$ & & & & & & \\
\hline
\end{tabular}

Q36 To what extent do you disagree or agree with each of the following statements about the FWS Lead Free Ammunition Outreach Program?

\begin{tabular}{|c|c|c|c|c|c|}
\hline & $\begin{array}{c}\text { Strongly } \\
\text { disagree (1) }\end{array}$ & Disagree (2) & $\begin{array}{c}\text { Neither agree } \\
\text { nor disagree (3) }\end{array}$ & Agree (4) & $\begin{array}{c}\text { Strongly agree } \\
\text { (5) }\end{array}$ \\
\hline $\begin{array}{l}\text { The program is an } \\
\text { optimal approach } \\
\text { to reducing lead } \\
\text { poisoning in bald } \\
\text { eagles. (1) }\end{array}$ & & & & & \\
\hline $\begin{array}{l}\text { The program is } \\
\text { compatible with } \\
\text { the goals and } \\
\text { objectives of my } \\
\text { agency and } \\
\text { cooperating } \\
\text { conservation } \\
\text { organizations. (2) }\end{array}$ & & & & & ) \\
\hline $\begin{array}{l}\text { There's minimal } \\
\text { complexity in } \\
\text { using and } \\
\text { implementing the } \\
\text { program. (3) }\end{array}$ & & & & & \\
\hline $\begin{array}{l}\text { A voucher } \\
\text { incentive } \\
\text { connected with } \\
\text { the program } \\
\text { would be helpful } \\
\text { for hunters to try } \\
\text { lead free } \\
\text { ammunition on a } \\
\text { trial basis without } \\
\text { having to pay for } \\
\text { it. (4) }\end{array}$ & & $\cap$ & $\cap$ & & \\
\hline
\end{tabular}




\begin{tabular}{c|cccc} 
& $\begin{array}{c}\text { Strongly } \\
\text { disagree (1) }\end{array}$ & Disagree (2) & $\begin{array}{c}\text { Neither agree } \\
\text { nor disagree (3) }\end{array}$ & Agree (4) \\
\hline $\begin{array}{c}\text { Shooting } \\
\text { demonstrations }\end{array}$ & \\
(e.g., using water \\
traps) would be \\
helpful as part of \\
the program \\
showing the \\
benefits of lead \\
free ammunition \\
and dangers of \\
lead poisoning. \\
(5)
\end{tabular}

Q37 What recommendations do you have for improving the FWS Lead Free Ammunition Outreach Program?

\section{Q38 NEXT, TELL US SOME INFORMATION ABOUT YOURSELF}

Q39 People respond to their environment in different ways. The statements below refer to ways people can respond. Please indicate the degree to which each statement applies to you.

\begin{tabular}{l|cc} 
My peers often \\
ask me for advice \\
or information. \\
(1)
\end{tabular}




\begin{tabular}{|c|c|c|c|c|c|}
\hline & $\begin{array}{c}\text { Strongly } \\
\text { disagree (1) }\end{array}$ & Disagree (2) & $\begin{array}{c}\text { Neither agree } \\
\text { nor disagree (3) }\end{array}$ & Agree (4) & $\begin{array}{c}\text { Strongly agree } \\
\text { (5) }\end{array}$ \\
\hline $\begin{array}{l}\text { I am suspicious of } \\
\text { new inventions } \\
\text { and new ways of } \\
\text { thinking. (6) }\end{array}$ & & & & & \\
\hline $\begin{array}{l}\text { I rarely trust new } \\
\text { ideas until I can } \\
\text { see whether the } \\
\text { vast majority of } \\
\text { people around } \\
\text { me accept them. } \\
\text { (7) }\end{array}$ & & & & & . \\
\hline $\begin{array}{l}\text { I feel that I am an } \\
\text { influential } \\
\text { member of my } \\
\text { peer group. (8) }\end{array}$ & & & & & \\
\hline $\begin{array}{l}\text { I consider myself } \\
\text { to be creative } \\
\text { and original in my } \\
\text { thinking and } \\
\text { behavior. (9) }\end{array}$ & & & & & \\
\hline $\begin{array}{l}\text { I am aware that I } \\
\text { am usually one of } \\
\text { the last people in } \\
\text { my group to } \\
\text { accept something } \\
\text { new. (10) }\end{array}$ & & & & & \\
\hline $\begin{array}{l}\text { I am an inventive } \\
\text { kind of person. } \\
\text { (11) }\end{array}$ & & & & & \\
\hline $\begin{array}{l}\text { I enjoy taking } \\
\text { part in the } \\
\text { leadership } \\
\text { responsibilities of } \\
\text { the group I } \\
\text { belong to. (12) }\end{array}$ & & & & & \\
\hline $\begin{array}{l}\text { I am reluctant } \\
\text { about adopting } \\
\text { new ways of } \\
\text { doing things until } \\
\text { I see them } \\
\text { working for } \\
\text { people around } \\
\text { me. (13) }\end{array}$ & 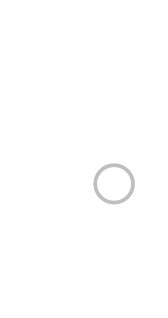 & ) & & & \\
\hline $\begin{array}{l}\text { I find it } \\
\text { stimulating to be } \\
\text { original in my } \\
\text { thinking and } \\
\text { behavior. (14) }\end{array}$ & & & & & \\
\hline
\end{tabular}




\begin{tabular}{|c|c|c|c|c|c|}
\hline & $\begin{array}{c}\text { Strongly } \\
\text { disagree (1) }\end{array}$ & Disagree (2) & $\begin{array}{c}\text { Neither agree } \\
\text { nor disagree (3) }\end{array}$ & Agree (4) & $\begin{array}{c}\text { Strongly agree } \\
\text { (5) }\end{array}$ \\
\hline $\begin{array}{l}\text { I tend to feel that } \\
\text { the old way of } \\
\text { living and doing } \\
\text { things is the best } \\
\text { way. (15) }\end{array}$ & & & & & \\
\hline $\begin{array}{l}\text { I am challenged } \\
\text { by ambiguities } \\
\text { and unsolved } \\
\text { problems. (16) }\end{array}$ & & & & & \\
\hline $\begin{array}{l}\text { I must see other } \\
\text { people using new } \\
\text { innovations } \\
\text { before I will } \\
\text { consider them. } \\
\text { (17) }\end{array}$ & & & & & \\
\hline $\begin{array}{l}\text { I am receptive to } \\
\text { new ideas. (18) }\end{array}$ & & & & & \\
\hline $\begin{array}{l}\text { I am challenged } \\
\text { by unanswered } \\
\text { questions. (19) }\end{array}$ & & & & & \\
\hline $\begin{array}{l}\text { I often find } \\
\text { myself skeptical } \\
\text { of new ideas. (20) }\end{array}$ & & & & & \\
\hline
\end{tabular}

Q40 Which best describes where you grew up as a child?

Large city or urban area (1)

Suburban area (2)

Small city or town (3)

Rural area (4)

Q41 Which best describes where you live now?

Large city or urban area (1)

Suburban area (2)

Small city or town (3)

Rural area (4) 
Q42 What is the highest level of formal education you have completed?

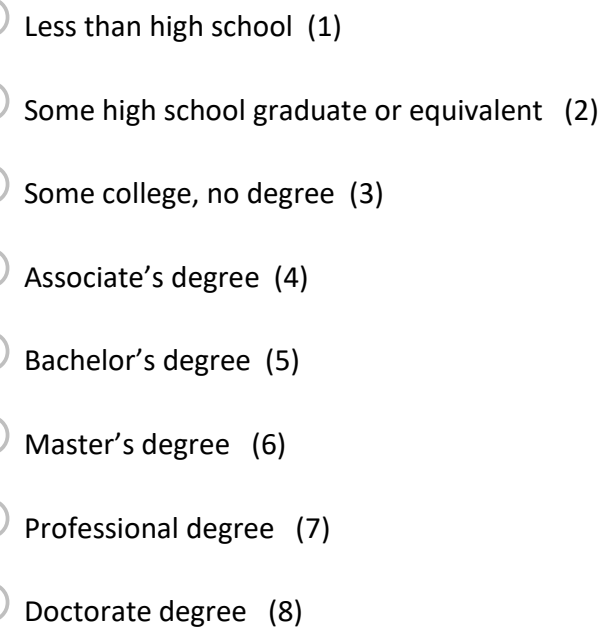

Q43 Are you?

Male (1)

Female (2)

Other (3)

Q44 What year were you born?

Q50 You're done! Your completed questionnaire has been received. Thank you very much for completing this survey! 
Appendix 5. Descriptive summary for each survey question for responses from U.S. Fish and Wildlife Service, National Wildlife Refuge staff, Region 3.

\section{Online Survey Results}

During 2018, 321 online surveys delivered with 167 responses (52.0\% response rate).

During 2019, 315 online survey delivered with 197 responses (62.5\% response rate).

365 survey responses both years.

$(167+197) /(321+315)=57.4 \%$ overall response rate for both years combined

No differences were found between years after a nonresponse bias check, the final dataset includes a single response from each participant using the most recent response (i.e., for paired responses, only the 2019 response was used); total $n=235$.

Time to complete survey

\begin{tabular}{lr|r|r|r|r} 
& N & Minimum & Maximum & Mean & Std. Deviation \\
\hline Survey Time in Minutes* & 210 & 1.05 & 93.60 & 23.3465 & 16.94007 \\
\hline Valid N (listwise) & 210 & & & & \\
\hline
\end{tabular}

*25 responses $>100$ minutes removed from time calculation because these participants completed the survey during multiple sessions while the timer was running.

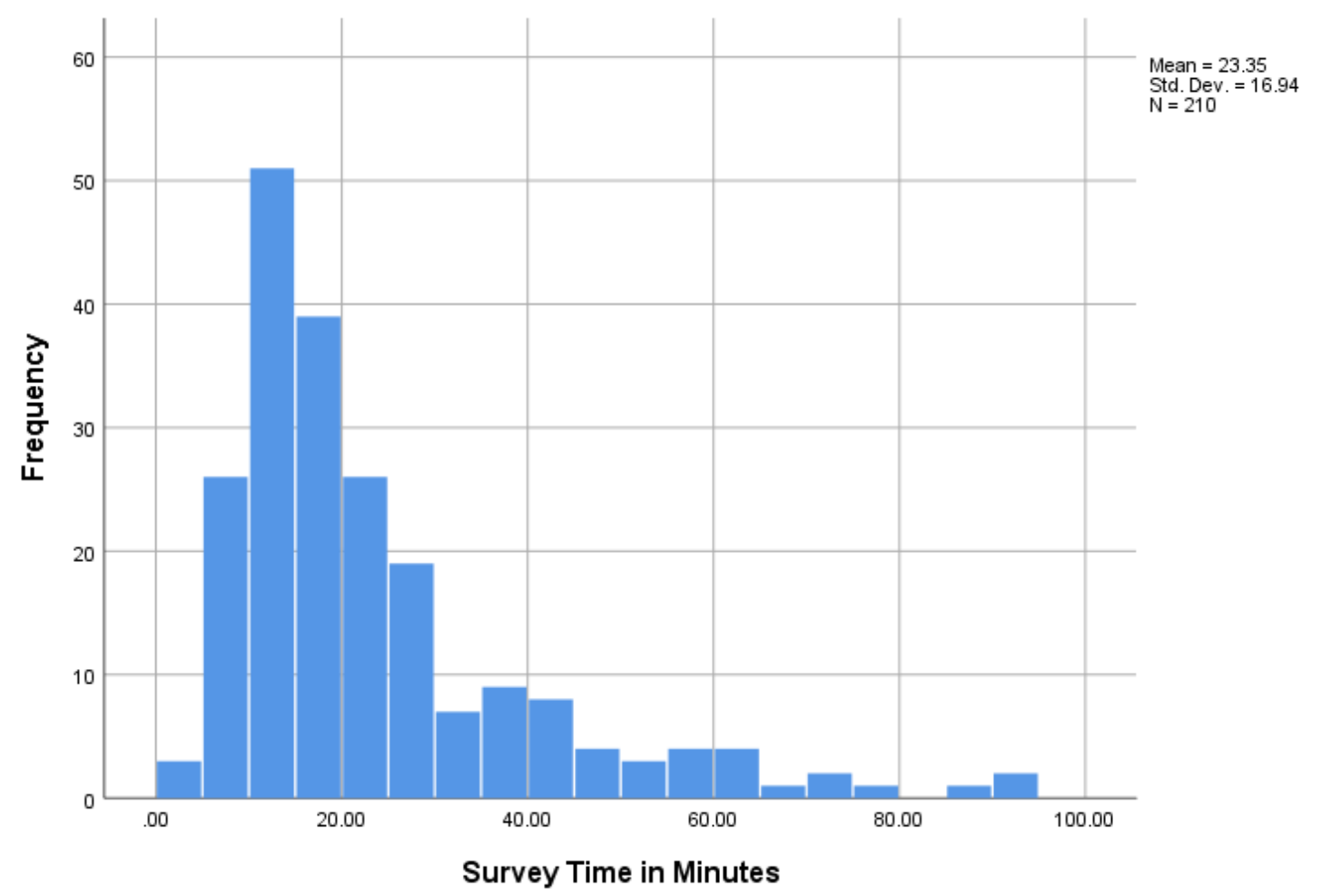




\begin{tabular}{|c|c|c|c|c|c|}
\hline \multicolumn{6}{|c|}{ Completed Surveys } \\
\hline & & Frequency & Percent & Valid Percent & Cumulative Percent \\
\hline \multirow[t]{4}{*}{ Valid } & Not & 30 & 12.8 & 12.8 & 12.8 \\
\hline & Completed & & & & \\
\hline & Completed & 205 & 87.2 & 87.2 & 100.0 \\
\hline & Total & 235 & 100.0 & 100.0 & \\
\hline
\end{tabular}

Q3 Do you consider yourself a deer hunter?

\begin{tabular}{llr|r|r|r} 
& & Frequency & \multicolumn{1}{c}{ Percent } & Valid Percent & Cumulative Percent \\
\hline \multirow{2}{*}{ Valid } & Yes & 130 & 55.3 & 61.0 & 61.0 \\
\cline { 2 - 7 } & No & 83 & 35.3 & 39.0 & 100.0 \\
\cline { 2 - 7 } & Total & 213 & 90.6 & 100.0 & \\
\hline Missing & System & 22 & 9.4 & & \\
\hline Total & & 235 & 100.0 & & \\
\hline
\end{tabular}

Q4_1 Have you hunted white-tailed at least once in the past 5 years?

\begin{tabular}{llr|r|r|r} 
& & Frequency & \multicolumn{1}{c|}{ Percent } & Valid Percent & Cumulative Percent \\
\hline \multirow{2}{*}{ Valid } & Yes & 141 & 60.0 & 60.8 & 60.8 \\
\cline { 2 - 7 } & No & 91 & 38.7 & 39.2 & 100.0 \\
\cline { 2 - 7 } & Total & 232 & 98.7 & 100.0 & \\
\hline Missing & System & 3 & 1.3 & & \\
\hline Total & & 235 & 100.0 & & \\
\hline
\end{tabular}

Q4_2 Have you hunted other big-game (mule deer, elk, bear, moose, etc.) at least once in the past 5 years?

\begin{tabular}{llr|r|r|r} 
& & Frequency & Percent & Valid Percent & Cumulative Percent \\
\hline \multirow{2}{*}{ Valid } & Yes & 46 & 19.6 & 20.4 & 20.4 \\
\cline { 2 - 6 } & No & 180 & 76.6 & 79.6 & 100.0 \\
\cline { 2 - 6 } & Total & 226 & 96.2 & 100.0 & \\
\hline Missing & System & 9 & 3.8 & & \\
\hline Total & & 235 & 100.0 & & \\
\hline
\end{tabular}


Q4_3 Have you hunted upland birds (pheasants, quail, grouse, doves, woodcock, etc.) at least once in the past 5 years?

\begin{tabular}{|c|c|c|c|c|c|}
\hline & & Frequency & Percent & Valid Percent & Cumulative Percent \\
\hline \multirow[t]{3}{*}{ Valid } & Yes & 115 & 48.9 & 50.0 & 50.0 \\
\hline & No & 115 & 48.9 & 50.0 & 100.0 \\
\hline & Total & 230 & 97.9 & 100.0 & \\
\hline Missing & System & 5 & 2.1 & & \\
\hline Total & & 235 & 100.0 & & \\
\hline
\end{tabular}

Q4_4 Have you hunted other small game (rabbits, squirrels, etc.) at least once in the past 5 years?

\begin{tabular}{llr|r|r|r} 
& & Frequency & Percent & Valid Percent & Cumulative Percent \\
\hline \multirow{2}{*}{ Valid } & Yes & 79 & 33.6 & 35.4 & 35.4 \\
\cline { 2 - 7 } & No & 144 & 61.3 & 64.6 & 100.0 \\
\cline { 2 - 7 } & Total & 223 & 94.9 & 100.0 & \\
\hline Missing & System & 12 & 5.1 & & \\
\hline Total & & 235 & 100.0 & & \\
\hline
\end{tabular}

Q4_5 Have you hunted waterfowl (ducks and geese) at least once in the past 5 years?

Frequency

Percent Valid Percent $\quad$ Cumulative Percent

\begin{tabular}{ll|r|r|r|r}
\hline Valid & Yes & 97 & 41.3 & 42.2 & 42.2 \\
\cline { 2 - 7 } & No & 133 & 56.6 & 57.8 & 100.0 \\
\cline { 2 - 7 } & Total & 230 & 97.9 & 100.0 & \\
\hline Missing & System & 5 & 2.1 & & \\
\hline Total & & 235 & 100.0 & & \\
\hline
\end{tabular}

Q5 How many years has it been since you started hunted? (Q5 - Q20 only for participants who responded 'yes' to Q4_1 about hunting deer in past 5-years)

\begin{tabular}{|c|c|c|c|c|c|}
\hline & $\mathrm{N}$ & Minimum & Maximum & Mean & Std. Deviation \\
\hline Percent of Age Hunted & 123 & 20.00 & 96.43 & 49.6219 & 16.24510 \\
\hline Valid N (listwise) & 123 & & & & \\
\hline
\end{tabular}


Q6 When deer hunting, where do you typically hunt?

Cumulative

\begin{tabular}{l|l|l|l} 
Frequency & Percent & Valid Percent & Percent \\
\hline
\end{tabular}

\begin{tabular}{ll|r|r|r|r}
\hline \multirow{2}{*}{ Valid } & Only on public land & 11 & 4.7 & 7.7 & 7.7 \\
\cline { 2 - 6 } & Mostly on public land & 47 & 20.0 & 33.1 & 40.8 \\
\cline { 2 - 6 } & Mostly on private land & 64 & 27.2 & 45.1 & 85.9 \\
\cline { 2 - 6 } & Only on private land & 20 & 8.5 & 14.1 & 100.0 \\
\cline { 2 - 6 } & Total & 142 & 60.4 & 100.0 & \\
\hline Missing & System & 93 & 39.6 & & \\
\hline Total & & 100.0 & & \\
\hline
\end{tabular}

Q7 During this past deer hunting season, did you deer hunt on a U.S. Fish and Wildlife Service National Wildlife Refuge (NWR), National Fish \& Wildlife Refuge (NFWR), Wetland Management District (WMD), or U.S. Fish and Wildlife Service Wildlife Management Area (WMA)?

\begin{tabular}{|c|c|c|c|c|c|}
\hline & & Frequency & Percent & Valid Percent & Cumulative Percent \\
\hline \multirow[t]{3}{*}{ Valid } & Yes & 40 & 17.0 & 28.2 & 28.2 \\
\hline & No & 102 & 43.4 & 71.8 & 100.0 \\
\hline & Total & 142 & 60.4 & 100.0 & \\
\hline Missing & System & 93 & 39.6 & & \\
\hline Total & & 235 & 100.0 & & \\
\hline
\end{tabular}

Q8 During the past deer hunting season, did you hunt on any of the National Wildlife Refuges (NWR), National Fish \& Wildlife Refuges (NFWR), Wetland Management Districts (WMD), or U.S. Fish and Wildlife Service Wildlife Management Areas (WMA) listed below?

\begin{tabular}{lr}
\hline & Yes \\
\hline Agassiz NWR & 1 \\
\hline Big Muddy NF\&WR & 0 \\
\hline Big Oaks NWR & 3 \\
\hline Big Stone NWR & 1 \\
\hline Big Stone WMD & 0 \\
\hline Boyer Chute NWR & 0 \\
\hline Clarence Cannon NWR & 0 \\
\hline Crab Orchard NWR & 3 \\
\hline Crane Meadows NWR & 0 \\
\hline Cypress Creek NWR & 2 \\
\hline
\end{tabular}




\begin{tabular}{|c|c|}
\hline & Yes \\
\hline DeSoto NWR & 2 \\
\hline Detroit Lakes WMD & 2 \\
\hline Detroit River IWR & 0 \\
\hline Driftless Area NWR & 0 \\
\hline Emiquon NWR & 0 \\
\hline Fergus Falls WMD & 0 \\
\hline Fox River NWR & 0 \\
\hline Glacial Ridge NWR & 0 \\
\hline Great River NWR - Delair Unit & 0 \\
\hline Great River NWR - Long Island Division & 0 \\
\hline Hackmatack NWR & 0 \\
\hline Hamden Slough NWR & 0 \\
\hline Harbor Island NWR & 0 \\
\hline Horicon NWR & 3 \\
\hline lowa WMD & 0 \\
\hline Kankakee NWR & 0 \\
\hline Kirtland's Warbler WMA & 0 \\
\hline Leopold WMD & 4 \\
\hline Litchfield WMD & 4 \\
\hline Loess Bluffs NWR (formerly Squaw Creek NWR) & 0 \\
\hline Middle Mississippi River NWR & 1 \\
\hline Mingo NWR & 1 \\
\hline Minnesota Valley NWR & 1 \\
\hline Minnesota Valley WMD & 0 \\
\hline Morris WMD & 5 \\
\hline Muscatatuck NWR & 2 \\
\hline Neal Smith NWR & 1 \\
\hline Necedah NWR & 0 \\
\hline Northern Tallgrass Prairie NWR & 0 \\
\hline Ottawa NWR & 2 \\
\hline Patoka River NWR & 0 \\
\hline Port Louisa NWR & 0 \\
\hline Rice Lake NWR & 0 \\
\hline Rydell NWR & 0 \\
\hline Seney NWR & 1 \\
\hline Sherburne NWR & 0 \\
\hline
\end{tabular}




\begin{tabular}{lr} 
& Yes \\
\hline Shiawassee NWR & 3 \\
\hline St. Croix WMD & 0 \\
\hline Swan Lake NWR & 0 \\
\hline Tamarac NWR & 3 \\
\hline Trempealeau NWR & 2 \\
\hline Two Rivers NWR - Apple Creek Division \& Calhoun & 0 \\
Division & \\
\hline Union Slough NWR & 0 \\
\hline Upper Mississippi River NW\&FR LaCrosse District & 1 \\
\hline Upper Mississippi River NW\&FR McGregor District & 0 \\
\hline Upper Mississippi River NW\&FR Savanna District & 0 \\
\hline Upper Mississippi River NW\&FR Winona District & 2 \\
\hline Windom WMD & 0 \\
\hline None of the above & 2 \\
\hline
\end{tabular}

\section{Q9 How many deer did you harvest on the refuge(s) you hunted this past deer hunting season?*}

\begin{tabular}{llr} 
& & Frequency \\
\hline Agassiz NWR & I did not harvest a deer on the refuge & 1 \\
\hline Big Oaks NWR & I did not harvest a deer on the refuge & 2 \\
\cline { 2 - 3 } & 1 deer & 1 \\
\hline Big Stone NWR & 1 deer & 1 \\
\hline & 2 deer & 2 \\
\hline Cypress Creek NWR & I did not harvest a deer on the refuge & 2 \\
\hline DeSoto NWR & 1 deer & 2 \\
\hline Detroit Lakes WMD & I did not harvest a deer on the refuge & 2 \\
\hline Horicon NWR & I did not harvest a deer on the refuge & 2 \\
\cline { 2 - 3 } & 1 deer & 1 \\
\hline Leopold WMD & I did not harvest a deer on the refuge & 4 \\
\hline Litchfield WMD & I did not harvest a deer on the refuge & 4 \\
\hline Middle Mississippi River NWR & I did not harvest a deer on the refuge & 1 \\
\hline Mingo NWR & I did not harvest a deer on the refuge & 1 \\
\hline Minnesota Valley NWR & I did not harvest a deer on the refuge & 1 \\
\hline Morris WMD & I did not harvest a deer on the refuge & 5 \\
\hline Muscatatuck NWR & I did not harvest a deer on the refuge \\
\hline Neal Smith NWR & I did not harvest a deer on the refuge \\
\hline
\end{tabular}




\begin{tabular}{llr}
\hline Ottawa NWR & 1 deer & 2 \\
\hline Seney NWR & I did not harvest a deer on the refuge & 1 \\
\hline Shiawassee NWR & I did not harvest a deer on the refuge & 1 \\
\cline { 2 - 3 } & 1 deer & 2 \\
\hline Tamarac NWR & I did not harvest a deer on the refuge & 1 \\
\cline { 2 - 3 } & 1 deer & 2 \\
\hline Trempealeau NWR & 1 deer & 2 \\
\hline $\begin{array}{l}\text { Upper Mississippi River NW\&FR LaCrosse } \\
\text { District }\end{array}$ & I did not harvest a deer on the refuge \\
\hline $\begin{array}{l}\text { Upper Mississippi River NW\&FR Winona } \\
\text { District }\end{array}$ & I did not harvest a deer on the refuge & 2 \\
\hline None of the above & & \\
\hline${ }^{*}$ Responses from only participant stating they hunted on that particular refuge.
\end{tabular}

Q10 During the past deer hunting season, did you use a firearm? (rifle, handgun, shotgun, muzzleloader)

\begin{tabular}{|c|c|c|c|c|c|}
\hline & & Frequency & Percent & $\begin{array}{c}\text { Valid } \\
\text { Percent }\end{array}$ & $\begin{array}{c}\text { Cumulative } \\
\text { Percent }\end{array}$ \\
\hline \multirow[t]{3}{*}{ Valid } & Yes & 112 & 47.7 & 78.9 & 78.9 \\
\hline & No & 30 & 12.8 & 21.1 & 100.0 \\
\hline & Total & 142 & 60.4 & 100.0 & \\
\hline Missing & System & 93 & 39.6 & & \\
\hline Total & & 235 & 100.0 & & \\
\hline
\end{tabular}

Q11 Which firearms do you currently use while deer hunting? (Select all that apply)

\begin{tabular}{lc|c} 
& Frequency $^{*}$ & Percent \\
\hline Center-fire rifle & 71 & 42.0 \\
\hline Handgun & 10 & 5.9 \\
\hline Muzzleloader rifle & 39 & 23.1 \\
\hline Shotgun & 49 & 29.0 \\
\hline Total & 169 & 100.0 \\
\hline
\end{tabular}


Q12 About how many shots do you typically shoot practicing prior to the deer hunting season?

\begin{tabular}{llr|r|r|r} 
& & & & \multicolumn{2}{c}{$\begin{array}{c}\text { Cumulative } \\
\text { Percent }\end{array}$} \\
\hline Valid & Frequency & Percent & Valid Percent & I do not target practice before \\
& deer hunting & 6 & 2.6 & 5.4 & 5.4 \\
\cline { 2 - 6 } & $1-5$ shots & 45 & 19.1 & 40.2 & 45.5 \\
\hline 6-20 shots & 43 & 18.3 & 38.4 & 83.9 \\
\hline 21-40 shots & 4 & 1.7 & 3.6 & 87.5 \\
\hline & More than 40 shots & 14 & 6.0 & 12.5 & 100.0 \\
\hline Missing & Sotal & 112 & 47.7 & 100.0 & \\
\hline Total & & 123 & 52.3 & & \\
\hline
\end{tabular}

Q13 About how many shots do you typically shoot while hunting during one deer hunting season?

\begin{tabular}{llr|r|r|r} 
& & & & \multicolumn{2}{c}{$\begin{array}{c}\text { Cumulative } \\
\text { Percent }\end{array}$} \\
\hline \multirow{2}{*}{ Valid } & Frequency & Percent & Valid Percent & Per.4 \\
\cline { 2 - 7 } & $1-5$ shots & 107 & 45.5 & 96.4 & 99.1 \\
\cline { 2 - 7 } & $6-20$ shots & 3 & 1.3 & 2.7 & 100.0 \\
\cline { 2 - 7 } & More than 40 shots & 1 & .4 & .9 & \\
\cline { 2 - 7 } & Total & 111 & 47.2 & 100.0 & \\
\hline Missing & System & 124 & 52.8 & & \\
\hline Total & & 235 & 100.0 & & \\
\hline
\end{tabular}

Q14 On average, how much do you typically spend on hunting ammunition for one deer hunting season?

\begin{tabular}{|c|c|c|c|c|c|}
\hline & & Frequency & Percent & Valid Percent & $\begin{array}{c}\text { Cumulative } \\
\text { Percent }\end{array}$ \\
\hline \multirow[t]{7}{*}{ Valid } & Less than $\$ 10$ & 24 & 10.2 & 21.4 & 21.4 \\
\hline & $\$ 10$ to $\$ 19$ & 27 & 11.5 & 24.1 & 45.5 \\
\hline & $\$ 20$ to $\$ 29$ & 25 & 10.6 & 22.3 & 67.9 \\
\hline & $\$ 30$ to $\$ 50$ & 21 & 8.9 & 18.8 & 86.6 \\
\hline & $\$ 51$ to $\$ 100$ & 6 & 2.6 & 5.4 & 92.0 \\
\hline & More than $\$ 100$ & 9 & 3.8 & 8.0 & 100.0 \\
\hline & Total & 112 & 47.7 & 100.0 & \\
\hline Missing & System & 123 & 52.3 & & \\
\hline Total & & 235 & 100.0 & & \\
\hline
\end{tabular}


Q15 Where do your purchase the majority of your deer hunting ammunition? Selected Choice

\begin{tabular}{|c|c|c|c|c|c|}
\hline & & Frequency & Percent & Valid Percent & $\begin{array}{c}\text { Cumulative } \\
\text { Percent } \\
\end{array}$ \\
\hline \multirow[t]{7}{*}{ Valid } & $\begin{array}{l}\text { Big-box or discount chain } \\
\text { store }\end{array}$ & 20 & 8.5 & 17.9 & 17.9 \\
\hline & $\begin{array}{l}\text { Local hunting and fishing } \\
\text { store }\end{array}$ & 29 & 12.3 & 25.9 & 43.8 \\
\hline & $\begin{array}{l}\text { Gas station convenience } \\
\text { store }\end{array}$ & 3 & 1.3 & 2.7 & 46.4 \\
\hline & $\begin{array}{l}\text { Internet website or mail-order } \\
\text { catalog }\end{array}$ & 11 & 4.7 & 9.8 & 56.3 \\
\hline & Other (please fill-in): & 14 & 6.0 & 12.5 & 68.8 \\
\hline & $\begin{array}{l}\text { Large sporting goods stores } \\
\text { (e.g., Cabela's, Bass Pro, } \\
\text { Gander Mountain, etc.) }\end{array}$ & 35 & 14.9 & 31.3 & 100.0 \\
\hline & Total & 112 & 47.7 & 100.0 & \\
\hline Missing & System & 123 & 52.3 & & \\
\hline Total & & 235 & 100.0 & & \\
\hline
\end{tabular}

Q16 Do you currently use lead free ammunition while deer hunting?

\begin{tabular}{llr|r|r|r} 
& & Frequency & \multicolumn{1}{c}{ Percent } & \multicolumn{1}{c}{ Valid Percent } & Cumulative Percent \\
\hline \multirow{2}{*}{ Valid } & Yes & 45 & 19.1 & 40.2 & 40.2 \\
\cline { 2 - 7 } & No & 67 & 28.5 & 59.8 & 100.0 \\
\cline { 2 - 7 } & Total & 112 & 47.7 & 100.0 & \\
\hline Missing & System & 123 & 52.3 & & \\
\hline Total & & 235 & 100.0 & & \\
\hline
\end{tabular}

Q17 Descriptive Statistics - How unlikely or likely will you continue using lead free ammunition for deer hunting?

\begin{tabular}{l|r|r|r} 
& N & Mean & \multicolumn{1}{c}{ Std. Deviation } \\
\hline $\begin{array}{l}\text { How unlikely or likely will you continue } \\
\text { using lead free ammunition for deer }\end{array}$ & 45 & 4.36 & 1.209 \\
hunting? & & & \\
\hline Valid N (listwise) & & & \\
\hline
\end{tabular}




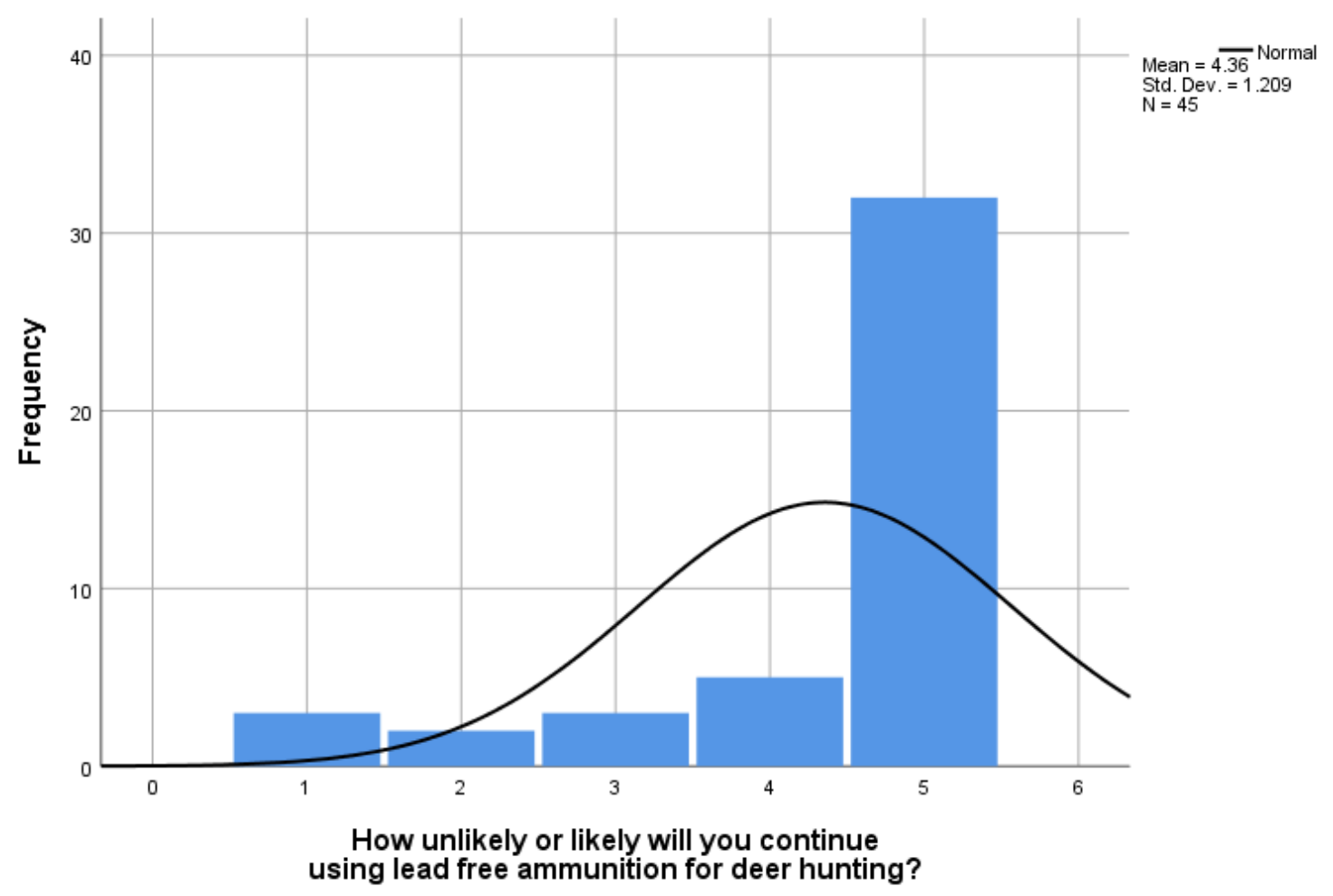

Q18 How unimportant or important were the following factors in your use of lead free ammunition for deer hunting?

\begin{tabular}{|c|c|c|c|}
\hline & $\mathrm{N}$ & Mean & Std. Deviation \\
\hline $\begin{array}{l}\text { Potential negative health effects on people from lead } \\
\text { ammunition }\end{array}$ & 45 & 4.07 & 1.286 \\
\hline Potential negative effects on wildlife from lead ammunition & 45 & 4.20 & 1.198 \\
\hline $\begin{array}{l}\text { Similar or better performance of lead free ammunition } \\
\text { compared to traditional lead ammunition }\end{array}$ & 45 & 3.96 & 1.186 \\
\hline $\begin{array}{l}\text { Availability of lead free ammunition in stores or internet } \\
\text { retailers }\end{array}$ & 45 & 3.60 & 1.321 \\
\hline $\begin{array}{l}\text { Cost difference between lead free ammunition and lead } \\
\text { ammunition }\end{array}$ & 45 & 2.64 & 1.151 \\
\hline Valid N (listwise) & 45 & & \\
\hline
\end{tabular}



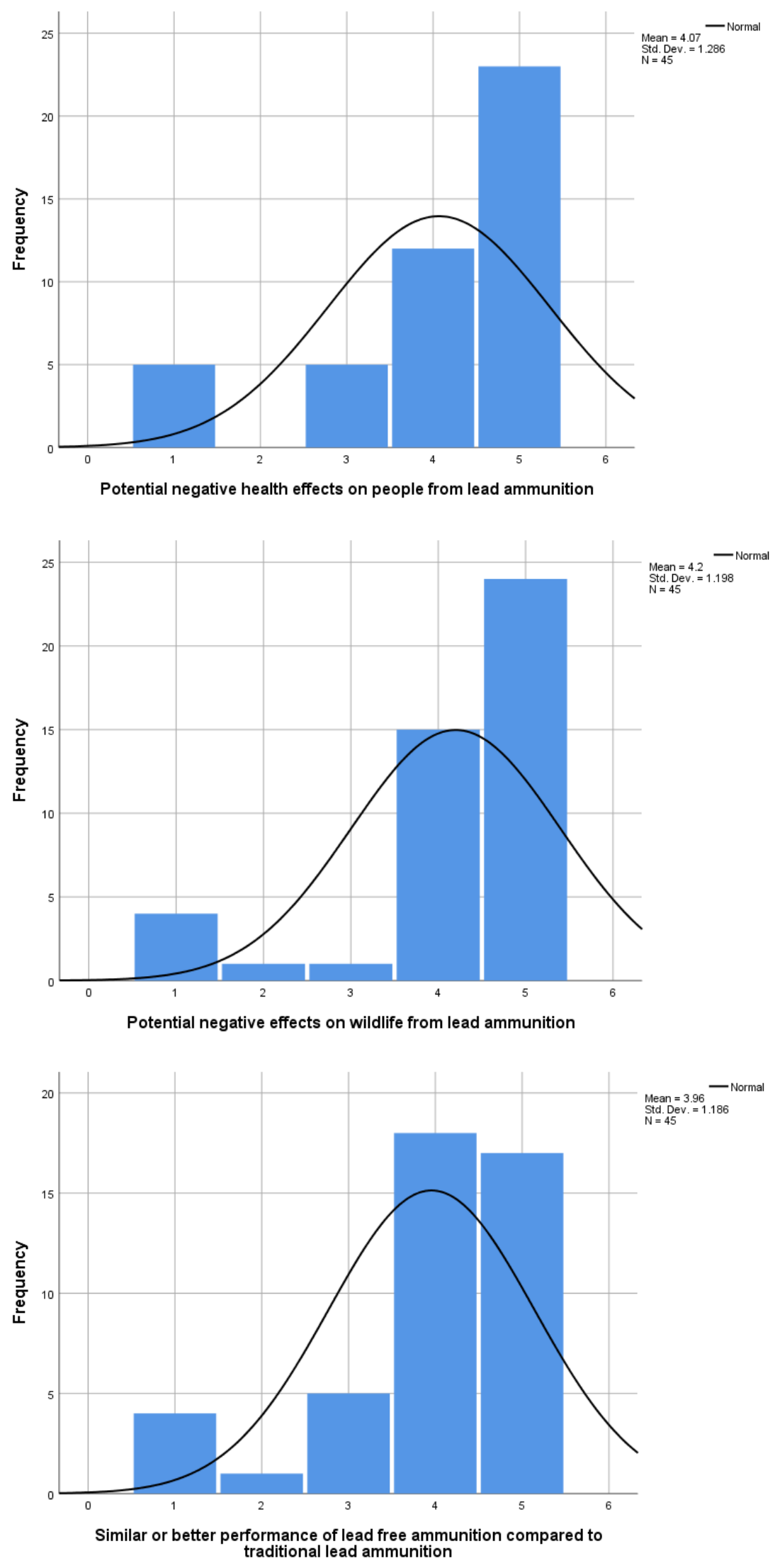

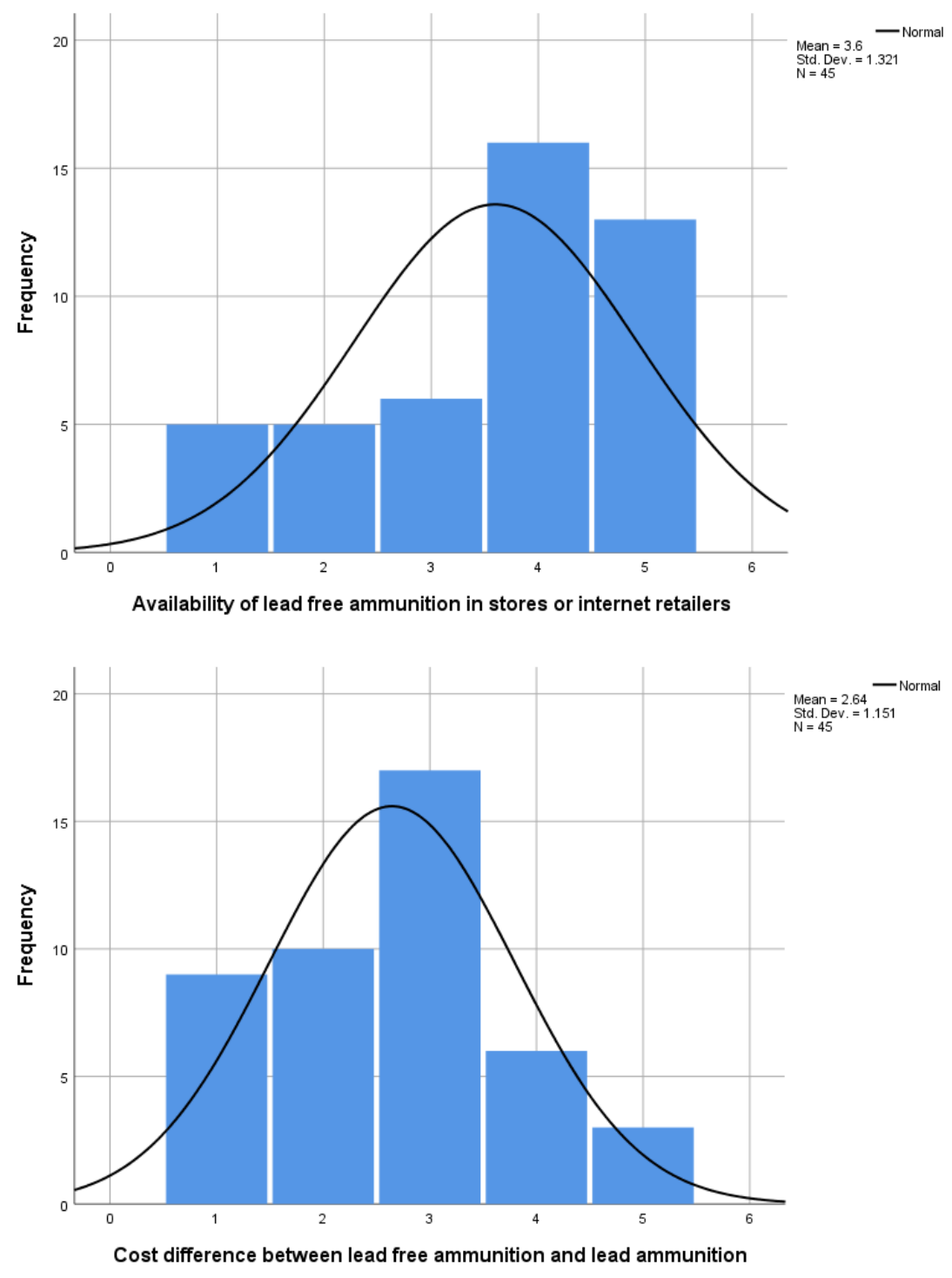

\section{Q19 Descriptive Statistics}

\begin{tabular}{|c|c|c|c|}
\hline & $\mathrm{N}$ & Mean & $\begin{array}{c}\text { Std. } \\
\text { Deviation }\end{array}$ \\
\hline $\begin{array}{l}\text { How unlikely or likely would you use lead free ammunition for deer } \\
\text { hunting? }\end{array}$ & 66 & 3.55 & 1.179 \\
\hline Valid N (listwise) & 66 & & \\
\hline
\end{tabular}




\section{Q20 How unlikely or likely would you be willing to use lead free ammunition given the following information?}

Std.

$\mathrm{N}$

Mean Deviation

\begin{tabular}{|c|c|c|c|}
\hline $\begin{array}{l}\text { If there was evidence of lead ammunition having negative health effects on } \\
\text { people }\end{array}$ & 66 & 4.00 & 1.190 \\
\hline $\begin{array}{l}\text { If there was evidence of lead ammunition having negative effects on bald } \\
\text { eagles }\end{array}$ & 66 & 3.86 & 1.149 \\
\hline $\begin{array}{l}\text { If lead free ammunition performed similar to traditional lead ammunition (e.g., } \\
\text { accuracy, killing efficiency, and sight-in) }\end{array}$ & 66 & 4.30 & .960 \\
\hline If there was greater availability of lead free ammunition in stores & 66 & 4.24 & 1.009 \\
\hline If the cost was the same or no more than traditional lead ammunition & 66 & 4.18 & 1.021 \\
\hline $\begin{array}{l}\text { If a coupon or voucher was available offsetting the additional cost of lead free } \\
\text { ammunition }\end{array}$ & 66 & 3.92 & 1.269 \\
\hline Valid N (listwise) & 66 & & \\
\hline
\end{tabular}

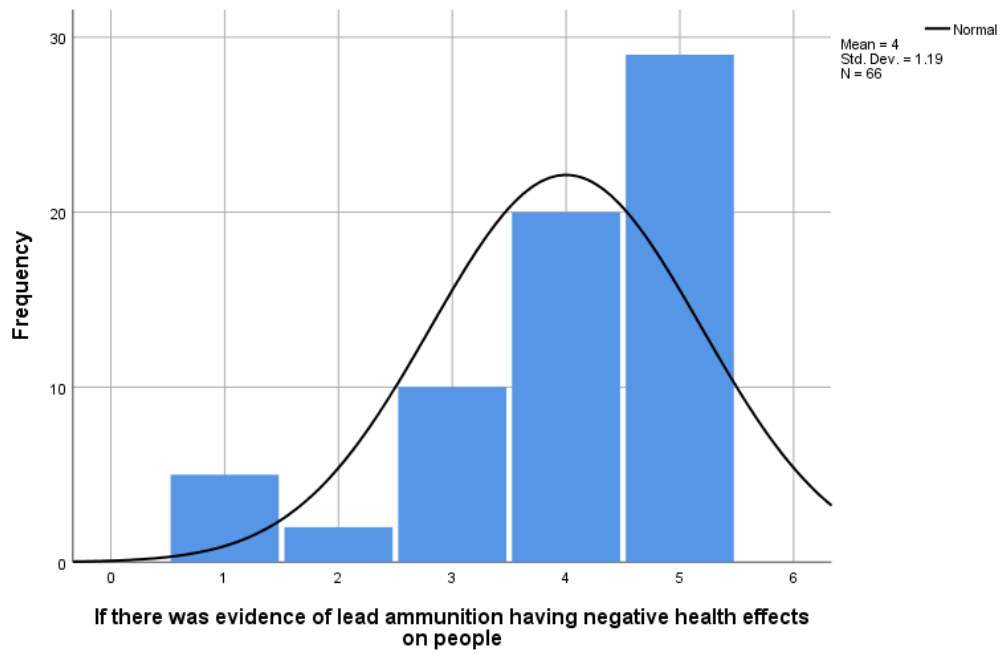




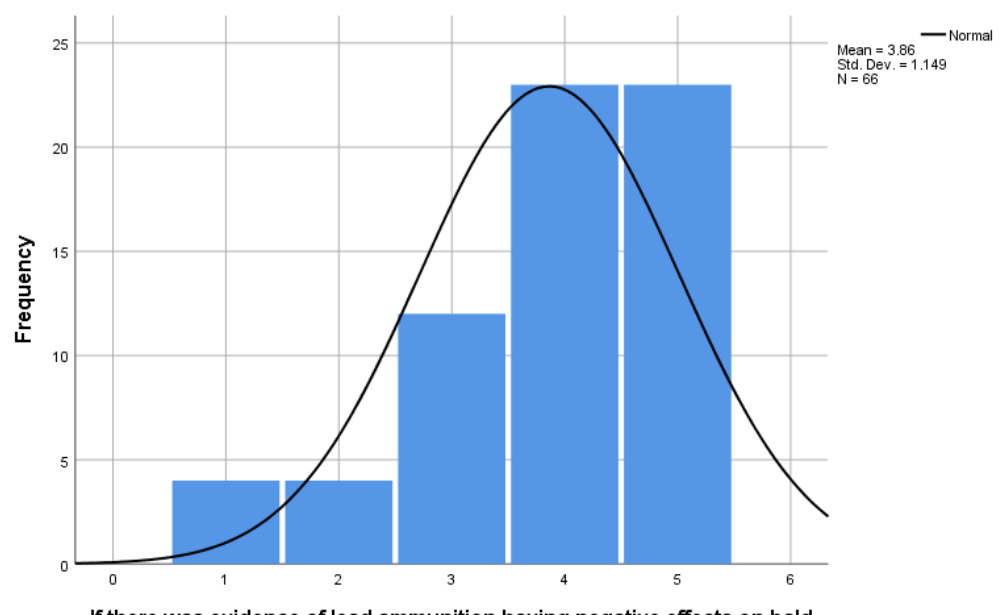

If there was evidence of lead ammunition having negative effects on bald eagles

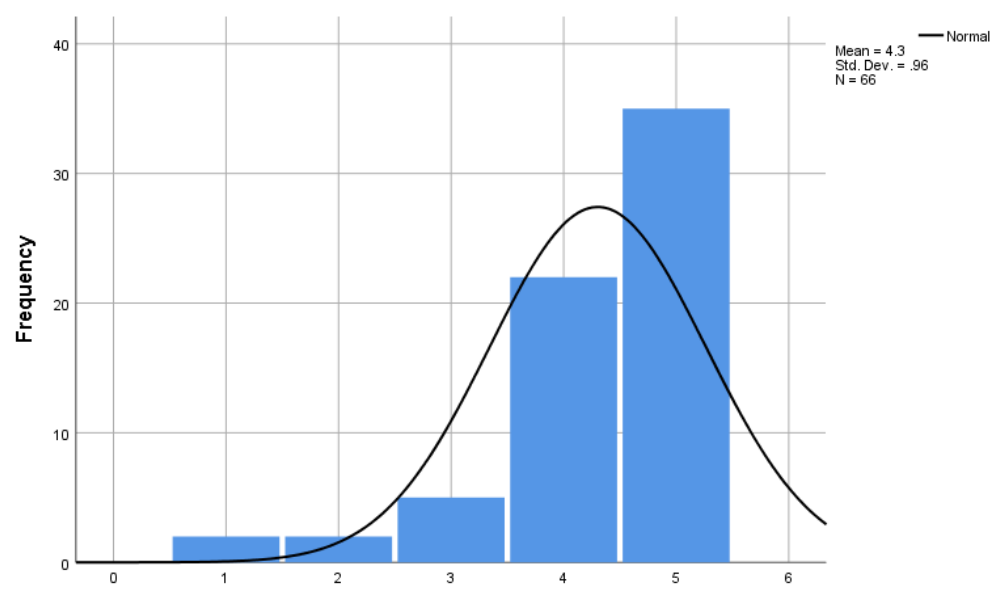

If lead free ammunition performed similar to traditional lead ammunition (e. g., accuracy, killing efficiency, and sight-in)

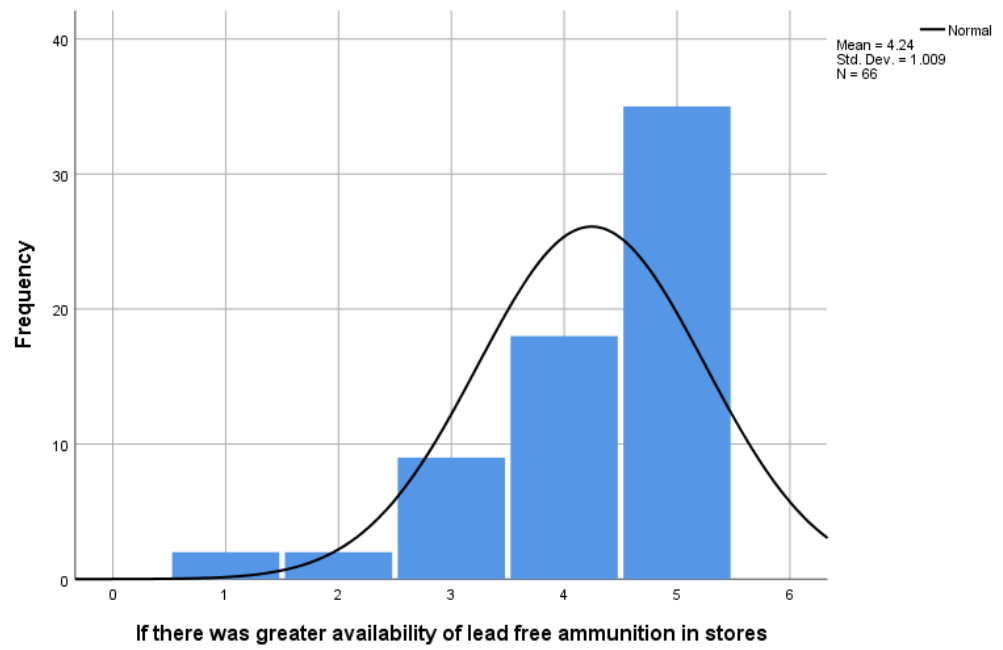



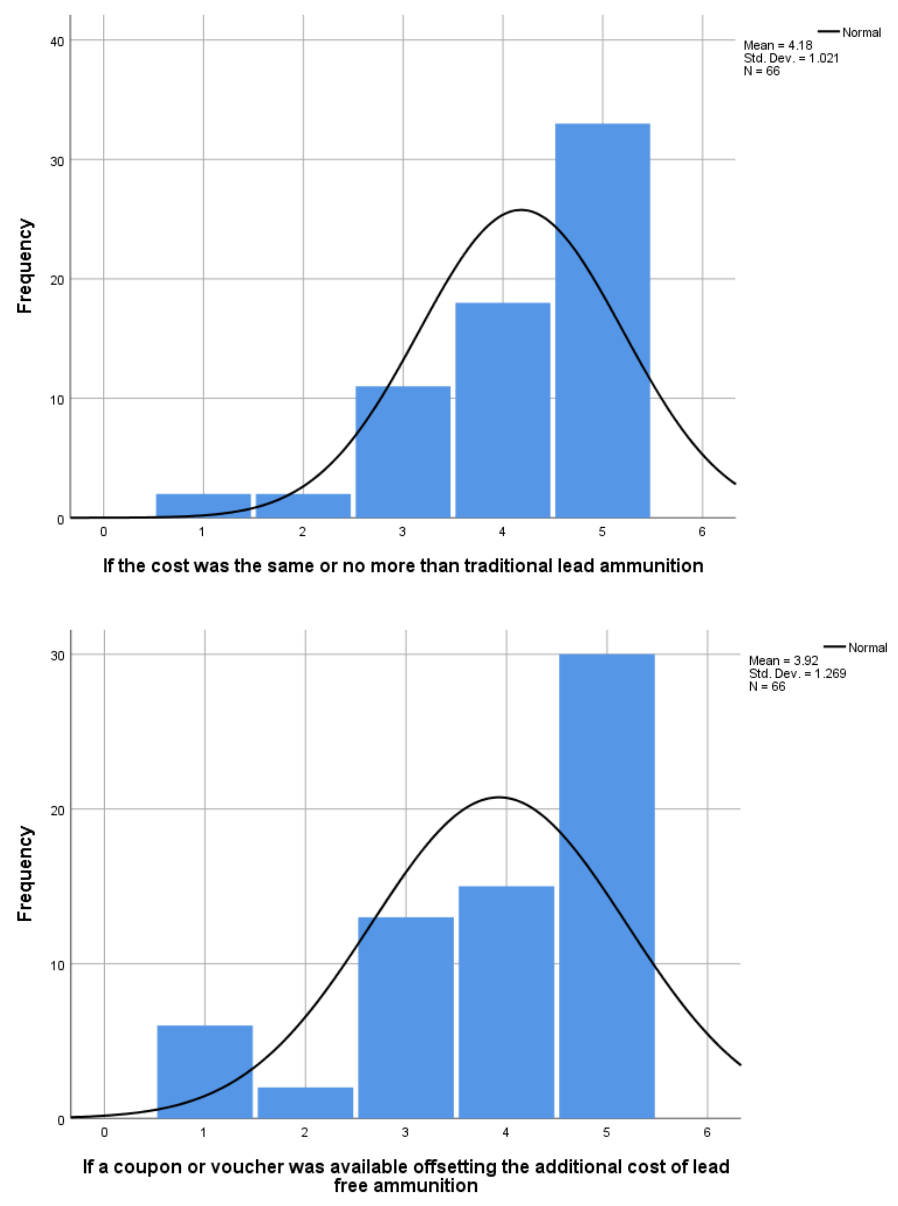

\section{Q17_Q19 NonPb Intention (continuous) Descriptive Statistics}

\begin{tabular}{|c|c|c|c|}
\hline & $\mathrm{N}$ & Mean & Std. Deviation \\
\hline $\begin{array}{l}\text { Intention to use or continue using nonPb ammunition } \\
\text { (continuous) }\end{array}$ & 111 & 3.87 & 1.251 \\
\hline Valid N (listwise) & 111 & & \\
\hline
\end{tabular}

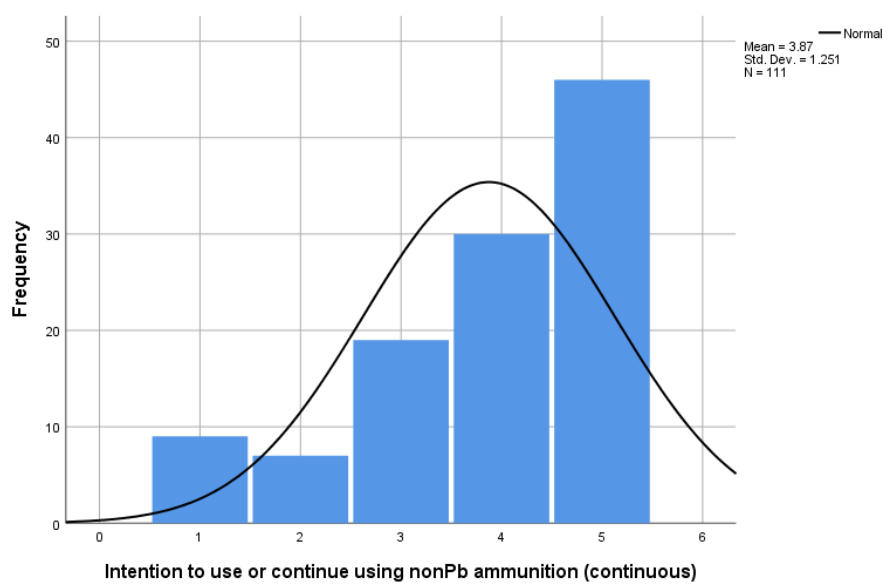


Q17_Q19 Intention to use or continue using nonPb ammunition (dichotomous)

\begin{tabular}{|c|c|c|c|c|c|}
\hline & & Frequency & Percent & Valid Percent & Cumulative Percent \\
\hline \multirow[t]{3}{*}{ Valid } & Unlikely & 35 & 14.9 & 31.5 & 31.5 \\
\hline & Likely & 76 & 32.3 & 68.5 & 100.0 \\
\hline & Total & 111 & 47.2 & 100.0 & \\
\hline Missing & System & 124 & 52.8 & & \\
\hline Total & & 235 & 100.0 & & \\
\hline
\end{tabular}

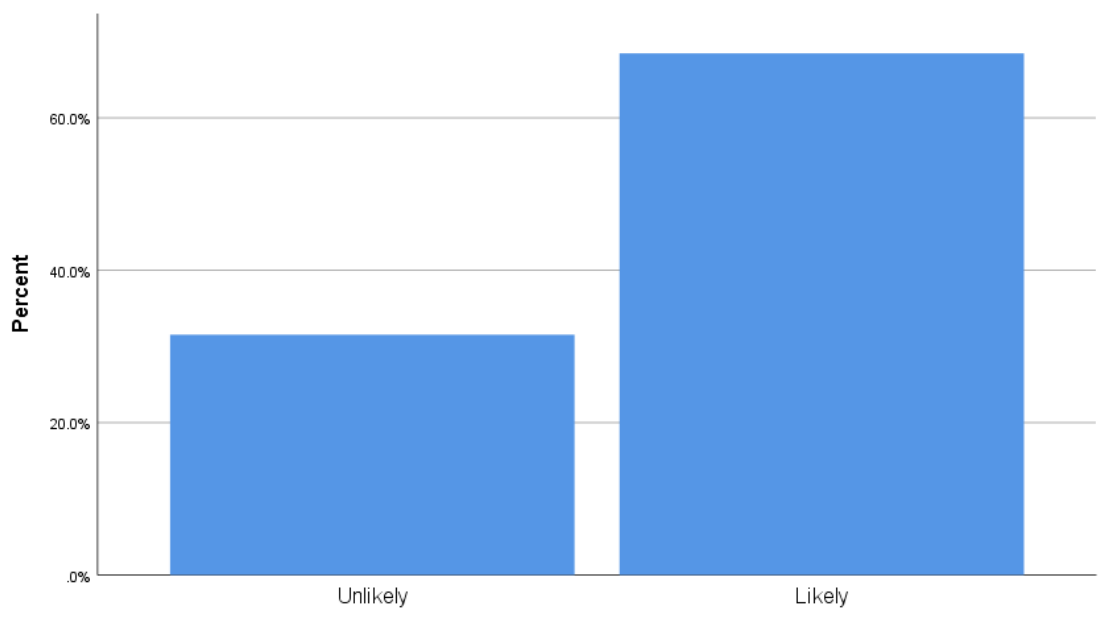

Intention to use or continue suing non $\mathrm{Pb}$ ammunition (dichotomous)

Q21 This section examines your attitudes and opinions about the impacts of lead ammunition (all participants)

Q22 How much do you disagree or agree that each of the following threats affect bald eagles?

\begin{tabular}{lr|r|r|r} 
& & & & \multicolumn{2}{l}{$\begin{array}{l}\text { Std. } \\
\text { Deviation }\end{array}$} \\
\hline Collisions with wind turbines & 227 & 3.55 & .056 & .837 \\
\hline Flying into windows on buildings & 228 & 2.80 & .054 & .819 \\
\hline Habitat loss & 228 & 3.89 & .066 & .990 \\
\hline $\begin{array}{l}\text { Poisoning through illegal use of pesticides or } \\
\text { herbicides }\end{array}$ & 228 & 4.04 & .058 & .879 \\
\hline $\begin{array}{l}\text { Lead poisoning from ingesting lead bullet } \\
\text { fragments in deer gut piles or carcasses }\end{array}$ & 228 & 4.20 & .063 & .948 \\
\hline Poaching or illegal shooting & & & & Std. Error \\
\hline Power line collisions & 228 & 3.82 & .059 & .890 \\
\hline Other (please describe): & 61 & 3.82 & .054 & .812 \\
\hline Valid N (listwise) & 60 & & .123 & .960 \\
\hline
\end{tabular}




\section{Q23 To what extent do you disagree or agree with each statement below about lead poisoning in bald eagles?}

\begin{tabular}{|c|c|c|c|c|}
\hline & $\mathrm{N}$ & Mean & $\begin{array}{l}\text { Std. } \\
\text { Error }\end{array}$ & $\begin{array}{c}\text { Std. } \\
\text { Deviation }\end{array}$ \\
\hline $\begin{array}{l}\text { Ingesting lead bullet fragments from deer gut piles or } \\
\text { carcasses is a serious problem for bald eagles. }\end{array}$ & 227 & 4.04 & .069 & 1.043 \\
\hline $\begin{array}{l}\text { Use of lead free hunting ammunition will reduce bald eagle } \\
\text { deaths. }\end{array}$ & 227 & 4.06 & .061 & .920 \\
\hline A very small amount of lead can poison a bald eagle. & 227 & 4.30 & .047 & .714 \\
\hline $\begin{array}{l}\text { There is insufficient scientific information supporting lead } \\
\text { poisoning of bald eagles. }\end{array}$ & 226 & 2.55 & .085 & 1.275 \\
\hline $\begin{array}{l}\text { Bald eagle populations are increasing despite ingesting lead } \\
\text { bullet fragments. }\end{array}$ & 227 & 3.63 & .048 & .720 \\
\hline $\begin{array}{l}\text { The issue of lead poisoning in bald eagles is a tactic to } \\
\text { advance gun-control regulations. }\end{array}$ & 227 & 1.89 & .070 & 1.054 \\
\hline $\begin{array}{l}\text { Some eagles might get sick from eating lead bullet } \\
\text { fragments but most recover. }\end{array}$ & 227 & 2.48 & .059 & .894 \\
\hline $\begin{array}{l}\text { The issue of lead poisoning in bald eagles is used by some } \\
\text { groups as an attempt to stop hunting. }\end{array}$ & 227 & 2.50 & .080 & 1.202 \\
\hline Valid N (listwise) & 226 & & & \\
\hline
\end{tabular}

\section{Q24 To what extent do you disagree or agree with each statement below about lead poisoning in people?}

\begin{tabular}{|c|c|c|c|c|}
\hline & $\mathrm{N}$ & Mean & Std. Error & Std. Deviation \\
\hline $\begin{array}{l}\text { A person with lead poisoning may not always } \\
\text { appear sick or show symptoms of poisoning. }\end{array}$ & 225 & 3.71 & .047 & .708 \\
\hline Lead poisoning in people can be prevented. & 226 & 4.16 & .047 & .700 \\
\hline $\begin{array}{l}\text { Lead bullet fragments in venison could pose a } \\
\text { risk of lead poisoning in people. }\end{array}$ & 226 & 3.86 & .058 & .871 \\
\hline $\begin{array}{l}\text { A very small amount of lead can negatively affect } \\
\text { a person. }\end{array}$ & 226 & 3.83 & .052 & .776 \\
\hline Valid N (listwise) & 225 & & & \\
\hline
\end{tabular}




\section{Q25 To what extent do you disagree or agree with each of the following statements about using lead free ammunition for deer hunting?}

\begin{tabular}{|c|c|c|c|c|}
\hline & $\mathrm{N}$ & Mean & $\begin{array}{l}\text { Std. } \\
\text { Error }\end{array}$ & $\begin{array}{c}\text { Std. } \\
\text { Deviation }\end{array}$ \\
\hline $\begin{array}{l}\text { Lead free ammunition is ballistically superior to traditional lead } \\
\text { ammunition. }\end{array}$ & 226 & 2.98 & .052 & .777 \\
\hline $\begin{array}{l}\text { Lead free ammunition is compatible with most modern firearms } \\
\text { used for deer hunting. }\end{array}$ & 226 & 3.79 & .051 & .765 \\
\hline $\begin{array}{l}\text { There is minimal complexity converting to lead free ammunition } \\
\text { (e.g., sighting in my firearm). }\end{array}$ & 226 & 3.57 & .058 & .878 \\
\hline $\begin{array}{l}\text { Voucher programs would be helpful for hunters to try lead free } \\
\text { ammunition for themselves. }\end{array}$ & 225 & 3.83 & .056 & .844 \\
\hline $\begin{array}{l}\text { None of my friends or relatives use lead free deer hunting } \\
\text { ammunition. }\end{array}$ & 226 & 3.02 & .065 & .977 \\
\hline $\begin{array}{l}\text { Shooting demonstrations would show deer hunters the benefits } \\
\text { of lead free ammunition and dangers of lead poisoning. }\end{array}$ & 226 & 3.70 & .057 & .863 \\
\hline $\begin{array}{l}\text { Lead free deer hunting ammunition costs too much compared } \\
\text { to lead ammunition. }\end{array}$ & 226 & 3.04 & .060 & .908 \\
\hline Lead free ammunition is difficult to find at local retail stores. & 226 & 3.50 & .059 & .886 \\
\hline $\begin{array}{l}\text { It is difficult to determine lead free ammunition by looking at the } \\
\text { package. }\end{array}$ & 225 & 3.12 & .062 & .928 \\
\hline Lead free deer hunting ammunition damages firearms. & 224 & 2.45 & .054 & .807 \\
\hline $\begin{array}{l}\text { Deer hunting guns will not shoot lead free ammunition } \\
\text { accurately. }\end{array}$ & 225 & 2.28 & .054 & .810 \\
\hline $\begin{array}{l}\text { Lead ammunition is significantly cheaper than lead free } \\
\text { alternatives. }\end{array}$ & 225 & 3.36 & .054 & .812 \\
\hline Traditional lead ammunition is more effective in killing deer. & 225 & 2.61 & .056 & .838 \\
\hline Valid N (listwise) & 223 & & & \\
\hline
\end{tabular}


Q26 From which of the following sources do you receive information regarding the effects of deer hunting ammunition? Source of information about effects of deer hunting ammunition?

\begin{tabular}{|c|c|c|c|}
\hline & \multirow{3}{*}{$\begin{array}{r}\text { Count } \\
114 \\
\end{array}$} & \multirow{3}{*}{$\begin{array}{r}\text { Percent } \\
51.6\end{array}$} \\
\hline & & & \\
\hline \multirow[t]{2}{*}{ Family and friends } & Yes & & \\
\hline & No & 107 & 48.4 \\
\hline \multirow{2}{*}{$\begin{array}{l}\text { Major outdoor or wildlife organization (e.g., Ducks Unlimited, Pheasants } \\
\text { Forever, or Safari Club International) }\end{array}$} & Yes & 115 & 53.0 \\
\hline & No & 102 & 47.0 \\
\hline \multirow{2}{*}{$\begin{array}{l}\text { Shooting sports organization (e.g., National Rifle Association (NRA), } \\
\text { National Shooting Sports Foundation (NSSF), local gun club or shooting } \\
\text { range) }\end{array}$} & Yes & 64 & 29.4 \\
\hline & No & 154 & 70.6 \\
\hline \multirow[t]{2}{*}{ Hunter safety course } & Yes & 63 & 29.0 \\
\hline & No & 154 & 71.0 \\
\hline \multirow[t]{2}{*}{ Hunting magazines or periodicals } & Yes & 105 & 48.2 \\
\hline & No & 113 & 51.8 \\
\hline \multirow[t]{2}{*}{ Local hunting or sporting goods store } & Yes & 58 & 26.6 \\
\hline & No & 160 & 73.4 \\
\hline \multirow[t]{2}{*}{ State wildlife agency website } & Yes & 122 & 55.2 \\
\hline & No & 99 & 44.8 \\
\hline \multirow[t]{2}{*}{ Federal agency website } & Yes & 152 & 68.8 \\
\hline & No & 69 & 31.2 \\
\hline \multirow[t]{2}{*}{ Television stories, public service announcements } & Yes & 66 & 30.3 \\
\hline & No & 152 & 69.7 \\
\hline \multirow[t]{2}{*}{ Scientific journals or technical reports } & Yes & 105 & 47.7 \\
\hline & No & 115 & 52.3 \\
\hline \multirow[t]{2}{*}{ Nature center or museum displays } & Yes & 80 & 36.7 \\
\hline & No & 138 & 63.3 \\
\hline
\end{tabular}

Q27 Given the information you received regarding deer hunting ammunition, how unimportant or important was each source to you? (importance recorded only if participant used the information source)

\begin{tabular}{|c|c|c|c|c|}
\hline & $\mathrm{N}$ & Mean & $\begin{array}{l}\text { Std. } \\
\text { Error }\end{array}$ & $\begin{array}{l}\text { Std. } \\
\text { Deviation }\end{array}$ \\
\hline Family and friends & 112 & 3.85 & .064 & .674 \\
\hline $\begin{array}{l}\text { Major outdoor or wildlife organization (e.g., Ducks Unlimited, } \\
\text { Pheasants Forever, or Safari Club International) }\end{array}$ & 114 & 3.80 & .081 & .864 \\
\hline $\begin{array}{l}\text { Shooting sports organization (e.g., National Rifle Association } \\
\text { (NRA), National Shooting Sports Foundation (NSSF), local } \\
\text { gun club or shooting range) }\end{array}$ & 63 & 3.56 & .110 & .876 \\
\hline Hunter safety course & 62 & 3.95 & .106 & .838 \\
\hline
\end{tabular}




\begin{tabular}{|c|c|c|c|c|}
\hline & $\mathrm{N}$ & Mean & $\begin{array}{l}\text { Std. } \\
\text { Error }\end{array}$ & $\begin{array}{c}\text { Std. } \\
\text { Deviation }\end{array}$ \\
\hline Hunting magazines or periodicals & 104 & 3.54 & .077 & .787 \\
\hline Local hunting or sporting goods store & 57 & 3.53 & .115 & .868 \\
\hline State wildlife agency website & 122 & 4.11 & .068 & .752 \\
\hline Federal agency website & 151 & 4.16 & .067 & .825 \\
\hline Television stories, public service announcements & 66 & 3.86 & .080 & .654 \\
\hline Scientific journals or technical reports & 103 & 4.32 & .068 & .689 \\
\hline Nature center or museum displays & 78 & 3.88 & .106 & .939 \\
\hline Valid N (listwise) & 4 & & & \\
\hline
\end{tabular}

Q28 This section deals with the FWS Lead Free Ammunition Outreach Program

Q29 Are you aware of the U.S. Fish and Wildlife Service (FWS) Lead Free Ammunition Outreach Program encouraging hunters to voluntarily use lead free ammunition while deer hunting on national wildlife refuges?

\begin{tabular}{|c|c|c|c|c|c|}
\hline & & Frequency & Percent & Valid Percent & $\begin{array}{c}\text { Cumulative } \\
\text { Percent }\end{array}$ \\
\hline \multirow[t]{3}{*}{ Valid } & Yes & 214 & 91.1 & 95.5 & 95.5 \\
\hline & No & 10 & 4.3 & 4.5 & 100.0 \\
\hline & Total & 224 & 95.3 & 100.0 & \\
\hline Missing & System & 11 & 4.7 & & \\
\hline Total & & 235 & 100.0 & & \\
\hline
\end{tabular}

Q30 From which of the following sources in the U.S. Fish and Wildlife Service (FWS) Lead Free Ammunition Outreach Program do you receive information regarding the effects of lead ammunition on bald eagles?

\begin{tabular}{llr|r} 
& & Count & Percent \\
\hline Information from the FWS Implementation Team (e.g., conference calls, & Yes & 124 & $59.6 \%$ \\
\cline { 2 - 4 } meeting summary notes, on-site training) & No & 84 & $40.4 \%$ \\
\hline Posters and banners at refuge visitors' centers and offices & Yes & 150 & $72.1 \%$ \\
\cline { 2 - 5 } & No & 58 & $27.9 \%$ \\
\hline Fliers, pamphlets, bookmarks, and brochures & Yes & 152 & $73.1 \%$ \\
\hline Signs or kiosks on refuges & No & 56 & $26.9 \%$ \\
\hline & Yes & 120 & $58.0 \%$ \\
\hline Information enclosed with managed hunt notification letter & No & 87 & $42.0 \%$ \\
\hline
\end{tabular}




\begin{tabular}{|c|c|c|c|}
\hline & & Count & Percent \\
\hline & No & 150 & $71.8 \%$ \\
\hline \multirow[t]{2}{*}{ Presentations at orientation sessions at refuges with managed hunts } & Yes & 68 & $32.5 \%$ \\
\hline & No & 141 & $67.5 \%$ \\
\hline \multirow[t]{2}{*}{ Information on refuge websites } & Yes & 123 & $59.1 \%$ \\
\hline & No & 85 & $40.9 \%$ \\
\hline \multirow[t]{2}{*}{ FWS news releases } & Yes & 138 & $66.0 \%$ \\
\hline & No & 71 & $34.0 \%$ \\
\hline \multirow[t]{2}{*}{ News or media stories (e.g., newspaper, online, TV, radio) } & Yes & 61 & $29.6 \%$ \\
\hline & No & 145 & $70.4 \%$ \\
\hline \multirow[t]{2}{*}{ Information at non-hunting events (e.g., Eagle Days) } & Yes & 56 & $27.1 \%$ \\
\hline & No & 151 & $72.9 \%$ \\
\hline \multirow{2}{*}{$\begin{array}{l}\text { Information at local retailers and partners (e.g., Pheasants Forever } \\
\text { chapter meeting) }\end{array}$} & Yes & 26 & $12.6 \%$ \\
\hline & No & 180 & $87.4 \%$ \\
\hline \multirow[t]{2}{*}{ Social media (e.g., Facebook, Twitter) } & Yes & 61 & $29.6 \%$ \\
\hline & No & 145 & $70.4 \%$ \\
\hline \multirow[t]{2}{*}{ Conversation with an FWS employee about lead free ammunition } & Yes & 177 & $84.7 \%$ \\
\hline & No & 32 & $15.3 \%$ \\
\hline \multirow[t]{2}{*}{ Conversation with an FWS volunteer about lead free ammunition } & Yes & 52 & $25.2 \%$ \\
\hline & No & 154 & $74.8 \%$ \\
\hline
\end{tabular}

\section{Q31 Of the FWS Lead Free Ammunition Outreach Program information sources used, how unimportant or important was each source of information to you for your own learning about the effects of lead free ammunition on bald eagles?}

\begin{tabular}{l|r|r|r|r} 
& $\mathrm{N}$ & Mean & Std. Error & $\begin{array}{c}\text { Std. } \\
\text { Deviation }\end{array}$ \\
\hline $\begin{array}{l}\text { Information from the FWS Implementation Team (e.g., } \\
\text { conference calls, meeting summary notes, on-site } \\
\text { training) }\end{array}$ & 122 & 4.00 & .087 & .962 \\
\hline $\begin{array}{l}\text { Posters and banners at refuge visitors' centers and } \\
\text { offices }\end{array}$ & 149 & 3.82 & .076 & .923 \\
\hline $\begin{array}{l}\text { Fliers, pamphlets, bookmarks, and brochures } \\
\text { Signs or kiosks on refuges }\end{array}$ & 150 & 3.85 & .076 & .932 \\
\hline $\begin{array}{l}\text { Information enclosed with managed hunt notification } \\
\text { letter }\end{array}$ & 58 & 4.10 & .097 & .742 \\
\hline $\begin{array}{l}\text { Presentations at orientation sessions at refuges with } \\
\text { managed hunts }\end{array}$ & 65 & 4.11 & .103 & .831 \\
\hline \begin{tabular}{l} 
Information on refuge websites \\
\hline
\end{tabular} & 121 & 3.84 & .075 & .827 \\
\hline
\end{tabular}


Std.

\begin{tabular}{l|r|r|r|r} 
& & & & \multicolumn{1}{c}{$\begin{array}{c}\text { Std. } \\
\text { Deviation }\end{array}$} \\
\hline FWS news releases & N & Mean & Std. Error & .823 \\
\hline $\begin{array}{l}\text { News or media stories (e.g., newspaper, online, TV, } \\
\text { radio) }\end{array}$ & 60 & 3.92 & .093 & .720 \\
\hline $\begin{array}{l}\text { Information at non-hunting events (e.g., Eagle Days) } \\
\text { Information at local retailers and partners (e.g., }\end{array}$ & 56 & 4.02 & .094 & .700 \\
\hline $\begin{array}{l}\text { Pheasants Forever chapter meeting) } \\
\text { Social media (e.g., Facebook, Twitter) }\end{array}$ & 26 & 4.04 & .171 & .871 \\
\hline $\begin{array}{l}\text { Conversation with an FWS employee about lead free } \\
\text { ammunition }\end{array}$ & 175 & 4.04 & .062 & .107 \\
\hline $\begin{array}{l}\text { Conversation with an FWS volunteer about lead free } \\
\text { ammunition }\end{array}$ & 52 & 4.10 & .107 & .819 \\
\hline \begin{tabular}{l} 
Valid N (listwise) \\
\hline
\end{tabular}
\end{tabular}

\section{Q32 Is your field station participating in the FWS Lead Free Ammunition Outreach Program?}

\begin{tabular}{llr|r|r|r} 
& & & & \multicolumn{2}{c}{$\begin{array}{c}\text { Cumulative } \\
\text { Percent }\end{array}$} \\
\hline Valid & Frequency & Percent & Valid Percent & Ptarted in 2016 \\
\cline { 2 - 6 } & Yes, started in 2017 & 52 & 22.1 & 24.4 & 24.4 \\
\cline { 2 - 6 } & Yes, to start in 2018 & 45 & 19.1 & 21.1 & 45.5 \\
\cline { 2 - 6 } & No, not participating in & 60 & 25.5 & 28.2 & 73.7 \\
\hline & program & 56 & 23.8 & 26.3 & 100.0 \\
\hline Missing & Total & & & & \\
\hline Total & System & 213 & 90.6 & 100.0 & \\
\hline
\end{tabular}

Q33 As a staff person working at a field station participating in the FWS Lead Free Ammunition Outreach Program, how dissatisfied or satisfied were you with each of the following to help you implement the program on your refuge? (respondents not participating removed from this summary)

\begin{tabular}{l|r|r|r|r} 
& N & Mean & Std. Error & $\begin{array}{c}\text { Std. } \\
\text { Deviation }\end{array}$ \\
\hline Conference calls with the Regional Implementation Team & 105 & 3.49 & .073 & .748 \\
\hline $\begin{array}{l}\text { On-site training by Regional Implementation Team (e.g., } \\
\text { videos and PowerPoint presentations) }\end{array}$ & 110 & 3.36 & .080 & .843 \\
\hline $\begin{array}{l}\text { Usefulness of informational materials on the Google drive } \\
\text { Organization of materials on the Google drive }\end{array}$ & 108 & 3.44 & .070 & .727 \\
\hline
\end{tabular}




\begin{tabular}{|c|c|c|c|c|}
\hline & $\mathrm{N}$ & Mean & Std. Error & $\begin{array}{l}\text { Std. } \\
\text { Deviation }\end{array}$ \\
\hline $\begin{array}{l}\text { Summary notes from the Regional Implementation Team } \\
\text { meetings }\end{array}$ & 109 & 3.39 & .068 & .707 \\
\hline Supply of Outreach Program information materials & 123 & 3.72 & .079 & .873 \\
\hline Valid N (listwise) & 94 & & & \\
\hline
\end{tabular}

Q34 To what extent do you disagree or agree with each of the following statements about your ability to implement the FWS Lead Free Ammunition Outreach Program?

\begin{tabular}{|c|c|c|c|c|}
\hline & $\mathrm{N}$ & Mean & Std. Error & $\begin{array}{l}\text { Std. } \\
\text { Deviation }\end{array}$ \\
\hline $\begin{array}{l}\text { I had sufficient training to become knowledgeable about the } \\
\text { topic. }\end{array}$ & 146 & 3.21 & .084 & 1.010 \\
\hline $\begin{array}{l}\text { I felt I had the necessary administrative support to freely } \\
\text { discuss the topic with deer hunters. }\end{array}$ & 146 & 3.29 & .082 & .991 \\
\hline $\begin{array}{l}\text { I was given ample time and opportunity to review the } \\
\text { available materials. }\end{array}$ & 146 & 3.41 & .080 & .966 \\
\hline $\begin{array}{l}\text { I was given ample time and opportunity to learn about the } \\
\text { topic. }\end{array}$ & 146 & 3.40 & .078 & .944 \\
\hline Valid N (listwise) & 146 & & & \\
\hline
\end{tabular}

Q35 In your opinion, how unimportant or important were each of the following information materials from the FWS Lead Free Ammunition Outreach Program in persuading hunters to use lead free ammunition? ('not applicable' responses not used in this question)

\begin{tabular}{|c|c|c|c|c|}
\hline & $\mathrm{N}$ & Mean & Std. Error & $\begin{array}{l}\text { Std. } \\
\text { Deviation }\end{array}$ \\
\hline $\begin{array}{l}\text { Information from the FWS Implementation Team (e.g., } \\
\text { conference calls, meeting summary notes, on-site training) }\end{array}$ & 122 & 3.31 & .102 & 1.121 \\
\hline Posters and banners at refuge visitors' centers and offices & 135 & 3.84 & .088 & 1.024 \\
\hline Fliers, pamphlets, bookmarks, and brochures & 136 & 3.89 & .087 & 1.016 \\
\hline Signs or kiosks on refuges & 133 & 3.83 & .087 & 1.004 \\
\hline Information enclosed with managed hunt notification letter & 115 & 3.87 & .091 & .978 \\
\hline $\begin{array}{l}\text { Presentations at orientation sessions at refuges with } \\
\text { managed hunts }\end{array}$ & 111 & 3.80 & .093 & .980 \\
\hline Information on refuge websites & 129 & 3.71 & .082 & .930 \\
\hline FWS news releases & 125 & 3.48 & .088 & .989 \\
\hline News or media stories (e.g., newspaper, online, TV, radio) & 110 & 3.61 & .091 & .959 \\
\hline
\end{tabular}




\begin{tabular}{|c|c|c|c|c|}
\hline & $\mathrm{N}$ & Mean & Std. Error & $\begin{array}{c}\text { Std. } \\
\text { Deviation }\end{array}$ \\
\hline Information at non-hunting events (e.g., Eagle Days) & 115 & 3.49 & .096 & 1.029 \\
\hline $\begin{array}{l}\text { Information at local retailers and partners (e.g., Pheasants } \\
\text { Forever chapter meeting) }\end{array}$ & 115 & 3.76 & .085 & .914 \\
\hline Social media (e.g., Facebook, Twitter) & 113 & 3.57 & .094 & .999 \\
\hline $\begin{array}{l}\text { Conversation with an FWS employee about lead free } \\
\text { ammunition }\end{array}$ & 132 & 3.96 & .081 & .928 \\
\hline $\begin{array}{l}\text { Conversation with an FWS volunteer about lead free } \\
\text { ammunition }\end{array}$ & 115 & 3.75 & .091 & .981 \\
\hline Valid N (listwise) & 79 & & & \\
\hline
\end{tabular}

\section{Q36 To what extent do you disagree or agree with each of the following statements about the FWS Lead Free Ammunition Outreach Program?}

\begin{tabular}{l|r|r|r|r} 
& N & Mean & Std. Error & $\begin{array}{c}\text { Std. } \\
\text { Deviation }\end{array}$ \\
\hline $\begin{array}{l}\text { The program is an optimal approach to reducing lead } \\
\text { poisoning in bald eagles. }\end{array}$ & 142 & 3.37 & .077 & .912 \\
\hline $\begin{array}{l}\text { The program is compatible with the goals and objectives of my } \\
\text { agency and cooperating conservation organizations. }\end{array}$ & 142 & 3.99 & .055 & .658 \\
\hline $\begin{array}{l}\text { There's minimal complexity in using and implementing the } \\
\text { program. }\end{array}$ & 141 & 3.35 & .077 & .910 \\
\hline $\begin{array}{l}\text { A voucher incentive connected with the program would be } \\
\text { helpful for hunters to try lead free ammunition on a trial basis } \\
\text { without having to pay for it. }\end{array}$ & 143 & 4.01 & .071 & .847 \\
\hline $\begin{array}{l}\text { Shooting demonstrations (e.g., using water traps) would be } \\
\text { helpful as part of the program showing the benefits of lead free } \\
\text { ammunition and dangers of lead poisoning. }\end{array}$ & 142 & 3.82 & .080 & .955 \\
\hline \begin{tabular}{l} 
Valid N (listwise) \\
\hline
\end{tabular} & & & & \\
\hline
\end{tabular}




\section{Q37 What recommendations do you have for improving the FWS Lead Free Ammunition Outreach Program?}

Having hunted my entire life and coming from a family consisting of 20 plus people that hunt every type of wild game large to small and put more days in the field harvesting game than the folks trying to ban lead ammo. also my family is very active in recreational shooting and reloading of ammunition and very knowledgeable in the ballistic performance of lead bullets I feel im entitled to a voice my observations, Having field dressed hundreds of deer and worked as a wild game butcher helping butcher 70-100 deer each year i will say that the thought of eagles getting lead from the dead deer I see is $99.9 \%$ unlikely deer are shot in the vital organs and the bullet passes through $99.9 \%$ of the time the one time I found a bullet remaining in a deer after field dressing i weighed it to see how much was lost due to fragmentation, the bullet weighing 240 grains when new weighed $238+$ grains and was only missing a small piece of the cooper jacket covering the bullet. the thought of lead filled gut piles in the woods after field dressing an animal is completely absurd and not accurate. what it comes down to is the quality of the bullet your shooting in my experience any quality bullet will not fragment therefor leaving no lead behind in the carcass and passing completely through therefore having absolutely no chance of harming a eagle. the fws non lead ammo info that i saw last hunting season was very bias showing lead bullets fragmented into hundreds of pieces which on any quality bullets just isnt the case from all my experience. Im not against lead free ammo it performs very well ive seen its performance and it matches lead in many cases, but if lead bullets become outlawed the cost for my hunting ammo will double and whats to say the lead ban wont begin to affect my recreational shooting hobby and begin to make it unaffordable something im not ok with especially when i see very bias test results being used to push an anti lead agenda

We as an agency are trying to use a feel good approach to reach hunters based on the effect of lead on bald eagles. If we really want to reach hunters, we need to focus more on the effectiveness of lead free ammunition. With that, we need to be mindful that not all firearms handle lead free the same. Most hunters want to use ammunition that is accurate and efficient. If the hunters firearm does not accurately shoot lead free ammo most hunters will not use it. Ammunition availability is a real issue for many hunters, currently the 450 bushmaster is becoming the predominate firearm in Lower Michigan. As of last hunting season, the only lead free ammunition available for this caliber came from custom suppliers and it cost twice as much as premium lead hunting ammunition. It may be worthwhile communicating with ammunition manufactures to increase lead free selection. The knowledge base of some of the people presenting this information is lacking when it comes to common hunter wants, needs and desires. It would be helpful it they were more familiar with things like ballistics, forms of rifling, bonded vs. non-bonded bullets vs copper. Bottom line is if we as an agency want to influence the way hunters view lead free alternatives we need to change our approach because right now it is failing.

1. Adopt a more assertive approach - greater emphasis placed on information outreach.

2. Add or expand a voucher program. 
About the questionnaire, I am not the member of a large group (Ducks Unlimited. Pheasants Forever) I could not answer some questions so left blank. I am not involved with hunter safety program so could not answer questions on it but I do think this is a great place to change hunters opinions young and old. If you can teach the students maybe the student can change other hunters (Dad - family) to non-toxic shot.

Hearing the ingestion of lead caught my attention but hearing ingestion of lead from venison by me is what caught my attention.

Directly talking with a service employee at a public meeting is where I was introduced to using copper. When I held a copper bullet that had been shot I could see the expansion and razor cutting effect of copper. To see the cutting like a broad head arrow tip rather than mushrooming and fragmentation of a bullet and could hold it in my hand I could see how much better copper kills. Then using it and seeing the quick kill in person, I was sold. I told other hunters to have them switch.

As a person who reloads, boxes of bullets were very hard to id. So, I looked at manufactured boxes and it was very difficult to distinguish copper from lead. Every box I looked at you had to read the fine print of the lead warning. I got so frustrated I grabbed a box of lead for my 30/30. I later learned copper is not made for a $30 / 30$.

I did find copper bullets for reloading my .243. The bullets I found were not heavy enough for big game. I looked for and found copper manufactured ammunition for the .243 but they too were a low weight bullet. The diversity of bullets in each case reload vs manufactured were very limited.

Shotgun was easy to find and works great.

\section{Ban lead on NWRs}

Can you prove bald eagles get lead by eating deer gut piles? I bet if you have 100 hunters kill 100 deer and you put up a trail camera on each gut pile not one gut pile will be eat by a bald eagle. I have hunted for 30 years and I have never saw a bald eagle eat one gut pile. A fox will eat it gut pile in 2 days. You take photos of a whole deer and an eagle eating it, this is not the same as a gut pile. Back up your information; prove by using deer cameras.

Continue educating the public and provide good information on the benefits of using non-lead ammunition

Continued outreach, and employee involvement. I am a new employee (7 months in) to a refuge that participates in the program, but I haven't heard anything from my supervision about the program or materials except for what pamphlets/materials located in the visitor's center. Point-of-sale educational materials at Wal-marts, farm and home stores, ammo dealers, etc. would be a good idea. 
During the entire program we were not allowed to discuss rear content. Information is available from other organization that discusses ballistics and shooting performance. Our messaging never used information useful to hunters and shooters. A major component of our information campaign was to non-shooting, no hunting public. Even if we convenience every non-shooter to agree, no change would happen in the real world. We had a very narrow scope of only deer Hunting on Refuge land. If we are actually going to see change we should have broadened our scope. Good ballistic characteristics are the same everywhere its science, physics don't change when you enter a refuge. It is very hard to expect retailers to stock non-lead for only refuge deer hunting. Encourage folks look at other calibers and hunted species to use non-lead ammunition on.

Encourage more active outreach at partner events (e.g., State DNR listening sessions; local PF, DU, NWTF, IWL chapters, etc.)

Get ammunition and arms manufacturers to (1) participate in the program, (2). actively develop weapons and ammunition to allow hunters to affordably switch to lead free ammunition, and (3) implement marketing campaigns to promote lead free ammunition and lead-free specific arms.

Get more information out to the employees and provide more literature for staff to hand out to hunters.

Historically hunters and fisherman have risen to the challenges to conserve wildlife, whether it's through the adoption of steel shot for waterfowl or protection of wetlands and grasslands. The North American model of wildlife conservation depends upon science and population management. If lead is affecting the population trajectory of eagles, then we need to make that science known. If there is not a demonstrable population level effect how can we justify this action when there are so many, and some major, conservation challenges looming.

I am a waterfowl, turkey and small game hunter. Although I do not use lead-free deer ammunition, I think that hunters make a choice and continually re-enforcing this issue may shift opinions and attitudes despite the cost. The other aspect is what they do with the un-used portions of the animal that may still contain lead.

I believe more advertising nationally needs to take place. In addition to that, more public outreach on refuge websites and other social media sites.

Also, education at the regional and local level with a variety of conservation and hunting groups as well as retailers. 
I don't think government employees in their uniforms are the right people to deliver this message to hunters. We need to get local sportsman and sportsman stores to be more on board and offer alternate ammo or you won't ever see a switch or shift in behavior. Have to make it easy and affordable for hunters to switch if you want it to be voluntary.

I hate to say it, but I think the one great way to get hunters to start using Lead Free Ammo is to provide a Coupon/Incentive to do it, otherwise I don't see much of a change happening.

I really like the program and would like to see it continue with Regional support. One item that backfired was the Facebook posts. Social media is a great tool but stations need to be ready for the fall out. We need to ensure the photos and captions are accurate. I feel our station lost some credibility with these.

I shoot lead free ammunition because of the ballistics. Lead free ammunition retains almost $98 \%$ weight retention after entering an animal. Unless you reload this ammunition is not as accurate and 2 times the cost as lead ammunition. The people that you are going to have to target are the older hunters suck in their ways and not wanting to double their spending on ammunition for the year. Yes, in the grand scheme of things it is not that much money but try telling a guy that he has to buy a $\$ 40$ box of ammo when he is used to purchasing lead ammo for $\$ 20$.

I suspect that a high percentage of people hunting the refuge access the refuge without stopping at visitor's center therefore are not likely to realize this is an issue. Efforts need to be publicized beyond the Blue Goose signs. Many hunters and gun owners see this as an anti-hunting ploy. FWS and others needs to do a better job of proving/convincing that gun/hunting groups that decisions related to lead are science/conservation based, not anti-gun/anti-hunt.

I don't think people (myself included) respond well to "talking points." I think presentations given by biologists and especially biologist who hunt will work better than a bunch of brochures. Presentations that discuss ballistic comparisons would also be helpful. Audiences need to be able to ask questions and hear the answers. This is obviously much more difficult putting up posters and filling kiosks with brochures.

I think that the up-front non-anti-hunting agenda is especially important to gain acceptance and compliance with using non-lead ammo.

Education is extremely important but supporting facts and documentation is crucial for success.

This survey is right on the money, your asking questions about the important issues that will be faced when dealing with the hunting population. The only issue is figuring out how to mitigate these issues effectively. The arguments your asking about cost, effectiveness are going to be difficult selling points to the public and hunters.

Open and frank discussions are definitely the key, keep it up! 
I think the voucher systems and community demonstrations would really help the public understand the benefits of lead-free products. It seems that the higher cost is the biggest deterrent and grant opportunities or incentive programs with ammo shops could work to increase lead free usage

I think this is a good program and should continue for the health of raptor populations, however I think refuges may not be the best venue to promote this. Refuges have such a small footprint on the land, most refuges are only open to archery and muzzleloader deer hunts, and the number of people who participate in refuge hunts are fairly low. Muzzleloader rounds barely fragment upon impact and in my mind pose little threat to eagles ingesting lead. The much larger issue is rifle slugs and small game cartridges (22 rounds) that fragment almost entirely. I understand someone must lead the way on this issue.

Most people in my opinion are more concerned about actually maintaining a place to hunt than the methods they are using to hunt. Hunter numbers are dropping enormously but the areas open to hunting are also becoming very scarce. With so much property being taken away from the average hunter from leases and guide services, most effort is spent worrying about this rather than what ammunition you'll use. My friends and family rarely talk about equipment used in the field any more. The conversation pertains mainly to loss of habitat, keeping up on regulations, and hunting access changes. I'm not sure what it'll take to make this a higher priority in their minds. I have tried to convey the message but for most they see it as firing one bullet per year to harvest an animal and that their hunting efforts have no effect. For me I don't think about it that much because I haven't actually purchased muzzleloader or rifle rounds for probably \&gt; 5 years because I just don't use them that much anymore.

I think you have to show that the impacts of these changes are significant enough to warrant the costs involved.

If you're going to implement this program, at least use real science. An idiot can figure out the difference between a pile of 100 dead deer (some shot multiple times) and individual dead deer in the woods.

I use lead free ammo because I was told to support our program. Period. I read both the study parameters, and the report. The whole thing is BS.

I am also a competitive shooter, with decades of data on ballistics. The issue that may come up, is that hunters are used to using a certain bullet weight. Rifle barrels are rifled according to the length of the average bullet in that chambering. Lead free bullets of the same weight and caliber will be longer, leading to instability and accuracy issues. Maybe noting in your literature that leadfree ammo should use slightly lighter weight bullets could help. Just a thought.

I myself have no problem using lead free because I can handload custom ammo that will work. Don't get me wrong here, I'm not against lead free ammo, but do it for the right reason, not some politically skewed ideal.

involving staff more, and not just managers 
It would be great if the FWS program could team up with a Human health organization to further show the importance of non-lead ammo to prevent human and animal sickness.

Just keep spreading the word!

Keep it going. Maybe update the graphic (rack card) every 2-3 years.

Keep it up! While there is a cost between lead and non-lead ammunition, the amount of ammunition used annually should be minimal if they are ethical hunters. I would like to see this voluntary program turn into a requirement down the road. It doesn't only affect bald eagles, but songbirds, crows, ravens, and other animals that visit gut piles are negatively impacted.

Keep up the great work. Remember we are a conservation organization. Leave the politics out and do what is best for the resources.

Likely need a national campaign showing the lead dangers to humans found in contaminated venison and dead eagles from lead ingestion. The stories would need to be picked up by the national news and associated press to get the impact needed to see some change. Also, the only lead-free shotgun rounds I could find were for rifled barrels. They may work in a non-rifled barrel, but I did not see any indication that one could use it that way, so I was not willing to try it.

List vender's on where you can purchase the ammo and list the comparable prices

More data on ballistics between lead and non-lead shot

More information to staff to enable us to have the conversation with visitors and hunters. If you are going to perform demonstrations for hunters why not for staff. Non-hunting staff at our refuge talk to far more visitors and hunters than the hunting staff do.

Using a photo of a swan on the banner as a bird killed by ingesting lead was questionable. It casts doubt on the information you are conveying. While I do know that sandhill cranes will eat from gut piles (for the corn in the stomachs), I've not heard of this occurring in swans.

more outreach to ammunition distributors.

More training for field station staff on the topic. 
My role in implementing the FWS Lead Free Ammunition Outreach Program was to update our social media pages with lead-free messaging. I don't think that our Facebook posts engaged the target audience, though the posts did draw attention to the issue, both positively and negatively. We received a lot of negative attention for one particular photo. It didn't appear that the messaging had been proofed a final time by the Lead Free Ammo Outreach committee before the messaging went "live." There was some confusion about when the timeline for implementing the messaging would begin.

We haven't done a lot with non-lead outreach apart from the social media campaign and hosting a banner/signs at key locations, partly because we do not have any managed hunts in our district on the refuge. We had some conversations with our Friends Group about working with partners to implement a voucher program for hunters but were told to hold off before starting a program by our regional team.

As we move forward with the program, I think our most powerful opportunities to influence hunters' attitudes about using nontoxic ammunition come from the relationships we build with partners like Whitetails Unlimited, Ducks Unlimited, Backcountry Hunters and Anglers - the organizations that hunters have trust with and are involved in, as well as working with State Departments of Natural Resources and other hunters' education practitioners to share the message.

As someone interacting with hunters, I feel like I personally need to understand the science of how ingesting lead fragments poisons bald eagles, and also explain why eagle populations may appear to increase over the short term even while in the long-run, lead accumulates in their bodies and eventually kills them .... knowing the science is important because that is our area of expertise. BUT, while I think it's important to be able to share this message, I think that understanding the science is not the barrier that keeps hunters from making

N/A. I'm not a hunter.

Need to have hands on demonstrations at the refuge, or local gun range. People/Americans are a visual. It would allow them to understand what is happening when a bullet strikes an animal and what its doing. It would also be a good time to go over the ballistics of lead free ammo, you could show that they can group as well and have the same performance as lead rounds. 
None continue on coarse in general lead is unhealthy for all living organisms. Minimalizing our use of the resource is for the betterment of all living things. To clarify I hunt with a black powder muzzle loader one shot is all I have ever needed. I have always used one shot to kill. I also locate the lead ball and remove all material back to healthy muscle. I believe most hunters are lacking skill and intelligence they are into nothing but their toy's. From my point of view hunting for sport is a wrongheaded way to hunt. I harvest food for my table and I do it for about $45 \$$ a year period. I will switch to no lead when I have used up the balls I have (about 100) it is not economically feasible for me to change and I do not pollute the hunt with any of the modern attitudes or weaponry. The hunting mentality of the American hunter needs a revaluation the NRA and big business has destroyed what a hunt is.

Best of luck and thanks for what you do.

Partner with state agencies to spread the word. MN DNR seems to have 1?, 2?, 3? more? area deer meetings each year. All are well attended. Meetings are more frequent in CWD areas. A very short (1 to 2 minute) presentation on human and wildlife effects of lead and lead fragments will at least get many hunters to start thinking.

Proof that eagles eat all deer gut piles even where their are no eagles and that their are lead fragments in all deer gut piles.

\section{Shorten this survey!}

The fact that tiny lead fragments end up through out the deer, when using High velocity lead rounds effected me more than the bald eagles. I do not want to feed that to my family. It's bad for us, our children and eagles. I think that better understanding of lead dispersal in the animal with various types of ammunition will more easily tip the scales to going lead free.

The focus has been exclusively on bald eagles. The message needs to include all other species of wildlife impacted by lead: ravens, crows, turkey vultures, woodpeckers, etc.

The individual that is trying to present the material to the public needs to have knowledge regarding guns and deer hunting. Several of our individuals that are trying to inform the public have no experience with guns or deer hunting. This does not go far with the public when trying to explain the benefits of changing to lead free. Having somebody that cares about eagles is okay, but make them a hunter also so the public can see both sides of the presenter. 
The solution has predominantly been technical approach to an adaptive challenge. In addition, folks have not been sufficiently empowered to actively work on implementing the program, or given marching orders to the degree of implementation (i.e., how much effort is expected to be put into the issue) most likely to due the politics of the situation.

this nothing more than a back door approach to stop or curtail hunting on public lands by government employees who are pushing their personal anti- hunting agenda. Almost all deer hunting caliber rifles shoot completely through the deer so the opinion that eagles are dying from lead poisoning is not true. Eagles are expanding in numbers there are more now than anytime in my life.

Until the cost of lead free ammunition comes down significantly I don't think you are going to see a change. My entire family uses lead free and we have a range of 20,16 and 12 gauge shotguns we use. It is almost impossible to find lead free for the 16 gauge. We have both 20 gauge smooth bore and rifled barrels. It is also difficult to find lead free for the 20 gauge smooth bore. So price and availability are the drivers in the system. I believe in using lead free but I get frustrated when even Cabela's doesn't carry what I need for lead free but have around 10 plus lead options at a third of the price. The packaging can also be misleading - some of the ammo is only copper coated - not solid copper!

use the outdoor news and do more media releases and billboards please 
We are still missing the mark on this issue. The majority of the effort needs to be put into the Companies producing the ammunition. The most common caliber used in this area is the .450 Bushmaster. At this time there is only one non-lead ammo choice and it is not a "normal" expanding bullet. It uses a new type of bullet that puts energy into Hydraulic shock to kill the animal. As an ethical hunter I am not going to try a new bullet type to see if it will humanly kill the animal I am hunting when I know the older bullets work quickly. Also, I have tried every non-lead round in all of my guns(20ga slug, .44 Mag, 12 ga slug, $.50 \mathrm{cal}$ muzzleloader) and only the muzzleloader provides sufficient accuracy to hunt with. In most cases its not even close. With my 20ga, I consistently shoot 1 inch 3 shot groups at 100 yds with a bonded lead bullet the three shot group with the best non-lead round jumps to 7 inches at $100 \mathrm{yds}$. As a hunter my goal is to shoot as accurately as possibly to provide the quickest most humane hunt as possible. I cannot in clear conscious hunt with non-lead ammo at this time knowing that I may wound an animal or put the animal through unneeded suffering. The vast majority of hunters I know would be open to changing to non-lead ammo but are stuck in the same situation that I am, no available option or poor preforming current options. The smaller percentage of hunters that still don't want to change need to be educated at the shooting range. One of our local clubs has a "Sight in Days" event where the public can come sight in the guns for a small fee. If free non-lead options were provided during this event hunters could try it out and see the results first hand. We could work with the ammunition companies to provide incentives to provide the ammo. Data could be collected for the companies to use in advertisements as well as our own products. This would provide competition between the companies to produce the best non-lead ammo. This would also provide a

We have to start talking about human health implications. Lead free outreach should focus on all the public and environmental health impacts. Only when we take a complete comprehensive approach to the outreach message will we be able to establish the credibility that what we are doing is trying to change the way hunters think about how the tools they use to take game can impact them after the hunt.

While it is a controversial topic, a partnership with the state would be beneficial for them to promote the same awareness. I did see MDC promote the use of non-lead ammunition on their Facebook page but don't think I saw anything in the Deer and Turkey Hunting brochure (fall hunting).

Without actually requiring lead-free ammo on the refuge, I can't see a lot of ways to improve the current program.

Work hard with partners and conservation orgs to take over the process and lead from their podiums. Retailers and hunting orgs have more community following and credibility than "the Feds" 
Q38 Next, tell us some information about yourself.

Q39 People respond to their environment in different ways. The statement below (20 items) refer to ways people can respond. Please indicate the degree to which each statement applies to you.
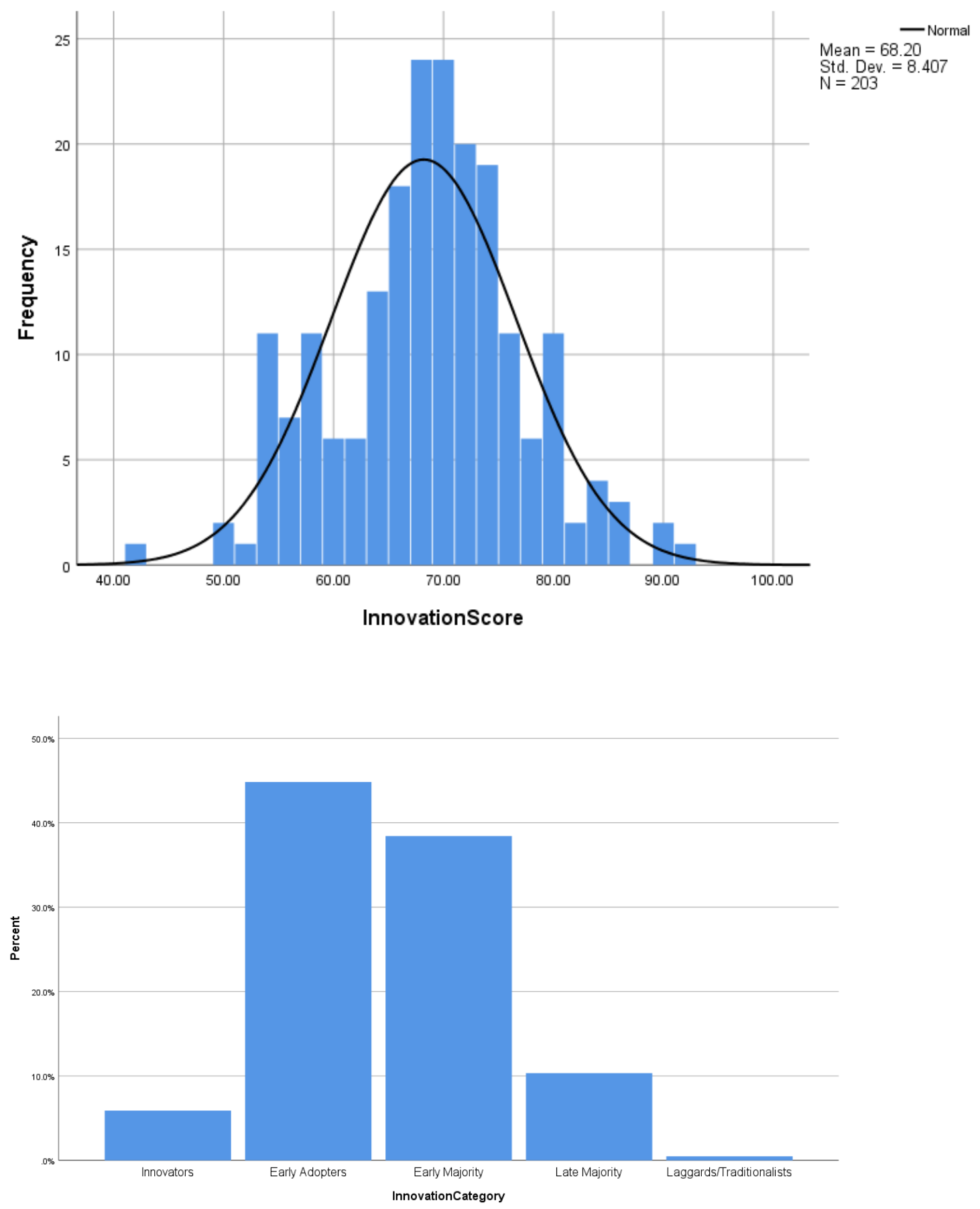
Q40 Which best describes where you grew up as a child?

\begin{tabular}{ll|r|r|r|r} 
& & & & \multicolumn{2}{c}{$\begin{array}{c}\text { Cumulative } \\
\text { Percent }\end{array}$} \\
\hline \multirow{2}{*}{ Valid } & Frequency & Percent & Valid Percent & 9.0 \\
\cline { 2 - 7 } & Large city or urban area & 19 & 8.1 & 9.0 & 30.5 \\
\cline { 2 - 7 } & Suburban area & 45 & 19.1 & 21.4 & 53.3 \\
\cline { 2 - 7 } & Small city or town & 48 & 20.4 & 22.9 & 100.0 \\
\cline { 2 - 7 } & Rural area & 98 & 41.7 & 46.7 & \\
\cline { 2 - 7 } & Total & 210 & 89.4 & 100.0 & \\
\hline Missing & System & 25 & 10.6 & & \\
\hline Total & & 235 & 100.0 & & \\
\hline
\end{tabular}

\begin{tabular}{|c|c|c|c|c|c|}
\hline & & Frequency & Percent & Valid Percent & $\begin{array}{c}\text { Cumulative } \\
\text { Percent }\end{array}$ \\
\hline \multirow[t]{5}{*}{ Valid } & Large city or urban area & 13 & 5.5 & 6.2 & 6.2 \\
\hline & Suburban area & 23 & 9.8 & 11.0 & 17.1 \\
\hline & Small city or town & 74 & 31.5 & 35.2 & 52.4 \\
\hline & Rural area & 100 & 42.6 & 47.6 & 100.0 \\
\hline & Total & 210 & 89.4 & 100.0 & \\
\hline Missing & System & 25 & 10.6 & & \\
\hline Total & & 235 & 100.0 & & \\
\hline
\end{tabular}

Q42 What is the highest level of formal education you have completed?

\begin{tabular}{|c|c|c|c|c|c|}
\hline & & Frequency & Percent & Valid Percent & $\begin{array}{c}\text { Cumulative } \\
\text { Percent }\end{array}$ \\
\hline \multirow[t]{9}{*}{ Valid } & Less than high school & 1 & .4 & .5 & .5 \\
\hline & $\begin{array}{l}\text { Some high school graduate } \\
\text { or equivalent }\end{array}$ & 5 & 2.1 & 2.4 & 2.9 \\
\hline & Some college, no degree & 19 & 8.1 & 9.0 & 11.9 \\
\hline & Associate's degree & 16 & 6.8 & 7.6 & 19.5 \\
\hline & Bachelor's degree & 101 & 43.0 & 48.1 & 67.6 \\
\hline & Master's degree & 64 & 27.2 & 30.5 & 98.1 \\
\hline & Professional degree & 1 & .4 & .5 & 98.6 \\
\hline & Doctorate degree & 3 & 1.3 & 1.4 & 100.0 \\
\hline & Total & 210 & 89.4 & 100.0 & \\
\hline Missing & System & 25 & 10.6 & & \\
\hline Total & & 235 & 100.0 & & \\
\hline
\end{tabular}


Q43 Are you?

\begin{tabular}{llr|r|r|r} 
& & Frequency & Percent & Valid Percent & Cumulative Percent \\
\hline \multirow{2}{*}{ Valid } & Male & 148 & 63.0 & 71.5 & 71.5 \\
\cline { 2 - 6 } & Female & 57 & 24.3 & 27.5 & 99.0 \\
\cline { 2 - 6 } & Other & 2 & .9 & 1.0 & 100.0 \\
\cline { 2 - 6 } & Total & 207 & 88.1 & 100.0 & \\
\hline Missing & System & 28 & 11.9 & & \\
\hline Total & & 235 & 100.0 & & \\
\hline
\end{tabular}

Q44 What year were you born? (age in 2019)

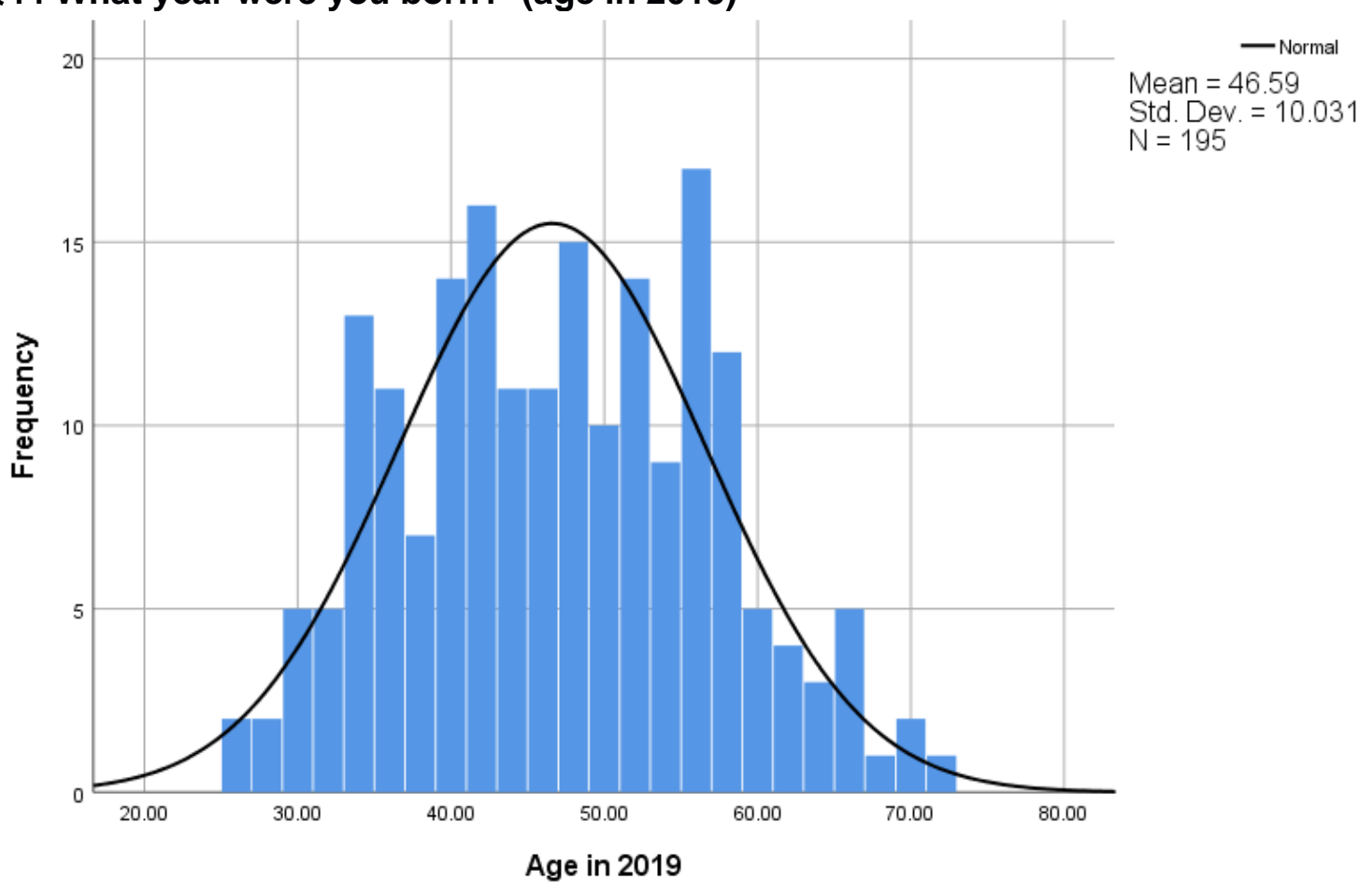


Appendix 6. Summary table of USFWS Staff Interviews followed by themes, subthemes, and example quotes.

\begin{tabular}{|c|c|c|c|c|c|c|c|c|}
\hline Participant & Date & Age & Gender & Job Description & Type & Deer Hunter? & Weapon Type & Ammo Used? \\
\hline $\mathrm{P} 1$ & $11-30-2017$ & 39 & $\mathrm{M}$ & $\begin{array}{l}\text { Assistant Refuge } \\
\text { Manager }\end{array}$ & In-person & Yes & Multiple rifles & $\begin{array}{l}\text { Mostly } \mathrm{Pb} \text {, but will try } \\
\text { nonPb if it's available }\end{array}$ \\
\hline $\mathrm{P} 2 *(\mathrm{Q}-1)$ & $11-30-2017$ & 46 & $\mathrm{M}$ & Refuge Manager & In-person & $\begin{array}{l}\text { Yes, but mainly } \\
\text { archery }\end{array}$ & $\mathrm{n} / \mathrm{a}$ & \\
\hline P3 & $12-01-2017$ & 45 & $\mathrm{~F}$ & $\begin{array}{l}\text { Visitors Services } \\
\text { Park Ranger }\end{array}$ & In-person & $\begin{array}{l}\text { No, but trying to } \\
\text { learn about } \\
\text { hunting }\end{array}$ & $\mathrm{n} / \mathrm{a}$ & \\
\hline P4 (Q-1) & $12-12-2017$ & 45 & $\mathrm{M}$ & District Manager & Phone & Yes & $\begin{array}{l}\text { Rifle, shotgun, } \\
\text { archery }\end{array}$ & nonPb \\
\hline P5 (Q-1) & $12-13-2017$ & 56 & $\mathrm{~F}$ & Refuge Manager & Phone & $\begin{array}{l}\text { Has deer hunted a } \\
\text { little, but generally } \\
\text { doesn't go deer } \\
\text { hunting }\end{array}$ & $\begin{array}{l}\text { Shotgun w/ } \\
\text { slugs }\end{array}$ & $\begin{array}{l}\text { Husband and family use } \\
\text { only } \mathrm{Pb} \text { ammunition }\end{array}$ \\
\hline P6 (Q-1) & $12-13-2017$ & 50 & $\mathrm{~F}$ & District Manager & Phone & Yes & $\begin{array}{l}\text { Didn't say, but } \\
\text { lives in shotgun } \\
\text { only zone of WI }\end{array}$ & $\begin{array}{l}\text { Nonlead; "because I } \\
\text { should" }\end{array}$ \\
\hline P7 (Q-1) & $12-18-2017$ & 35 & $\mathrm{~F}$ & $\begin{array}{l}\text { Visitors Services } \\
\text { Park Ranger }\end{array}$ & Phone & $\begin{array}{l}\text { No but gone along } \\
\text { with others before }\end{array}$ & $\mathrm{n} / \mathrm{a}$ & \\
\hline P8 (Q-3) & $12-18-2017$ & 45 & $\mathrm{M}$ & $\begin{array}{l}\text { Project Leader } \\
\text { (Refuge Manager?) }\end{array}$ & Phone & $\begin{array}{l}\text { Yes; sons also } \\
\text { deer hunt }\end{array}$ & $\begin{array}{l}\text { Several } \\
\text { different rifles }\end{array}$ & nonPb \\
\hline P9 (Q-5) & $12-20-2017$ & 44 & $\mathrm{~F}$ & $\begin{array}{l}\text { Deputy Manager } \\
\text { (Assistant } \\
\text { Manager?) }\end{array}$ & Phone & $\begin{array}{l}\text { No, but gone } \\
\text { along with others } \\
\text { a few times }\end{array}$ & $\mathrm{n} / \mathrm{a}$ & \\
\hline P10 (Q-1) & $1-6-2018$ & 53 & $\mathrm{M}$ & $\begin{array}{l}\text { Visitors Services } \\
\text { Park Ranger }\end{array}$ & In-person & Yes & modern rifle & nonPb \\
\hline
\end{tabular}




\begin{tabular}{|c|c|c|c|c|c|c|c|c|}
\hline Participant & Date & Age & Gender & Job Description & Type & Deer Hunter? & Weapon Type & Ammo Used? \\
\hline P11 (Q-5) & $1-6-2018$ & 44 & $\mathrm{M}$ & Refuge Manager & In-person & Yes & modern rifle & nonPb \\
\hline $\mathrm{P} 12(\mathrm{Q}-3)$ & $1-6-2018$ & $\begin{array}{l}\text { ? maybe } \\
\text { mid-30s }\end{array}$ & $\mathrm{M}$ & Refuge Manager & In-person & Yes & $\begin{array}{l}\text { rifle and } \\
\text { shotgun }\end{array}$ & $\begin{array}{l}\text { rifle }-\mathrm{Pb} ; \\
\text { muzzleloader }- \text { nonPb }\end{array}$ \\
\hline P13 & $1-6-2018$ & 46 & $\mathrm{M}$ & Federal Agent & In-person & Yes & $\begin{array}{l}\text { Archery and } \\
\text { Firearms }\end{array}$ & Lead \\
\hline P14 & $1-6-2018$ & 38 & $\mathrm{M}$ & $\begin{array}{l}\text { Natural Resource } \\
\text { Specialist Ranger }\end{array}$ & In-person & Yes & modern rifles & Lead \\
\hline P15 (Q-3) & $1-8-2018$ & 66 & $\mathrm{M}$ & Refuge Manager & In-person & Yes & rifle & $\begin{array}{l}\mathrm{Pb} \text { now, maybe nonPb if } \\
\text { it works in my guns }\end{array}$ \\
\hline P16 (Q-3) & $1-9-2018$ & 31 & $\mathrm{M}$ & $\begin{array}{l}\text { Visitors Services } \\
\text { Park Ranger }\end{array}$ & Phone & Yes & $\begin{array}{l}\text { Primarily } \\
\text { archery, some } \\
\text { muzzleloader }\end{array}$ & would use nonPb now \\
\hline $\mathrm{P} 17$ & $1-10-2018$ & 38 & $\mathrm{~F}$ & Refuge Manager & In-person & Yes & $\begin{array}{l}\text { Archery and } \\
\text { Firearms }\end{array}$ & Yes, just switched \\
\hline P18 & $1-10-2018$ & $\begin{array}{l}\text { ? maybe } \\
\text { mid-30s }\end{array}$ & $\mathrm{M}$ & $\begin{array}{l}\text { Assistant Refuge } \\
\text { Manager }\end{array}$ & In-person & $\begin{array}{l}\text { Yes, but not in last } \\
\text { few years }\end{array}$ & $\begin{array}{l}\text { Archery and } \\
\text { Firearms }\end{array}$ & $\begin{array}{l}\text { nonPb for shotgun } \\
\text { hunting, } \mathrm{Pb} \text { for deer } \\
\text { hunting (but might } \\
\text { change) }\end{array}$ \\
\hline P19 (Q-3) & $1-11-2018$ & 50 & $\mathrm{M}$ & $\begin{array}{l}\text { Refuge Manager } \\
\text { (Project Leader) }\end{array}$ & Phone & Yes & $\begin{array}{l}\text { Primarily } \\
\text { Firearms, } \\
\text { muzzleloader }\end{array}$ & $\begin{array}{l}\text { nonPb purchased in local } \\
\text { store }\end{array}$ \\
\hline $\mathrm{P} 20$ & $1-12-2018$ & 32 & $\mathrm{M}$ & $\begin{array}{l}\text { Visitor Services } \\
\text { Park Ranger }\end{array}$ & Phone & $\begin{array}{l}\text { Yes, started after } \\
\text { getting job at the } \\
\text { refuge; no deer yet }\end{array}$ & $\begin{array}{l}\text { Firearms and } \\
\text { archery }\end{array}$ & lead/nonPb \\
\hline P21 (Q-3) & $1-18-2018$ & 50 & $\mathrm{M}$ & Refuge Manager & Phone & $\begin{array}{l}\text { Yes, "grew up } \\
\text { deer hunting" }\end{array}$ & $\begin{array}{l}\text { Series of } \\
\text { different rifles }\end{array}$ & lead \\
\hline P22 (Q-1) & 3-29-2019 & 32 & $\mathrm{M}$ & Wildlife Biologist & Phone & $\begin{array}{l}\text { Used to deer hunt; } \\
\text { lapsed hunter }\end{array}$ & Shotgun & lead \\
\hline
\end{tabular}




\begin{tabular}{|c|c|c|c|c|c|c|c|c|}
\hline Participant & Date & Age & Gender & Job Description & Type & Deer Hunter? & Weapon Type & Ammo Used? \\
\hline $\mathrm{P} 23$ & 4-1-2019 & 59 & M & $\begin{array}{l}\text { Private Lands } \\
\text { Biologist }\end{array}$ & Phone & Yes & shotgun & $\begin{array}{l}\text { lead; careful to cut meat } \\
\text { around wound channel }\end{array}$ \\
\hline P24 (Q-2) & 4-4-2019 & 28 & $\mathrm{~F}$ & $\begin{array}{l}\text { Wildlife Refuge } \\
\text { Specialist }\end{array}$ & Phone & $\begin{array}{l}\text { Used to hunt; } \\
\text { lapsed, stopped in } \\
\text { graduate school }\end{array}$ & $\begin{array}{l}\text { shotgun in the } \\
\text { past; bowhunt } \\
\text { now }\end{array}$ & $\mathrm{n} / \mathrm{a}$ \\
\hline $\mathrm{P} 25$ & 4-4-2019 & 52 & $\mathrm{M}$ & $\begin{array}{l}\text { Maintenance } \\
\text { Mechanic }\end{array}$ & Phone & Yes & modern rifle & lead \\
\hline P26 & $4-4-2019$ & 51 & $\mathrm{M}$ & $\begin{array}{l}\text { Wildlife Refuge } \\
\text { Specialist }\end{array}$ & Phone & Yes & shotgun & nonPb \\
\hline P27 & $4-4-2019$ & 41 & $\mathrm{M}$ & Range Technician & Phone & $\begin{array}{l}\text { Yes; since } 12 \text { yrs } \\
\text { old }\end{array}$ & modern rifle & nonPb \\
\hline P28 & $4-11-2019$ & 65 & $\mathrm{~F}$ & $\begin{array}{l}\text { Administrative } \\
\text { Support Assistant }\end{array}$ & Phone & $\begin{array}{l}\text { Used to deer hunt } \\
\text { but not last } 10 \text { yrs. }\end{array}$ & $\mathrm{n} / \mathrm{a}$ & $\mathrm{n} / \mathrm{a}$ \\
\hline P29 & 5-11-2019 & $\begin{array}{l}\text { maybe } \\
\text { late 50s } \\
\text { early } \\
60 \mathrm{~s}\end{array}$ & $\mathrm{M}$ & $\begin{array}{l}\text { Refuge Manager } \\
\text { (Project Leader) }\end{array}$ & Phone & Yes & shotgun & nonPb \\
\hline $\begin{array}{l}\text { Q37 Survey } \\
\text { Response } \\
\text { (Q-16) }\end{array}$ & & & & & & & & \\
\hline
\end{tabular}

Summary of themes, subthemes, description, and example quotes.

\begin{tabular}{|l|l|l|l|}
\hline Themes & Subthemes & Description & Example Quotes \\
\hline $\begin{array}{l}\text { 1. Internal factors and } \\
\text { challenges }\end{array}$ & $\begin{array}{l}1.1 \text { Persuasive and } \\
\text { legitimate messaging }\end{array}$ & $\begin{array}{l}\text { Message credibility of } \\
\text { hunters talking to other } \\
\text { hunters or shooters }\end{array}$ & $\begin{array}{l}\text { (Q37 Response) "Having somebody that cares about eagles is fine, but it is } \\
\text { important that they're a hunter." }\end{array}$ \\
\hline
\end{tabular}




\begin{tabular}{|c|c|c|c|}
\hline Themes & Subthemes & Description & Example Quotes \\
\hline & & $\begin{array}{l}\text { Complex problem not } \\
\text { fixed with brochures; no } \\
\text { simple solutions } \\
\text { Lack of specific target } \\
\text { audience } \\
\text { Public perceptions of } \\
\text { federal employees } \\
\text { Professional myopathy }\end{array}$ & $\begin{array}{l}\text { (P19) "It's a reality within our agency that a lot of folks don't hunt and don't } \\
\text { have [hunting] experience, [but] make sure you know what you're saying." } \\
\text { (Q37 Response) "Education is the key, but it's a fine line. The info needs to } \\
\text { come from people who have actually hunted and have experience with } \\
\text { different types of ammo." } \\
\text { (P8) "It's important for hunters to simply understand nonlead shoots equal or } \\
\text { better than lead ammunition. Ballistic details help, but dead is dead when it } \\
\text { comes to deer hunting." } \\
\text { (Q37 Response) "Presentations by biologists who hunt will work better than a } \\
\text { bunch of brochures ... this is obviously much more difficult than putting up } \\
\text { posters and filling kiosks with brochures." } \\
\text { (P9) "What we're doing hasn't been very targeted. It's been the same way we } \\
\text { put out any other information ... we fall back on what we traditionally do and } \\
\text { keep doing it." } \\
\text { (P24) "So, it's I guess it's more [about] knowing your audience in order to } \\
\text { have the message prepped for that group." } \\
\text { (P6) "We don't know who our clientele is. For example, there's an exhibit at } \\
\text { the national eagle center [about lead poisoning in eagles] but that's not targeted } \\
\text { toward deer hunters, it's for bird watchers." } \\
\text { (P19) “... a lot of times we lose the fact that as soon as you're in a uniform or } \\
\text { you're with the federal government there's a wall going up between you and } \\
\text { the public." } \\
\text { (P4) "We look through wildlife lenses all the time, the public doesn't always } \\
\text { see things the same way we do." } \\
\text { (P16) “[We] need to focus on talking to hunters before the season ... we're } \\
\text { trying to reach hunters when they're in the field and don't want to be } \\
\text { distracted." }\end{array}$ \\
\hline
\end{tabular}




\begin{tabular}{|c|c|c|c|}
\hline Themes & Subthemes & Description & Example Quotes \\
\hline & $\begin{array}{l}1.2 \text { Administrative } \\
\text { reticence and } \\
\text { uncertainty (new) }\end{array}$ & $\begin{array}{l}\text { Frustrations and } \\
\text { uncertainties of program } \\
\text { boundaries and } \\
\text { commitment from } \\
\text { regional leadership } \\
\text { We've got smart people, } \\
\text { let us do our job } \\
\text { Stay and script and follow } \\
\text { the rules (opposite of } \\
\text { decentralized neoliberal } \\
\text { thought) }\end{array}$ & $\begin{array}{l}\text { (P9) "We were ready to start talking with people and getting excited about the } \\
\text { program. But then, we got reigned in ... we're not fully engaging with issue } \\
\text { because we're not } 100 \% \text { sure of where our boundaries are and what we can } \\
\text { and can't do." } \\
\text { (P15) "We need to be careful about not pushing too hard. I don't want to } \\
\text { initiate a directive that tells us to shut up or muzzle the program." } \\
\text { (P8) "We need approval from regional leadership ... to move forward ... but } \\
\text { we're being restrained in using our talented staff to make it happen. We're } \\
\text { intelligent, hard-working, go-getters that know how to get the job done ... The } \\
\text { longer we stay in this "Do as much as you can, but not too much" mode, I } \\
\text { think frustration will grow and people will move on to other tasks ." } \\
\text { (P7) “... for me I'm not going outside the box because I don't want to make } \\
\text { any trouble or get myself in a situation with a message that wasn't approved." }\end{array}$ \\
\hline & $\begin{array}{l}1.3 \text { Competing refuge } \\
\text { priorities }\end{array}$ & $\begin{array}{l}\text { Don't have money for } \\
\text { everything } \\
\text { Don't have much extra } \\
\text { time for another new } \\
\text { program } \\
\text { Finite resources }\end{array}$ & $\begin{array}{l}\text { (P12) "Why are we focusing on this lead poisoning issue when we have broken } \\
\text { infrastructure on our refuges that we can't pay for; we don't have the funds to } \\
\text { provide habitat that's really needed. Why is this our priority; it's an important } \\
\text { question we need to keep asking." } \\
\text { (P5) "From a management standpoint, it's one more thing I have to deal with. } \\
\text { We have to make those types of choices every day. I don't have time to } \\
\text { research nonlead ammunition ... I just don't have the time to do that. So, I } \\
\text { need bullet points [laughs]." } \\
\text { (P6) "We're already working three weekends in a row for waterfowl hunters, } \\
\text { then we get a little break, and then kick back into deer hunting? It's just not a } \\
\text { priority." } \\
\text { (P12) "We have other [refuge] priorities ... and finite resources ... if now } \\
\text { isn't the right time, we should stop and come back when the timing is better." }\end{array}$ \\
\hline
\end{tabular}




\begin{tabular}{|c|c|c|c|}
\hline Themes & Subthemes & Description & Example Quotes \\
\hline & $\begin{array}{l}\text { 1.4 Nonlead } \\
\text { skepticism among } \\
\text { staff }\end{array}$ & $\begin{array}{l}\text { Disbelief about existing } \\
\text { science }\end{array}$ & $\begin{array}{l}\text { (Q37 Response) "I'm not against nonlead ammo, but do it for the right reason, } \\
\text { not some politically skewed ideal." } \\
\text { (Q37 Response) "I'm not ok with the very biased test results being used [by } \\
\text { the program] to push an anti-lead agenda." } \\
\text { (P21) "I would not be comfortable presenting the information I have seen on } \\
\text { the impacts of eagles from gut piles of lead having significant impacts on } \\
\text { eagles. I would not be comfortable presenting that as a scientific person to the } \\
\text { public or anything with the information I've seen, and I do know that there's } \\
\text { several that feel that way." } \\
\text { (Q37 Response) "The FWS nonlead info I saw was very biased showing lead } \\
\text { bullets fragmented into hundreds of pieces ... this just isn't my experience." } \\
\text { (Q37 Response) "I cannot in clear conscious hunt with nonlead ammo at this } \\
\text { time knowing that I may wound an animal or put the animal through unneeded } \\
\text { suffering." }\end{array}$ \\
\hline $\begin{array}{l}\text { 2. External factors and } \\
\text { challenges }\end{array}$ & $\begin{array}{l}\text { 2.1 External political } \\
\text { influences }\end{array}$ & $\begin{array}{l}\text { Tensions and political } \\
\text { constraints related to the } \\
\text { implied and explicit gun- } \\
\text { related issues } \\
\text { Incremental baby steps } \\
\text { avoid major changes } \\
\text { Danger of losing program } \\
\text { due to politics } \\
\text { External sensitivities }\end{array}$ & $\begin{array}{l}\text { (P9) "I think the way we're going about it with baby steps and voluntary } \\
\text { messages is a good first step. I don't know, however, if at the field level we're } \\
\text { doing as much as we could to educate because of the politics." } \\
\text { (Q37 Response) "Many hunters and gun owners see this as an anti-hunting } \\
\text { ploy. FWS and others needs to do a better job of proving/convincing that } \\
\text { gun/hunting groups that decisions related to lead are science/conservation } \\
\text { based, not anti-gun/anti-hunt." } \\
\text { (P9) "Politics of the issue is the main challenge ... we're treading carefully } \\
\text { because we know what can happen with the politics ... baby steps and } \\
\text { voluntary messages is a good start." } \\
\text { (P11) “... given the current climate ... we just have to keep the program } \\
\text { going; put out the information and educate a few people. Hopefully we can } \\
\text { keep under the radar but keep spreading the word. If we push much harder... }\end{array}$ \\
\hline
\end{tabular}




\begin{tabular}{|c|c|c|c|}
\hline Themes & Subthemes & Description & $\begin{array}{l}\text { Example Quotes } \\
\text { it will come down on us like the wrath of God. We can't push too hard, or [the } \\
\text { program] will get killed." } \\
\text { (P9) "I don't know if we're doing as much as we could because of the politics . } \\
\text {.. it's a touchy issue. It's touchy between us and the state, and us and the } \\
\text { politics, and the lobbyist groups." } \\
\text { (P8) “. . . timing is a critical element whenever we roll a large initiative of this } \\
\text { nature. While I commend the leadership, the foot soldiers in the field } \\
\text { recognize the timing is not good politically." }\end{array}$ \\
\hline & $\begin{array}{l}\text { 2.2 External social } \\
\text { influences (new) }\end{array}$ & $\begin{array}{l}\text { Have hunting groups } \\
\text { carry the message to their } \\
\text { members } \\
\text { Importance of having } \\
\text { partners and ammunition } \\
\text { industry } \\
\text { Stressing partnerships and } \\
\text { collaborations with other } \\
\text { organizations }\end{array}$ & $\begin{array}{l}\text { (Q37) "I think our state agencies partners and organizations such as DU } \\
\text { [Ducks Unlimited], RMEF [Rocky Mountain Elk Foundation], etc. would be } \\
\text { more effective at carrying our message to hunters. We also need the ammo } \\
\text { companies to get behind it" } \\
\text { (P4) "We implemented this voluntary program I brought it up with all of our } \\
\text { partnering rod and gun clubs, a lot of other conservation groups, Trout } \\
\text { Unlimited, Pheasants Forever, DU, all of them." } \\
\text { (Q37) "I believe [we need] more advertising and outreach on websites and } \\
\text { social media at the regional and local level with a variety of conservation and } \\
\text { hunting groups as well as retailers." } \\
\text { (Q37) "We could work with the ammunition companies to provide incentives } \\
\text { for nonlead ammo. Data could be collected for the companies to [improve] } \\
\text { nonlead ammo." }\end{array}$ \\
\hline & $\begin{array}{l}2.3 \text { Perceptions of } \\
\text { regulatory and } \\
\text { voluntary approaches }\end{array}$ & $\begin{array}{l}\text { Attitudes about regulatory } \\
\text { and voluntary approaches } \\
\text { to the issue } \\
\text { Attitudes about } \\
\text { regulations and rationale }\end{array}$ & $\begin{array}{l}\text { (P12) "If it's a really big priority, we should have gone the regulatory route, } \\
\text { but I was quickly told that can't do that because of political realities." } \\
\text { (P2) “.... who am I to tell somebody what ammunition to use if it's not a } \\
\text { regulation? Everybody in this field, me included, knows lead is bad and is }\end{array}$ \\
\hline
\end{tabular}




\begin{tabular}{|c|c|c|c|}
\hline Themes & Subthemes & Description & Example Quotes \\
\hline & & $\begin{array}{l}\text { Attitudes about voluntary } \\
\text { programs and rationale }\end{array}$ & $\begin{array}{l}\text { harmful to eagles. I'm all for trying to reduce that, but until it's a regulation } \\
\text { it's just not my fight." } \\
\text { (P15) "It's been an issue my whole career ... If we're going to require nonlead } \\
\text { ammunition for hunting deer on a refuge we should just do it, explain why it's } \\
\text { being done, and implement the [regulation]. No exceptions." } \\
\text { (P11) "We broke the ice } 30-40 \text { years ago with the steel shot regulation for } \\
\text { waterfowl hunting, and we survived. I don't think it's as big a deal as people } \\
\text { are making it out to be ... I don't think there would be much push-back } \\
\text { today." } \\
\text { (P12) "If we said we're doing this voluntary program because in ten years } \\
\text { we're going to this regulatory program, I think people would say "Ok" because } \\
\text { they can see where we're headed. But right now, with just a voluntary program } \\
\text { and no long-term objective, I think it's going to just die." } \\
\text { (P11) “... It's going to spread by word of mouth. You talk to } 500 \text { hunters, } \\
\text { and maybe only one will buy nontoxic ammunition and he tells his buddies ... } \\
\text { it's going to spread organically. With a voluntary program, that's how we } \\
\text { have to do it." } \\
\text { (P19) "I think we're just at that baby stage where we're starting to educate } \\
\text { people about the problem and the options we have. We don't have to make it a } \\
\text { law, we don't have to be heavy handed with it." } \\
\text { (P5) "I think the public information campaign approach is the way to go, and } \\
\text { people need to clearly understand that's the approach we're following. Even } \\
\text { though we have the [regulatory] authority ... it's not politically feasible, so we } \\
\text { really need to stay the course with the public relations campaign and let people } \\
\text { come to their own conclusions." }\end{array}$ \\
\hline & $\begin{array}{l}2.4 \text { Nonlead cost and } \\
\text { availability } \\
\text { perceptions }\end{array}$ & $\begin{array}{l}\text { Issues related to finding } \\
\text { non } \mathrm{Pb}\end{array}$ & $\begin{array}{l}\text { (Q37 Response) “... but if lead bullets become outlawed the cost for my } \\
\text { hunting ammo will double and what's to say the lead ban won't begin to affect } \\
\text { my recreational shooting hobby and begin to make it unaffordable." }\end{array}$ \\
\hline
\end{tabular}




\begin{tabular}{|c|c|c|c|}
\hline \multirow[t]{2}{*}{ Themes } & Subthemes & Description & Example Quotes \\
\hline & & NonPb costs too much & $\begin{array}{l}\text { (P7) "My friend was looking for steel-shot for duck hunting and went to five } \\
\text { different stores ... and none of them had nontoxic steel shot for his shotgun. } \\
\text { If we can’t find steel shot for duck hunting, how are people supposed to find } \\
\text { nonlead ammunition for deer hunting?" } \\
\text { (P21) “And probably I would say the biggest reason that I don't use it would } \\
\text { be cost and would be availability. I know I've checked around here and you } \\
\text { can't get it anywhere around here." } \\
\text { (Q37) "In the grand scheme of things it's not that much money but try telling a } \\
\text { guy to buy a } \$ 40 \text { box of [nonlead] ammo when he's used to purchasing lead } \\
\text { ammo for } \$ 20 . "\end{array}$ \\
\hline & $\begin{array}{l}2.5 \text { Too narrow of } \\
\text { scope and scale of } \\
\text { program (new) }\end{array}$ & $\begin{array}{l}\text { Limited focus on just } \\
\text { eagles and just hunters } \\
\text { using NWRs } \\
\text { Efficacy of bald eagle } \\
\text { focus; need to connect } \\
\text { eagles to people }\end{array}$ & $\begin{array}{l}\text { (Q37 Response) "It is very hard to expect retailers to stock non-lead for only } \\
\text { refuge deer hunting." (move to narrow and limited scope/scale) } \\
\text { (Q37 Response) "We had a very narrow scope of only deer hunting on refuge } \\
\text { land. If we are actually going to see change, we should have broadened our } \\
\text { scope." } \\
\text { (Q37 Response) "The geographical footprint of the refuges is small when } \\
\text { thinking about the overall scope of deer hunting... I think more thought and } \\
\text { effort should go into thinking of ways to reach out further than our federal land } \\
\text { borders." } \\
\text { (P11) "No offense, nobody wants to kill an eagle, but eagles are everywhere, } \\
\text { and you see them all the time. "Aren't they off the endangered species list?", } \\
\text { or "Is there any concern when the populations are increasing?" - those of } \\
\text { some of the questions or comments I get. } \\
\text { (P16) "I definitely got the understanding we should focus our message } \\
\text { specifically on bald eagles and what the study showed within our region about } \\
\text { effects of lead on bald eagles and lead in gut piles as a potentially source of } \\
\text { lead." }\end{array}$ \\
\hline
\end{tabular}




\begin{tabular}{|c|c|c|c|}
\hline Themes & Subthemes & Description & Example Quotes \\
\hline & & & $\begin{array}{l}\text { (P10) "If people aren't exposed to the eagle portion of the message, they won't } \\
\text { see [the problem]. If you see } 200 \text { eagles sitting in a single tree and you've got } \\
50 \text { dead birds [from lead poisoning], that opens peoples' eyes. They have a } \\
\text { connection with it." }\end{array}$ \\
\hline \multirow[t]{2}{*}{ 3. Human health risk } & $\begin{array}{l}\text { 3.1 Not an agency } \\
\text { responsibility }\end{array}$ & $\begin{array}{l}\text { Agency's primary mission } \\
\text { is wildlife and let } \\
\text { responsible groups with } \\
\text { human health } \\
\text { responsibility deal with it } \\
\text { FWS staff not human } \\
\text { health experts }\end{array}$ & $\begin{array}{l}\text { (P15) "We're not supposed to get into [the human health aspect] because ... } \\
\text { we don't have that expertise or training." } \\
\text { (P16) "The human health aspect would be a game changer, but they advised } \\
\text { we're not specialists in that area. We shouldn't be speaking about that, just } \\
\text { refer them to information about lead and human health. It's not something that } \\
\text { we should use as our main message because we're a wildlife agency dealing } \\
\text { with impacts to wildlife, in particular bald eagles." } \\
\text { (P10) "I don't talk about the human health issue. It's not part of the } \\
\text { information I was given. If somebody brings it up, I'll say that's a personal } \\
\text { decision you have to make on your own whether you believe there's exposure } \\
\text { to you or not. I don't have any data on that. If I'm asked what I think, I'd } \\
\text { would tell I made the switch, so I don't have worry about it." } \\
\text { (P22) "I think it's definitely worth mentioning [i.e., human health risk], but I } \\
\text { would hate to have something completely focused on it. I think the message } \\
\text { would come better from a different organization, a different medical } \\
\text { organization or something like that." }\end{array}$ \\
\hline & $\begin{array}{l}\text { 3.2 Personal risk to } \\
\text { family and friends }\end{array}$ & $\begin{array}{l}\text { Frames the lead poisoning } \\
\text { issue within the context of } \\
\text { lead exposure to family } \\
\text { and friends }\end{array}$ & $\begin{array}{l}\text { (Q37 Response) "The fact that tiny lead fragments end up throughout the deer } \\
\text { affected me more than the bald eagles. I do not want to feed that to my family. } \\
\text { It's bad for us, our children and eagles. [This] ... will more easily tip the } \\
\text { scales to going lead free." }\end{array}$ \\
\hline
\end{tabular}




\begin{tabular}{|c|c|c|c|}
\hline \multirow[t]{3}{*}{ Themes } & Subthemes & Description & Example Quotes \\
\hline & & & $\begin{array}{l}\text { (P11) "I heard about this study at a food pantry where almost every package of } \\
\text { venison had lead fragments, and I thought I was feeding that to my family. I } \\
\text { mean, I've got four kids. That was the biggest factor. We put two, three, and } \\
\text { sometimes four deer in our freezer every year and that's the meat we use most } \\
\text { of the time." } \\
\text { (P9) "If someone was offering me some venison, I'd ask them how they shot it } \\
\text { before eating it or giving it to my family." } \\
\text { (P19) "Do I think about it as a hunter? Yes. But, if I'm talking to the public, I } \\
\text { won't say their health is at risk, but I'll ask if they feel comfortable ingesting } \\
\text { lead. If the answer's yes, then they don't need to listen (laughs). }\end{array}$ \\
\hline & $\begin{array}{l}3.3 \text { Not a human } \\
\text { health problem }\end{array}$ & $\begin{array}{l}\text { Just need to be careful } \\
\text { when butchering your } \\
\text { deer } \\
\text { Most lead bullets don't } \\
\text { fragment with proper shot } \\
\text { placement }\end{array}$ & $\begin{array}{l}\text { (P21) "We're pretty cognizant of where there's a wound on the deer and we } \\
\text { don't use that area. We cut a pretty good chunk around that out. We always } \\
\text { have." } \\
\text { (Q37 Response) [I] have hunted my entire life and ... field dressed hundreds } \\
\text { of deer and worked as a wild game butcher helping butcher } 70-100 \text { deer each } \\
\text { year... } 99.9 \% \text { of the deer are shot in the vital organs and the bullet passes } \\
\text { through } 99.9 \% \text { of the time. One time I found a bullet remaining in a deer after } \\
\text { field dressing and it was only missing a small piece of the cooper jacket } \\
\text { covering the bullet." }\end{array}$ \\
\hline & & & \\
\hline
\end{tabular}




\section{Vita}

John H. Schulz grew up in southern Minnesota and graduated from Minnesota State University with a B.S. and M.A. in Biology. He worked for the Minnesota Department of Natural Resources for six years at the Farmland Wildlife Research Station before moving to Missouri to become the assistant deer biologist for the Missouri Department of Conservation (MDC). Shortly thereafter, John was promoted to Research Biologist and directed the statewide research programs for ring-necked pheasants, mourning doves, woodcock, and provided guidance to the Central Flyway Technical Committee and Central Flyway Council on a suite of webless migratory game bird management issues. After his career with the MDC, John worked shortly for the American Bird Conservancy as the national nonlead ammunition program coordinator. Before returning to school, John worked part-time for the University of Missouri wrapping up several unfinished research projects and publishing numerous manuscripts. John has been a member of The Wildlife Society during his career and has served in leadership positions at the state, regional, and national levels while also being active in numerous natural resource management organizations. 